\title{
Antagonistic fluorescent pseudomonads cause evasion of the plant pathogen Verticillium by controlling hyphal growth and polarity
}

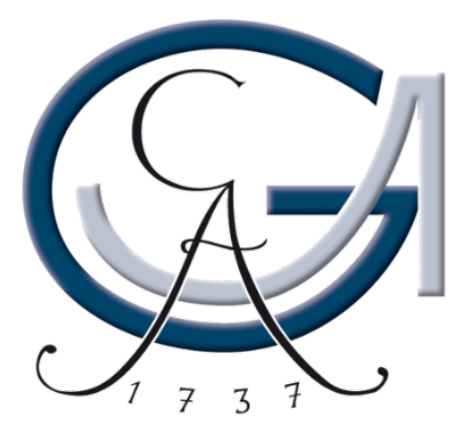

Dissertation

for the award of the degree

"Doctor rerum naturalium"

Division of Mathematics and Natural Sciences

of the Georg-August-Universität Göttingen

within the doctoral program "Microbiology and Biochemistry" of the Georg-August University School of Science (GAUSS)

submitted by

Kai Nesemann

from Georgsmarienhütte

Göttingen 2020 
Thesis Committee:

Referee: Prof. Dr. Gerhard H. Braus,

Department of Molecular Microbiology and Genetics,

Georg-August University of Göttingen

$2^{\text {nd }}$ referee: Prof. Dr. Rolf Daniel,

Department of Genomic and Applied Microbiology,

Georg-August University of Göttingen

$3^{\text {rd }}$ referee: Prof. Dr. Stefanie Pöggeler,

Department of Genetics of Eukaryotic Microorganisms,

Georg-August University of Göttingen

Members of the Examination Board:

Prof. Dr. Andrea Polle,

Department of Forest Botany and Tree Physiology, Büsgen Institute, GeorgAugust University of Göttingen

Prof. Dr. Ursula Kües,

Department of Forest Botany and Tree Physiology, Büsgen Institute, GeorgAugust University of Göttingen

Prof. Dr. Oliver Gailing,

Department of Forest Genetics and Tree Breeding, Büsgen Institute, GeorgAugust University of Göttingen

Date of the oral examination: 2021 , January $12^{\text {th }}$ 
This work was accomplished in the group of Prof. Dr. Gerhard H. Braus, at the

Department of Molecular Microbiology and Genetics, Institute of Microbiology and Genetics, Georg-August University of Göttingen. 


\section{Contents}

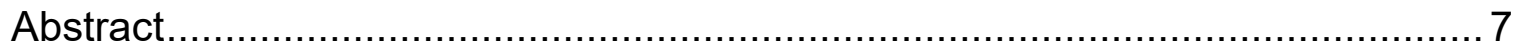

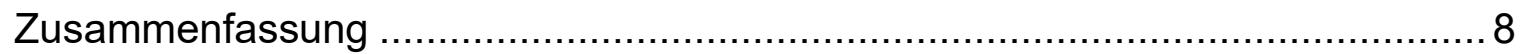

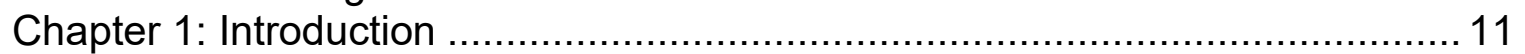

Fungal plant pathogens ..................................................................... 11

Life cycle and taxonomy of the vascular plant pathogen Verticillium............... 12

The amphidiploid $V$. longisporum is an interspecific hybrid of different haploid

Verticillia .............................................................................................. 14

Conidia and resting structures of Verticillium species and their impact on plant

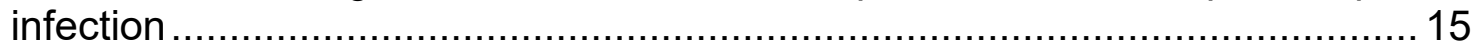

Interactions in the plant rhizosphere .................................................. 17

Natural rhizobacteria as antagonists of microbial pathogens ........................ 18

Aims and structure of this study .............................................................. 25

Chapter 2: Draft genome sequence of the beneficial rhizobacterium

Pseudomonas fluorescens DSM8569 ...................................................... 29

Chapter 3: Draft genome sequence of the phenazine producing Pseudomonas

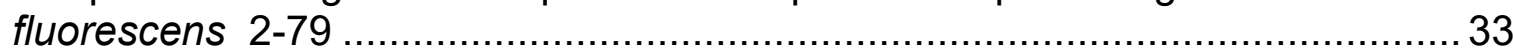

Chapter 4: Fluorescent pseudomonads pursue media-dependent strategies to

inhibit growth of pathogenic Verticillium fungi ............................................. 37

Chapter 5: Pathogenic Verticillia Follow Evasion and Detoxification Strategies

during Confrontation with Fluorescent Pseudomonads.....................................5 53

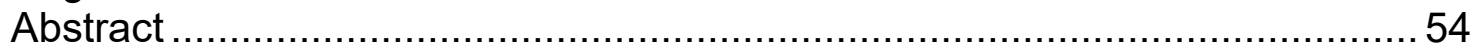

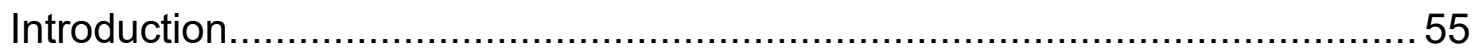

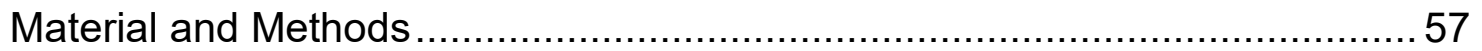

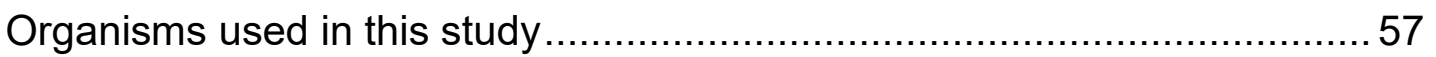

Cultivation conditions of bacteria and fungi........................................59

Microfluid device system............................................................... 59

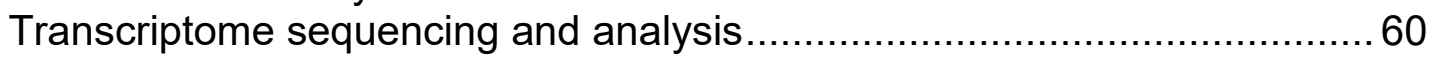

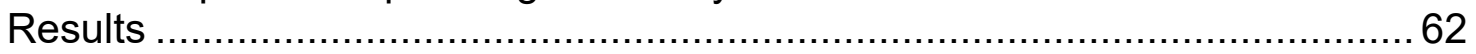

$90 \%$ of Verticillia polar hyphal growth can be reduced by fluorescent

pseudomonads in confrontation assays................................................6 62

An intact GacA/GacS regulatory system of fluorescent pseudomonads can contribute to $30 \%$ bacterial inhibition potential against Verticillia hyphal growth in microchannels.

Phenazines and GacA/GacS-controlled metabolites of fluorescent

pseudomonads change polarity of Verticillium hyphae.

$P$. protegens alters transcriptional profiles of $V$. longisporum genes including up-regulation of detoxification related genes and decreased levels of transcripts for protein biosynthesis and plant polysaccharide degradation. . 70

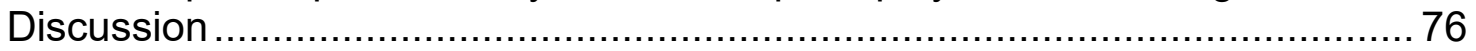

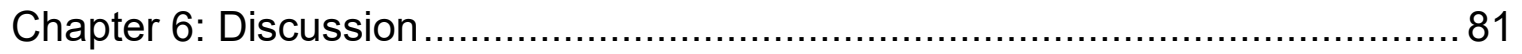

Growth control of Verticillium by fluorescent pseudomonads ...................... 81

Relevance of fungal secondary metabolism during interaction with fluorescent pseudomonads................................................................................... 81

The impact of phenazines and the GacA/GacS regulation system on fungal growth highly depends on nutrition. 
. .84

The fungal detoxification and evasion strategy

The positive and negative connotation of beneficials and pathogens as an anthropocentric view.

Main findings of Verticillium's interaction to cope with the impact of

Pseudomonas...

Outlook

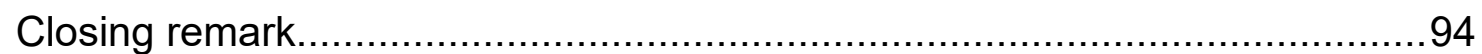

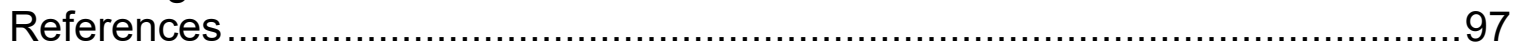

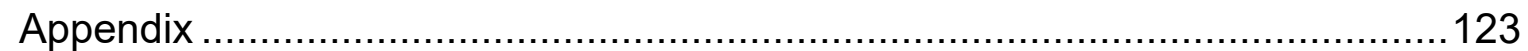

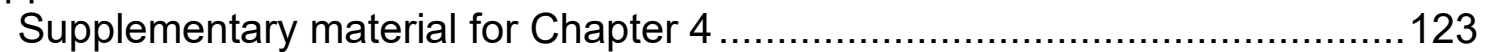

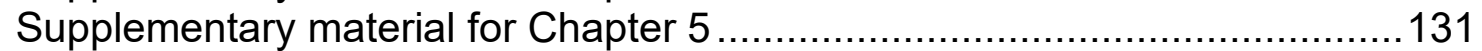

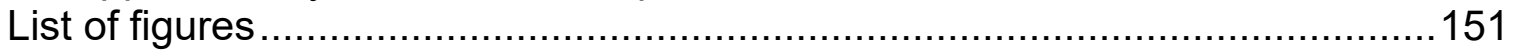

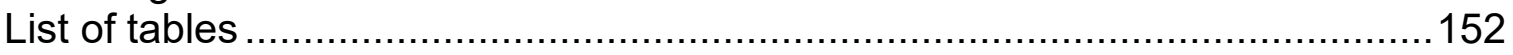

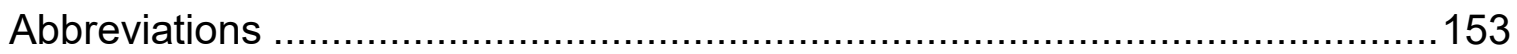

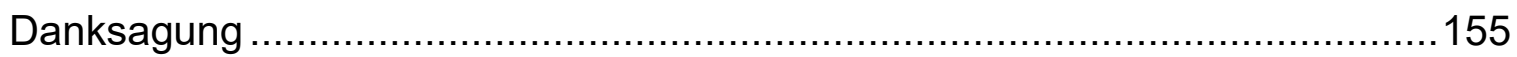

Curriculum vitae ..................................... Fehler! Textmarke nicht definiert. 


\section{Abstract}

Soil borne phytopathogenic Verticillia constitute increasing yield losses. Due to a lack of resistant cultivars as well as appropriate fungicides, the usage of biocontrol agents like fluorescent pseudomonads might be a promising option to ecologically manage the pest. The impact of different mycotoxins against Verticillium is highly media dependent. Pseudomonas fluorescens DSM8569, an isolate from $B$. napus rhizosphere, is able to inhibit fungal growth on surfaces of rich medium containing high glucose independent of phenazines or GacA/GacS-regulated toxins but not on a complex medium with plant pectins and amino acids. In microfluidic interaction channels, this inhibitive potential has been quantified to $80 \%$ growth reduction. An impact of a phenazine gene cluster on Verticillium growth on surface media could only be determined in a glucose environment. In microchannels filled with liquid pectins and amino acids, a phenazine gene cluster could increase the suppressive potential of the bacterium for about $30 \%$. An influence on Verticillium growth by genes responsible for single mycotoxins of a GacA/GacS regulation could not be proven. The sensor kinase GacS (a global regulator) as well as the response regulator GacA fulfill essential functions for fungal control especially on pectins and amino acids with an inhibition potential of approx. $30 \%$. In total, the entire regulation system leads to the strongest observed fungal suppression in this study of more than $90 \%$. Hyphal polarity has been altered in presence of the bacterium. The strongest effect was observed for $P$. protegens $\mathrm{CHAO}$ potentially expressing a diverse mycotoxin cocktail resulting in more than $80 \%$ curled hyphal tips compared to parallel hyphae in the fungal control without bacterium. This phenomenon might be interpreted as an evading strategy followed by Verticillium that tries to escape the bacterial impact. Fungal genetic response was addressed by sequencing the Verticillium transcriptome after co-cultivation with $P$. protegens $\mathrm{CHA0}$. About one third of the total gene set was up-regulated in presence of the bacterium, including genes involved in detoxification possibly as a direct reaction to bacterial toxicity. The fungus presumably follows a detoxification and evasion strategy and drives back processes required for nutrient up-take like plant polysaccharide hydrolases associated to its reduced growth activity. In summary it can be considered, that in a static environment Verticillia have developed strategies to physically avoid fluorescent Pseudomonas by adapting their growth rates and by changing their growth direction. Transferring these findings gained from an artificial setup in a microfluidic confrontation design to the natural heterogeneous environment in the rhizosphere with areas of diverse suppressivness, Verticillium might potentially escape from a threatening to a more appropriate ecological niche for survival and to approach new host plant roots for infection. If evasion is no option for the fungus, like it is during artificial agitated co-cultivation or under natural conditions in the soil being located in a very widely spread Pseudomonas population, Verticillium possibly utilizes its capability to detoxify antifungal toxins to cope with bacterial antagonism. 


\section{Zusammenfassung}

Bodenbürtige phytopathogene Verticillien führen zu enormen Ernteausfällen. Da bislang keine resistenten Kultursorten oder geeignete Fungizide zur Verfügung stehen, könnte die Verwendung von Biokontrollbakterien wie fluoreszierenden Pseudomonaden eine ökologische Alternative sein. Die Wirkung verschiedener Mykotoxine gegen Verticillium ist äußerst medienabhängig. Pseudomonas fluorescens DSM8569, ein natürliches Isolat aus der Rhizosphäre von $B$. napus ist in der Lage ohne Phenazine und GacA/GacS-regulierte Toxine das Pilzwachstum auf reichhaltigem Oberflächenmedium mit hohem Glukosegehalt zu inhibieren, allerdings nicht auf einem Komplexmedium mit Pektinen und Aminosäuren. In mikrofluidischen Interaktionskanälen konnte dieses Inhibitionspotential auf $80 \%$ Wachstumsreduzierung quantifiziert werden. Ein signifikanter Einfluss eines Phenazine-Genclusters auf das Wachstum von Verticillium auf Oberflächenmedien konnte nur unter Glukosebedingungen bestimmt werden. In Mikrokanälen, gefüllt mit einem Pektin-Aminosäure-Medium, konnte das Phenazine-Gencluster das Hemmpotential des Bakteriums zusätzlich um ca. 30 \% steigern. Gene für einzelne Mykotoxine, die durch ein GacA/GacS System reguliert werden, haben jeweils keinen individuellen Einfluss auf das Wachstum von Verticillium. Die Sensorkinase GacS (ein globaler Regulator) sowie der Antwortregulator GacA zeigen essentielle Funktionen für die Pilzkontrolle, vor allem auf einem Pektin-Aminosäure-Medium mit einem Hemmpotential von ca. $30 \%$. Insgesamt führt ein vollständiges Regulationssystem, zur stärksten beobachteten Pilzhemmung in dieser Studie von über $90 \%$. Auch die Polarität der Hyphen wurde unter Pseudomonaseinfluss verändert. Der stärkste Effekt wurde durch P.protegens CHAO verursacht, mit mehr als $80 \%$ gekräuselten Hyphenspitzen im Vergleich zu parallel wachsenden Hyphen der Pilzkontrolle ohne Bakterium. Dieses Phänomen könnte als Vermeidungsstrategie durch Verticillium interpretiert werden, welcher versucht dem intensiven Einfluss des Bakteriums zu entkommen um geeignetere Wurzeln zu infizieren. Pilzliche Antworten wurden durch Sequenzierung des Verticillium Transkriptoms nach Kokultivierung mit $P$. protegens CHAO untersucht. Etwa ein Drittel aller Gene wurde in Anwesenheit des Bakteriums hochreguliert, inklusive der Gene, die an Detoxifizierung beteiligt sind. Dies könnte möglicherweise als direkte Antwort auf die bakterielle Toxizität interpretiert werden. Vermutlich verfolgt der Pilz eine Fluchtstrategie und fährt Prozesse zurück, die für die Nährstoffaufnahme entscheidend sind, wie etwas Pflanzen-Polysaccharid-Hydrolasen, und während reduzierter Wachstumsaktivität weniger benötigt werden. Zusammenfassend lässt sich festhalten, dass Verticillium unter statischen Bedingung Strategien entwickelt hat, um bestimmten fluoreszierenden Pseudomonaden räumlich auszuweichen, etwa durch Anpassung ihrer Wachstumsrate sowie Änderung Ihrer Wachstumsrichtung. Versucht man diese Erkenntnisse vom artifziellen Versuchsaufbau in einem mikrofluidischen Konfrontationsdesign auf die natürlichen heterogenen Bedingungen in der Rhizosphäre mit Bereichen unterschiedlicher Suppressivität zu übertragen, so lässt sich schlussfolgern, dass Verticillium potentiell versucht, lebensfeindliche Bereich zu verlassen und besser geeignete ökologische Lebensräume zu besetzten. Hier könnte der Pilz womöglich erhöhte Überlebenschancen vorfinden und somit die Möglichkeit neue 
Pflanzenwurzeln zu infizieren. Wenn für den Pilz die Fluchtstrategie keine Möglichkeit darstellt, etwa während schwenkender Kokultivierung im Labor oder unter natürlichen Bedingung im Boden in großräumigen Bereichen hoher Pseudomonaskonzentration, könnte Verticillium möglicherweise seine Fähigkeit nutzen, um antimykotische Toxine zu detoxifizieren und somit zu versuchen, dem bakteriellen Antagonismus standzuhalten. 


\section{Chapter 1: Introduction}

\section{Fungal plant pathogens}

Fungal plant pathogens rank as one of the most abundant and destructive pests in agriculture and lead to numerous complex diseases (Beckman, 1987; Atallah et al., 2010; Rodriguez-Moreno et al., 2018). Fungal infection can take place preharvest at growing plants with high yield losses estimated at more than US $\$ 200$ billion (Birren et al., 2002) or post-harvest with infestation and destruction of crop storage. Damage is even increased by production of mycotoxins during storage like aflatoxin by Aspergilli (Frisvad et al., 2019) or deoxynivalenol and zearalenon secreted by Fusarium spp. (Khaneghah et al., 2018) with harmful impact on human health. Thus, phytopathogenic fungi cause a considerable risk in human world food affairs in past as well as present and with increasing population probably also in future. A broad range of crops can be affected with a huge morphological and molecular variability in fungal pathogenic mode of infection (Horbach et al., 2011; Jain et al., 2019). Phytopathogenic fungi have different modes of trophic relationships to their host plants. There are several Basidiomycota that live biotrophicly like Puccinia graminis causing stem rust in cereals (Figueroa et al., 2018). The biotrophic ascomycete Blumeria graminis is responsible for powdery mildew in many plants (Schnepf et al., 2018). A large group of fungal plant pathogens that have huge agricultural impact live necrotrophicly, e.g. Fusarium graminearum (Wiemann et al., 2013; Brodhun et al., 2013; Bönninghausen et al., 2019), Botrytis cinerea (Kretschmer et al., 2009; Veloso and van Kan, 2018; Petrasch et al., 2019), Alternaria spp. (Tralamazza et al., 2018) or Cochliobolus heterostrophus (Kang et al., 2018). The hemibiotrophic phytopathogenic fungi change the trophic mode during their life cycle in the plant from biotrophic to necrotrophic like Magnaporthe grisea (Park et al., 2013; Figueroa et al., 2018), Phytophthora infestans (Rodenburg et al., 2018), Colletotrichum spp. (Yan et al., 2018) or Verticillium spp. (Pegg and Brady, 2002; Tran et al., 2013; Timpner et al., 2013; Hoppenau et al., 2014; Bui et al., 2019; Leonard et al., 2020). 


\section{Life cycle and taxonomy of the vascular plant pathogen Verticillium}

Like the genus Trichoderma, the genus Verticillium belongs to the order of the Hypocreales of the ascomycetes. Verticillium consists of nine different haploid species as well as one amphidiploid species that is an interspecific hybrid out of two different haploid parents (Verticillium longisporum). These different Verticillium species are spread in temperate regions around the globe (Inderbitzin et al., 2011; Carroll et al., 2018). V. dahliae exhibits the broadest host range within the Verticillium genus causing wilt disease in more than 200 wooden and non-wooden plant species also covering many crops of agricultural interest e.g. cotton, olive, lettuce, potato and tomato (Pegg and Brady, 2002; Gordon et al., 2006; Fradin and Thomma, 2006; Klostermann et al., 2009; Depotter et al., 2019a). In contrast to $V$. dahliae, $V$. longisporum has a narrow host range and mainly colonizes Brassicaceae like oilseed rape, cauliflower and horseradish (Heale and Karapapa, 1999; Zeise and von Tiedemann, 2001; Singh et al., 2012; Zheng et al., 2019). The symptoms can differ depending on the host plant. In oilseed rape $V$. longisporum infection can lead to stem striping as well as early senescence and stunting of the host plant (Depotter et al., 2016 and 2017) whereas for cauliflower wilting symptoms similar to $V$. dahliae are described (Franca et al., 2013). Simultaneously to the increasing relevance of oilseed rape as vegetable oil for nutrition and regenerative fuel production, also the ecological and economical relevance of $V$. longisporum as a fungal pathogen increases. With progressive global warming, the infection intensity of $V$. longisporum might increase (Siebold and von Tiedemann, 2012 and 2013). The intensity of a potential yield loss of oilseed rape due to $V$. longisporum infection depends on the inoculum level and varies from cultivar to cultivar but also individually between single plants of the same cultivar (Depotter et al., 2019b). Due to its highly melanized resting structures, called microsclerotia, that can survive in the soil for many years, it is rather difficult to control the expansion of the filamentous soil borne fungus Verticillium (Wilhelm, 1955; Schnathorst, 1981; Heale and Karapapa, 1999; Yu et al., 2019b; Bui et al., 2019). Under appropriate environmental conditions, the microsclerotia can germinate towards the root and penetrate the root cortex (Figure 1.1). 


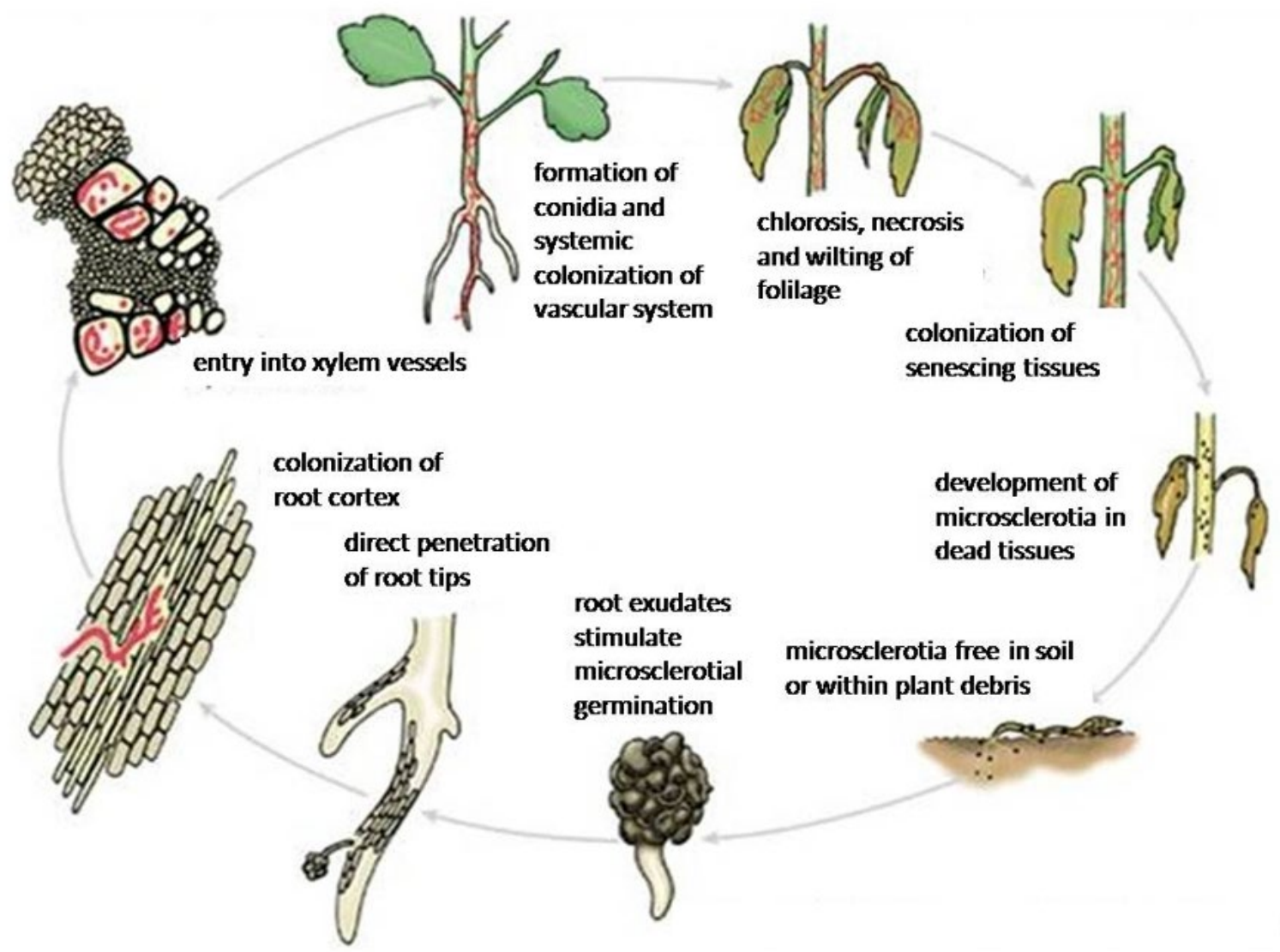

Figure 1.1: Life cycle of the soil borne phytopathogen Verticillium. The Verticillium resting structures, so-called microsclerotia, can survive free in the soil or in dead host plant material for a long period of time even under harsh climate conditions. They start germinating stimulated by root exudates that are specific for their respective host plant. The mycelium grows towards the host root and enters the plant by penetrating the rhizodermis. Subsequently, the root cortex is colonized and the hyphae enter the xylem vessels. This way conidia of the phytopathogenic fungus are transported with the transpiration flow within the vascular system spreading over the whole plant. First infection symptoms are visible by chlorotic and necrotic changes of the leaf surface and lead to a stunted plant phenotype. The disease symptoms can be summarized as early senescence of the plant development. In the dead plant material, the microsclerotia are formed and get into the soil again. There, they remain until a next stimulation via host plant root exudates takes place (from Berlanger and Powelson, 2000; drawing by Vickie Brewster, colored by Jesse Ewing).

The vascular pathogen Verticillium spreads all over the host by colonizing its xylem system (Pegg, 1989; Zhang et al., 2018). Most of the infection time, the fungus lives biotrophically and colonizes the xylem vessels of the whole plant without any 
apparent symptoms. Only in the later necrotrophic infection phase stem striping, early senescence and necrosis on leafs of stunted plants can be recognized sometimes in coincidence with substantial yield losses (Eynck et al., 2007; Tyvaert et al., 2019).

\section{The amphidiploid $V$. longisporum is an interspecific hybrid of different haploid Verticillia}

Understanding the evolution of $V$. longisporum is rather complex. $V$. longisporum is an interspecific hybrid of different haploid parental Verticillium species resulting in an amphidiploid genome (about 1.8x; Tran et al., 2013; Depotter et al., 2016, Fogelqvist et al., 2018). V. longisporum is the only non-haploid species within the Verticillium genus. These hybridization events happened at least three times in various geographical regions with different parental lineages of $V$. dahliae and further unknown species resulting in three isolates of $V$. longisporum. Figure 1.2 shows all four single ancestors of $V$. longisporum, the two unknown species A1 and D1 as well as the two V. dahliae lineages D2 and D3.

(a)

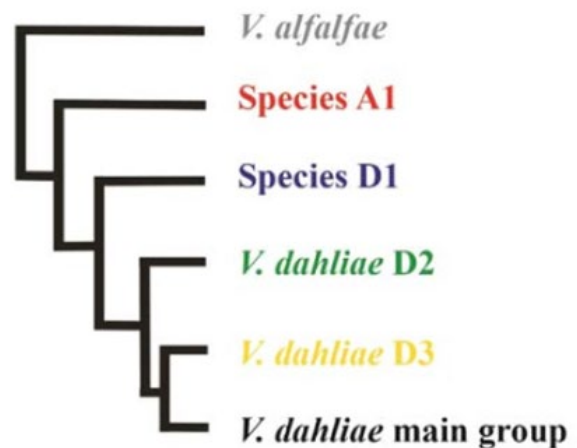

(b)

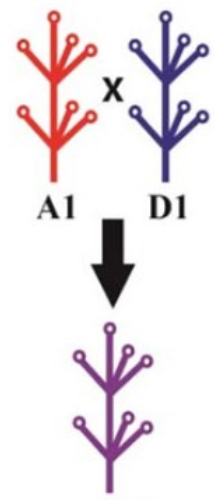

A1/D1

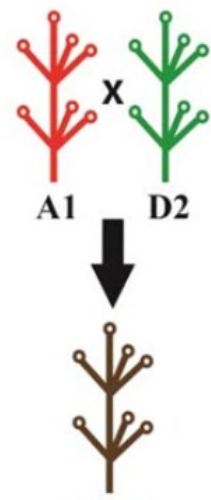

A1/D2

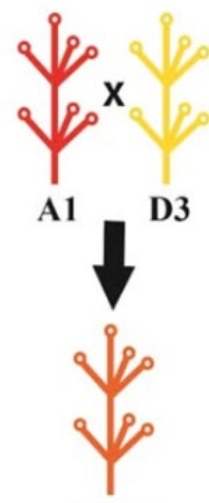

A1/D3 
Figure 1.2: Evolution of $\boldsymbol{V}$. longisporum as an interspecific hybrid of different Verticillium species. (a) Phylogenetic tree of respective progenitors of $V$. longisporum. Species A1 and D1 are regarded as unknown species, whereas $\mathrm{D} 2$ and D3 belong to two different lineages of $V$. dahliae that already have been described. (b) The four ancestors A1, D1, D2 and D3 shown in (a) hybridized in three individual hybridization events resulting in three different $V$. longisporum lineages. The unknown species A1 is present in all three hybrids as one parental strain: A1/D1, A1/D2 and A1/D3 (from Depotter et al., 2016).

The hybrids can be differentiated into A1xD1, A1xD2 and A1xD3 (Tran et al., 2013). The $V$. longisporum hybrids belonging to a combination of $A 1 \times D 1$ are considered to be virulent in Brassicaceae e.g. the lineage VI43, that have been isolated in Mecklenburg, Germany, and further investigated in this study. The two lineages A1xD2, so far only proven to be located in North America (Inderbitzin et al., 2011) as well as A1xD3 are not included in this study. The intensity of the symptoms depends different parameters like the species of the host plant, the nutrition conditions as well as on the specific isolate.

\section{Conidia and resting structures of Verticillium species and their impact on plant infection}

The different Verticillium isolates described above cannot only be discriminated genetically but also morphologically. All Verticillium species and lineages are characterized by asexual spore formation. Figure 1.3 shows differences in its physical shapes. 
(a)

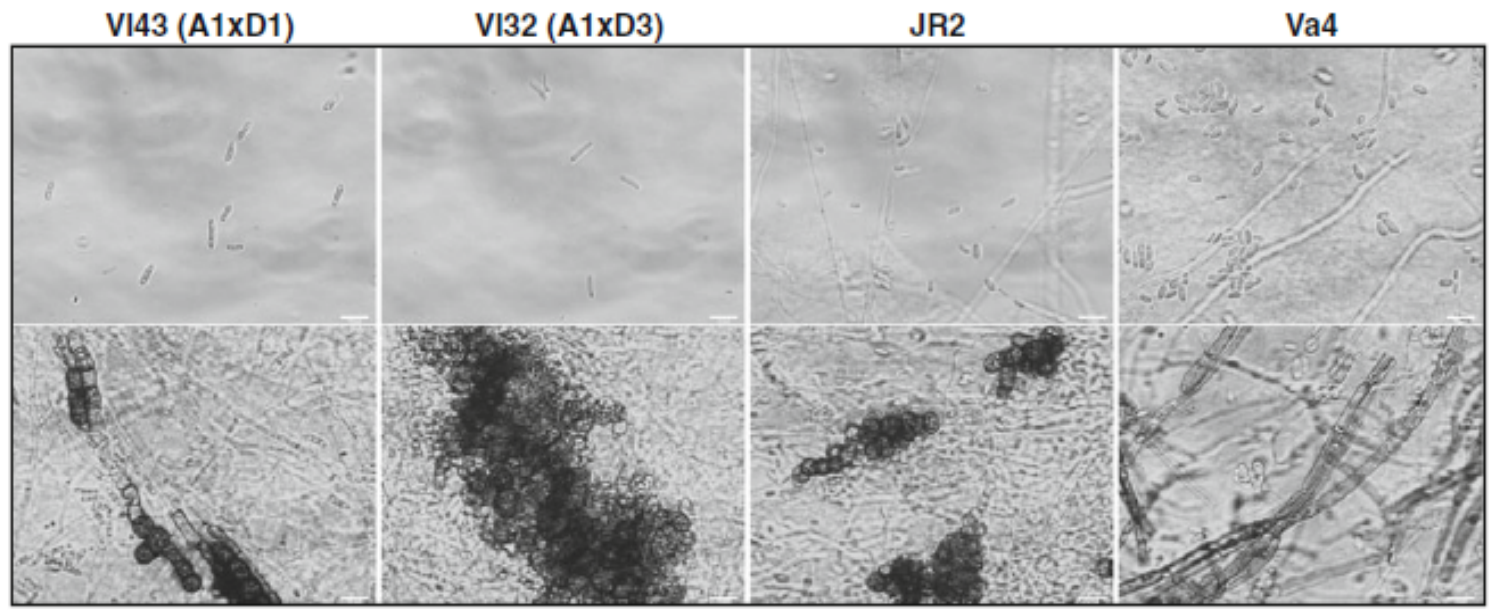

(b)

\begin{tabular}{|c|c|c|c|c|c|}
\hline & & $\begin{array}{c}\text { V. longisporum } \\
\text { A1xD1 }\end{array}$ & $\begin{array}{c}\text { V. longisporum } \\
\text { A1xD3 }\end{array}$ & V. dahliae & V. nonalfalfae \\
\hline \multicolumn{2}{|c|}{ Long asexual conidia } & + & + & rare & rare \\
\hline Microsclerotia: & $\begin{array}{l}\text { elongate } \\
\text { compact } \\
\text { melanized } \\
\text { long cell } \\
\text { round cell }\end{array}$ & $\begin{array}{l}+ \\
+ \\
+ \\
+ \\
+\end{array}$ & $\begin{array}{l}- \\
+ \\
+ \\
- \\
+\end{array}$ & $\begin{array}{l}- \\
+ \\
+ \\
- \\
+\end{array}$ & no microsclerotia \\
\hline \multicolumn{2}{|c|}{$\begin{array}{l}\text { Black mycelium } \\
\text { (melanized and thickened cell wall) }\end{array}$} & - & - & - & + \\
\hline
\end{tabular}

Figure 1.3: Morphological comparison of selected Verticillium species and isolates with regard to asexual conidia as well as resting structures. (a) Morphological differences in conidia and microsclerotia formation of two $V$. longisporum hybrids A1XD1 (virulent strain VI43) and A1XD3 (avirulent strain VI32) as well as V. dahliae JR2 and V. nonalfalfae (formerly named V. albo-atrum strain Va4). (b) Overview about conidia shapes and melanized resting structures as differentiators between $V$. longisporum (A1xD1 and $\mathrm{A} 1 \mathrm{xD} 3), V$. dahliae and $V$. nonalfalfae (from Tran et al., 2013, modified).

Microscopy pictures from asexual spores of different Verticillia taken by Tran et al. (2013) show conidia from $V$. dahliae and V. nonalfalfa (formerly named V. alboatrum strain Va4), which have a round egg-shaped structure with a length of 3.5 to $5.5 \mu \mathrm{m}$. In contrast, the conidia from $V$. longisporum have a long shape that gives the species name, with a double length of 7.1 to $8.8 \mu \mathrm{m}$ (Zeise and von Tiedemann, 2001). The asexual spores play an important role during plant infection. While initial stages of plant infection are dominated by hyphal growth during penetration of the root tip and colonization of the root cortex and the xylem vessels, the spores are 
responsible for a systemic colonialization of the vascular system of the host plant. With the transpiration flow, the conidia are translocated throughout the whole plant. After spore germination, the hyphae infest increasing areas of the plant and the final necrotrophic phase starts causing typical infection symptoms (Eynck et al., 2007; Depotter et al., 2016).

When the host plant dies, the fungus starts to produce resting structures in the dead plant material. These so-called microsclerotia exhibit a highly increased content of melanin and are released to soil with plant debris. They are produced in the stem cortex beneath the epidermis in the oilseed rape plant (Depotter et al., 2016). In contrast to the Verticillium conidia and hyphae that are predominantly present in the plant, the microsclerotia also occur in the soil. Since they are quite resistant against harsh ecological conditions, like frost, UV light, $\mathrm{pH}$ range or drought stress the melanized resting structures are able to survive in the soil for many years (Pegg and Brady, 2002; Harting et al., 2020). V. dahliae and $V$. longisporum can form microsclerotia in high quantity depending on the nutrition composition (Tran et al., 2013). The virulent A1xD1 lineage VI43 that is investigated in this study, can form big microsclerotia complexes made out of melanized hyphae in multiple shapes as elongated, compact and also rounded cells (Figure 1.3). V. nonalfalfae does not produce any complex microsclerotia but instead the fungus is able to embed thick melanin layers in the hyphal cell wall, which is visible under the microscope as black mycelium.

\section{Interactions in the plant rhizosphere}

As a soil borne organism, Verticillium is part of the rhizosphere of several plant species. Plant rhizospheres represent highly heterogeneous habitats, which are the basis for diverse biocoenoses including complex microbiomes. The microbiota are of particular importance for plant growth, health and stress resilience (Compant et al., 2019). Biochemical interactions are mainly driven by the secretion of secondary metabolites or signaling molecules from the different interaction partners as well as impacted by nutritional competition (Shaikh et al., 2018). The majority of plant-microbe interactions is characterized by a beneficial ecological relationship as many microbes act as decomposer providing the plant with nutrients 
and organic substances but also remove soil pollutants, and eliminate pathogens (Islam, 2018).

Rhizospheres consist of various bacteria and fungi dynamically interacting in an antagonistic or mutualistic way. Nazir et al. (2009) describes microbial communication in the rhizosphere as a crucial factor for the vitality of the ground substrate and calls it microbial fitness of the soil. In this context, beneficial effects of Lyophyllum spp. towards the development of Burkholderia terrae have been investigated. Lyophyllum spp. hyphae colonizing the surrounding of Burkholderia terrae support transportation and utilization of fungal exudates as nutrients for the bacterium (Warmink et al., 2011). In addition, competitive biocoenoses have been described. Toxin containing vesicles secreted by Streptomyces lividans result in significant growth suppression of Aspergillus proliferans and Verticillium dahliae (Schrempf and Merling, 2015).

Extended knowledge about the function of fungal-bacterial biocoenoses in the rhizosphere and their mechanisms of controlling each other may help to invent new strategies in using soil-microbes as biocontrol organisms against plant pathogens.

\section{Natural rhizobacteria as antagonists of microbial pathogens}

Agriculturists that are affected by soil borne pathogens in their cultivar can profit by the existing microbiota in the rhizosphere or even specifically improve the microbial composition in the soil (Gouda et al., 2018; Orozco-Mosqueda et al., 2018; Compant et al., 2019). Unfortunately, the arsenal of opportunities to react to microbial infections in agriculture is rather limited. First, resistant cultivars can be chosen to avoid an infection per se. In many cases, resistant cultivars are not available or the pathogens can overcome the resistance. Therefore, pesticides are often applied resulting in severe ecological and health risks. Alternatively, natural rhizosphere microbes can be utilized against phytopathogenic organisms (Carmona-Hernandez et al., 2019). This way, a suppressive potential of the soil can be specifically build up to counteract the pathogen using existing biological capabilities (Sikora, 1992; Steinberg et al., 2019). 
Different microbes have been characterized as antagonists against pathogens. Many filamentous fungi can be utilized to suppress pathogenic growth (Baron et al., 2019) like the beneficial rhizofungus Coniothyrium minitans that possesses activity against the phytopathogen Sclerotinia sclerotiorum (Zeng et al., 2012). A suppressive activity has also been reported for the nematophage Pochonia chlamydosporia (formerly named Verticillium chlamydosporia) with strong antagonism against plant-pathogenic nematodes (Lin et al., 2018; Uddin et al., 2019). Also bacteria can be utilized as natural antagonists. Rhizobacteria like Bacilli have been identified as effective suppressors of fungal pathogens (Albayrak; 2019). Bacillus subtilis can be used to control the growth of several phytopathogens like Ralstonia solanacearum that can infect tomato plants leading to wilting symptoms (Chen et al., 2013). Bacillus subtilis also acts against Podosphaera fusca causing powdery mildew diseases in cucurbit by activation of plants's jasmonate- and salicylic acid-dependent defense response (GarciaGutierrez et al., 2013). Bacillus thuringiensis and B. weihenstephanensis strains isolated from root-associated soil of field-grown tomatoes exhibit significant inhibition potential against the tomato pathogen $V$. dahliae JR2 but also against the oilseed rape pathogen V. longisporum VI43 (Hollensteiner et al., 2017). Against Verticillium wilt in olive Paenibacillus alvei has been identified to be an effective antagonist against $V$. dahliae also in field experiments (Martinez-Garcia et al., 2015; Markakis et al., 2016).

During this interplay, the plant, the pathogen and the biocontrol organism are intensively communicating and interacting with each other (Figure 1.4). 


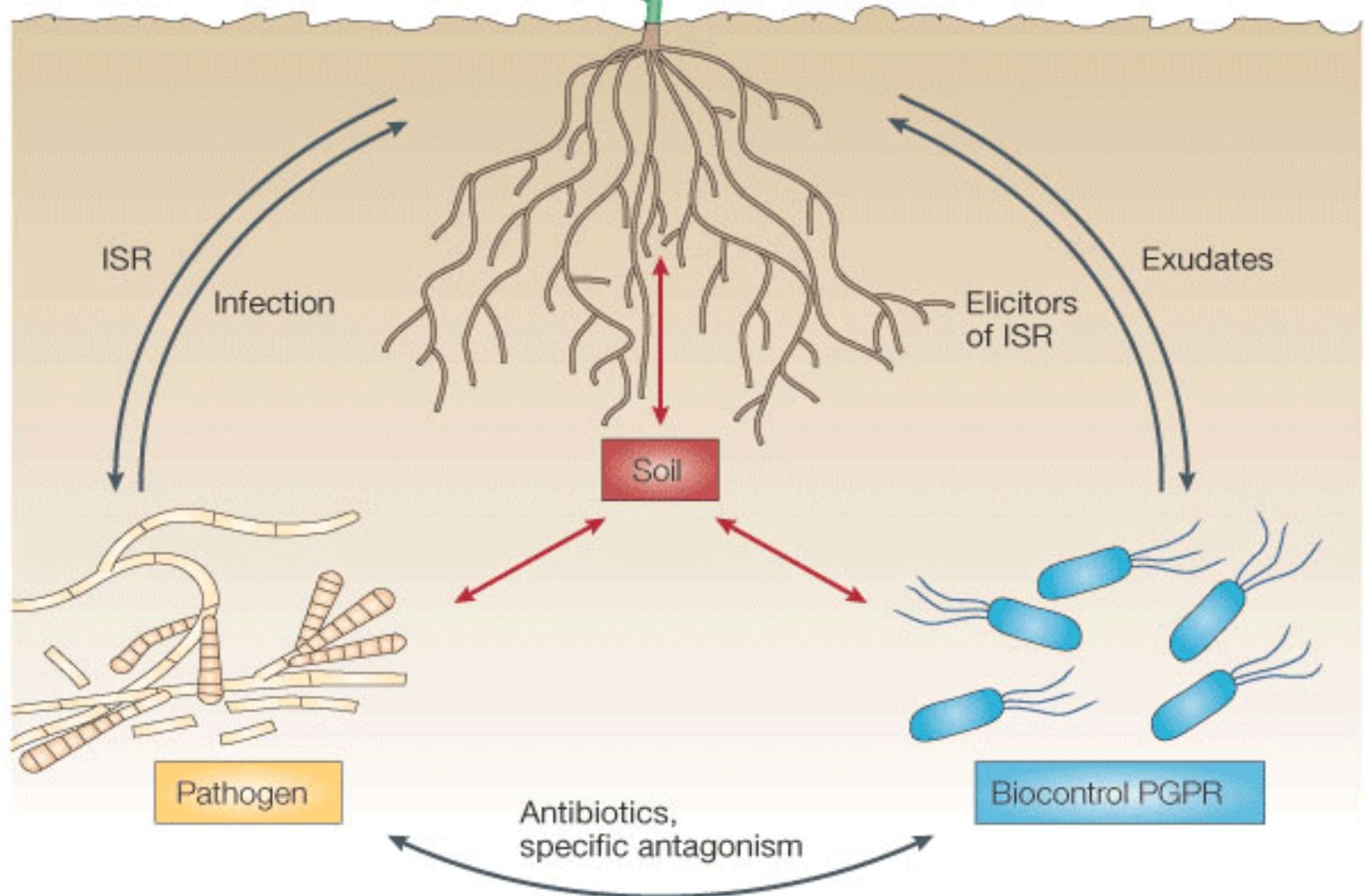

Figure 1.4: Interactions between growth-promoting rhizobacterium, plant, pathogen and soil. The interplay of diverse organisms colonizing the soil is rather complex and can influence their development directly and indirectly. A plant has to cope with a variety of soil born pathogenic species that possess a direct infection potential towards the root of specific host plants. The plant itself is able to induce systemic resistance (ISR) to repel the infection process. Antagonistic bacteria as fluorescent pseudomonads or Bacilli can also be stimulated by root exudates and even promote plant growth rate. Plant-beneficial rhizobacteria can also directly interact with the plant-pathogenic organisms, often in an antagonistic manner by the secretion of toxic metabolites. If the growth-promoting rhizobacteria (PGPR) successfully suppress the growth of the pathogen, this has an additional indirect plant supporting effect by decreasing the infection intensity of the pathogen (from Haas and Défago, 2005). 
Bacterial and fungal biocontrol organisms can protect host plants against fungal pathogens by diverse mechanisms. Many beneficial microorganisms have a direct plant growth promotion effect (Khan et al., 2019). Additionally, they are able to prime the host plant by inducing systemic resistance with specific secreted elicitors like siderophores or O-antigens before a putative pathogen has the chance to invade the plant (Conrath et al., 2002; Haas and Défago, 2005; Abuamsha et al., 2010; Berendsen et al., 2012; Goh et al., 2013; Kupferschmied et al., 2013; Kannojia et al., 2019). Besides growth promotion effects, also parasitism of the pathogen (mycoparasitism in case of fungal pathogens) plays an important role to suppress its infection intensity. A direct competition between the pathogen and the biocontrol organism for nutrients or infection spots on the plant surface can lead to a suppression of pathogenicity towards the host plant. By secretion of bioactive compounds like antibiotics, reactive oxygen species, cyanides, lipopeptides or siderophores, the antagonist can also control the growth of the phytopathogen (Weller, 2007; Yu et al., 2019a). There is a wide range of organisms with putative suppressive properties against pathogens. Bacillus thuringiensis and $B$. licheniformis for example generate their antifungal potential by the production of the cell wall degrading enzyme chitinase (Gomaa, 2012). Clonostachys rosea detoxifies the mycotoxin zearalenone of Fusarium graminearum by the production of zearalenone hydrolases (Kosawang et al., 2014).

Many different fluorescent pseudomonad species from the group of $\square$ proteobacteria have been discovered as antagonistic rhizobacteria that can install a suppressive potential in the rhizosphere expressed by a diverse arsenal of bioactive substances (Sahu et al.; 2018; Mishra and Arora, 2018). Pseudomonas protegens $\mathrm{CHAO}$ is one of the best characterized antifungal strains and has been intensively investigated by different groups (Haas and Défago, 2005; Weller, 2007; Flury et al., 2019). A multiple range of antibiotic secondary metabolites like 2,4diacetylphloroglucinol (DAPG), biosurfactants, pyoluteorin and hydrogen cyanide ( $\mathrm{HCN})$ can be secreted by $P$. protegens CHAO that are regulated by the twocomponent system GacA/GacS (Haas and Défago, 2005; Mazzola, 2007; Yan et al., 2018). 
The GacA/GacS two-component system is part of a complex posttranscriptional signal-transduction pathway, that has been discovered in Pseudomonas protegens strain CHAO (Figure 1.5). GacA/GacS initiates the translation of pathogenicity related genes. The consequence is synthesis and secretion of bioactive secondary metabolites in a stress dependent manner. Key target genes controlled by this signal pathway are involved in the synthesis of specific bioactive compounds like DAPG (operon phIA,F), HCN (operon $h c n A B C$ and anr) or pyoluteorin (p/t), are constitutively expressed. These operons are constitutively expressed but the transcripts are not translated because of the translational repressors RsmA and RsmE, which bind to the ribosomal binding site. The GacS sensor kinase is located in the membrane and is stimulated by the perception of appropriate environmental stress stimuli. This results in phosphorylation of the response regulator GacA, which activates the formation of the small regulatory RNAs $r s m X, r s m Y$ and $r s m Z$. The regulatory RNAs bind the translational repressors RsmA and RsmE and allow the translation of the mRNAs of the target genes (Figure 1.5). Under stress-induced derepression, the translation of the target genes $p h I A, F, h c n A B C$, anr or plt are activated and the resulting enzymes produce the corresponding secondary metabolites, which are released by the cell (Laville et al., 1992; Zuber et al., 2003; Heeb et al., 2005; Gonzalez et al., 2008; Brencic et al. 2009; Wei et al., 2013; Nandi et al., 2015; Traxler and Kolter, 2015; Yan et al., 2018). 


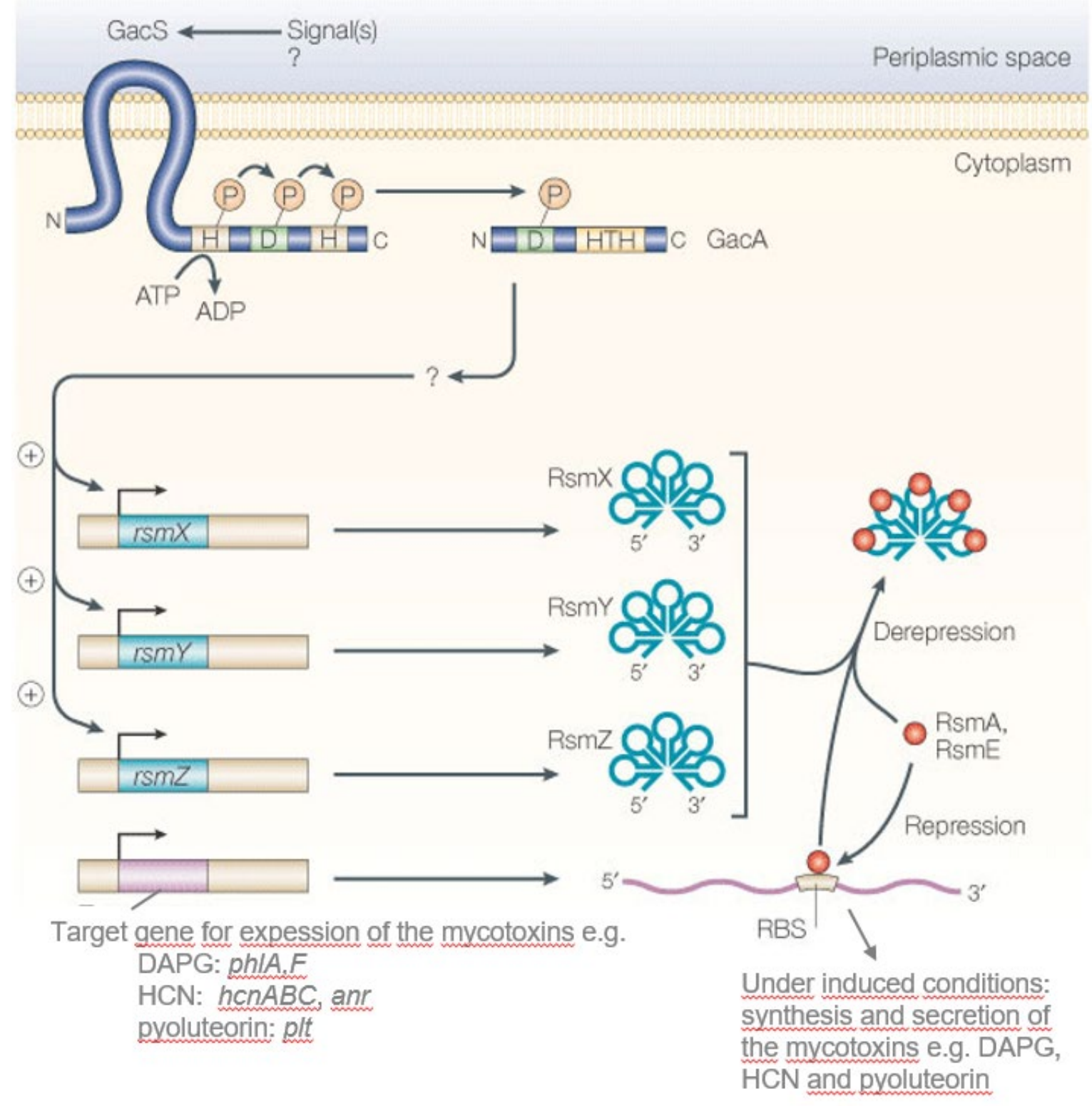

Figure 1.5: Model of the GacA/GacS signal-transduction pathway in Pseudomonas protegens strain CHA0. A diverse pattern of genes coding for antifungal compounds, in the figure called 'target genes', are constantly expressed: the operon phIA,F codes for the enzymes to form 2,4-diacetylphloroglucinol (DAPG); the operon $h c n A B C$ codes for the enzymes to form hydrogen cyanide $(\mathrm{HCN})$; the gene plt codes for pyoluteorin producing enzymes. The respective mRNAs are post-transcriptionally inhibited by the small proteins RsmA and RsmE binding at the ribosome-binding site (RBS). Stimulated by external signals, e.g. specific root exudates, the sensor kinase GacS, an integrated membrane protein, is phosphorylated. Along the signal transduction, the phosphate is transferred to the response regulator GacA. In this induced form, GacA activates the expression of the small RNAs rsmX, rsmY and rsmZ that act as derepressors of RsmA and RsmE. This way the translation inhibition of the target mRNAs is nullified under inducing conditions caused by the external signal. The synthesis of the bioactive toxins as well as their secretion takes place (from Haas and Défago, 2005). 
Besides the DAPG producer P. protegens CHA0, also the phenazine producer $P$. synxantha 2-79 (formerly named $P$. fluorescens 2-79) is further investigated in this study. Phenazines show a broad-range antibiotic spectrum against many different microbial pathogens (Biessy and Filion, 2018). Different phenazine derivates are synthesized during the phenazine pathway. $P$. synxantha 2-79 is capable of the production of the well-characterized and highly effective antibiotic phenazine-1-carboxylic acid (PCA). Figure 1.6 shows the pathway of PCA with multiple steps catalyzed by the seven-gene operon phzABCDEFG (Mavrodi et al., 1998 and 2006; Biessy and Filion, 2018).

(a) Pseudomonas synxantha 2-79

$p h z \mid \vec{A}>\vec{B}>C \Rightarrow \vec{D} \Rightarrow \vec{F}>\vec{G}$

(b)

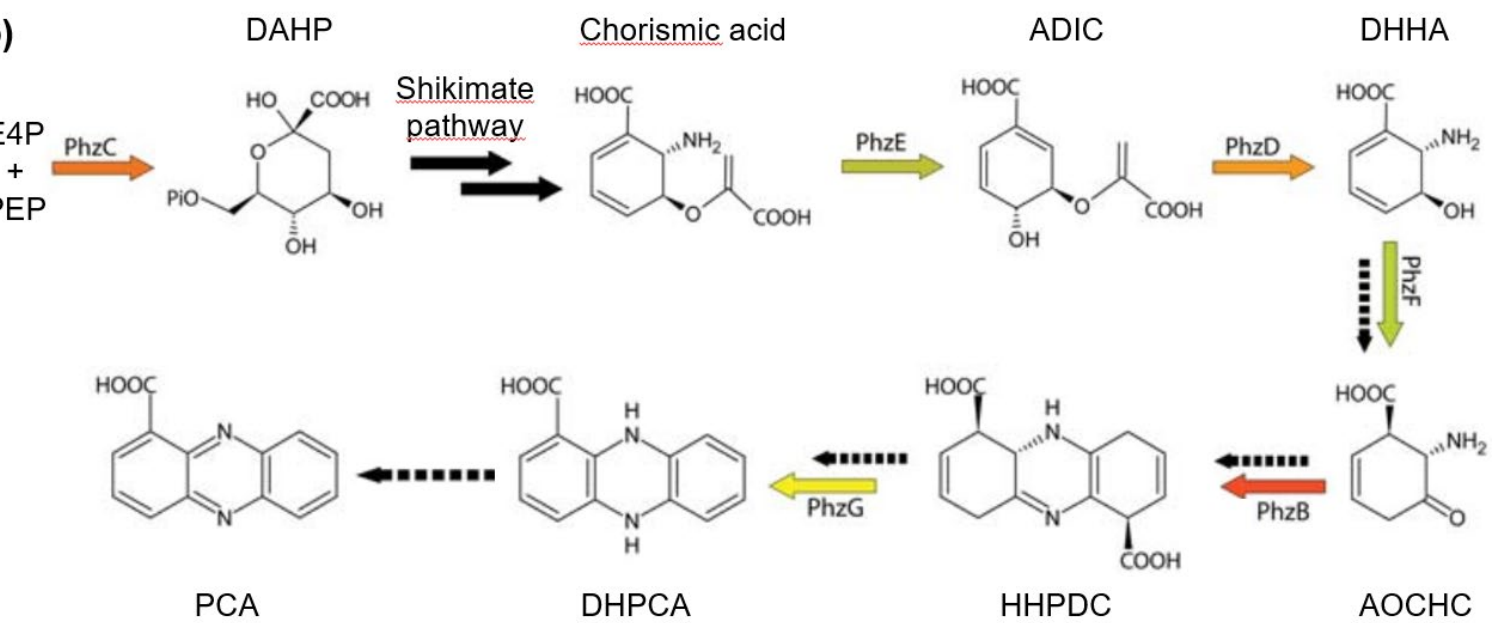

Figure 1.6: Phenazin seven-gene operon and pathway in phenazine-secreting Pseudomonas spp. (a) Arrangement of the seven genes phzA-G coding for enzymes involved in the phenazine biosynthesis inter alia of $P$. synxantha 2-79 (formerly named $P$. fluorescens 2-79). (b) Function of the seven enzymes PhzA-G during the phenazine pathway resulting in the phenazine derivate phenazine-1carboxylic acid (PCA). Colored arrows correspond to the gene color of the respective phenazine gene from (a) and mark a catalyzed reaction. Dotted black arrows symbolize spontaneous and uncatalyzed conversions. Solid black arrows during the shikimate pathway indicate further unpresented reactions from 3-deoxyD-arabinoheptulosonate-7-phosphate (DAHP) to chorismate. Further abbreviations: E4P: erythrose-4-phosphate; PEP: phosphoenolpyruvate; ADIC: 2amino-4-deoxychorismic acid; DHHA: trans-2,3-dihydro-3-hydroxyanthranlic acid; AOCHC: 6-amino-5-oxo-cyclohex-2-ene-1-carboxylic acid; HHPDC: hexahydrophenazine-1,6-dicarboxylic acid; DHPCA: 5,10-dihydrophenazine-1carboxylic acid (from Biessy and Filion, 2018; modified). 
The formation of the secondary metabolite phenazine is connected to the primary metabolism of the shikimate pathway, which produces the aromatic amino acids phenylalanine, tyrosine and tryptophan. The initial step of the shikimate pathway is the conjunction of erythrose 4-phosphate $(\mathrm{E} 4 \mathrm{P})$ from the pentose phosphate pathway and phosphoenolpyruvate (PEP) from glycolysis to 3-deoxy-Darabinoheptulosonate-7-phosphate (DAHP) catalyzed by the enzyme PhzC. Aromatic amino acid biosynthesis continues through shikimate to chorismate. Already 1972, shikimate has been described as precursor for phenazine synthesis (Longley et al., 1972). In five subsequent enzymatic reactions catalyzed by PhzE, PhzD, PhzF, PhzB and PhzG the antibiotic phenazine metabolite phenazine-1carboxylic acid (PCA) is formed which is secreted by $P$. synxantha 2-79 (Mavrodi et al., 1998; Biessy and Filion, 2018). The phenazine deficient 2-79 stain used in this study lacks the full seven-gene locus and is generally impaired in the expression of any phenazine (Mavrodi et al., 1998).

\section{Aims and structure of this study}

The major goal of this study was to compare the mutual impact on growth of phytopathogenic fungal Verticillia and fluorescent pseudomonads as soil bacteria during co-cultivation in different settings and with different nutrition. Possible suppressive impacts of the bacterium due to different antifungal strain-specific capabilities towards fungal growth rate, morphology and expression patterns should be analyzed on solid or liquid media with and without spatial limitations.

Starting point of the thesis was the determination of the genomic potential of two selected bacteria (chapters 2 \& 3), followed by co-cultivations of Verticillia and wildtype and mutant bacterial strains during different nutritional conditions on agar plates (chapter 4) and finally in liquid media including a microfluidic confrontation assay (chapter 5).

In chapter 2 (Nesemann et al., 2015a) the draft genomic sequence of the beneficial rhizobacterium Pseudomonas fluorescens DSM8569 is presented. P. fluorescens DSM8569 have been isolated in Rostock, Germany, and have initially been 
described by Berg and Ballin in 1994. This strain has been selected as a putative candidate for growth inhibition of $V$. longisporum VI43, infecting oil seed rape, as it is a natural isolate of the same rhizosphere. This is why in this study $P$. fluorescens DSM8569 is called $P_{\text {_rhizo. }}$

In chapter 3 (Nesemann et al., 2015b) the draft genome sequence of $P$. synxantha 2-79 is presented. $P$. synxantha 2-79 (formerly named $P$. fluorescens 2-79; Weller and Cook; 1983) is capable of the synthesis of phenazines. It was analyzed for its potential in growth suppression of V. longisporum VI43. Mazurier et al. (2009) showed that $P$. synxantha 2-79 is capable of secreting antifungal phenazines but not of DAPG. This is why in this study $P$. synxantha 2-79 is called P_phen.

In chapter 4 (Nesemann et al., 2018), virulent phytopathogenic Verticillium strains have been selected for co-cultivation with potential natural antagonistic rhizobacteria. It was analyzed whether a soil bacterium, derived from a specific

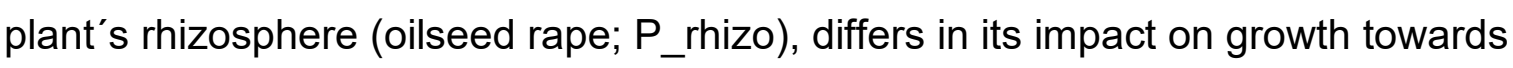
the corresponding fungal plant pathogen of the same plant rhizosphere ( $V$. longisporum on oilseed rape) compared to pathogens of other hosts ( $V$. dahliae on tomato). Further, it was analyzed, whether different growth conditions as high glucose environment or restricted nutrition on a complex pectin containing plant medium change the potential biocontrol of fungal growth by bacteria. Various coculture experiments of three different Pseudomonas strains combined with two fungal pathogens were performed. $P$. fluorescens DSM8569 (P_rhizo), derived from the rhizosphere of oilseed rape. $P$. synxantha 2-79 produces phenazines (P_phen), whereas P. protegens CHAO (P_DAPG) possesses no genes for enzymes for phenazines, but for different other antifungal secondary metabolites, including 2,4-diacetylphloroglucinol (DAPG). The haploid fungus $V$. dahliae JR2 infects tomato, whereas the amphidiploid V. Iongisporum VI43 hybrid fungus infects oilseed rape.

In chapter 5, the mutualistic interaction of Verticillium and Pseudomonas was analyzed in a microfluidic interaction device with embedded interaction channels. The fungus and the bacteria were inoculated on opposite sides of the channels. 
The narrow microchannels limit the amount of hyphae accessing the channel. They were filled with a liquid medium rich in pectins and amino acids. This improves the microscopic observance by physically restricting hyphae to grow only in one direction. The impact of respective bacterial strains on Verticillium growth was quantified and the hyphal growth distance was measured under microscopic magnification. This method also allows deeper insights into fungal morphological adaption to bacterial impact. The Verticillium transcriptome in interaction with the DAPG-producing $P$. protegens CHAO (P_DAPG) in liquid media was sequenced to gain further information about activated and deferred fungal pathways during bacterial co-cultivation.

Finally, chapter 6 is a general discussion regarding the topics presented in the single chapters above. 


\section{Chapter 2: Draft genome sequence of the beneficial rhizobacterium Pseudomonas fluorescens DSM8569}

Kai Nesemann ${ }^{\mathrm{a}}$, Susanna A. Braus-Stromeyer ${ }^{\mathrm{a}}$, Andrea Thuermer ${ }^{\mathrm{b}}$, Rolf Daniel ${ }^{\mathrm{b}}$, Gerhard H. Brausa\#

alnstitute of Microbiology and Genetics, Department of Molecular Microbiology and Genetics, Georg-August-Universität, Göttingen, Germany.

${ }^{b}$ Göttingen genomics laboratory (G2L) at the Institute of Microbiology and Genetics, Department of Genomic and Applied Microbiology, Georg-AugustUniversität, Göttingen, Germany.

\#Corresponding author: Gerhard H. Braus; Telephone: +49-551-3933771; Fax: +49-551-3933330; E-mail: gbraus@gwdg.de

Author contributions:

Culturing and harvesting of Pseudomonas biomass: KN

DNA extraction and measurement: KN

Preparation of sequencing setup: KN

Further DNA sample preparation for sequencing: AT

Generation of a shotgun-sequencing library: AT

Sequencing of the whole genome: AT

De novo assembly of shotgun reads: AT

Draft genome annotation: AT

Data interpretation: $\mathrm{KN}$

Supervision: GB; RD; SB

Manuscript: GB, RD, SB, AT, KN 


\section{Draft Genome Sequence of the Beneficial Rhizobacterium Pseudomonas fluorescens DSM 8569, a Natural Isolate of Oilseed Rape (Brassica napus)}

\section{Kal Nesemann," Susanna A. Braus-Stromeyer,, Andrea Thuermer, ${ }^{b}$ Rolf Danlel, ${ }^{b}$ Gerhard H. Braus ${ }^{\mathrm{a}}$}

Department of Molecular Microbiology and Genetics, Institute of Microbiology and Genetics, Georg-August Universitat, Gottingen, Germany"; Department of Genomic and Applied Microbiology \& Gottingen Genomics Laboratory, Institute of Microbiology and Genetics, Georg-August Universitat, Gottingen, Germany'

Pseudomonas fluorescens DSM 8569 represents a natural isolate of the rhizosphere of oilseed rape (Brassica napus) in Germany and possesses antagonistic potential toward the fungal pathogen Verticillium. We report here the draft genome sequence of strain DSM 8569, which comprises 5,914 protein-coding sequences.

Recelved 4 February 2015 Accepted 18 February 2015 Published 26 March 2015

Citation Nesemann K, Braus-Stromeyer SA. Thuermer A. Danvel R. Braus GH. 2015. Draft genome sequence of the beneficlal rhizobacterlum Pseudomonas fluorescens DSM BS69, a natural Isolate of ollseed rape (Frassica napus). Genome Announc 302):e00137-15 dot:10.1128/genomea.00137-15.

Copyright $\Theta 2015$ Nesemann et al. This is an open-access artide distributed under the terms of the Greative Commons Attributicn 3.0 Unported licerise

Address correspondence to Gerhard H. Braus, gbrausegwdg.de.

seudomonas represents an abundant bacterial genus in many antagonistic root-associated communities (1). Pseudomonas fluorescens DSM 8569 was isolated from the rhizosphere of the Verticillium host oilseed rape (Brassica napus) in Rostock, Germany (2). The phytopathogenic fungus Verticillium requires an activator of adhesion for systemic infection of plant roots (3). The bacterium revealed a strong antimycotic effect on the phytopathogenic fungus Verticillium (4). A variety of secreted secondary metabolites with antimycotic impact were described in fluorescent pseudomonads, such as 2,4-diacetylphloroglucinol (DAPG), pyoluteorin, $\mathrm{HCN}$, or pyrrolnitrin. A two-component system, gacAgacS, was discovered in Pseudomonas protegens $\mathrm{CHA0}$, which posttranscriptionally regulates the synthesis and secretion of these compounds (1). The synthetic pathway of phenazines in P. fluorescens 2-79 was investigated previously $(5,6)$. The chemical group of phenazines causes oxidative stress by accumulating toxic superoxide radicals and hydrogen peroxide in the target cell (7). Currently, it is unknown which suppressive mechanisms are responsible for the antagonistic potential of $P$. fluorescens DSM 8569. Genomic sequencing will be helpful in understanding the plant-promoting and antagonistic potentials of fluorescent pseudomonads.

The biocontrol strain $P$. fluorescens DSM 8569 was obtained from the DSMZ (Braunschweig, Germany). The genomic DNA was isolated using the MasterPure complete DNA and RNA purification kit (Epicentre, Madison, WI, USA). A shotgun sequencing library was generated, employing the Nextera DNA sample preparation kit, according to the manufacturer's instructions. The whole genome of DSM 8569 was sequenced with the Genome Analyzer IIx (Illumina, San Diego, CA, USA). In total, 8.3 million paired-end reads of $112 \mathrm{bp}$ were generated. The de novo assembly of all shotgun reads using SPAdes 3.0.0 (8) resulted in 135 contigs $>3 \mathrm{~kb}$ and 119-fold coverage. The draft genome sequence comprises $6.6 \mathrm{Mb}$ and $\mathrm{a} \mathrm{G}+\mathrm{C}$ content of $61.01 \%$. Genome annotation was performed by the use of Prokka (9). The draft genome was found to harbor 2 rRNA clusters, 43 tRNA genes, 4,560 protein- coding genes with a predicted function, and 1,354 genes coding for hypothetical proteins.

The proteins involved in secondary metabolism were analyzed. The genes necessary for pyoluteorin synthesis (GenBank accession numbers 15560761, 15560764, 15560758, 15560774, and 15560768) and the entire phenazine operon described for P. fluorescens 2-79 (L48616.1) are absent. At least one gene (phlG [15563823]) required for the regulation of 2,4-diacetylphloroglucinol synthesis is missing in DSM 8569. In contrast, the genes responsible for HCN synthesis (15560558 and 15559866) are present in DSM 8569.

Nucleotide sequence accession numbers. This whole-genome shotgun project has been deposited at DDBJ/EMBL/GenBank under the accession no. JXOE00000000. The version described in this paper is the first version, JXOE01000000.

\section{ACKNOWLEDGMENTS}

This work was supported by the Federal Ministry of Education and Research (BMBF) BioFung project and the DFG through grants awarded to G.H.B.

\section{REFERENCES}

1. Haas D, Défago G. 2005. Biological control of soil-borne pathogens by fluorescent pseudomonads. Nat Rev Microbiol 3:307-319. http:// dx.doi.org/10.1038/nrmicrol129.

2. Berg G, Ballin G. 1994. Bacterial antagonists to Verticillium dahliae Kleb. J Phytopathol 141:99-110. http://dx.doi.org/10.1111/j.1439 $-0434.1994 . t b 01449 . x$

3. Tran VT, Braus-Stromeyer SA, Kusch H, Reusche M, Kaever A, Kuhn A, Valerius O, Landesfeind M, A\&hauer K, Tech M, Hoff K, Pena-Centeno T, Stanke M, Lipka V, Braus GH. 2014. Verticillium transcription activator of adhesion $\mathrm{Vta} 2$ suppresses microsclerotia formation and is required for systemic infection of plant roots. New Phytol 202:565-581. http:// dx.doi.org/10.1111/nph.12671.

4. Berg G, Opelt K, Zachow C, Lottmann J, Gotz M, Costa R, Smalla K. 2006. The rhizosphere effect on bacteria antagonistic towards the pathogenic fungus Verticillium differs depending on plant species and site. FEMS Microbiol Ecol 56:250-261. http://dx doi-org/10.1111/j.1574 $-6941.2005 .00025 x$. 
Nesemann et al.

5. Mavrodi DV, Ksenzenko VN, Bonsall RF, Cook RJ, Boronin AM, Thomashow LS. 1998. A seven-gene locus for synthesis of phenazine-1-carboxylic acid by Pseudomonas fluorescens 2-79. J Bacteriol 180:2541-2548.

6. Mavrodi DV, Peever TL, Mavrodi OV, Parejko JA, Raaijmakers JM, Lemanceau P, Mazurier S, Heide L, Blankenfeldt W, Weller DM, Thomashow LS. 2010. Diversity and evolution of the phenazine biosynthesis pathway. Appl Environ Microbiol 76:866-879. http://dx.doi.org/10.1128/
AEM.02009-09.

7. Hassett DJ, Woodruff WA, Wozniak DJ, Vasil ML, Cohen MS, Ohman DE. 1993. Cloning and characterization of the Pseudomonas aeruginosa

sod $A$ and sod $B$ genes encoding manganese- and iron-cofactored superoxide dismutase: demonstration of increased manganese superoxide dismutase activity in alginate-producing bacteria. J Bacteriol 175:7658-7665.

8. Bankevich A, Nurk S, Antipov D, Gurevich AA, Dvorkin M, Kulikov AS, Lesin VM, Nikolenko SI, Pham S, Prjibelski AD, Pyshkin AV, Sirotkin AV, Vyahhi N, Tesler G, Alekseyev MA, Pevzner PA. 2012. SPAdes: a new genome assembly algorithm and its applications to single-cell sequencing. I Comput Biol 19:455-477. http://dx.doi.org/10.1089/cmb.2012.0021.

9. Seemann T. 2014. Prokka: rapid prokaryotic genome annotation. Bioinformatics 30:2068-2069. http://dx.doi.org/10.1093/bioinformatics/btul 53. 


\section{Chapter 3: Draft genome sequence of the phenazine producing Pseudomonas fluorescens 2-79}

Kai Nesemann ${ }^{a}$, Susanna A. Braus-Stromeyer ${ }^{\mathrm{a}}$, Andrea Thuermer ${ }^{\mathrm{b}}$, Rolf Daniel ${ }^{\mathrm{b}}$, Dmitri Mavrodic ${ }^{c}$ Linda S. Thomashow ${ }^{c}$, Gerhard H. Braus ${ }^{\text {a\# }}$

alnstitute of Microbiology and Genetics, Department of Molecular Microbiology and Genetics, Georg-August-Universität, Göttingen, Germany.

${ }^{b}$ Göttingen genomics laboratory (G2L) at the Institute of Microbiology and Genetics, Department of Genomic and Applied Microbiology, Georg-AugustUniversität, Göttingen, Germany.

'Department of Plant Pathology, USDA-ARS Root Disease and Biocontrol Research Unit, Washington State University, Pullmann, WA, USA.

\#Corresponding author: Gerhard H. Braus; Telephone: +49-551-3933771; Fax: +49-551-3933330; E-mail: gbraus@gwdg.de

Author contributions:

Providing Pseudomonas strain: DM, LT

Culturing and harvesting of Pseudomonas biomass: KN

DNA extraction and measurement: KN

Preparation of sequencing setup: KN

Further DNA sample preparation for sequencing: AT

Generation of a shotgun-sequencing library: AT

Sequencing of the whole genome: AT

De novo assembly of shotgun reads: AT

Draft genome annotation: AT

Data interpretation: $\mathrm{KN}$

Supervision: GB, RD, SB

Manuscript: GB, RD, SB, AT, KN 


\title{
Draft Genome Sequence of the Phenazine-Producing Pseudomonas fluorescens Strain 2-79
}

\author{
Kal Nesemann," Susanna A. Braus-Stromeyer," Andrea Thuermer, ${ }^{b}$ Rolf Danlel, ${ }^{b}$ Dmitri V. MavrodI, ${ }^{\circ}$ LInda S. Thomashow, ${ }^{d}$ \\ David M. Weller, ${ }^{\text {d Gerhard H. Braus }}{ }^{\text {a }}$
}

Department of Molecular Microbiology and Genetics, Institute of Microbiology and Genetics, Georg-August Universitatt, Gottingen, Germany"; Department of Genomic and Applied Microbiology and Gottingen Genornics Laboratory, Institute of Microbiology and Genetics, Georg-August Universitat, Gottingen, Germanyb; Department of Biological Sciences, University of Southern Mississippi, Hattiesburg, Mississippi, USAE; USDA-ARS Root Disease and Biological Control Research Unit, Washington State University, Pullinan, Washington, USA

Pseudomonas fluorescens strain 2-79, a natural isolate of the rhizosphere of wheat (Triticum aestivum L.), possesses antagonistic potential toward several fungal pathogens. We report the draft genome sequence of strain 2-79, which comprises 5,674 proteincoding sequences.

Recelved 4 February 2015 Accepted 18 February 2015 Published 26 March 2015

Citation Nesemann K. Braus-Stromeyer SA. Thuermer A, Dankel R. Mavrodi DV, Thomashow LS, Weller DM, Braus GH. 2015. Draft genorne sequence of the phenazineproducing Pseudomonas fiucrescens strain 2-79. Genome Announc. 3(2)e00130-15. dok10.1 128/genomeA.00130-15.

Copyright 02015 Nesemann et al. This is an open-access article distributed under the terms of the Greative Commons Autribution 3.0 Unported licerise.

Address correspondence to Gerhard H. Braus, gbrausegwdg.de.

he concentration and composition of antibiotic-producing,
root-colonizing organisms are important factors that partially
determine the suppressiveness of soils toward certain soil-borne
diseases (1).
Fluorescent pseudomonads play a major role in suppressing
take-all disease of wheat caused by the fungal pathogen Gaeuman-
nomyces graminis var. tritici (Sacc.) (2). In 1979, Weller and Cook
isolated bacteria from roots of wheat plants grown in take-all sup-
pressive soils in Washington state, USA (3). Pseudomonas fluore-
scens $2-79$ (NRRL B-15132) was characterized as a strong biolog-
ical control agent suppressing G. graminis in vitro and in planta.
Wheat plants infected with G. graminis var. tritici and additionally
treated with P. fluorescens $2-79$ resulted in taller plants, more
heads, and fewer symptoms of root disease compared to the con-
trol plants without bacterial treatment. Bacterial treatment could
increase the yield up to $147 \%$ in soils fumigated with methyl bro-
mide and up to $27 \%$ in natural soils (3). P. fluorescens $2-79$ pro-
duces phenazines, which represent a diverse chemical group of
nitrogen-containing heterocyclic pigments possessing broadly in-
hibitory properties toward bacteria and fungi (4). Phenazines un-
dergo redox reactions with NADH/NADPH, leading to an in-
crease of toxic superoxide radicals and hydrogen peroxide in the
target cells (5). Mavrodi et al. investigated the biosynthesis path-
way of phenazines in P. fluorescens $2-79$ (6).
Genomic DNA of P. fluorescens $2-79$ was isolated by using the
MasterPure Complete DNA and RNA purification kit (Epicen-
tre, Madison, WI, USA). A shotgun sequencing library was
generated employing the Nextera DNA sample preparation kit
following the manufacturer's instructions. The whole genome
of $P$. fluorescens $2-79$ was sequenced with the Genome Analyzer
IIx (Illumina, San Diego, CA, USA). In total, 8.5 million
paired-end reads of 112 bp were generated. De novo assembly of
all shotgun reads using SPAdes version 3.0 .0 ( 7 ) resulted in 143
contigs $>3$ kb and 123 -fold coverage. The draft genome se-
quence comprises 6.4 Mb and a GC content of $59.83 \%$. Ge- nome annotation was performed by using Prokka (8). The draft genome harbored 1 rRNA cluster, 47 tRNA genes, 4,286 protein-encoding genes with function prediction, and 1,388 genes coding for hypothetical proteins.

Proteins involved in secondary metabolism were analyzed. The gene hcnA (GenBank accession no. 15560558) involved in HCN synthesis and the phenazine operon (GenBank accession no. L48616.1) are present in P. fluorescens 2-79. The gene phlD (GenBank accession no. 15563828) necessary for the synthesis of 2,4diacetylphloroglucinol (DAPG) is absent in 2-79.

Nucleotide sequence accession numbers. This whole-genome shotgun project has been deposited at DDBJ/EMBL/GenBank under the accession number JXCQ00000000. The version described in this paper is the first version, JXCQ01000000.

\section{ACKNOWLEDGMENTS}

This work was supported by the Federal Ministry of Education and Research (BMBF) BioFung project and the DFG through grants awarded to G.H.B. We also are grateful for support provided by USDA-NRI grant no 2011-67019-30212 from the USDA-NIFA Soil Processes program.

\section{REFERENCES}

1. Haas D, Défago G. 2005. Biological control of soil-borne pathogens by fluorescent pseudomonads. Nat Rev Microbiol 3:307-319. http:// dx.doi.org/10.1038/nrmicrol129.

2. Cook RJ, Rovira AD. 1976. The role of bacteria in the biological control of Gaeumannomyces graminis by suppressive soils. Soil Biol Biochem 8:269-273. http://dx.doi.org/10.1016/0038-0717(76)90056-0.

3. Weller DM, Cook RJ. 1983. Suppression of take-all of wheat by seed treatments with fluorescent pseudomonads. Phytopathology 73:463-469. http://dx.doi.org/10.1094/Phyto-73-463.

4. Mavrodi DV, Blankenfeldt W, Thomashow LS. 2006. Phenazine compounds in fluorescent Pseudomonas spp. biosynthesis and regulation. Annu Rev Phytopathol 44:417-445. http://dx.doi.org/10.1146/ annurevRev Phytopathol 44:417.

5. Hassett DJ, Woodruff WA, Wozniak DJ, Vasil ML, Cohen MS, Ohman DE. 1993. Cloning and characterization of the Pseudomonas aeruginosa sod $A$ and sod $B$ genes encoding manganese- and iron-cofactored superoxide 
dismutase: demonstration of increased manganese superoxide dismutase activity in alginate-producing bacteria. J Bacteriol 175:7658-7665.

6. Mavrodi DV, Peever TL, Mavrodi OV, Parejko JA, Raaijmakers JM, Lemanceau P, Mazurier S, Heide L, Blankenfeldt W, Weller DM, Thomashow LS. 2010. Diversity and evolution of the phenazine biosynthesis pathway. Appl Environ Microbiol 76:866-879. http://dx.doi.org/10.1128/ AEM.02009-09.
7. Bankevich A, Nurk S, Antipov D, Gurevich AA, Dvorkin M, Kulikov AS, Lesin VM, Nikolenko SI, Pham S, Priibelski AD, Pyshkin AV, Sirotkin AV, Vyahhi N, Tesler G, Alekseyev MA, Pevzner PA. 2012. SPAdes: a new genome assembly algorithm and its applications to single-cell sequencing. J Comput Biol 19:455-477. http://dx.doi.org/10.1089/cmb.2012.0021.

8. Seemann T. 2014. Prokka: rapid prokaryotic genome annotation. Biolnformatics 30:2068455-2069. http://dx.doi.org/10.1093/bioinformatics/btul53. 


\section{Chapter 4: Fluorescent pseudomonads pursue media-dependent strategies to inhibit growth of pathogenic Verticillium fungi}

Kai Nesemann ${ }^{1}$, Susanna A. Braus-Stromeyer ${ }^{1}$, Rebekka Harting ${ }^{1}$, Annalena Höfer $^{1}$, Harald Kusch ${ }^{1,2}$, Alinne Batista Ambrosio ${ }^{1}$, Christian Timpner ${ }^{1}$, Gerhard H. Braus $^{1^{*}}$

${ }^{1}$ Institute of Microbiology and Genetics and Göttingen Center for Molecular Biosciences (GZMB), Georg-August-Universität Göttingen, Germany.

${ }^{2}$ present address: Department of Medical Informatics, Georg-August-Universität Göttingen, Germany.

* Corresponding author: Gerhard H. Braus, Grisebachstraße 8, 37077 Göttingen, Germany, Telephone: +49-551-3933771; Fax: +49-551-3933330; E-mail: gbraus@gwdg.de

Author contributions:

Fig 1: $A A, K N$

Fig 2: AA, KN

Fig 3: $\mathrm{AA}, \mathrm{KN}$

Fig 4: AA, KN

Fig 5: AA, KN

Fig 6: $\mathrm{RH}, \mathrm{AH}$

Fig 7: $\mathrm{RH}, \mathrm{AH}$

Fig S1: RH, CT

Table 1: KN

Table: 2: $\mathrm{RH}, \mathrm{AH}$

Table S1: RH, AH, KN

Table S2: RH, CT

Table S3: RH, CT

Table S4: KN

Supervision and scientific advice: GB, SB, RH, HK Manuskript: GB, RH, AH, KN 


\title{
Fluorescent pseudomonads pursue media-dependent strategies to inhibit growth of pathogenic Verticillium fungi
}

\author{
Kai Nesemann ${ }^{1}$ - Susanna A. Braus-Stromeyer ${ }^{1} \cdot$ Rebekka Harting $^{1} \cdot$ Annalena Höfer $^{1}$. \\ Harald Kusch ${ }^{1,2}$. Alinne Batista Ambrosio ${ }^{1}$. Christian Timpner ${ }^{1}$. \\ Gerhard H. Braus ${ }^{1}$ (D)
}

Received: 9 August 2017 /Revised: 30 October 2017 / Accepted: 30 October 2017

(1) Springer-Verlag GmbH Germany, part of Springer Nature 2017

\begin{abstract}
Verticillium species represent economically important phytopathogenic fungi with bacteria as natural rhizosphere antagonists. Growth inhibition pattems of Verticillium in different media were compared to saprophytic Aspergillus strains and were significantly more pronounced in various co-cultivations with different Pseudomonas strains. The Brassica napus rhizosphere bacterium Pseudomonas fluorescens DSM8569 is able to inhibit growth of rapeseed (Verticillium longisporum) or tomato (Verticillium dahliae) pathogens without the potential for phenazine or 2,4-diacetylphloroglucinol (DAPG) mycotoxin biosynthes is. Bacterial inhibition of Verticillium growth remained even after the removal of pseudomonads from cocultures. Fungal growth response in the presence of the bacterium is independent of the fungal control genes of secondary metabolism $L A E 1$ and CSN5. The phenazine producer P. fluorescens 2-79 (P_phen) inhibits Verticillium growth especially on high glucose solid agar surfaces. Additional phenazine-independent mechanisms in the same strain are able to reduce fungal surface growth in the presence of pectin and amino acids. The DAPG-producing Pseudomonas protegens CHA0 (P_DAPG), which can also produce hydrogen cyanide or pyoluteorin, has an additional inhibitory potential on fungal
\end{abstract}

Electronic supplementary material The online version of this article (https://doi.org/10.1007/s00253-017-8618-5) contains supplementary material, which is available to authorized users.

\footnotetext{
A Gerhard H. Braus gbraus@gwdg.de

Institute of Microbiology and Genetics and Goettingen Center for Molecular Biosciences (GZMB), University of Goettingen, Griscbachstraße 8, 37077 Goettingen, Germany

2 Present address: Department of Medical Informatics, Univers ity of Goettingen, Goettingen, Germany
}

growth, which is independent of these antifungal compounds, but which requires the bacterial $\mathrm{GacA} / \mathrm{GacS}$ control system. This translational two-component system is present in many Gram-negative bacteria and coordinates the production of multiple secondary metabolites. Our data suggest that pseudomonads pursue different media-dependent strategies that inhibit fungal growth. Metabolites such as phenazines are able to completely inhibit fungal surface growth in the presence of glucose, whereas $\mathrm{GacA} / \mathrm{GacS}$ controlled inhibitors provide the same fungal growth effect on pectin/amino acid agar.

Keywords Phenazines +2,4-diacetylphloroglucinol · gacA/ gacS-two component system - Verticillium + Pseudomonas

\section{Introduction}

The dynamic microbiome of the plant rhizosphere comprises various bacteria and fungi with mutual interactions. Biocontrol of fungal plant pathogens requires the understanding of fungal-bacterial biocoenosis and the investigation of antagonistic mechanisms. Hemibiotrophic pathogens of the genus Verticillium enter the endosphere of host plants from the rhizosphere through the roots and colonize the xylem vessels (Pegg 1989). Three main pathogenic Verticillium species are distributed within temperate world regions (Inderbitzin et al. 2011). Verticillium dahliae and Verticillium albo-atrum exhibit a host range of more than 200 plant species, including important crops such as cotton, olive, and tomato (Pegg and Brady 2002; Fradin and Thomma 2006). Verticillium longisporum is an amphidiploid hybrid of Verticillium dahliae and unknown haploid Verticillium species, which mainly infects Brassicaceae such as oil-containing rapeseed (Singh et al. 2012; Tran et al. 2013; Depotter et al. 2016). The ecological and economical relevance of the fungal pathogen 
$V$. longisporum increased with the utilization of rapeseed oil for nutrition and regenerative fuel production.

The use of naturally occurring microorganisms from the rhizosphere with antagonistic biocontrol activity is an approved alternative to chemical treatment of plants in agriculture. Antagonists with a suppressive potential towards pathogens in the soil include fungi as well as bacteria (Sikora 1992). The beneficial rhizofungus Coniothyrium minitans for example is commercially produced (Bayer CropScience Biologics $\mathrm{GmbH} 2017$ ) and exhibits biocontrol activity against the plant pathogenic fungus Sclerotinia sclerotiorum (Zeng et al. 2012). The rhizobacterium Bacillus subtilis exhibits antagonism, mediated by biofilm formation on plant roots, towards several phytopathogenic organisms such as Ralstonia solanaceanum, which causes tomato wilt (Chen et al. 2013). Tomato rootassociated Bacillus strains were able to inhibit $V$. dahliae growth on plate (Hollensteiner et al. 2017).

Fluorescent pseudomonads represent a diverse group of $\gamma$-proteobacteria that interact with plants and possess wellcharacterized beneficial properties (Weller et al. 2002). They secrete diffusible and volatile bioactive compounds, which act antagonistically towards fungal pathogens (Bender et al. 1999; Traxler and Kolter 2015). Phenazines are common colored bacterial secondary metabolites, which interact synergistically with biosurfactants (Pemeel et al. 2008). Biosurfactants permeabilize host membranes, allowing phenazines to enter the cells and inhibit mitochondrial electron transport (Pemeel 2006; Mavrodi et al. 2010). The mycotoxins 2,4diacetylphloroglucinol (DAPG), pyoluteorin, pyrrolnitrin, hydrogen cyanide $(\mathrm{HCN})$, as well as exoproteases are regulated by the translational GacA/GacS-two-component system. Still unknown external signals trigger the autophosphorylation of the GacS sensor kinase and the phosphate transfer to the GacA response regulator, which induces translational repression of target mRNAs (Haas and Défago 2005; Nandi et al. 2015). The 2,4-diacetylphloroglucinol producing Pseudomonas protegens $\mathrm{CHA} 0$ from the rhizosphere has been identified as an organism possessing one of the broadest biocontrol repertoires (Weller 2007).

The media-dependent interplay between fluorescent pseudomonads, which differ in their genetic potential to produce secreted bioactive metabolites and the growth potential of various fungal Verticillium spp. strains was compared. Bacteria reduced fungal growth by distinct different strategies when nutritional conditions change from glucose to pectin/amino acids. The bacterial GacA/GacS-two-component system, which controls numerous metabolites, is important for bacterial-meditated inhibition of fungal growth, whereas the fungal control of metabolites by regulators as Lael or Csn 5 are not relevant for the bacterial-fungal interaction under the tested conditions. Bacterial inhibition of fungal growth was so efficient that removal of pseudomonads from a co-culture did not allow $V$. dahliae to resume growth. The inhibition potential of pseudomonads towards saprophytic Aspergillus species is significantly reduced in comparison to plant pathogenic Verticillium species.

\section{Materials and methods}

Bacterial and fungal strains are listed in Table S1, primers in Table S2 and plasmids in Table S3. Figure artwork has been performed with Adobe Illustrator, Adobe Photoshop, GIMP (The GIMP team, version 2.8) and ChemDraw (랑 PerkinElmer Informatics).

\section{Cultivation and co-cultivation of bacteria and fungi}

The media for fungal cultivation included potato dextrose agar (PDA; from Roth, Karlsruhe, Germany) consisting of potato starch, as well as the pectin and amino acids-containing simulated xylem medium (SXM; casein hydrolysate from Oxoid, Hamphire, England; Pectin from citrus peel from SigmaAldrich Chemie GmbH, St. Louis, USA). The latter was based on the recipe from (Neumann and Dobinson 2003) and modified as follows: $0.4 \%$ casein; $0.2 \%$ pectin; $2 \% 50 \times$ AspA (3.5 M NaNO $3,350 \mathrm{mM} \mathrm{KCL}, 550 \mathrm{mM} \mathrm{KH}_{2} \mathrm{PO}_{4}$ ); $0.2 \%$ $1 \mathrm{M} \mathrm{MgSO}_{4}$; and $1 \times$ trace elements (Scott and Kafer 1982). For cultivation in liquid medium, $1 \times 10^{6}$ spores were inoculated in $150 \mathrm{ml}$ medium in $500 \mathrm{ml}$ Erlenmeyer flasks, which were incubated on a shaker at $150 \mathrm{rpm}$. Plates contained $2 \%$ agar and were inoculated with $1 \times 10^{5}$ spores, which were spread using glass beads. Fungal cultures were incubated for 6 days at $25^{\circ} \mathrm{C}$. SXM cultures were filtered through Miracloth (EMD Millipore Corp., Billerica, USA) to harvest spores. The filtrate was centrifuged for $3 \mathrm{~min}$ at $3500 \mathrm{rpm}$ and washed twice with sterile water. The spores were stored in a physiological solution $(0.96 \% \mathrm{NaCl}, 0.05 \%$ Tween 80$)$ at $4{ }^{\circ} \mathrm{C}$. The number of spores was determined with a particle counter (Beckman Coulter, Brea, CA USA) and adjusted to a concentration of $1 \times 10^{6}$ spores $\mathrm{ml}^{-1}$.

Bacteria were cultivated in Lysogeny broth (Bertani 1951) or SXM medium overnight at $30^{\circ} \mathrm{C}$. The concentration was determined by photometry and converted to colony-forming units (CFU; $\mathrm{OD}_{600 \mathrm{~mm}}=1$ or $\approx 5 \times 10^{8} \mathrm{CFU} \mathrm{m}^{-1}$ ) (Cui 2005). For co-cultivations on solid medium, spores were plated, a hole of $1 \mathrm{~cm}$ in diameter was excised in the center of the plate and $60 \mu \mathrm{l}$ of a bacterial suspension $\left(\mathrm{OD}_{600 \mathrm{~mm}}=1\right)$ were used for inoculation. Plates were incubated for 7 days at $25^{\circ} \mathrm{C}$. The diameter of the resulting cyclic inhibition zone was measured and documented. Comparative co-cultivation experiments on solid media with $V$. dahliae, Aspergillus nidulans and Aspergillus fumigatus were conducted on PDA and pectin and amino acids containing SXM as described before. Plates were incubated for 4 days at $25^{\circ} \mathrm{C}$. 
For co-cultivations in liquid medium, $100 \mu \mathrm{l}$ of a bacterial suspension $\left(\mathrm{OD}_{600 \mathrm{rm}}=1\right)$ were used for inoculation of $\mathrm{SXM}$ or potato dextrose medium (PDM; potato dextrose glucose broth from Roth, Karlsuhe, Germany) together with $1 \times 10^{6}$ $V$ dahliae spores. Co-cultures were grown under constant agitation. After $0,12,24,48,72$, and $96 \mathrm{~h}, 3 \times 10 \mu \mathrm{l}$ of the culture were plated on SXM or PDA plates containing kanamycin (final concentration $50 \mu \mathrm{g} \mathrm{ml}^{-1}$; from AppliChem $\mathrm{GmbH}$, Maryland Heights, USA); cefotaxime (final concentration $300 \mu \mathrm{g} \mathrm{ml}^{-1}$; from Wako Pure Chemical Industries, Osaka, Japan), and doxycycline (final concentration $40 \mu \mathrm{g} \mathrm{m}^{-1}$; from Sigma-Aldrich Chemie GmbH, St. Louis, USA). Plates were incubated for 3 days at $25^{\circ} \mathrm{C}$. Bacterial survival was tested after $96 \mathrm{~h}$ of co-cultivation. Then, $10 \mu \mathrm{l}$ of the culture were plated on LB medium and incubated at $25^{\circ} \mathrm{C}$ for 3 days.

\section{Construction of $\boldsymbol{V}$. dahliae deletion and gene disruption} strains

For construction of a gene disruption cassette, $5^{\prime}$ and $3^{\prime}$ flanking regions of the $L A E I$ gene were amplified by PCR with primers VDLAEF1Le/VDLAEF1Rc and VDLAEF2Lc/ VDLAEF2Rc, respectively. The 3' flanking region of LAE1 was inserted 3 ' of the nourseotricin resistance cassette into the pKO2 vector (Timpner et al. 2013) using BamHI/PstI restriction sites. Next, the 5 ' flanking region of the gene was inserted into the vector using $E \propto O R / / E c o$ RV restriction sites, placing it $5^{\prime}$ of the nourseotricin resistance marker. The resulting plasmid pME3990 (Table S3) was used for Agrobacterium tumefaciens-mediated transformation (Bundock et al. 1995) of $V$. dahliae JR2 (Fradin et al. 2009). For the deletion of CSN5, the flanking regions of the gene were amplified with the primers CSN5 $\mathrm{P} 1, C S N 5 \mathrm{P} 2, C S N 5 \mathrm{P} 3$, and CSN5 $\mathrm{P} 4$. The fragments were inserted into the $\mathrm{pKO} 2$ vector using $E c o \mathrm{RI} /$ EcoRV or $\mathrm{Xbal} / \mathrm{Hin} \mathrm{dIII}$ restriction sites, respectively. The resulting plasmid pME4412 (Table S3) was used for A. tumefaciens-mediated transformation of $V$. dahliae JR2. Transformants were verified by Southem hybridization using the AlkPhos Direct Labeling and Detection System (GE healthcare life sciences, Buckinghamshire, UK).

\section{Analysis of Pseudomonas genome data}

The genomes of the Pseudomonas wild-type strains used in this study were searched for secondary metabolism related genes, which might be involved in the antagonistic activity of the isolate. Genome sequences of P_phen and P_rhizo (Nesemann et al. 2015a, b) were further analyzed by biblast search using the sequence of P_DAPG (Jousset et al. 2014) as reference.

\section{Results}

Pseudomonas fluorescens DSM8569 isolated from the Brassica rhizosphere exhibits a similar inhibition potential for the rapeseed pathogen $V$. longisporum as for the tomato pathogen $V$. dahliae

Fluorescent pseudomonads can inhibit the growth of fungal pathogens and are therefore used as biocontrol organisms (Weller et al. 2002). Pseudomonas fluorescens DSM8569 (P_rhizo) colonizes the rhizosphere of the plant Brassica napus and was isolated in northem Germany (Berg and Ballin 1994). The genome of $P_{-}$rhizo does not contain the gene cluster for the production of the mycotoxic phenazines, which are secreted by other pseudomonads. The DAPG gene cluster for the production of the antifungal compound 2,4diacetylphloroglucinol is only partially conserved in this strain (Table 1, S4) (Nesemann et al. 2015a).

It was examined whether this bacterium is able to affect the growth of the $B$. napus pathogen $V$. longisporum. The $1 \times 10^{5}$ Verticillium spores were distributed on a D-glucose rich medium plate (PDA), containing a central hole filled with $7 \times$ $10^{7} \mathrm{CFU}$ of P_rhizo. An inhibition zone without fungus of $8 \mathrm{~mm}$ was visible after 7 days of incubation (Fig. 1a), indicating that the bacteria inhibit growth of the $B$. napus pathogen V. longisporum. The observed growth inhibition on PDA medium was compared to co-cultivation on SXM plates, which contain pectins and amino acids. On this medium, no inhibition zone was observed. Fungal control plates in the presence of Escherichia coli (DH5 $\alpha$ ) or in the absence of any bacteria were unaffected in growth (Fig. 1a). The lack of a phenazine cluster and the presence of an incomplete DAPG cluster in the P_rhizo genome suggest that bacterial inhibition of fungal growth in the presence of glucose requires neither phenazines nor DAPG.

P rhizo was isolated from the Brassica rhizosphere (Berg and Ballin 1994). We analyzed whether related fungal pathogens, which are pathogens in rhizospheres of other plant hosts, are similarly affected in growth. Co-cultivation experiments of P_rhizo with the tomato pathogen $V$. dahliae JR2 (Fradin et al. 2009) revealed a similar inhibition potential to the rapeseed pathogen $V$. longisporum on high glucose medium (inhibition zone $9.3 \mathrm{~mm} \pm 0.8)$ and a slight inhibition on pectin/amino acid agar (inhibition zone $2.3 \mathrm{~mm} \pm 0.5$ ) (Fig. 1b). Thus, the antifungal activity of P_rhizo is not limited to fungal pathogens from its natural habitat.

Fungi produce numerous bioactive secondary metabolites (Bayram and Braus 2012), which could influence fungalbacterial interactions. It was examined whether genes that control secondary metabolism of model fungi influence the suppressive effect of pseudomonads against $V$. dahliae. The A. nidulans methyltransferase LaeA represents a conserved global regulator of secondary metabolism in many 
Appl Microbiol Biotechnol

Table 1 Comparison of genome potentials of $P$. fluorescens DSM8569 (P rhizo), P. fluorescens 2-79 (P phen), and P. protegens CHA0 (P DAPG)

\begin{tabular}{lllllll}
\hline Organism & $\begin{array}{l}\text { Phenazine } \\
\text { cluster }\end{array}$ & $\begin{array}{l}\text { DAPG } \\
\text { cluster }\end{array}$ & HCN cluster & $\begin{array}{l}\text { Pyohuteorin- } \\
\text { cluster }\end{array}$ & $\begin{array}{l}\text { GacA/GacS- } \\
\text { system }\end{array}$ & $\begin{array}{l}\text { GacA/GacS- } \\
\text { regulation }\end{array}$ \\
\hline P_hizo & - & 0 & + & - & + & 0 \\
P_phen & + & - & 0 & - & + & 0 \\
P_DAPG & - & + & + & + & + & + \\
\hline
\end{tabular}

Gene clusters for bioactive compounds as phenazines, DAPG, HCN, pyohuteorin, or the GacA/GacS control system are indicated: gene cluster completely present: +; partial gene cluster: 0 ; gene cluster absent -

ascomycetes (Bok and Keller 2004; Bayram et al. 2008; Sarikaya-Bayram et al. 2010). A V. dahliae LAEI deletion strain (Vd $L A E I)$ was constructed (Fig. S1) to investigate whether growth of the fungal mutant is further reduced in the presence of the P_rhizo bacterium. Vd $L A E E 1$ displayed a similar growth inhibition as the wild type during co-

(a) V. longisporum - Rapeseed pathogen

Potato Dextrose Agar

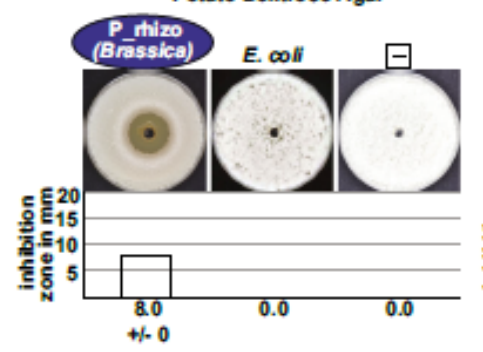

Simulated Xylem Medium

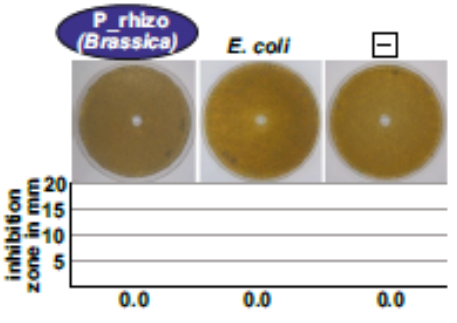

(b) V. dohliae-Tomato pathogen

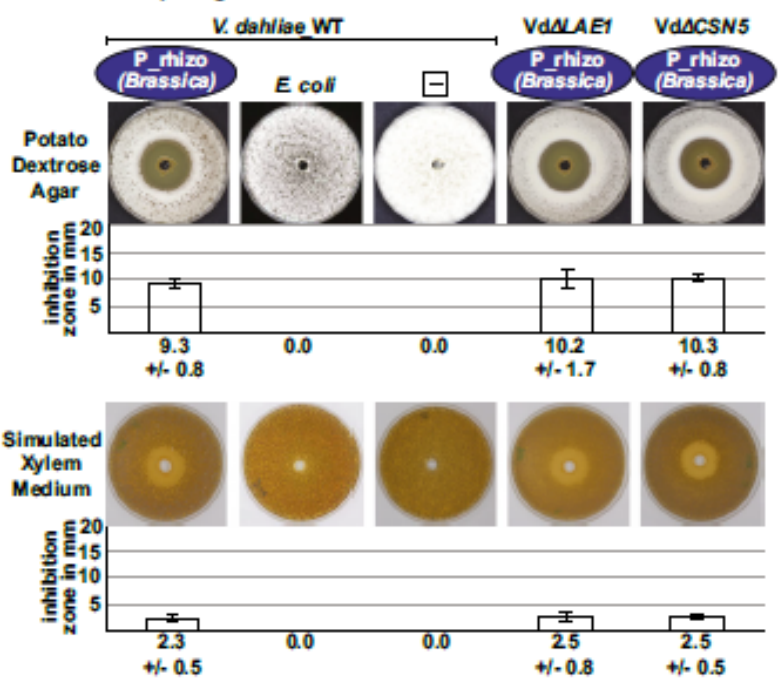

Fig. 1 Inhibition wone during co-cultivation of the rapeseed pathogen Verticillium longisponum V443 or the tomato pathogen $V$ dahliae JR2 with the Brassica rhizosphere isolate $P$. fluorescens DSM8569 (P rhizo). Co-cultivations were performed on solid potato dextrose medium (containing glucose) and simulated xylem medium (containing pectin and amino acids). $1 \times 10^{5}$ fungal spores were homogeneously inoculated on the plates. Then, $7 \times 10^{7}$ colony-forming units of a bacterial culture were inoculated into a central hole in the agar plate. The diameter of the hyphae-free inhibition zone in millimeters was determined after 7 days of incubation at $25^{\circ} \mathrm{C}$. Example plates are depicted. The graph includes data of two biological (including each three technical) replicates. An inhibition zone was defined as an area where no hyphae could be monitored and fungal growth was completely suppressed. The mean values and standard deviations are given beneath the graph. a Co-cultivation of Brassica-hosting $V$. longisponam Vl43 in the presence ( $\mathrm{P}$ rhizo; Brassica) and absence $(-)$ of the Brassica rhizosphere isolate $\mathrm{P}$ rhizo (P. fluorescens DSM8569), as well as in the presence of $E$ ooli (strain DH5 $\alpha$ ). b Cocultivation of the tomato-hosting $V$. dahliae $\mathrm{JR} 2$ in the presence and absence of $\mathrm{P}$ thizo, as well as in the presence of $E$. coli (strain DHS $\alpha$ ) and $V$. dahliae JR2 deletion strains lacking LAEI (Vd $\triangle L A E I$ ) or CSNS (Vd $\triangle$ CSNS) 
cultivation with P_rhizo on glucose rich PDA medium (inhibition zone $10.2 \mathrm{~mm} \pm 1.7$ ) and pectin-containing SXM (inhibition zone $2.5 \mathrm{~mm} \pm 0.8$ ) (Fig. 1b), suggesting that Lae1 controlled fungal secondary metabolites are not relevant for fungal growth during the Verticillium-Pseudomonas interaction.

The fungal COP9 signalosome controls cellular ubiquitination and protein degradation and is required for coordinated secondary metabolism (Nahlik et al. 2010). In the absence of the COP9 deneddylase subunit, the secondary metabolism of A. nidulans is misregulated. The $V$. dahliae CSN5 gene, which encodes the deneddylase subunit, was deleted (Fig. S1). Growth of the Vd $\triangle C S N 5$ strain was similar to wild type during co-cultivation with $\mathrm{P}_{-}$rhizo (inhibition zone $10.3 \mathrm{~mm} \pm 0.8$ for cultivation on PDA and $2.5 \mathrm{~mm} \pm 0.8$ for cultivation on SXM) (Fig. 1b). This suggests that neither Lae1 nor Csn 5 controlled fungal secondary metabolism is relevant for Pseudomonas fungal interactions.

In summary, the $B$. napus rhizosphere bacterium P. fluorescens DSM8569 (P_rhizo), is not only able to inhibit the growth of a rapeseed pathogenic fungus, but also that of a tomato pathogen, without having the potential to synthesize typical Pseudomonas mycotoxins such as phenazines or DAPG. Fungal growth response in the presence of the bacterium is independent of fungal control genes of secondary metabolism such as LAEI or CSN5.

Phenazine-mediated growth inhibition of Verticillium species on solid agar surfaces is increased in high glucose medium

Pseudomonas fluorescens $\mathrm{P}_{-}$rhizo does not require an intact phenazine gene cluster to reduce fungal growth (Nesemann et al. 2015a) (Table 1, S4). Surface growth of V. longisporum or $V$. dahliae was analyzed in the presence of Pseudomonas strains secreting phenazines to monitor whether the fungal strains are sensitive. The phenazine producer $P$. fluorescens 2-79 ( $\mathrm{P}$ phen) has been isolated from wheat roots suppressive to the plant disease "take-all" (Weller and Cook 1983). Significant surface growth inhibition of $V$. longisporum and $V$. dahliae was caused by the phenazine producer $\mathrm{P}$.phen on high glucose agar (inhibition zone $7.7 \mathrm{~mm} \pm 0.8$ for V. longisporum and $5.8 \mathrm{~mm} \pm 0.8$ for $V$. dahliae). In the presence of pectin and amino acids, bigger inhibition zones of $13.0 \mathrm{~mm} \pm 0.6$ for $V$. longisporum and $15.0 \mathrm{~mm} \pm 0.9$ for $V$ dahliae were visible (Fig. 2). Co-cultivation with the isogenic phenazine-deficient mutant strain $\mathrm{P}$ phen $\Delta p h z$ (Khan et al. 2005) revealed that growth inhibition of $V$. longisporum (inhibition zone $13.2 \mathrm{~mm} \pm 1.8$ ) and $V$ dahliae (inhibition zone $15.0 \mathrm{~mm} \pm 0.6$ ) on pectin/amino acid agar is independent of the phenazine cluster. These genes are only required for fungal growth inhibition on high glucose agar as on this medium an inhibition zone was neither visible for $V$. longisporum nor for $V$. dahliae (Fig. 2).
Co-cultivation with $V$. dahliae $\mathrm{Vd} \triangle L A E I$ and $\mathrm{Vd} \triangle C S N 5$ strains suggested that there is no significant function of the fungal $L A E 1$ or $C S N 5$ control genes of secondary metabolism for bacterial-fungal interactions (Fig. 3). On high-glucose medium, the inhibition zone of co-cultures with the P_phen wildtype was $6.2 \mathrm{~mm} \pm 0.8$ for the $L A E I$ deletion strain and $4.7 \mathrm{~mm} \pm 1.5$ for the CSN5 deletion strain, which is very similar to the effects observed for the wild type (inhibition zone $5.8 \mathrm{~mm} \pm 0.8$ ). For the phenazine-deficient bacterial mutant strain, no inhibition of the $L A E 1$ and the CSN5 deletion strain could be observed on PDA medium. The inhibition zones on SXM ranged between 14 and $16 \mathrm{~mm}$ for the two deletion strains, which is comparable to that of the wild-type strain (inhibition zone $15 \mathrm{~mm} \pm 0.9$ ) (Fig. 2). Our experiments support a media-dependent fungal growth inhibition by phenazines on high glucose agar. Additional phenazineindependent mechanisms in the phenazine-deficient P. phen $\Delta p h z$ strain are able to reduce fungal surface growth in the presence of pectin and amino acids.

Bacterial inhibition of Verticillium surface growth on pectin/amino acid medium is independent of an intact gene cluster for 2,4-diacetylphloroglucinol

Several fluorescent pseudomonads produce the antifungal secondary metabolite

2,4-diacetylphloroglucino (DAPG) (Meyer et al. 2009; Kwak et al. 2011). The genome of P_rhizo encodes only a partial DAPG cluster and it is therefore unlikely that this bacterium produces DAPG (Table 1, S4). A DAPG secreting P. protegens strain CHA0 (P_DAPG) was isolated from tobacco rhizosphere suppressive against the fungal disease black root rot (Stutz et al. 1986; Schnider-Keel et al. 2000). The impact of CHA0 (P_DAPG) on Verticillium growth was analyzed by co-cultivation on agar plates. Co-cultivations with P DAPG and $V$. longisporum or $V$. dahliae resulted in a clear inhibitory effect on pectin/amino acid as well as on high glucose agar (Fig. 4). When V. longisporum was co-cultured with P_DAPG on potato dextrose medium, an inhibition zone of $9.3 \mathrm{~mm} \pm 2.3$ was observed. The effect of the bacterium on $V$. dahliae on this medium was similar with an area without fungal growth of $7.2 \mathrm{~mm} \pm 1.7$. On simulated xylem medium, the effect on $V$. longisporum (inhibition zone $7.7 \mathrm{~mm} \pm 1.6$ ) and $V$. dahliae (inhibition zone $8.0 \mathrm{~mm} \pm 0.9$ ) was also comparable.

Fungal co-cultivations with $P$. protegens strains lacking or overproducing DAPG (P_DAPG $\triangle p h l A$ and P_DAPG $\Delta p h l F$, respectively) resulted in a similar inhibition of fungal growth as observed for the P. protegens wild type on pectin/amino acid medium. Respective inhibition zones averaged $7.7 \mathrm{~mm} \pm$ 0.5 for cultivation of P_DAPG $\triangle p h l A$ and $7.2 \mathrm{~mm} \pm 0.4$ for P_DAPG $\triangle p h l F$ together with V. longisporum. For cocultivation with $V$. dahliae, the areas without fungal growth 
Fig. 2 Inhibition zone during cocultivation of $\mathrm{V}$. longisponum

V143 or V. dahlize JR2 with

phenazine-producing

$P$. fluorescens $2-79$. Co-

cultivation of $1 \times 10^{5}$ fungal

spores and $7 \times 10^{7}$ colony-

forming units of bacterial culture

was parformed on potato dextrose

agar and simulated xylem

medium as described in Fig. 1.

Diameters of hyphae-free

inhibition zones in millimeter

were determined after 7 days of

incubation at $25^{\circ} \mathrm{C}$ as described

in Fig. 1. Co-cultivation of

Verticillium spp. in the presence

of the phenazine-producing $\mathbf{P}$

phen wild type (WT:

P. fluarescens 2-79), as well as in

presence of a phenazine-deficient

deletion strain $(\Delta p h z)$. a Co-

cultivation with Brassica-

infecting V. longisponum VL43. b

Co-cultivation with tomato-

infecting $V$ dahliae $J R 2$ (a) V. Iongisporum - Rapeseed pathogen
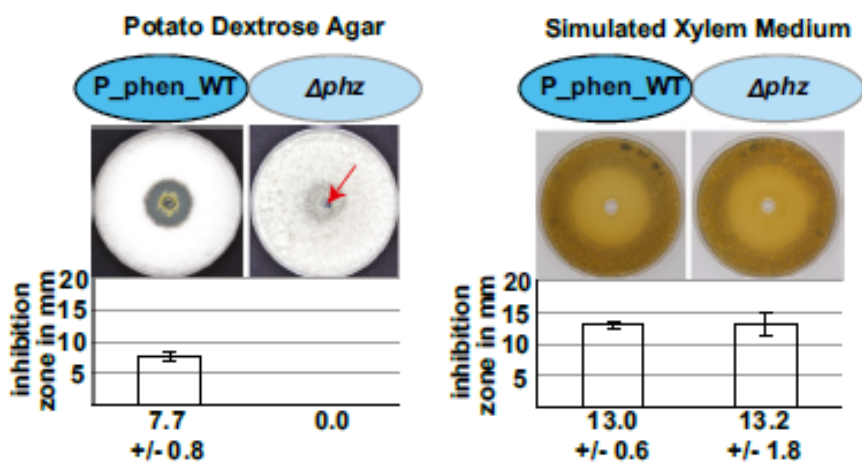

(b) V. dahliae - Tomato pathogen
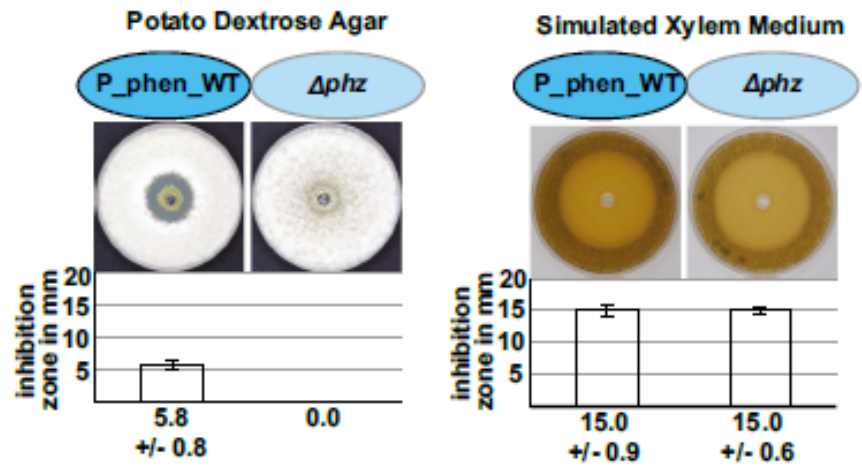

were $8.3 \mathrm{~mm} \pm 0.5$ for P_DAPG $\triangle p h l A$ and $8.5 \mathrm{~mm} \pm 0.8$ for P_DAPG $\triangle p h l F$. On high glucose agar, a contribution of DAPG on the size of inhibition zones was observed. Deletion of $p h l A$ slightly reduced the inhibitory effect (inhibition zone $7.0 \mathrm{~mm} \pm 0.6$ for $V$. longisporum and $6.3 \mathrm{~mm} \pm 1.5$ for $V$. dahliae). Overproduction of DAPG in the phlF deletion strain had the opposite effect. Whereas the inhibitory potential of the bacterium is slightly increased towards $V$. longisporum (inhibition zone $11.7 \mathrm{~mm} \pm 0.8$ ), the area without fungal growth is approximately doubled in co-cultures with $V$. dahliae (inhibition zone $14.5 \pm 2.1$ ) compared to the inhibition zone of the fungus with the bacterial wild type. This suggests that DAPG production contributes to the inhibitory effect of the bacterium on fungal growth on high glucose medium but there is a DAPG-independent fungal growth inhibition mechanism on both media (Fig. 4).

The P_DAPG strain secretes a number of additional bioactive metabolites. Hydrogen cyanide $(\mathrm{HCN})$ acts by blocking the oxygen-binding site in the respiratory chain (Hamel 2011). Bacterial mutant strains with deletions in $\mathrm{HCN}$-producing genes (P_DAPG $\Delta h c n, \Delta a n r$ ) resulted in fungal inhibition zones ranging between 7 and $9 \mathrm{~mm}$, which are similar in size compared to the inhibition of the bacterial wild type on both tested media (Fig. 4). Antifungal pyoluteorin composed of a bichlorinated pyrrole ring (Nowak-Thompson et al. 1999) is produced by P_DAPG. A pyoluteorin deficient mutant strain (P_DAPG $\Delta p l t$ ) still reduced $V$. longisporum or $V$. dahliae growth c.f. wild type (inhibition zones of $8.7 \mathrm{~mm} \pm 2.3$ and $6.7 \mathrm{~mm} \pm 2.0$ on PDA and $6.7 \mathrm{~mm} \pm 0.8$ and $8.3 \mathrm{~mm} \pm 1.4$ on SXM, respectively) (Fig. 4).

These data indicate that $P$. protegens $\mathrm{CHA} 0$ (P_DAPG) has the potential to inhibit fungal growth using mechanisms that are independent of the production of antifungal compounds such as DAPG, hydrogen cyanide or pyoluteorin.

The bacterial GacA/GacS control system coordinating multiple secondary metabolites is required for fungal growth inhibition on pectin agar surfaces

The $P$. protegens $\mathrm{CHA} 0$ (P_DAPG) genome lacks the phenazine gene cluster but possesses genes of the $\mathrm{GacA} / \mathrm{GacS}$-twocomponent system (Table 1, S4). The sensor kinase GacS is autophosphorylated by external signals and transfers the phosphate to the response regulator GacA. Deletion of either gacA or gacS leads to loss of secretion of bioactive metabolites including DAPG, hydrogen cyanide and pyoluteorin (Laville 
Fig. 3 Inhibition zone during cocultivation of $V$ dahliae JR2

$L A E I$ and CSNS deletion strains with phenazine-producing

P. fluorescens 2-79 or DAPG-

producing $P$. protegens CHA 0 .

Co-cultivation of $1 \times 10^{5}$ fungal

spores and $7 \times 10^{7}$ colony-

forming units of bacterial culture

was paformed on potato dextrose agar and simulated xylem

medium as described in Fig. 1.

The diameter of the hyphae-free

inhibition mone in mm was

determined after 7 days of

incubation at $25{ }^{\circ} \mathrm{C}$ as described

in Fig. 1. a Co-cultivation of

$V$ dahliae JR2 deletion strains

lacking $L A E I$ (Vd $L A E I$ ) or

CSNS (Vd $\triangle$ CSNS) in presence of

the phenazine-producing $P$ phen

wild type (WT: $P$. fluorescens $2-$

79 ), as well as in presence of a

phenazine deficient deletion strain

$(\Delta p h z)$. b Co-cultivation of

V. dahliae JR2 deletion strains

lacking $L A E I$ (Vd $\triangle L A E I)$ or

CSN5 (Vd $\triangle C S N 5$ ) in thepresence

of the DAPG-producing P

DAPG wild type (WT:

P. protegens $\mathrm{CHA} 0$ ), and deletion

strains restricted in multiple

mycotoxin production: $\triangle$ gacA

and $\triangle \mathrm{gacS}$ in which one of the

two units for the regulation of

multiple toxin production is

deleted (a) $V$ dahllaeALAE1 and $V$. dahllaeACSN5 with P_Phen

VdALAE1

VdACSNS

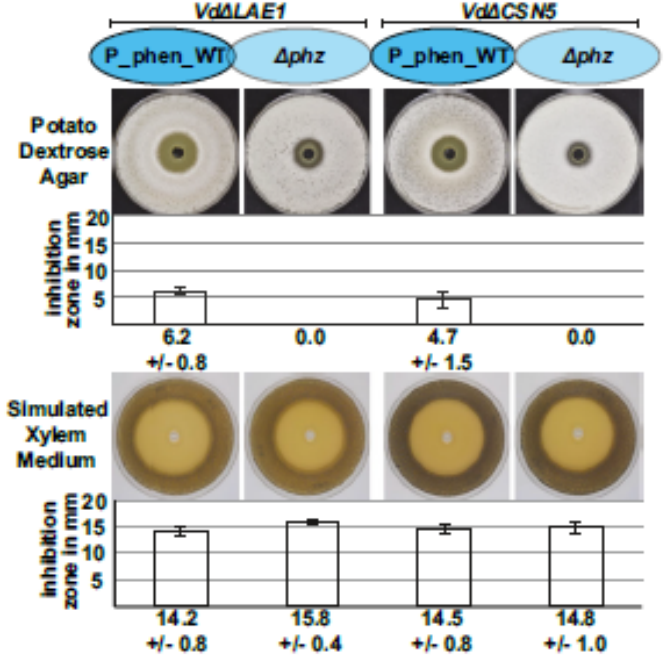

(b) $V$. dahllaeALAE1 and $V$. dahllaeACSN5 with P_DAPG

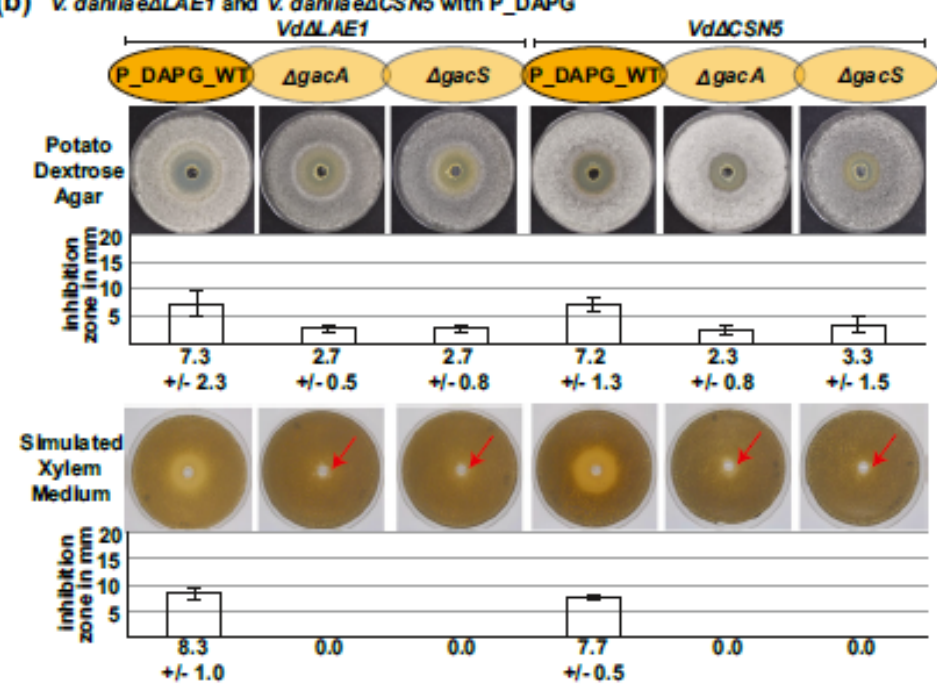

et al. 1992; Zuber et al. 2003). The constitutively expressed target genes of the $\mathrm{GacA} / \mathrm{GacS}$-system are posttranscriptionally repressed by RsmA and RsmE (Haas and Défago 2005). Phosphorylated GacA activates the expression of derepressors, which inhibit RsmA and RsmE (Laville et al. 1992; Brencic et al. 2009).

Deletion mutants P_DAPG $\triangle g a c A$ and P_DAPG $\triangle g a c S$ cocultivated with $V$. longisporum or $V$. dahliae were unable to inhibit fungal wild-type growth on agar plates with media of pectin and amino acids (Fig. 5). Similarly, V. dahliae CSN5 and $L A E I$ deletion strains were not inhibited (Fig. 3). The bacterial mutant strains P_DAPG $\triangle g a c A$ and P_DAPG $\triangle g a c S$ were still able to inhibit $\bar{V}$. longisporum or $V$. dahliae growth on glucose medium agar but with reduced intensity (Fig. 5).
The inhibition zones were reduced by more than $50 \%$ when $V$. longisporum was co-cultured with the gacA or gacS deletion strain (inhibition zones $3.2 \mathrm{~mm} \pm 0.4$ and $4.3 \mathrm{~mm} \pm 0.5$, respectively) when compared to cultivations with the wildtype isolate P_DAPG. The inhibitory potential of P_DAPG towards $V$. dahliae was almost completely lost when gacA or gacS were deleted in the bacterium (inhibition zone of $1.2 \mathrm{~mm} \pm 1.3$ for P_DAPG $\Delta g a c A$ and $1 \mathrm{~mm} \pm 0.9$ for P_DAPG $\triangle$ gacS).

This suggests distinct media-dependent strategies of pseudomonads in the control of fungal growth. Metabolites such as phenazines control fungal surface growth with glucose, whereas $\mathrm{GacA} / \mathrm{GacS}$ provides inhibitors of fungal growth on pectin/amino acid agar. 
Fig. 4 Inhibition zone during cocultivation of $V$. longisponum

VL43 and $V$. dahliae JR2 with

DAPG-producing $P$. protegens

CHA 0 . Co-cultivation of $1 \times 10^{5}$

fungal spores and $7 \times 10^{7}$ colony-

forming units of bacterial culture

was paformed on potato dextrose

agar and simulated $x y l e m$

medium as described in Fig. 1.

The diameter of the hyphae-free

inhibition zone in millimeters was

determined after 7 days of

incubation at $25{ }^{\circ} \mathrm{C}$ as described

in Fig. 1. Co-cultivation of

Verticillium spp. in the presence

of DAPG-producing P DAPG

wild type (WT: P. protegens

CHA 0 ), or one of the following

bacterial delction strains: $\triangle p h l A$ -

lacking one essential gene for

DAPG synthesis, without DAPG

production; $\triangle p h I F$ - lacking the

inhibitor of DAPG production,

leading to increased DAPG

secretion (Schnider-Keel et al.

2000); $\triangle$ hcn $A B C$ - essential gene

for $\mathrm{HCN}$ production deleted;

$\triangle a n r-H C N$ regulator anr deleted

with deficient $\mathrm{HCN}$ secretion;

$\Delta p l t$ - essential gene for

pyohuteorin synthesis deleted

strain $(\Delta p h z)$. a Co-cultivation

with Brassica-infecting

V. longisponem VL43. b Co-

cultivation with tomato-infecting

V. dahliae JR2 (a) V. longisporum - Rapeseed pathogen

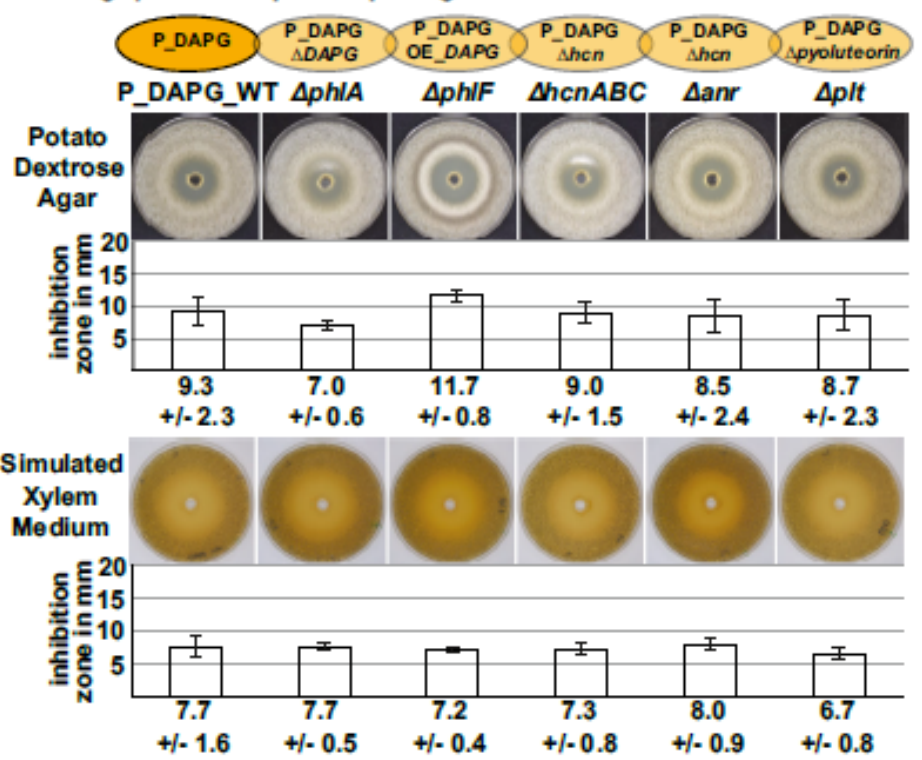

(b) V. dahliae - Tomato pathogen

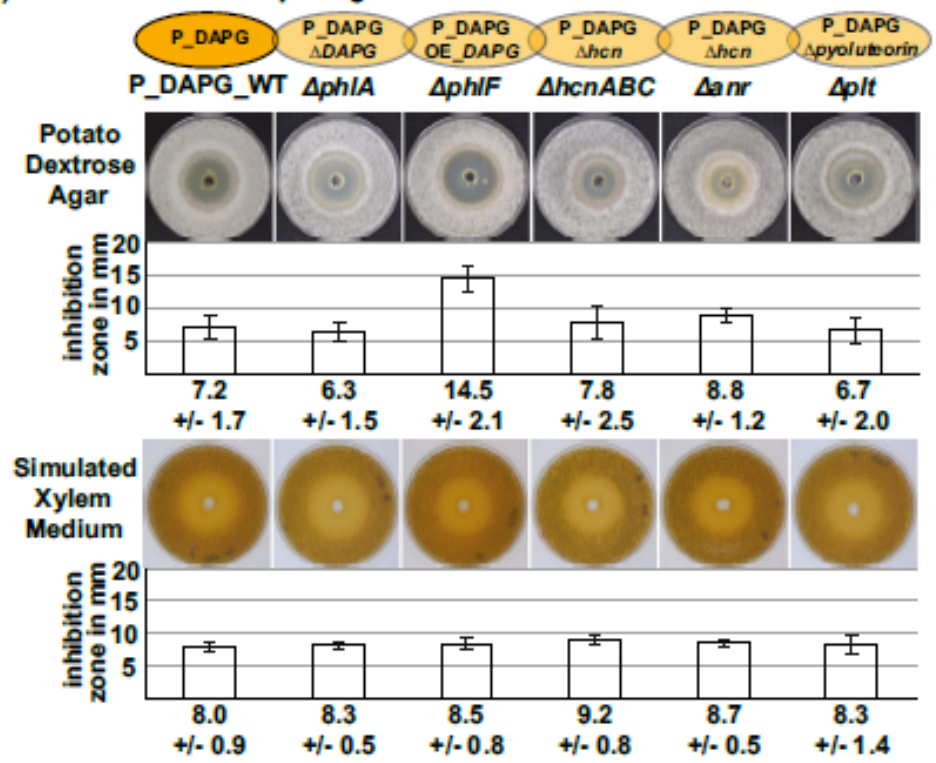

Efficient fungal growth inhibition of Brassica rhizosphere and of phenazine-producing bacteria depends on the nutrient source

All tested bacterial wild-type strains showed a similar inhibitory effect towards both $V$. dahliae and $V$. longisporum, when cocultivated on solid agar surfaces, which was dependent on nutrition. Co-cultivation experiments of fungal spores together with bacterial cells were performed in liquid medium to further analyze the effect of the different pseudomonads on V. dahliae, pectin/amino acid SXM, and high-glucose PDM were used as in the experiments on plates. Culture aliquots were plated on antibiotic containing agar plates after $0,12,24,48,72$, and $96 \mathrm{~h}$ of incubation to remove the bacterial cells and to monitor whether the fungus is able to regain growth. Fungal spores cultivated in the absence of pseudomonads or together with $E$. coli cells served as controls. The strongest effect of $\mathrm{P}_{-}$rhizo on fungal growth was observed in high glucose medium 
(a) V. longisporum - Rapeseed pathogen

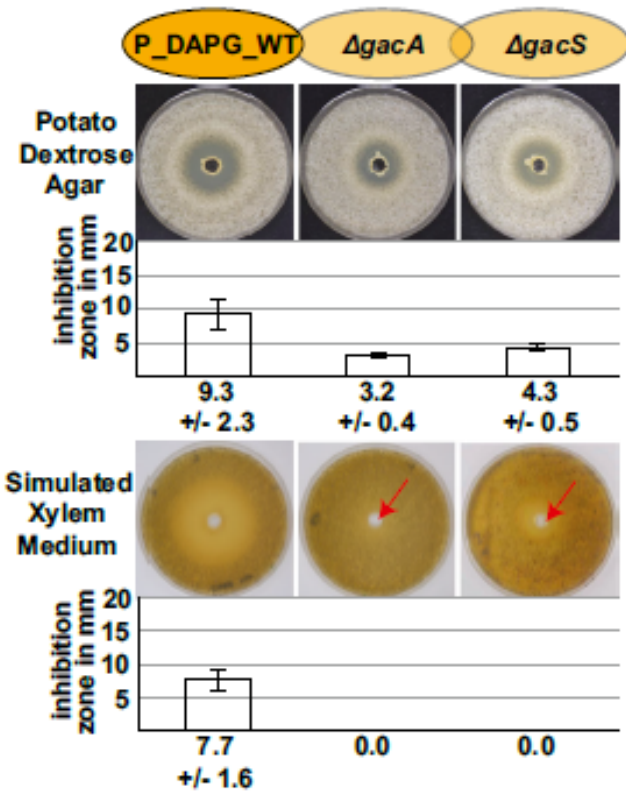

(b) V. dahliae - Tomato pathogen

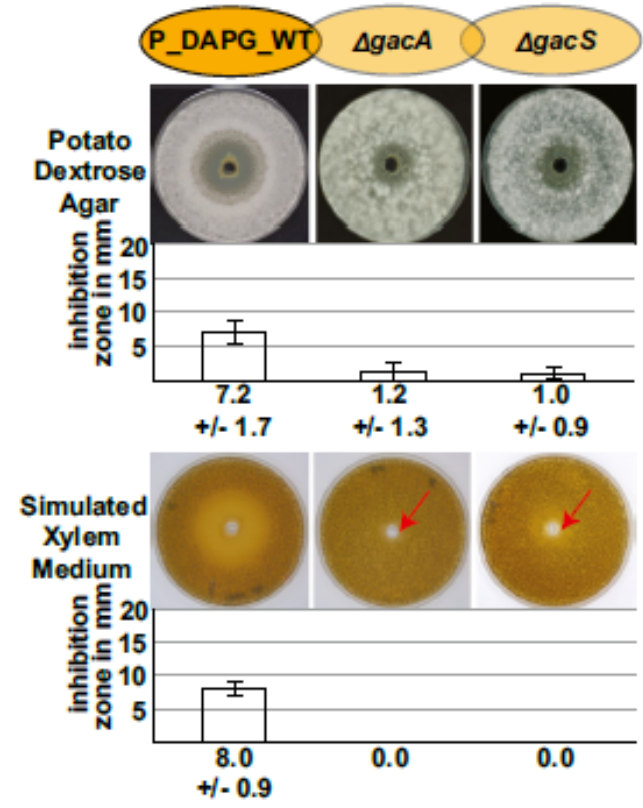

(Table 2). The fungus was unable to form colonies after cocultivation for $48 \mathrm{~h}$ when the bacterium was removed by the antibiotic cocktail. This was different for the other tested pseudomonads. For P_DAPG and P_phen fungal growth inhibition in some cultivations was only visible after 72 or $96 \mathrm{~h}$ of cocultivation, respectively, suggesting that these bacteria need
4 Fig. 5 Inhibition zone during co-cultivation of V. longispanum VL43 and V. dahliae JR2 with bacterial gacA and gacS deletion strains. $\mathrm{Co}-$ cultivation of $1 \times 10^{5}$ fungal spores and $7 \times 10^{7}$ colony-forming units of bacterial culture was performed on potato dextrose agar and simulated xylem medium as described in Fig. 1. The diameter of the hyphae-free inhibition zone in millimeters was determined after 7 days of incubation at $25^{\circ} \mathrm{C}$ as described in Fig. 1. Co-cultivation of Verticillium spp. in presence of DAPG-producing P_DAPG wild type (WT: P. protegens $\mathrm{CHA} 0$ ) and corresponding deletion strains restricted in multiple mycotoxin production: $\triangle \mathrm{gac} A$ and $\triangle \mathrm{gac} S$ in which one of the two units for the regulation of multiple toxin production is deleted. a Co-cultivation with Brassica-infecting V. longisporım VL43. b Co-cultivation with tomato-infecting $V$. dahliae $\mathrm{JR} 2$

more time in co-culture to persistently inhibit fungal growth. When cultured together with $E$. coli, no effects on $V$. dahliae growth could be observed. All bacterial cells were able to form colonies on LB agar plates after $96 \mathrm{~h}$ of cultivation with the fungus, supporting our previous observations that the fungus does not compromise bacterial growth. In pectin-/amino acidcontaining medium, the strongest effect on the fungus was observed for P_phen: after $24 \mathrm{~h}$ of co-cultivation, fungal growth could only be observed on some plates and after $48 \mathrm{~h}$, no fungal growth could be detected. E. coli, P_DAPG andP_rhizo did not show significant effects on fungal growth after co-cultivation for up to $96 \mathrm{~h}$ and all bacteria formed colonies on LB medium. Our results are in accordance with the observation of the

Table 2 Influence of $P$. fluorescens 2-79 ( $\mathrm{P}$. phen), P. protegens CHA0P_DAPG, and $P$. fluorescens DSM8569 (P_tizo) on $V$. dahliae growth afta co-cultivation in liquid medium. Bacterial strains ware cocultivated with $V$. dahliae JR2 spores in liquid pectin/amino acid simulated xylem medium or liquid high glucose potato dextrose medium for $0,12,24,48,72$, and $96 \mathrm{~h}$, respectively. Aliquots were plated on antibiotics containing medium and fungal growth was observed after 3 days of incubation at $25^{\circ} \mathrm{C}$. Fungal cultures without bacteria (w/o bacteria) served as control. Data were derived from two independent experiments with three replications each

\begin{tabular}{|c|c|c|c|c|c|}
\hline & w/o bacteria & $E$ coli & P_phen & P_DAPG & P_tizo \\
\hline \multicolumn{6}{|c|}{$\mathrm{J} 2$ 2 potato dextrose medium } \\
\hline $0 \mathrm{~h}$ & + & + & + & + & + \\
\hline $12 \mathrm{~h}$ & + & + & + & + & + \\
\hline $24 \mathrm{~h}$ & + & + & + & + & + \\
\hline $48 \mathrm{~h}$ & + & + & + & + & - \\
\hline $72 \mathrm{~h}$ & + & + & $+/-$ & + & - \\
\hline $96 \mathrm{~h}$ & + & + & $+/-$ & $+/-$ & - \\
\hline \multicolumn{6}{|c|}{$\mathrm{JR} 2$ simulated $x y l e m$ medium } \\
\hline $0 \mathrm{~h}$ & + & + & + & + & + \\
\hline $12 \mathrm{~h}$ & + & + & + & + & + \\
\hline $24 \mathrm{~h}$ & + & + & $+/-$ & + & + \\
\hline $48 \mathrm{~h}$ & + & + & - & + & + \\
\hline $72 \mathrm{~h}$ & + & + & - & + & + \\
\hline $96 \mathrm{~h}$ & + & + & - & + & + \\
\hline
\end{tabular}

$+=$ growth in all replicates; $-=$ no growth in all replicates; $+/=$ = growth in some replicates but not all 
inhibitory potential on agar surfaces: P_rhizo had the strongest effect on high glucose medium, whereas $\mathrm{P}$ phen is most effective on pectin/amino acid medium. This bacterial inhibition of fungal growth is persistent because the fungus was unable to resume growth, even after the bacterium had been removed.

The inhibition potential of pseudomonads towards saprophytic Aspergillus species is reduced in comparison to plant pathogenic $V$. dahliae

Bacteria in the rhizosphere encounter not only plantpathogenic fungi as $V$. longisporum or $V$. dahliae but also soilbome saprophytic fungi as Aspergillus species. We performed co-cultivation experiments with $A$. nidulans or the opportunistic human pathogen $A$. fumigatus with all three bacterial wild-type strains to investigate the specificity of the inhibitory potential on fungal growth. The inhibition effects of all tested pseudomonads towards the Aspergillus strains are decreased when compared to the effects on $V$. dahliae (Fig. 6).
On high-glucose PDA medium, there was only a minimal effect (approx. 1-mm inhibition) observed for the cocultivation of P_DAPG with A. fumigatus but not for cocultures of $\mathrm{P}_{\text {p }}$ phen and $\mathrm{P}_{-}$rhizo with this fungus. None of the three bacterial isolates showed any restriction of A. nidulans. This is in contrast to the observations made for $V$. dahliae where all three bacterial strains reduced fungal growth with inhibition zones of approximately $5.8 \mathrm{~mm}$ (P_phen), $7.2 \mathrm{~mm}$ (P_DAPG), and $9.3 \mathrm{~mm}$ (P_rhizo).

The inhibitory potential towards both Aspergillus species was stronger on pectin/amino acid containing SXM than on high-glucose medium. Co-cultivations with $V$. dahliae usually resulted in a zone without or a minimum of fungal growth whereas we could observe two different areas in cocultivation experiments with Aspergillus species on this medium: in addition to zones without fungal growth, in some cocultures, sectors with a reduced amount of hyphae and conidiophores could be observed. On pectin/amino acid medium P_phen had the strongest inhibition effect on $V$. dahliae

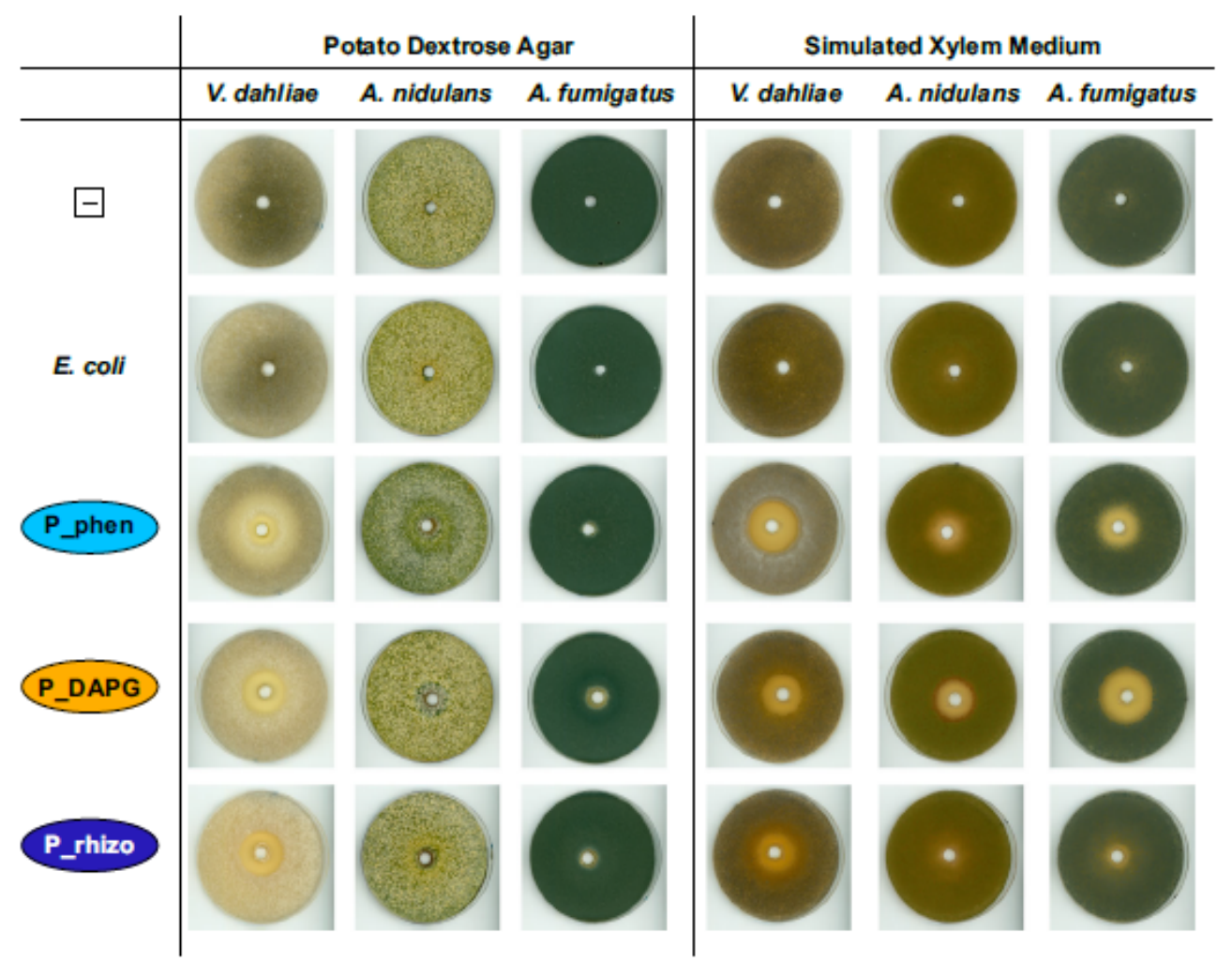

Fig. 6 Inhibition potential of $P$. fuorescens 2-79 (p_phen), $P$. protegens CHA0 (p DAPG) and $P$. fluarescens DSM8569 (P rhizo) on $V$ dahliae, A. nidulans, and A. fumigatus. Co-cultivation of $1 \times 10^{5}$ fungal spores and $7 \times 10^{7}$ colony-forming units of bacterial culture was performed on simulated xylem medium and potato dextrose agar. Plates were incubated for 4 days at $25{ }^{\circ} \mathrm{C}$. Two biological replicates were performed, each having three technical replicates. V. dahliae wild type JR2, the A. nidulans wild type A4, and the A. fivmigates strain AfS 35 were co-cultivated with phenazine-producing $\mathrm{P}$ phen (P. fluorescens 279), DAPG-producing P_DAPG ( $P$. protegens CHA0) and Brassica thizosphere isolate $\mathrm{P}_{-}$thizo (P. fluorescens DSM8569). $E$ coli $(\mathrm{DH} 5 \alpha)$ as well as untreated fungus (-) served as controls

\section{느 Springer}


(inhibition zone approximately $15 \mathrm{~mm}$ ). The effect on both Aspergillus species is reduced, as we could observe hyphae and conidiophores in the area surrounding the bacterial application site but no zones without fungal growth. This area of growth reduction was $3 \mathrm{~mm} \pm 0.5$ for $A$. nidulans and $7 \mathrm{~mm} \pm$ 0.5 for A. fumigatus. In co-cultures of $V$. dahliae with P DAPG, an inhibition zone of approximately $8 \mathrm{~mm}$ was observed, whereas this area without fungal growth was reduced to $3 \mathrm{~mm} \pm 0.4$ when the bacterium was cultured together with $A$. nidulans. For $A$. fumigatus incubated with P_DAPG, we observed a sector of $9 \mathrm{~mm} \pm 1.5$ in which the fungus was affected. However, a complete inhibition was only observed in the inner $3.6 \mathrm{~mm} \pm 0.6$ around the bacteria application site whereas in the rest of the sector some hyphae and conidiophores could be detected.

This suggests that pseudomonads have a specific and highly efficient effect on the growth of plant-pathogenic fungi as $V$. dahliae or $V$. longisporum, but only a minor inhibitory impact on fungi as saprophytic Aspergillus species.

\section{Discussion}

Verticillium and pseudomonads are part of the microbiome of the plant rhizosphere. The fungus Verticillium has to face and compete with the rhizosphere microbiome, which might be densely populated during different seasons under varying ecological or nutritional conditions. Root exudates of an appropriate host induce germination of Verticillium microsclerotia and hyphal growth towards host plant roots (Zhou et al. 2006; Eynck et al. 2007). Microsclerotia are fungal resting structures, which are formed to survive during winter after the death of the host plant in the soil (Pegg 1989; Pegg and Brady 2002; Tran et al. 2014). We have analyzed the Verticillium-Pseudomonas growth interference in a simplified model and found as a common feature that bacterial growth was never significantly compromised by the fungus. By contrast, fungal growth was inhibited by the bacterium on different solid media surfaces. The potential of pseudomonads to reduce fungal growth was not restricted to fungi living in the rhizosphere, where the bacterium had originally been identified. Liquid co-cultivation of fungal spores with bacteria led also to an inhibitory effect on $V$. dahliae, which was so persistent in some cases that the fungus was even unable to regain the potential to grow after removal of the bacterium from the co-culture. This suggests that pseudomonads can damage or destroy fungal spores or germinating hyphae. The inhibitory potential of the pseudomonas strains was significantly milder towards saprophytic fungi such as A. nidulans or A. fumigatus. Plant-pathogens have to deal in a significant part of their life cycle with plant immune responses, whereas saprophytes might be specifically adapted in their hyphal growth mode to acquire competitively nutrients in the habitat soil.
Another finding was that the presence of general regulatory genes for the coordinated fungal expression of numerous specific secondary metabolism genes as the epigenetic Lael methyltransferase (Sarikaya-Bayram et al. 2015) or the Csn5 deneddylase for specific protein turnover regulation (Braus et al. 2010) are not relevant for bacterial-fungal interaction during co-cultivation. Specific inductions of secondary metabolites had been described for some Streptomyces-Aspergillus interactions (Schroeckh et al. 2009; Nützmann et al. 2011).

We found only under specific conditions that a single bacterial compound was responsible for fungal growth inhibition. Phenazine, which had been described as fungal inhibitor (Kerr et al. 1999), specifically reduced fungal growth when nutrients as high amounts of glucose are provided, which would allow faster growth in the absence of bacteria. Phenazines are not required for fungal growth control on pectin/amino acid medium, where a lack of phenazine synthesis can be compensated by a plethora of genes encoding for a cocktail of other antifungal metabolites. Fungal colonies develop more rapidly on a high glucose medium than on pectin amino acid agar surfaces. Bacterial phenazine producers interfere and reduce this faster fungal growth.

Pseudomonads, which do not possess phenazine biosynthetic genes, are highly capable to reduce fungal growth as well in an environment of slower fungal growth in a pectin/ amino acids medium or in the presence of high glucose. A combination of genes for several bacterial metabolites or mycotoxins rather than a single gene for a single toxin is presumably responsible for the Pseudomonas-mediated effects on vegetative Verticillium growth (Fig. 7). The GacA/GacS genetic network regulates the formation of mycotoxins, such as 2,4-diacetylphloroglucinol, pyoluteorin, and hydrogen cyanide (Heeb and Haas 2001). This system is robust to control fungal growth because the deletions for the genes for GacA/GacS regulators had a significant impact on fungal growth but not single deletions of biosynthetic genes of single antifungal compounds.

The fungus might follow distinct nutrient-dependent growth strategies. Nutritional conditions can induce the option to respond to the presence of the phenazineproducing bacterium by growing in other directions. Alternatively, attractive carbon sources might induce a "wait and see" behavior, where the fungus reduces the growth rate of vegetative hyphae. Wait and see fungal responses have been described in A. fumigatus in nutrient-rich but hostile environments as human blood (Irmer et al. 2015). The distribution of secreted bacterial metabolites depends on the specific location of the organisms in a particular set-up (i.e., agar). On solid agar medium, the fungus is inoculated throughout the whole petri dish and the bacterium starts to grow at a single inoculation point. The bacterium inoculated in the center produces a metabolite gradient (decreasing concentration of 
Appl Microbiol Biotechnol

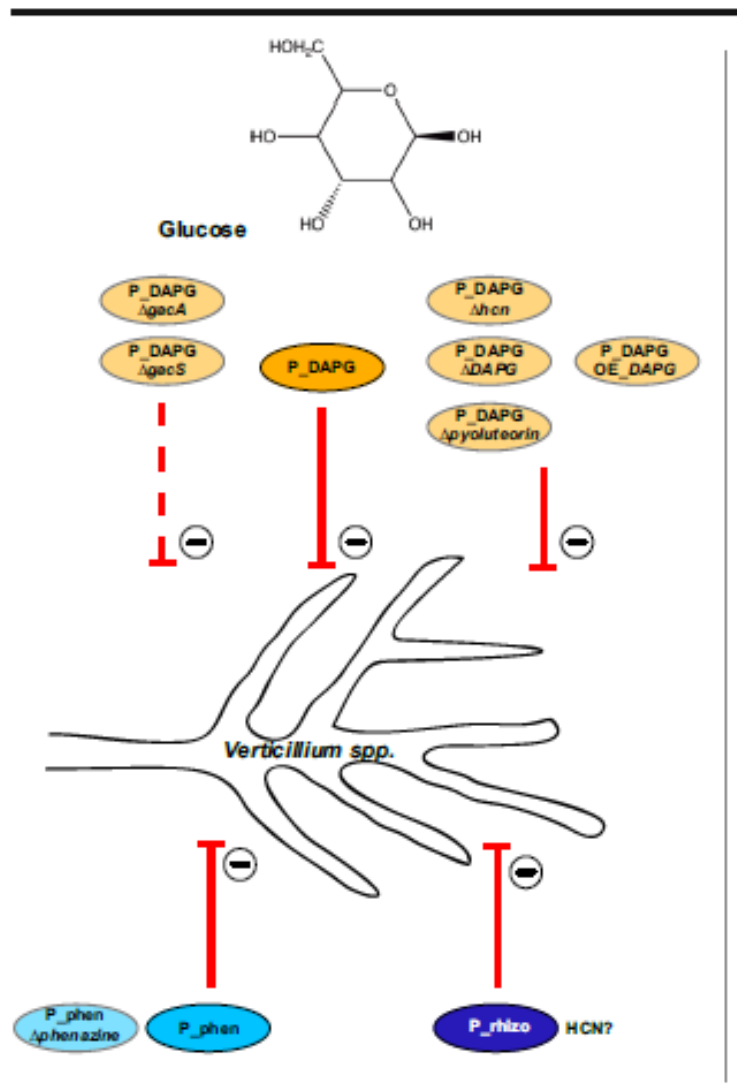

Fig. 7 Model summarizing the effects of different fluorescent pseudomonads to inhibit $V$. longisponum or $V$ dahliae growth. All Pseudomanas wild-type strains (P DAPG (dark orange); P phen (dark turquois); $P_{-}$thizo (dark bhue)) were able to inhibit $V$. longisponom and $V$. dahliae growth (marked with red connectors and minus). The inhibition potential of strains with deletions in different genes coding for proteins involved in the production of metabolites is summarized. Corresponding mutants of the P DAPG strain are depicted in light orange and the mutant of the $\mathrm{P}$ phen strain is depicted in light turquois. Left: on glucose-containing medium the inhibitory effect of the P_DAPG wild type was similar to strains carrying deletions in genes coding for proteins involved in the production of HCN (P DAPG $\Delta h c n)$, DAPG $(P$ DAPG $\triangle D A P G$ ) and pyoluteroin (P_DAPG $\triangle$ pyoluteroin). Also, overexpression of DAPG (P DAPG $\overline{O E} D A P G$ ) did not change the inhibition potential. Strains with deletions in the genes coding for gacA

metabolites further away from the center), which can be perceived by the fungus. Secreted bacterial metabolites might cause a negative chemotaxis in the petri dish format, which results in fungal branching and colony formation thus avoiding the bacterium to a certain extent.

Co-cultivations of different fluorescent pseudomonads with Verticillium species revealed an interesting potential for biocontrol protection of crops against these emerging pathogens. Plants can specifically induce the production of bacterial metabolites with antifungal properties in the rhizosphere upon fungal infection (Jousset et al. 2011). Pseudomonads primarily produce a cocktail

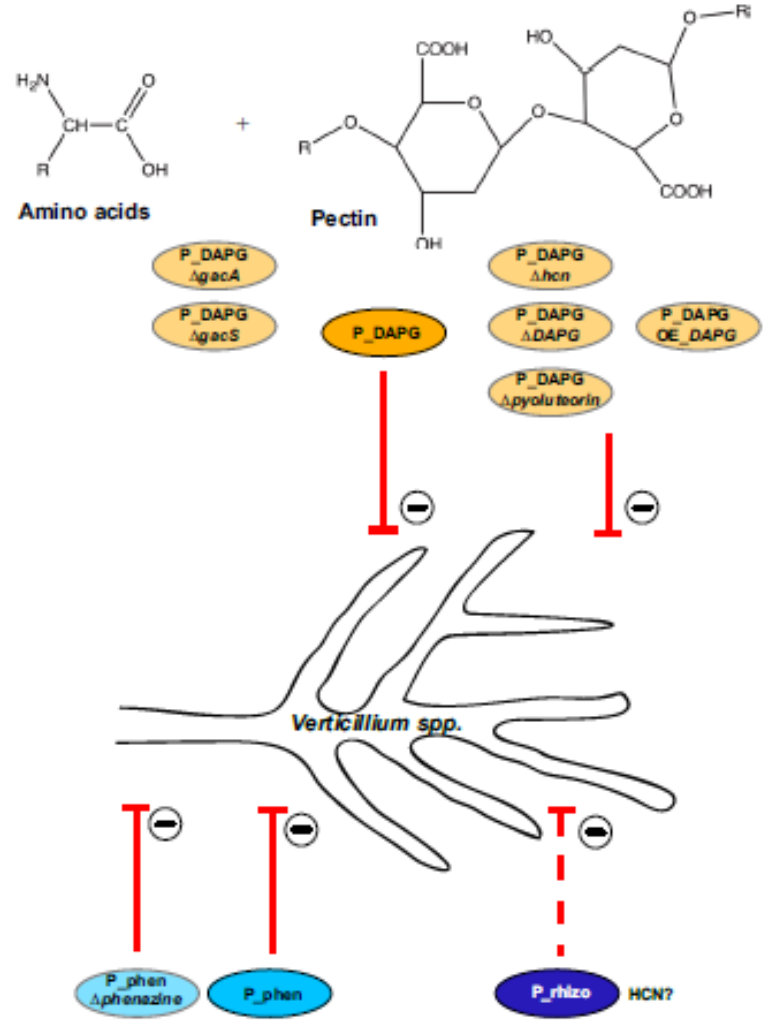

(P_DAPG $\triangle g a c A)$ or gacS (P_DAPG $\triangle$ gacS), respectively, which are involved in the control of several metabolites, showed slightly decreased inhibitory effects on the fungi (dashed line). The ability of $P_{-}$ phen to inhibit Verticillium spp. growth was dependent on an intact phenarine gene cluster. The mutant strain ( $\mathrm{P}$ phen Aphenazine) did not show any impact on the fungus. The role of $\mathrm{HCN}$ production of P-rizo remains elusive. Right: on pectin/amino acid containing medium, the inhibitory potential of P DAPG was comparable to P DAPG $\Delta / c n, P$ DAPG $\triangle D A P G$, P DAPG OE DAPG, and P DAPG $\overline{-}$ Apyohuteroin. In contrast, P_DAPG $\overline{\Delta g a c A}$ and $\overline{\mathbf{P}}$-DAPG $\Delta g a c \bar{S}$ were not able to inhibit Verticillium spp. growth. The inhibitory effect of $\mathbf{P}$ phen on fungal growth was independent from an intact phenazine cluster. $\mathbf{P}$ rhizo showed slight inhibitory effects towards $V$. dahliae but not towards V. longis porum (dashed line)

of bioactive compounds, which reduces fungal growth. Both an intact phenazine cluster as well as an intact $\mathrm{GacA} / \mathrm{GacS}$-system are important for the antagonistic activities of the bacteria towards the fungus. A combination of different fluorescent pseudomonads for biocontrol might be an interesting path for a wider antimycotic spectrum in the rhizosphere. An improved biocontrol of Verticillium by Pseudomonas spp. requires a more detailed understanding of mutual fungal and bacterial actions and responses in the rhizosphere. Such an endeavor might be worthwhile, because these fungi are of increasing interest to agriculture. 
Acknowledgements The authors thank Linda Thomashow for strain Pf2-79 $\Delta p h z$. Dicter Haas for PfCHA-mutants, and Tuan Tran forplasmid pKO2. We are grateful to Josua Schinke and Bastian Joehnk for proofreading and Sarah Zunken for technical support.

Funding This study was funded by the Deutsche Forschungsgemeinschaft (DFG) grant BR 1502/15-1 and by the Federal Ministry of Education and Research (BMBF) BioFung project.

\section{Compliance with ethical standards}

Conflict of interest The authors declare that they have no competing interests.

Ethical approval This article does not contain any studies with human participants or animals performed by any of the authors.

\section{References}

Bayram Ō, Braus GH (2012) Coordination of secondary metabolism and development in fungi: the velvet family of regulatory proteins. FEMS Microbiol Rev 36(1):1-24. https://doi.ory/10.1111/j.1574. $6976.2011 .00285 x$

Bayram O, Krappmann S, Ni M, Bok JW, Helmstaedt K, Valerius O Braus-Stromeyer S, Kwon N-J, Keller NP, J-H Y, Braus GH (2008) VelB/VeA/LaeA complex coordinates light signal with fungal development and secondary metabolism. Science 320(5882): 1504-1506. https://doi.org/10.1126/science.1155888

Bayer CropScience Biologics GmbH Contans WG for control of Sclerotinia spp. http:/www. biologics.baycr.com/. Accessed 5 May 2017

Bender C, Rangaswamy V, Loper J (1999) Polyketide production by plant-associated pseudomonads. Annu Rev Phytopathol 37(1): 175-196. https:/doi.org/1 0.1146/annurevphyto.37.1.175

Berg G, Ballin G (1994) Bacterial antagonists to Verticillium dahliae Kleb. J Phytopathol 141(1):99-110. https://doi.org/10.1111/j.14390434.1994.tb01449.x

Batani G (1951) Studies on Lysogenesis I. The mode of phageliberation by lysogenic Eschericia ooli. J Bacteriol 62:293-300

Biologics Bayer Bayer CropScience Biologics GmbH Contans WG for control of Sclerotinia spp. http://www.biologics.bayer.com/. Accessed 5 May 2017

Bok JW, Keller NP (2004) LaeA, a regulator of secondary metabolism in Aspergillus spp. Eukaryot Cell 3(2):527-535. https://doi.org/10. 1128/EC. 3.2.527-535.2004

Braus GH, Irniger S, Bayram Õ (2010) Fungal development and the COP9 signalosome. Curr Opin Microbiol 13(6):672-676. https $/ /$ doi.org/10.1016/j.mib.2010.09.011

Brencic A, McFarland KA, McManus HR, Castang S, Mogno I, Dove SL, Lory S (2009) The GacS/GacA signal transcuction system of Pseudomonas aenuginos a acts exclusively through its control over the transcription of the RsmY and RsmZ regulatory small RNAs. Mol Microbiol 73(3):434-445. https//doi.org/1 0.1111/j.1365-2958. 2009.06782.x

Bundock P, den Dulk-Ras A, Beijersbergen A, Hooykaas PJ (1995) Trans-kingdom T-DNA transfa from Agrobacterium tumefaciens to Saccharonyces cerevisiae. EMBO J 14(2):3206-3214. https $/$ doi.org/10.1016/j.fgb.2006.07.006
Chen Y, Yan F, Chai Y, Liu H, Kolter R, Losick R, Guo J (2013) Biocontrol of tomato wilt disease by Bacillus subtilis isolates from natural environments depends on conscrved genes mediating biofilm formation. Environ Microbiol 15(3):848-864. https://doi.ong/ $10.1111 / \mathrm{f} .1462-2920.2012 .02860 x$

Cui J (2005) Pseudomonas syringae manípulates systemic plant defenses against pathogens and herbivores. Proc Natl Acad Sci US A 102(5): 1791-1796. https $/ /$ doi.org/10.1073/pnas.0409450102

Depotter JRL, Deketelaere S, Indabitzin P, Von TA, Hofte M, Subbarao KV, Wood TA, Thomma BPHJ (2016) Verticillium longisponum, the invisible threat to oilseed rape and other brassicaceous plant hosts. Mol Plant Pathol 17(7):1004-1016. https://doi.org/10.1111/mpp. 12350

Eynck C, Koopmann B, Grunewal dt-Stoecker G, Karlovsky P, von Tiedemann A (2007) Differential interactions of Verticillium bngisponem and $V$. dahliae with Brassica napus detected with molecular and histological techniques. Eur J Plant Pathol 118(3):259274. https://doi.org/10.1007/s10658-007-9144-6

Fradin EF, Thomma BPHJ (2006) Physiology and molecular aspects of Verticillium wilt diseases caused by $V$ dahiae and $V$ albo-abum. Mol Plant Pathol 7(2):71-86. https://doi.org/10.1111j.1364-3703. 2006.00323.x

Fradin EF, Zhang Z, Juarez Ayala JC, Castroverde CDM, Nazar RN, Robb J, Liu C-M, Thomma BPHJ (2009) Genctic dissection of Verticillium wilt resistance mediated by tomato Ve1. Plant Physiol 150(1):320-332. https://doi.org/10.1104/pp.109.136762

Haas D, Défago G (2005) Biological control of soil-borne pathogens by fluorescent pseudomonads. Nat Rev Microbiol 3(4):307-319. https://doi.ong/10.1038/nmicro 1129

Hamel J (2011) A review of acute cyanide poisoning with a treatment update. Crit Care Nurse 31(1):72-82. https://doi.org/10.4037/ crn2011799

Heeb S, Haas D (2001) Regulatory roles of the GacS/GacA twocomponent system in plant-as sociated and other gram-negative bacteria Mol Plant-Microbe Interact 14(12):1351-1363. https://doi.org/ 10.1094/MPMI.2001.14.12.1351

Hollensteina J, Wemheuer F, Harting R, Kolarzyk AM, Dizz Valario SM, Poehlein A, Brzuszkiewicz EB, Nesemann K, Braus-Stromeyer SA, Braus GH, Daniel R, Liesegang H (2017) Bacillus thuringiensis and Bacillus weihenstephanensis inhibit the growth of Phytopathogenic Verticillium species. Front Microbiol 7:2171. https://doi.org/10. 3389/fmicb. 2016.02171

Inderbitzin P, Bostock RM, Davis RM, Usami T, Platt HW, Subbarao KV (2011) Phylogenetics and tax onomy of the fungal vascular wilt pathogen Verticillium, with the descriptions of five new species. PLoS One 6(12):e28341. https://doi.org/10.1371/joumal.pone.0028341

Irmer H, Tarazona S, Sasse C, Olbermann P, Loeffler J, Krappmann S, Conesa A, Braus GH (2015) RNAseq analysis of Aspergillus fumigatus in blood reveals a just wait and see resting stage bchavior. BMC Genomics 16(1):640. https://doi.org/10.1 186/s 12864-0151853-1

Jousset A, Rochat L, Lanoue A, Bonkowski M, Keel C, Scheu S (2011) Plants respond to pathogen infection by enhancing the antifungal gene expression of root-associated bacteria. Mol Plant-Microbe Interact 24(3):352-358. https://doi.org/10.1094/MPMI-09-10-0208

Jousset A, Schuldes J, Keel C, Maurhofer M, Daniel R, Scheu S, Thuermer A (2014) Full-genome sequence of the plant growthpromoting bacterium Pseudomonas protegens CHA0. Genome Announc 2. https://doi.org/10.1128/genomeA.00322-14

Kerr JR, Taylor GW, Rutman A, Høiby N, Coke PJ, Wilson R (1999) Pseudomonas aenuginasa pyocyanin and 1-hydroxyphenazine inhibit fungal growth. J Clin Pathol 52(5):385-387. https://doi.org/ $10.1136 / j$ cp. 52.5 .385

Khan SR, Mavrodi DV, Jog GJ, Suga H, Thomashow LS, Farrand SK (2005) Activation of the phz operon of Pseudomonas fluarescens 279 requires the LuxR homolog PhzR, N-(3-OH-Hexanoyl)-L- 
homoserine lactone produced by the LuxI homolog PhzI, and a cisacting phz box. J Bacteriol 187(18):6517-6527. https://doi.org/10. 1128/JB.187.18.6517-6527.2005

Kwak YS, Han S, Thomashow LS, Rice JT, Paulitz TC, Kim D, Weller DM (2011) Saccharonyces cerevis ize genome-wide mutant screen for sensitivity to 2,4-diacetylphloroglucinol, an antibiotic produced by Pseudomonas fluorescens. Appl Environ Microbiol 77(5):17701776. https://doi.org/10.1128/AEM.02151-10

Laville J, Voisard C, Keel C, Maurhofer M, Défago G, Haas D (1992) Global control in Pseudomonas fluarescens mediating antibiotic synthesis and suppression of black root rot of tobacco. Proc Nat Acad Sci U S A 89(5):1562-1566. https://doi,org/10.1073/pnas.89. 5.1562

Mavrodi DV, Peever TL, Mavrodi OV, Parejko JA, Raajmakers JM, Lemanceau P, Mazuria S, Heide L, Blankenfeldt W, Weller DM, Thomashow LS (2010) Diversity and ewohtion of the phenazine biosynthesis pathway. Appl Environ Microbiol 76(3):866-879. https://doi.ong/10.1128/AEM.02009-09

Meyer SLF, Halbrendt JM, Carta LK, Skantar AM, Liu T, Abdelnabby HME, Vinyard BT (2009) Toxicity of 2,4-diactylphloroglucinol (DAPG) to plant-parasitic and bacterial-feeding nematodes. J Nematol 41(4):274-280

Nahlik K, Dumkow M, Bayram Ō, Helmstaedt K, Busch S, Valerius O, Gerke J, Hoppart M, Schwier E, Opitz L, Westermann M, Grond S, Feussner K, Goebel C, Kaeva A, Meinicke P, Feussner I, Braus GH (2010) The COP9 signalosome mediates transcriptional and metabolic response to hormones, oxidative stress protection and cell wall rearrangement during fungal development. Mol Microbiol 78(4): 964-979. https $/ /$ doi.org/10.1111/j.1365-2958.2010.07384.x

Nandi M, Selin C, Brassinga AKC, Belmonte MF, Fernando WGD, Loewen PC, de Kievit TR (2015) Pyrrolnitrin and hydrogen cyanide production by Pseudomonas chlororaphis strain PA23 exhibits nematicidal and repellent activity against Caenorhabditis elegans. PLoS One 10(4):e0123184. https://doi.org/10.1371/joumal.pone. 0123184

Nesemann K, Braus-Stromeyer SA, Thuerma A, Daniel R, Braus GH (2015a) Draft genome sequence of the beneficial Rhisobacterium Pseudomonas fluorescens DSM 8569, a natural isolate of oilseed rape (Brassica napus). Genome Announc 3(2):e00137-e00115. https://doi.org/10.1128/genomeA.00137-15

Nesemann K, Braus-Stromeya SA, Thuerma A, Daniel R, Mavrodi DV, Thomashow LS, Weller DM, Braus GH (2015b) Draft genome sequence of the Phenazine-producing Pseudomanas fuorescens strain 2-79. Genome Announc 3(2):e00130-e00115. https://doi.org/10. 1128/genomeA.00130-15

Neumann MJ, Dobinson KF (2003) Sequence tag analysis of gene expression during pathogenic growth and microsclerotia development in the vascular wilt pathogen Verticillium dahliae. Fungal Genet Biol 38(1):54-62. https://doi.org/10.1016/S1087-1845(02)00507-8

Nowak-Thompson B, Chaney N, Wing JS, Gould SJ, Lopa JE (1999) Charactarization of the pyoluteorin biosynthetic gene cluster of Pseudomonas fluorescens Pf-5. J Bacteriol 181(7):2166-2174

Nützmann H-W, Reyes-Dominguez Y, Scherlach K, Schroeckh V, Horn F, Gacek A, Schümann J, Hatweck C, Strauss J, Brakhage AA (2011) Bacteria-induced natural product formation in the fungus Aspergillus nidulans requires Saga/Ada-mediated histone acetylation. Proc Natl Acad Sci U S A 108(34):14282-14287. https://doi. org/10.1073/pnas. 1103523108

Pegg GF (1989) Pathogenesis in vascular diseases of plants. In: Tjamos EC, Beckman CH (eds) Vascular wilt diseases of plants. Springer Barlin Heidelbarg, Barlin, Heidelberg, pp 51-94. https://doi.org/10. 1007/978-3-642-73166-2_4

Pegg GF, Brady BL (2002) Varticillium wilts. CABI Pub, Wallingford. https://doi.ong/10.1079/9780851995298.0000
Paneel M (2006) The root rot pathogen Pythium myriotylum on cocoyam (Xanthosoma sagittifolium (L.) Schott): intraspecific variability and biological control. Proefschrift Universiteit Gent

Parneel M, D'hondt L, De Maeyer K, Adiobo A, Rabacy K, Höfte M (2008) Phenazines and biosurfactants interact in the biological control of soil-borne diseases caused by Pythium spp. Environ Microbiol 10(3):778-788. https://doi.org/10.1111/j.1462-2920. 2007.01501.x

Sarikaya-Bayram O, Bayram O, Valerius O, Park HS, Irniga S, Garke J, Ni M, Han K-H, J-H Y, Braus GH (2010) LaeA control of velvet family regulatory proteins for light-dependent development and fungal cell-type specificity. PLoS Genet 6(12):e1001226. https://doi. org/10.1371/journal.pgen. 1001226

Sarikaya-Bayram Ō, Palmer JM, Keller N, Braus GH, Bayram Ō (2015) One Juliet and four Romeos: VeA and its methyltransferases. Front Microbiol 6:1-7. https://doi.org/10.3389/fmicb.2015.00001

Schnider-Keel U, Secrnatter A, Maurhofer M, Blumer C, Duffy B, GigotBonnefoy C, Reimmann C, Notz R, Défago G, Haas D, Keel C (2000) Autbinduction of 2,4-diactylphloroglucinol biosynthesis in the biocontrol agent Pseudomonas fluorescens CHA0 and repression by the bacterial metabolites salicylate and pyoluteorin. J Bacteriol 182(5):1215-1225. https://doi.org/10.1128/JB.182.5. 1215-1225.2000

Schroeckh V, Scherlach K, Nutzmann H-W, Shelest E, Schmidt-Heck W, Schuemann J, Martin K, Hertweck C, Brakhage AA (2009) Intimate bacterial-fungal interaction triggers biosynthesis of archetypal polyketides in Aspergillus nidulans. Proc Natl Acad Sci 106(34): 14558-14563. https://doi.org/10.1073/pnas.0901870106

Scott BR, Kafer E (1982) Aspergillus nidulans: an organism for detecting a range of genetic damage. In: Chemical mutagens. pp 447-479. https://doi.ory/10.1007/978-1-4615-6625-0_11

Sikora RA (1992) Management of the antagonistic potential in agricultural ecosystems for the biological control of plant parasitic nematodes. Annu Rev Phytopathol 30(1):245-270. https://doi.org/10. 1146/annurev.py. 30.090192 .001333

Singh S, Braus-Stromeyer SA, Timpner C, Valerius O, von Tiedemann A, Karlovsky P, Druebert C, Polle A, Braus GH (2012) The plant host Brassica napus induces in the pathogen Verticillium longisponum the expression of functional catalase peroxidase which is required for the late phase of disease. Mol Plant-Microbe Interact 25(4):569581. https://doi.org/10.1094/MPMI-08-11-0217

Stutz EW, Défago G, Kem H (1986) Naturally occurring fluorescent pseudomonads involved in suppression of black root rot of tobacco. Phytopathology 76(2):181-185. https $/ /$ doi.org/10.1094/Phyto-76181

Timpner C, Braus-Stromeycr SA, Tran VT, Braus GH (2013) The Cpc1 regulator of the cross-pathway control of amino acid biosynthesis is required for pathogenicity of the vascular pathogen Verticillium longisponum. Mol Plant-Microbe Interact 26(11): 1312-1324. https://doi.ong/10.1094/MPMI-06-13-0181-R

Tran VT, Braus-Stromeyer SA, Timpner C, Braus GH (2013) Molecular diagnosis to discriminate pathogen and apathogen species of the hybrid Verticillium bngisponam on the oilseed crop Brassica napus. Appl Microbiol Biotechnol 97(10):4467-4483. https $/ /$ doi.org/10. 1007/s00253-012-4530-1

Tran V-T, Braus-Stromeyer SA, Kusch H, Reusche M, Kaevar A, Kühn A, Valerius O, Landesfeind M, ABhauer K, Tech M, Hoff K, PenaCenteno T, Stanke M, Lipka V, Braus GH (2014) Verticillium transcription activator of adhesion Vta2 suppresses microsclerotia formation and is required for systemic infection of plant roots. New Phytol 202(2):565-581. https://doi.org/10.1111/nph. 12671

Traxler MF, Kolter R (2015) Natural products in soil microbe interactions and evolution. Nat Prod Rep 32(7):956-970. https://doi.org/10. 1039/c5np00013k 
Weller DM (2007) Pseudomonas biocontrol agents of soilbome pathogens: looking back over 30 years. Phytopathology 97(2):250-256. https://doi.org/10.1094/PHYTO-97-2-0250

Welker DM, Cook RJ (1983) Supression of take-all of wheat by seed treatments with fluorescent pseudomonads. Phytopathology 73(3): 463-469. https $/ /$ doi.org/1 0.1094/Phyto-73-463

Weller DM, Raajimakers JM, Gardena BBM, Thomashow LS (2002) Microbial populations responsible for specific soil suppressiveness to plant pathogens. Annu Rev Phytopathol 40(1):309-348. https:// doi.ory/10.1146/annurev,phyto. 40.030402 .110010

Zeng W, Wang D, Kirk W, Hao J (2012) Use of Caniothyrium minitans and other microorganisms for reducing Sclerotinia sderotionum.
Biol Control 60(2):225-232. https://doi,org/10.1016/j.biocontrol. 2011.10 .009

Zhou L, Hu Q, Johansson A, Dixelius C (2006) Venticillium longispanum and $V$ dahliae, infection and disease in Brassica napus. Plant Pathol 55:137-144. https://doi.org/10.1111/j. 1365-3059.2005.01311.x

Zuber S, Carnuthars F, Keel C, Mattart A, Blumer C, Pessi G, GigotBonnefoy C, Schnider-Keel U, Heeb S, Reimmann C, Haas D (2003) GacS sensor domains pertinent to the regulation of exoproduct formation and to the biocontrol potential of Pseudomonas fluorescens CHA0. Mol Plant-Microbe Interact 16(7):634-644. https://doi.org/10.1094/MPMI.2003.16.7.634 


\section{Chapter 5: Pathogenic Verticillia Follow Evasion and Detoxification Strategies during Confrontation with Fluorescent Pseudomonads}

Kai Nesemann ${ }^{1}$, Rebekka Harting ${ }^{1}$, Annalena Höfer ${ }^{1}$, Harald Kusch ${ }^{2}$, Claire E. Stanley $^{3}$, Martina Stöckli ${ }^{4}$, Manuel Landesfeind ${ }^{1}$, Alexander Kaever ${ }^{1}$, Katharina Hoff ${ }^{5}$, Mario Stanke ${ }^{5}$, Andrew J. deMello ${ }^{3}$, Markus Künzler ${ }^{4}$, Markus Aebi ${ }^{4}$, Susanna A. Braus-Stromeyer ${ }^{1}$, Gerhard H. Braus ${ }^{1}$

${ }^{1}$ Institute of Microbiology and Genetics and Göttingen Center for Molecular Biosciences (GZMB), Georg-August-Universität Göttingen, Germany.

${ }^{2}$ Department of Medical Informatics, Georg-August-Universität Göttingen, Germany.

${ }^{3}$ Institute of Chemical and Bioengineering, ETH Zürich, Switzerland.

${ }^{4}$ Institute of Microbiology, ETH Zürich, Switzerland.

5 Institute of Mathematics and Computer Science, Ernst-Moritz-Arndt-Universität Greifswald, Germany.

* Corresponding author: Gerhard H. Braus, Grisebachstraße 8, 37077 Göttingen, Germany, Telephone: +49-551-3933771; Fax: +49-551-3933330; E-mail: gbraus@gwdg.de

Author contributions: Table 5.1: KN

Fig 5.1: CS, MS, AdM, MK, MA

Fig 5.2: CS, MS, KN

Fig 5.3: CS, MS, KN

Fig 5.4: CS, MS, KN

Fig 5.5: SB, RH, AH, HK, ML, AK, KH, MS, KN

Table 5.2: SB, RH, AH, HK, ML, AK, KH, MS, KN

Table S5: SB, RH, AH, HK, ML, AK, KH, MS, KN

Table S6: SB, RH, AH, HK, ML, AK, KH, MS, KN

Table S7: SB, RH, AH, HK, ML, AK, KH, MS, KN

Supervision and scientific advice: GB, SB, RH, HK

Manuscript: GB, SB, RH, KN 


\section{Abstract}

Verticillia are phytopathogenic fungi responsible for increasing yield losses in numerous economical important crops. The impact of different fluorescent pseudomonads on fungal growth was analyzed in microfluidic interaction channels. A Brassica-rhizosphere derived Pseudomonas fluorescens, which neither carries the genes for phenazine nor 2,4-diacetyphloroglucinol (DAPG) synthesis, reduces Verticillium polar hyphal growth by almost $60 \%$ in comparison to E. coli as control in a confrontation assay in microfluidic interaction channels filled with a liquid pectin and amino acid medium. A Pseudomonas synthaxa with an intact phenazine cluster reduces fungal growth by $30 \%$ more than a corresponding mutant strain. A DAPG producing Pseudomonas protegens strain can reduce fungal microfluidic growth by $90 \%$. The contribution for this inhibition of the two-component system GacA/GacS control system for a response regulator and a sensor kinase corresponds to $30 \%$ and includes a $10 \%$ inhibition provided by an intact DAPG cluster. An intact phenazine or GacA/GacS system induces in addition a strong change in hyphal polarity. This suggests that the fungus attempts to evade the confrontation with corresponding bacteria. During liquid media co-cultivation, $P$. protegens alters transcriptional profiles of $V$. longisporum genes after two hours with one third up-regulated genes including detoxification related genes and a decrease of a comparable portion of fungal transcripts involved in protein biosynthesis, plant infection or nutrition. The fungus presumably follows an evasion strategy to escape from bacterial toxicity, which includes avoiding contact by changing growth direction through morphological adaption combined with intensifying expression of genes coding for detoxifying enzymes.

Key words: Verticillium, fluorescent pseudomonads, GacA/GacS two-component system, DAPG, phenazines, microfluidics, transcriptome analysis 


\section{Introduction}

Soil is a highly diverse habitat with complex relationships between multiple inhabitant species. In particular, bacterial-fungal interactions play a major role for microbial fitness in soils (Nazir et al., 2009). The heterogeneous microbiota of the rhizosphere of a plant can contain different phytopathogenic species with negative impact on agricultural yields. The ascomycete Verticillium longisporum is an interspecific hybrid of two haploid parental strains and contains an amphidiploid genome. The soil-born pathogen mainly infects Brassicaceae and can survive in the soil for many years due to highly melanized resting structures, so called microsclerotia (Pegg and Brady, 2002; Harting et al., 2020). After germination in the soil, Verticillium hyphae enter the root cortex and colonizes the vascular system of its host plant (Eynck et al., 2007; Tran et al., 2014; Zhang et al., 2018). In the absence of appropriate fungicides or resistant cultivars, there are hardly any strategies available to control the infection process of vascular plant pathogens. Besides chemical treatments, it is an approved method in agriculture to use natural microorganisms with antagonistic activity from the rhizosphere as biological control organisms. By the application of specific bacterial or fungal antagonists as biocontrol agents, a suppressive potential towards pathogens can be installed in the soil (Sikora, 1992).

One of the largest groups of biocontrol organisms are fluorescent pseudomonads that belong to $\square$-proteobacteria and possess well-characterized and distinct beneficial properties in the interaction with plants (Haas and Défago, 2005). Several compounds secreted by fluorescent pseudomonads with crucial antagonistic impact against fungal pathogens could be identified in the recent years including 2,4-diacetylphloroglucinol (DAPG), phenazines, biosurfactants, pyoluteorin, pyrrolnitrin, hydrogen cyanide $(\mathrm{HCN})$, pyoverdine siderophore, indoleacetic acid and exoproteases (Haas and Défago, 2005; Mazzola, 2007). $P$. protegens $\mathrm{CHAO}$ has been identified as a biocontrol agent exhibiting one of the broadest repertoires of potential antagonistic and plant growth-promoting mechanisms so far (Weller, 2007).

Pseudomonas spp. have been described as an appropriate biocontrol agent against Verticillium wilt in literature (Martinez-Garcia et al., 2015; Markakis et al., 
2016; Deketelaere et al., 2017). Fluorescent pseudomonads can cause suppressive effects on the growth of different Verticillium species in co-cultivation studies on different agar-containing media (Nesemann et al., 2018). The presence of a phenazine gene cluster coding for a single component is sufficient to suppress fungal growth under high glucose growth conditions. In a complex pectin medium the genetic potential for the secretion of different substances regulated by the twocomponent regulatory system GacA/GacS is essential for inhibition. P. protegens $\mathrm{CHAO}$ genes controlled by the GacA/GacS signal-transduction pathway include phIA and phIF (for DAPG synthesis), hcnABC and anr (for HCN) and plt (for pyoluteorin). Corresponding mRNAs are constitutively expressed and are under non-inducing conditions posttranscriptionally inhibited by repressors RsmA and RsmE, which block translation, synthesis and finally secretion of bioactive metabolites. Environmental stress signals trigger autophosphorylation of the membrane sensor protein GacS, which transfers subsequently the phosphate group to the response regulator GacA. This activates the expression of the small RNAs rsmXYZ acting as derepressors of RsmA and RsmE, which bind to the ribosomal binding sites of the transcripts for the secondary metabolite producing enzymes and prevent translation during non-stress conditions. As a result, the translation of enzymes, and subsequently synthesis and secretion of the respective toxins can take place (Laville et al., 1992; Zuber et al., 2003; Heeb et al., 2005; Gonzalez et al., 2008; Brencic et al. 2009; Wei et al., 2013; Nandi et al., 2015; Traxler and Kolter, 2015; Yan et al., 2018; Zhang et al., 2020).

In this study, the plant pathogen Verticillium longisporum strain V143 was analyzed with different rhizobacteria in a liquid confrontation assay for better morphological observations and compared to previous surface studies for the same fungus (Nesemann et al., 2018). These surface studies revealed differences in the bacteria-fungus interplay for fluorescent pseudomonads with different potential to synthesize bioactive compounds. Verticillium mutant strains deficient in secondary metabolism by deleting the global regulator of secondary metabolism LAE1 (Bok and Keller, 2004; Bayram et al., 2008; Sarikaya-Bayram et al., 2010) or the deneddylase subunit CSN5 resulting in derepressed secondary metabolism (Nahlik et al., 2010) showed the same inhibition patterns as wildtype on agar surfaces. An inhibitory effect on fungal spore germination was also described 
recently after co-cultivation of $V$. dahliae with different fluorescent pseudomonads in two liquid media types (Nesemann et al., 2018). In microfluidic interaction channels, the growth response of Verticillium hyphae was monitored in presence of three distinct Pseudomonas species with differences in their genetic potential. The P. synthaxa strain (P_phen) carries genes for phenazine and $P$. protegens (P_DAPG) for DAPG production, respectively. The $P$. fluorescens strain derives from the rhizosphere of oilseed rape (P_rhizo) and carries neither an intact phenazine nor DAPG cluster. P_rhizo could suppress Verticillium polar growth in confrontation microchannels independently of the presence of phenazines or DAPG producing genes. A contribution of $30 \%$ fungal growth inhibition is provided by an intact phenazine cluster or as well when the genetic information for a complex combination of different GacA/GacS-regulated metabolites including DAPG is present in the bacterial genome. The genetic potential for GacA/GacScontrolled metabolites or phenazines leads to an altered morphology of Verticillium hyphae with a polarity change to avoid bacteria. P. protegens induces after two hours of co-cultivation alterations in $V$. longisporum gene expression including upregulation of detoxification related genes as well as decreased levels of transcripts for protein biosynthesis and degradation of plant polysaccharides. Taken together, Verticillium rather follows an evasion and detoxification strategy to avoid contact to Pseudomonas.

\section{Material and Methods}

\section{Organisms used in this study}

Bacterial and fungal strains used in this study are listed in table 5.1. 
Table 5.1 Organisms and strains used in this study.

*DSMZ - Leibniz Institute - German Collection of Microorganisms and Cell Cultures $\mathrm{GmbH}$, Braunschweig, Germany

\begin{tabular}{|c|c|c|}
\hline organism & characteristics & reference \\
\hline \multicolumn{3}{|l|}{ Verticillium longisporum } \\
\hline V. longisporum 43 & $\begin{array}{l}\text { wild type - isolated from oilseed } \\
\text { rape in Mecklenburg, Germany }\end{array}$ & $\begin{array}{l}\text { Zeise and von } \\
\text { Tiedemann, } 2001\end{array}$ \\
\hline $\begin{array}{l}\text { V. longisporum } \\
43 \mathrm{Gfp}\end{array}$ & green fluorescent VI43 & Tran et al., 2014 \\
\hline \multicolumn{3}{|l|}{ Pseudomonas fluorescens } \\
\hline P_rhizo (DSM8569) & $\begin{array}{l}\text { wild type - natural isolate from } \\
\text { oilseed rape rhizosphere }\end{array}$ & $\mathrm{DSMZ}^{*}$ \\
\hline \multicolumn{3}{|l|}{ Pseudomonas synxantha } \\
\hline P_phen (2-79) & $\begin{array}{l}\text { wild type, producing phenazines } \\
\text { (formerly named } P \text {. fluorescens) }\end{array}$ & $\begin{array}{l}\text { Weller and Cook, } \\
1983\end{array}$ \\
\hline P_phen $\Delta p h z$ & $\begin{array}{l}\text { production of phenazines } \\
\text { blocked }\end{array}$ & $\begin{array}{l}\text { Mavrodi et al., } \\
1998\end{array}$ \\
\hline \multicolumn{3}{|l|}{ Pseudomonas protegens } \\
\hline P_DAPG (CHA0) & $\begin{array}{l}\text { wild type, producing e.g. DAPG, } \\
\text { HCN, pyoluteorin }\end{array}$ & Stutz et al., 1986 \\
\hline P_DAPG_mCherry & red fluorescent $\mathrm{CHAO}$ & $\begin{array}{l}\text { Rochat et al., } \\
2010\end{array}$ \\
\hline $\begin{array}{l}\mathrm{P} \text { _DAPG } \Delta g a c A:: \Omega \mathrm{K} \\
\mathrm{m}^{\mathrm{r}}\end{array}$ & $\begin{array}{l}\text { key enzyme in biosynthesis of } \\
\text { several antibiotics; no production } \\
\text { of } 2,4-D A P G, H C N \text {, pyoluteorin }\end{array}$ & $\begin{array}{l}\text { Laville et al., } \\
1992\end{array}$ \\
\hline P_DAPG $\Delta g a c S$ & $\begin{array}{l}\text { key enzyme in biosynthesis of } \\
\text { several antibiotics; no production } \\
\text { of } 2,4-\mathrm{DAPG}, \mathrm{HCN} \text {, pyoluteorin }\end{array}$ & Zuber et al., 2003 \\
\hline $\begin{array}{l}\text { P_DAPG } \Delta g a c S \_m C h \\
\text { erry }\end{array}$ & red fluorescent $\mathrm{CHAO}$ & Keel, unpublished \\
\hline P_DAPG $\triangle h c n A B C$ & almost no production of $\mathrm{HCN}$ & $\begin{array}{l}\text { Laville et al., } \\
1998\end{array}$ \\
\hline P_DAPG $\Delta a n r:: \Omega H g^{r}$ & $\begin{array}{l}\text { transcription factor for } \mathrm{HCN}- \\
\text { production; } 8 \% \mathrm{HCN} \text { production } \\
\text { compared to wild type }\end{array}$ & $\begin{array}{l}\text { Laville et al., } \\
1998\end{array}$ \\
\hline P_DAPG $\Delta p / t:: T n 5$ & no production of pyoluteorin & $\begin{array}{l}\text { Maurhofer et al., } \\
1994\end{array}$ \\
\hline P_DAPG $\Delta p h I A$ & $\begin{array}{l}\text { gene in phl-operon for } 2,4-D A P G \\
\text { synthesis; no production of } 2,4- \\
\text { DAPG }\end{array}$ & $\begin{array}{l}\text { Schnider-Keel et } \\
\text { al., } 2000\end{array}$ \\
\hline P_DAPG $\Delta p h I F:: \Omega K m^{r}$ & $\begin{array}{l}\text { repressor gene for } 2,4-\mathrm{DAPG} \\
\text { synthesis; enhanced production } \\
\text { of } 2,4-\mathrm{DAPG}\end{array}$ & $\begin{array}{l}\text { Schnider-Keel et } \\
\text { al., } 2000\end{array}$ \\
\hline \multicolumn{3}{|l|}{ Escherichia coli } \\
\hline $\mathrm{DH} 5 \alpha$ & wild type & $\begin{array}{l}\text { Meselson and } \\
\text { Yuan, } 1968 \\
\end{array}$ \\
\hline
\end{tabular}




\section{Cultivation conditions of bacteria and fungi}

Fungi and bacteria were inoculated and cultivated as described in Nesemann et al., 2018.

\section{Microfluid device system}

Detailed interaction studies with Verticillium and Pseudomonas were performed in microfluidic interaction devices. Microfluidic applications facilitate miniaturized analytics of physical processes in micrometer scale to control pl- $\mu$ liquid volumes, in this case cultural medium (deMello, 2006). Thus, we were able to follow their interaction in vivo on single cell level under the microscope. The devices were developed by Stanley et al., 2014.

Verticillium was pre-cultivated on SXM plates, and inoculated with hyphae on an agar block at the one side of the device. After the hyphae passed a narrow bridge of $10 \mu \mathrm{m}$ diameter about 10 to 20 hyphae can grow into an interaction channel. In total, 28 parallel channels exist with a diameter of $100 \mu \mathrm{m}$ and a length of $6650 \mu \mathrm{m}$. As soon as the hyphal tips reach the beginning of the channel, $40 \mu \mathrm{l}$ of bacterial suspension out of the exponential phase $\left(\mathrm{OD}_{600 \mathrm{~nm}}=1 ; 5 \times 10^{7} \mathrm{CFU}\right)$ was applied at the opposite site of the channel. A fluid inlet hole is connected to the interaction channels. This way, the bacterial cells can distribute within the device. Fungal growth behavior and morphology was documented every 24 hours. For better optical illustration we used a green-fluorescent-protein(Gfp)-expressing strain of V. longisporum VI43 (Eynck et al., 2007) and P.protegens CHAO mCherry expressing strains P_DAPG (Rochat et al., 2010) and P_DAPG $\Delta$ gacS (Zuber et al., 2003).

Furthermore, growth tests using the supernatant of $P$. fluorescens were performed in the microfluid device system. For the non-induced supernatant a bacterial culture with $\mathrm{OD}_{600 \mathrm{~nm}}=1$ in $\mathrm{SXM}$ was sterile filtered. As the induction of secondary metabolite secretion might require the presence of Verticillium, $V$. longisporum_Gfp was pre-cultured in $150 \mathrm{ml}$ liquid SXM for 6 days and $P$. fluorescens culture with $\mathrm{OD}_{600 \mathrm{~nm}}=1 \mathrm{in} 50 \mathrm{ml}$ SXM. The fungal mycelium was filtered by Miracloth and transferred to $120 \mathrm{ml}$ of fresh SXM. Additionally, $30 \mathrm{ml}$ of 
the overnight Pseudomonas culture was added to a total volume of $150 \mathrm{ml}$. A cocultivation period of 3 hours at $25^{\circ} \mathrm{C}$ with agitation at $150 \mathrm{rpm}$ followed. Afterwards, the co-culture was filtered again by Miracloth membrane and sterile filtered (Filtropur S 0.2, Sarstedt, Nümbrecht, Germany). After the pre-growth of Verticillium in the device, the medium was exchanged to $40 \mu \mathrm{l}$ of the non-induced or induced supernatant, respectively.

The Zeiss Axio Observer Z.1 system (Carl Zeiss AG, Germany) in combination with the Laser Lunch System (Model 3iL32, Intelligent Imaging Innovations Inc, Colorado, USA) was used to obtain fluorescence microscopy applied with Zeiss PlanAPOCHROMAT 40x/1,4oil or Zeiss PlanAPOCHROMAT 100x/1,4oil objective, respectively. Pictures were taken with the QuantEM:512SC camera (Photometrics, Arizona, USA) and the Slide Book 5.0 imaging software (Intelligent Imaging Innovations Inc.) with an exposure time of $150 \mathrm{~ms}$ for Gfp and $500 \mathrm{~ms}$ for mCherry.

\section{Transcriptome sequencing and analysis}

Nine cultures of Verticillium longisporum 43 have been precultivated for five days with $1 \times 10^{6}$ spores in $150 \mathrm{ml}$ of liquid SXM at $25^{\circ} \mathrm{C}$ with $150 \mathrm{rpm}$. The total amount of $1.350 \mathrm{ml}$ of fungal culture was pooled and slightly sedimented. The top $350 \mathrm{ml}$ medium was discarded and the remaining $1000 \mathrm{ml}$ culture was equally distributed to eight $500 \mathrm{ml}$ flasks with $125 \mathrm{ml}$ of culture each. Additionally, six cultures of Pseudomonas protegens CHAO were grown at the same conditions (in $150 \mathrm{ml}$ SXM at $25^{\circ} \mathrm{C}$ with $\left.150 \mathrm{rpm}\right)$ up to an OD $600 \mathrm{~nm}=1\left(5 \times 10^{7} \mathrm{CFU}\right)$. The single cultures were pooled and concentrated to an $\mathrm{OD}_{600 \mathrm{~nm}}=3$ by centrifuging at $5000 \mathrm{~g}$ and resuspended in fresh SXM. Six of the eight flasks filled with $125 \mathrm{ml}$ fungal culture were immediately mixed with $25 \mathrm{ml}$ of bacterial culture $\left(\mathrm{OD}_{600 \mathrm{~nm}}=3\right)$, leading to a co-culture of $V$. longisporum VI43 and $P$.protegens $\mathrm{CHAO}$ with a final $\mathrm{OD}_{600 \mathrm{~nm}}=0,5$. At the same time the two remaining flasks with $125 \mathrm{ml}$ fungal culture were mixed with $25 \mathrm{ml}$ fresh SXM and served as an untreated control. The six cocultures and the two pure fungal cultures were further incubated at the same conditions as described before. The co-cultures as well as the fungal control cultures without bacteria were harvested after 120 min by filtering the cultures 
through Miracloth filters and directly shock-frozen in liquid N2. RNA extraction was performed by using the RNeasy Plant Mini Kit from Qiagen (Hilden, Germany). RNA sequencing was performed by GATC Biotech AG (Konstanz, Germany). The sequences are released at $\mathrm{NCBI}$ under the Accession-number SRP068348; http://www.ncbi.nlm.nih.gov/sra/?term=SRP068348. By selecting the poly-A ${ }^{+}$-part of the eukaryotic mRNA, only the fungal RNA was sequenced. All $V$. longisporum VI43 transcripts have been mapped against V. dahliae JR2 (VDAG_JR2v.4.0; de Jounge et al., 2012; deposited at www.fungi.ensembl.org/Verticillium dahliaejr2/Info/Index; Howe et al., 2019). A filter and cluster analysis of all transcripts was performed using the MarVis-Cluster interface (Kaever et al., 2009) within the MarVis-Suite software (Kaever et al., 2015; http://marvis.gobics.de) into three groups representing the down-, non- and up-regulated fungal genes when the bacterium is present. The complete transcriptomic dataset has been automatically annotated by Ensembl- (Howe et al., 2019) and Gene Ontology (GO; Ashburner et al., 2000; Gene Ontology Consortium, 2019) database. For subsequent functional characterization only transcripts with adjusted $p$-values (padj) of $<0,01$ were chosen to ensure that only candidates are included with highest probability that Verticillium gene regulation reflects Pseudomonas treatment. To identify most up- and down-regulated genes for further analysis, transcripts with Log2_Fold_Change $>4$ were regarded as most up-regulated and transcripts with Log2_Fold_Change $<-3$ were regarded as most down-regulated ones. This selected dataset was manually annotated by amino-acid sequence BLAST for domain prediction in SMART (http://smart.embl-heidelberg.de/; Letunic et al., 2015 and 2018). Based on this annotation the candidates have been manually assigned to functional categories. 


\section{Results}

\section{$90 \%$ of Verticillia polar hyphal growth can be reduced by fluorescent pseudomonads in confrontation assays.}

Growth of Verticillia within microchannels is unaffected by $E$. coli. Fungal growth inhibition by bacteria in SXM containing pectin and amino acids was analyzed when single polar hyphae were grown in microchannels filled with liquid SXM. Confrontation assays with single hyphae of $V$. longisporum, which constitutively express green fluorescent protein (Gfp; Tran et al., 2014) and different Pseudomonas strains were performed in microfluidic devices. The length of labeled hyphae growing within these interaction channels was measured after 7 days using fluorescence microscopy. Fungi and bacteria were inoculated at opposing ends of the device. After 7 days the hyphae reached the end of the channel when bacteria are absent. The fungal growth rate of approximately $950 \mu \mathrm{m}$ per day ( $\mu \mathrm{m} \mathrm{d}-1)$ did not change substantially upon inoculation with $E$. coli cells or cell free supernatants of Pseudomonas spp. Hyphae cultivated in physiological salt solution instead of SXM showed poor growth, suggesting a rather low nutrition effect by the agar inoculation block (Figure 5.1).

Verticillia polar hyphal microchannel growth is reduced by almost $60 \%$ by rhizosphere fluorescent pseudomonads without intact phenazine or DAPG gene cluster. Confrontation assays in microfluidic devices of $V$. longisporum with the rhizosphere isolate of rapeseed ( $P$. fluorescens DSM8569, $P_{-}$rhizo) lacking a phenazine or DAPG cluster reduced the fungal growth rate by more than half to $397 \mu \mathrm{m} \mathrm{d}^{-1}$ in comparison to $950 \mu \mathrm{m} \mathrm{d}^{-1}$ of $V$. longisporum hyphae grown without inhibition. These data suggest a strong potential of rhizosphere pseudomonads to inhibit fungal growth in a confrontation assay with physical constraints in a liquid pectin amino acid medium, which is independent of the genetic potential to produce either phenazines or DAPG.

Verticillia polar hyphal microchannel growth is reduced by $\mathbf{7 0} \%$ due to rhizosphere fluorescent pseudomonads with intact phenazine gene cluster. 
The presence of an intact phenazine cluster ( $P$. synxantha 2-79, P_phen), reduced the fungal growth rate in microchannels containing pectin amino acid to almost a third (hyphae grew $286 \mu \mathrm{m} \mathrm{d}^{-1}$ compared to $950 \mu \mathrm{m} \mathrm{d}^{-1}$ without bacteria). The analysis of the phenazine cluster deletion strain $\mathrm{P}$ _phen $\Delta p h z$ resulted in fungal growth of $546 \mu \mathrm{m} \mathrm{d}^{-1}$ (approximately $60 \%$ of wildtype fungal growth) and revealed that an intact phenazine cluster can contribute to about $30 \%$ of fungal growth reduction caused by the bacteria (Figure 5.1).

Verticillia polar hyphal microchannel growth is reduced by $90 \%$ due to rhizosphere fluorescent pseudomonads with intact compared to defective DAPG gene cluster. The presence of an intact DAPG cluster ( $P$. protegens $\mathrm{CHAO}$, P_DAPG, constitutively expressing the red fluorescent protein, Rfp) only enabled the fungus to grow $67 \mu \mathrm{m} \mathrm{d}^{-1}$ corresponding to less than $10 \%$ of the wildtype fungus resulting in the largest observed reduction in Verticillium growth rate (more than $90 \%$ ) of the conditions tested using the microfluidic assay. A mutant strain defective in the DAPG cluster ( $\triangle p h I A$ deletion) improved fungal growth from $67 \mu \mathrm{m} \mathrm{d}^{-1}$ to $182 \mu \mathrm{m} \mathrm{d}^{-1}$ (compared to $950 \mu \mathrm{m}$ per day without bacteria) and revealed that the DAPG cluster contributes to about $10 \%$ of the bacteria-induced fungal growth inhibition (Figure 5.1). 


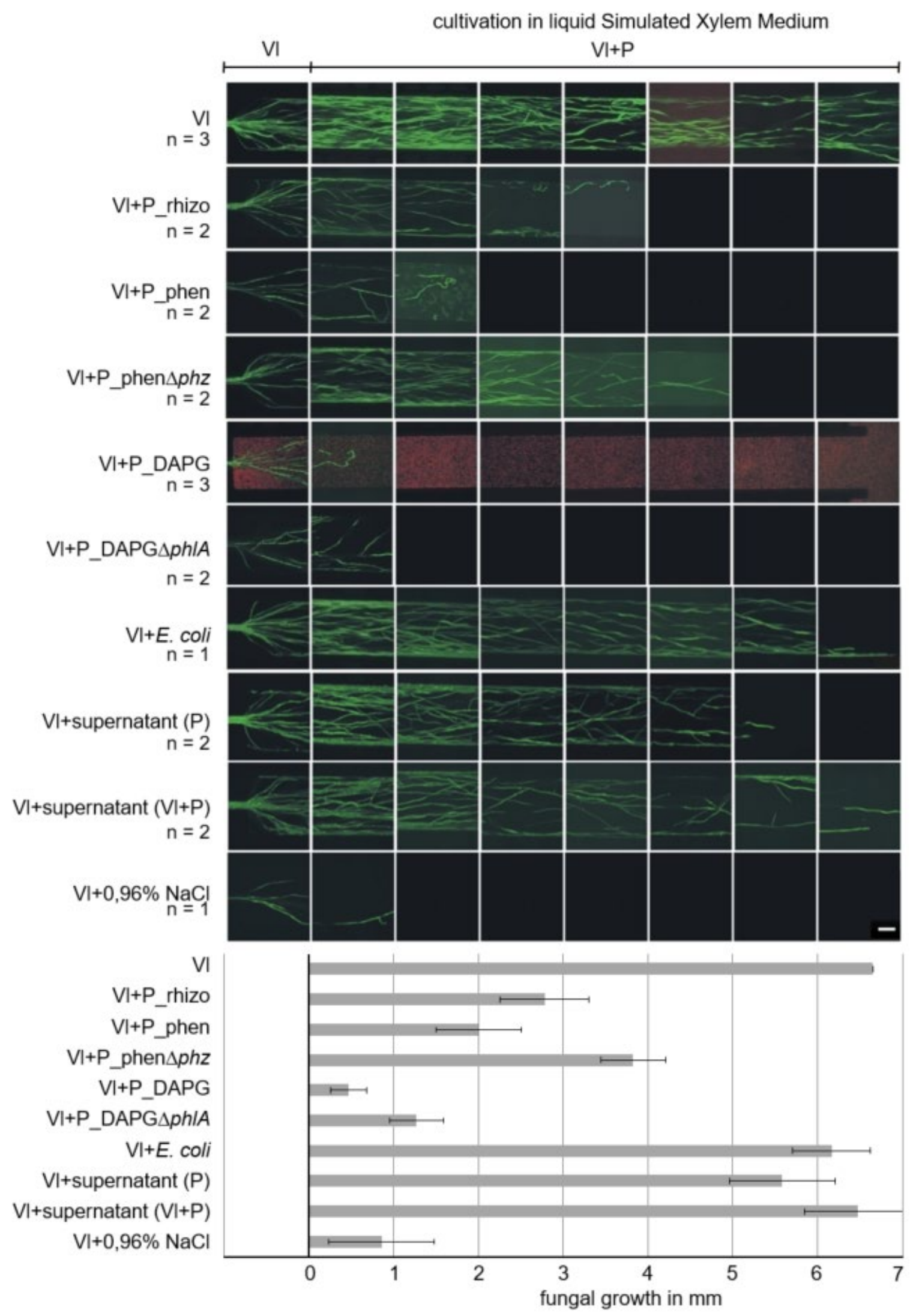


Figure 5.1: Co-cultivation in microfluidic devices of $V$. longisporum VI43 and different wild type fluorescent pseudomonads as well as deletion strains lacking genomic potential for phenazine or DAPG. Co-cultivation was performed in liquid simulated xylem medium containing complex plant molecules such as pectin. $V$. longisporum VI43 (VI) was inoculated at the fungal inoculation site. The device was incubated until the hyphae entered the microchannels. As soon as the fungal hyphae reached the beginning of the interaction channels fluorescent pseudomonads were inoculated at the opposite end of the channel. Bacteria spread throughout the device. Hyphal growth is displayed in $\mathrm{mm}$ (scale bar $=10 \mu \mathrm{m}$ ). The diagram shows the arithmetic average of all measured values. The amount of biological replicates $(n)$ is given, respectively. $V$. longisporum expressing the green fluorescent protein was co-cultivated with: the Brassica rhizosphere isolate $\mathrm{P}$ rhizo ( $P$. fluorescens DSM8569); the phenazine-producing P_phen wild type (WT: P. synxantha 2-79) and the phenazine deficient deletion strain ( $\Delta p h z)$; the DAPG-producing P_DAPG (WT: P.protegens CHA0), expressing the red fluorescent protein and deletion strains lacking one essential gene for DAPG synthesis phIA $(\Delta p h I A)$. Further, $V$. longisporum was treated with sterile supernatant of $P$ _DAPG mono-culture $(P)$, sterile supernatant of $P$ DAPG and $V$. longisporum co-culture $(\mathrm{VI}+\mathrm{P})$ as well as $0.96 \% \mathrm{NaCl}$. Co-cultivation with E. coli served as a neutral control.

\section{An intact GacA/GacS regulatory system of fluorescent pseudomonads can contribute to $\mathbf{3 0} \%$ bacterial inhibition potential against Verticillia hyphal growth in microchannels.}

An intact DAPG cluster compared to an intact phenazine cluster can contribute to the growth inhibition of fluorescent pseudomonades in microchannels to $10 \%$ and $30 \%$, respectively. Increased DAPG secretion by deleting the $\Delta p h I F$ gene for the inhibitor PhIF did not result in a further reduction of the fungal growth rate (P_DAPG $\Delta$ phIF; Figure 5.2). An additional contribution of $50 \%$ of fungal growth inhibition (as in P_rhizo) can be independent of the presence of either an intact DAPG or phenazine cluster. Several bacterial mycotoxin gene clusters including the DAPG cluster are under control of the bacterial GacA/GacS two component system. Deletion in P. protegens CHAO (P_DAPG) of either the gacA or gacS gene leads to a recovery in the hyphal growth rate of Verticillium from $67 \mu \mathrm{m} \mathrm{d}^{-1}$ to $336 \mu \mathrm{m} \mathrm{d}^{-1}$ (P_DAPG_gacA) or $299 \mu \mathrm{m} \mathrm{d}^{-1}$ (P_DAPG_gacS) compared to approximately $950 \mu \mathrm{m}$ per day fungal growth without bacterial inhibition (Figure 5.2). This suggests that the two-component system coordinates a substantial portion of $30 \%$ of the bacterial potential to inhibit fungal growth. Several additional 
bacterial mutant strains revealed GacA/GacS mediated contributions of the genes for HCN-production ( $\triangle h c n A B C$ lacks three essential genes for formation of HCN and $\Delta a n r$ deficient in $\mathrm{HCN}$ secretion) and for pyoluteorin synthesis ( $\Delta$ plt) lacking the essential gene for pyoluteorin synthesis (Figure 5.2).

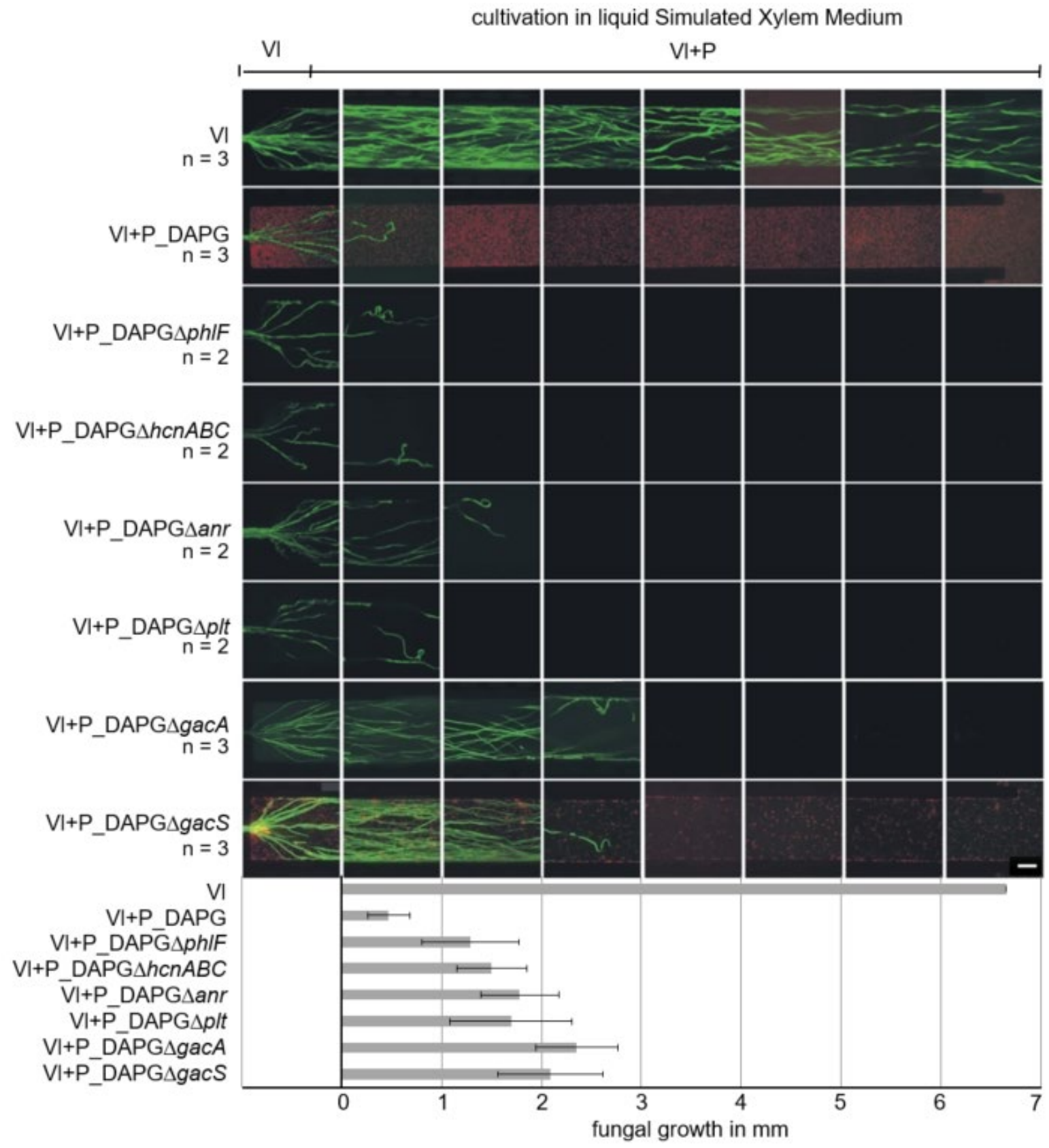


Figure 5.2: Co-cultivation in microfluidic devices of $V$. longisporum VI43 and wild type fluorescent pseudomonads as well as deletion strains missing regulators for multiple or single metabolite synthesis. Co-cultivation was performed in liquid simulated xylem medium containing pectin, which mimics conditions in dead plant material. V. longisporum VI43 (VI) was inoculated on an agar block at the fungal inoculation site and incubated until the mycelium grew into the channel. As soon as the fungal hyphae reached the entrance to the interaction channels fluorescent pseudomonads were inoculated at the opposite end of the channel. Bacteria spread throughout the whole channel. Hyphal growth is displayed in $\mathrm{mm}$ (scale bar $=10 \mu \mathrm{m}$ ). The diagram shows the arithmetic average of all measured values. The amount of biological replicates $(n)$ is given, respectively. $V$. longisporum expressing the green fluorescent protein was cocultivated with a DAPG producing P_DAPG ( $P$. protegens $\mathrm{CHA0}$ ) and compared to the following deletion strains: $\triangle p h \overline{I F}$ - lacking the inhibitor of DAPG-production leading to increased DAPG secretion; $\triangle h c n A B C$ - lacking essential genes for HCNproduction; $\triangle a n r$ - lacking the $\mathrm{HCN}$ regulator anr with deficient $\mathrm{HCN}$ secretion; $\Delta p / t$ - lacking the essential gene for pyoluteorin synthesis; one of the two units for regulation of multiple toxin production gacA $(\triangle g a c A)$ or gacS ( $\triangle$ gacS; expressing the red fluorescent protein).

In summary, a complex combination of several bacterial genes and gene clusters for bioactive compounds can together provoke a Pseudomonas-mediated inhibition of the fungal $V$. longisporum growth in microchannels filled with liquid SXM medium in a confrontation assay. More than $90 \%$ fungal growth inhibitions could be monitored including different contributions as $30 \%$ of GacA/GacScontrolled genes, including the DAPG cluster, or a $30 \%$ contribution of the genes for phenazine.

\section{Phenazines and GacA/GacS-controlled metabolites of fluorescent pseudomonads change polarity of Verticillium hyphae.}

Besides the distinct growth inhibition of Verticillium hyphae in presence of different fluorescent pseudomonads also the bacterial impact on the morphology of Verticillium has been investigated. $V$. longisporum grows in a straight manner parallel to the channel wall in the microfluidic devices. Polar fungal growth was neither affected by $E$. coli, Pseudomonas cell-free supernatants nor a $0.96 \% \mathrm{NaCl}$ solution (Figure 5.3). 
(a)

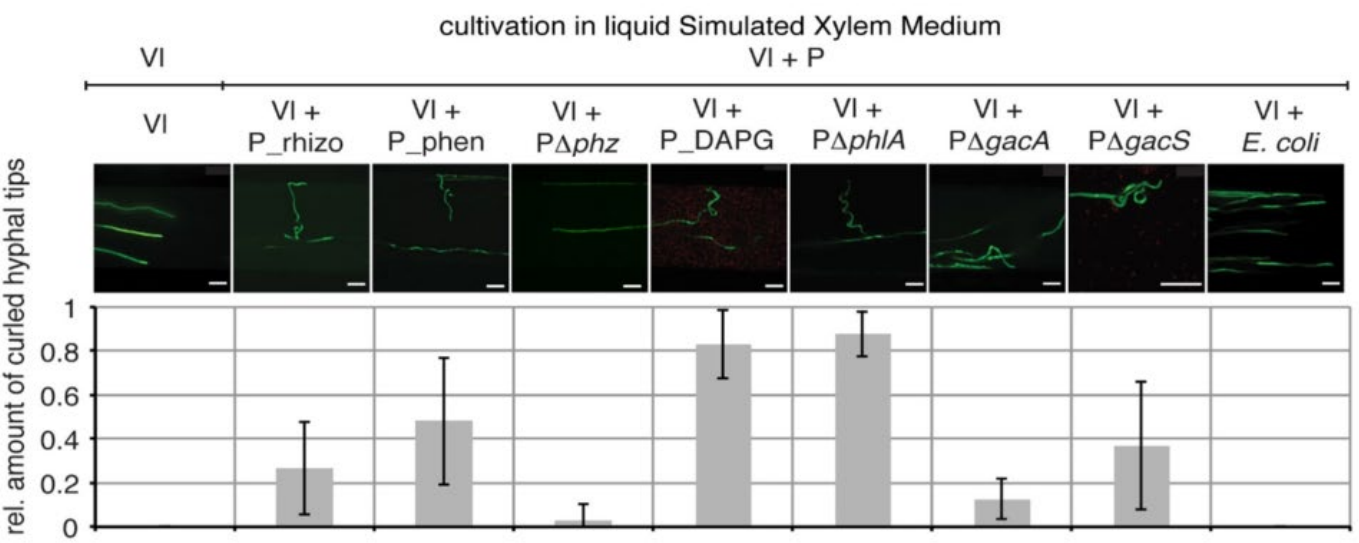

(b)

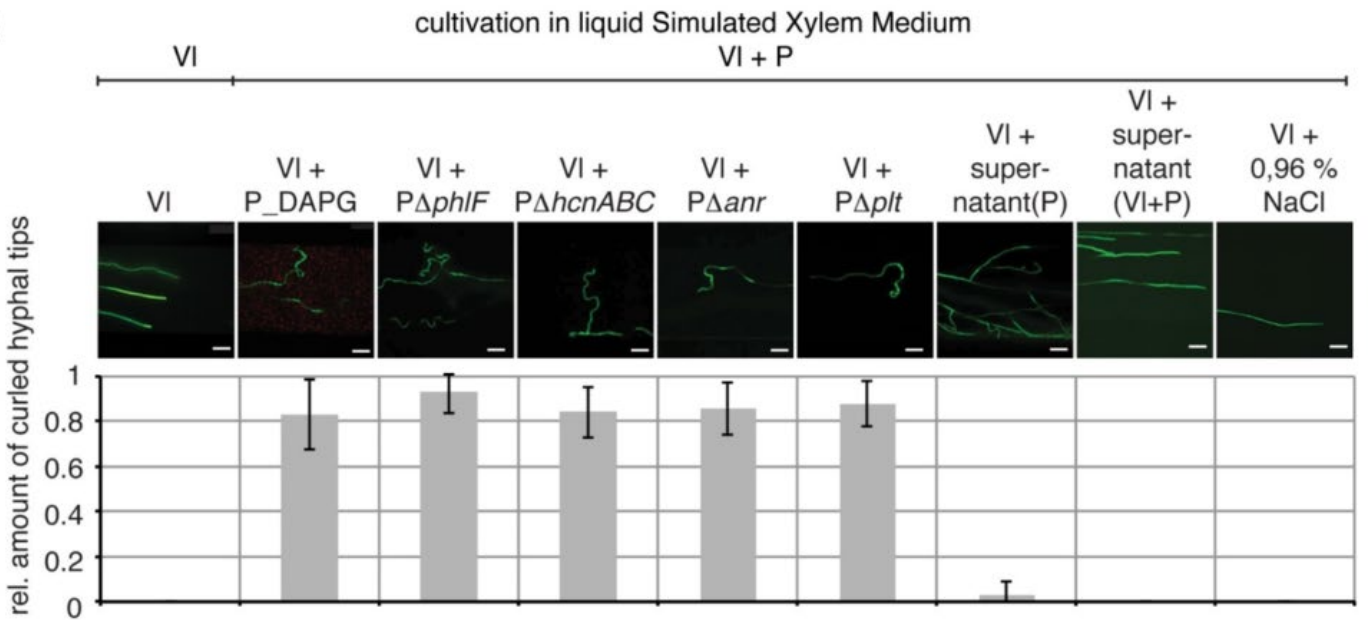

Figure 5.3: Alteration in hyphal polarity of $V$. longisporum VI43 during cocultivation with different wild type fluorescent pseudomonads as well as deletion strains. (a) $\mathrm{V}$. longisporum VI43 expressing the green fluorescent protein was co-cultivated with the Brassica rhizosphere isolate $P$ _rhizo ( $P$. fluorescens DSM8569); the phenazine-producing $P$ _phen wild type ( $P$. synxantha 2-79) and the phenazine deficient deletion strain $(\Delta p h z)$; the DAPG producing P_DAPG (WT: $P$. protegens $\mathrm{CHAO}$ ) expressing the red fluorescent protein and deletion strains lacking one essential gene for DAPG synthesis $p h I A(\triangle p h I A)$ or one of the two units for regulation of multiple toxin production gacA $(\triangle g a c A)$ or gacS ( $\triangle$ gacS; expressing the red fluorescent protein). Co-cultivation with $E$. coli served as a neutral control. (b) $V$. longisporum expressing the green fluorescent protein was co-cultivated with a DAPG producing P_DAPG ( $P$.protegens $\mathrm{CHAO}$ ) and compared to the following deletion strains: $\bar{p} h / F$ - lacking the inhibitor of DAPGproduction leading to increased DAPG secretion; $\triangle h c n A B C$ - lacking the essential gene for HCN-production; $\triangle a n r$ - lacking the $\mathrm{HCN}$ regulator anr with deficient $\mathrm{HCN}$ secretion; $\Delta p / t$ - lacking essential gene for pyoluteorin synthesis. Furthermore, $V$. longisporum was treated with sterile supernatant of $P$ _DAPG mono-culture $(P)$, sterile supernatant of $\mathrm{P}$ _DAPG and $V$. longisporum co-culture $(\mathrm{VI}+\mathrm{P})$ and $0.96 \%$ $\mathrm{NaCl}$. (scale bars $=10 \mu \mathrm{m}$; note: different magnification in picture $\mathrm{VI}+\mathrm{P} \Delta g a c S$ ) The relative amount of hyphal tips possessing a curled phenotype compared to the fungal control without bacteria is displayed in the diagram. The diagram shows the arithmetic average of all measured values derived from two biological replicates. 
Confrontations of Verticillium with pseudomonads did not result in an observable formation of enriched bacterium associations in fungal proximity. Closer inspection of polar fungal growth of $V$. longisporum in confrontation with Pseudomonas spp. revealed a curly tip phenotype and changes in growth direction. The rapeseed rhizosphere $P$. fluorescens DSM8569 (P_rhizo) affected almost one third of hyphal tips. Phenazine-producing $P$. synxantha 2-79 (P_phen) led to about $50 \%$ of tips being curled, whereas $P$. protegens $\mathrm{CHAO}$ (P_DAPG) resulted in a mostly curly phenotype (83\%) (Figure 5.3a).

Confrontation experiments with the mutant strains P_DAPG $\triangle p h I F$, P_DAPG $\triangle h c n A B C$, P_DAPG $\triangle a n r, \quad P \_D A P G \Delta p / t$ impaired in either single metabolite synthesis of DAPG, HCN or pyoluteorin showed a comparable curled phenotype compared to bacterial wildtype. However, the curly phenotype was not observed in confrontation experiments involving the phenazine deficient strain P_phen $\Delta p h z$. In addition, deletion of either of the translational control network genes, gacA and gacS of $P$. protegens $\mathrm{P}$ _DAPG, reduced the curly phenotype by more than $80 \%$ to $13 \%$ for P_DAPG $\triangle$ gacA and more than $60 \%$ to $37 \%$ for P_DAPG $\Delta$ gacS (Figure 5.3).

These data indicate that the genetic information for phenazines and GacA/GacSdependent bacterial metabolites induce polar changes in fungal hyphae. Changes in growth direction, which are rather restricted within the channel of the microfluidic devices, might allow the hyphae in nature to avoid bacteria. 
$P$. protegens alters transcriptional profiles of $V$. longisporum genes including up-regulation of detoxification related genes and decreased levels of transcripts for protein biosynthesis and plant polysaccharide degradation.

P. protegens CHAO (P_DAPG) had the greatest impact of $90 \%$ polar growth inhibition in microfluidic device confrontation assays using liquid SXM pectin/amino acids medium. A snapshot of an initial transcriptional fungal response on the bacterium in a non-constrained liquid environment was analyzed after two hours of co-cultivation. Therefore, $V$. longisporum was precultured in liquid SXM for six days and then mixed with P_DAPG. Mycelia in the presence of bacteria were harvested after two hours of further cultivation and compared to corresponding fungal control samples in the absence of bacteria. Total bacterial and fungal RNAs were isolated and fungal RNAs were sequenced (NCBI-Accession-number SRP068348; http://www.ncbi.nlm.nih.gov/sra/?term=SRP068348). The reads were mapped to the genome of $V$. dahliae JR2 (de Jonge et al., 2012). 11,439 sequenced fungal transcripts were clustered using the MarVis-Cluster tool (Kaever et al., 2009) as a function of the MarVis-Suite software (Kaever et al., 2015; http://marvis.gobics.de). 4,020 fungal genes representing $35 \%$ of the total amount of fungal transcripts were down-regulated in the presence of $P$. protegens P_DAPG. The expression of an almost equal amount of 4,277 genes (37\%) was induced by co-cultivation with $P$. protegens. The remaining 2,895 transcripts representing one quarter of the total gene set, were not differentially expressed. 247 transcripts differed too much between the two replicates and remained as unclassified. The transcriptome dataset was statistically filtered using MarVis-Filter to identify and select robustly regulated gene candidates (Figure 5.4). 
(a)

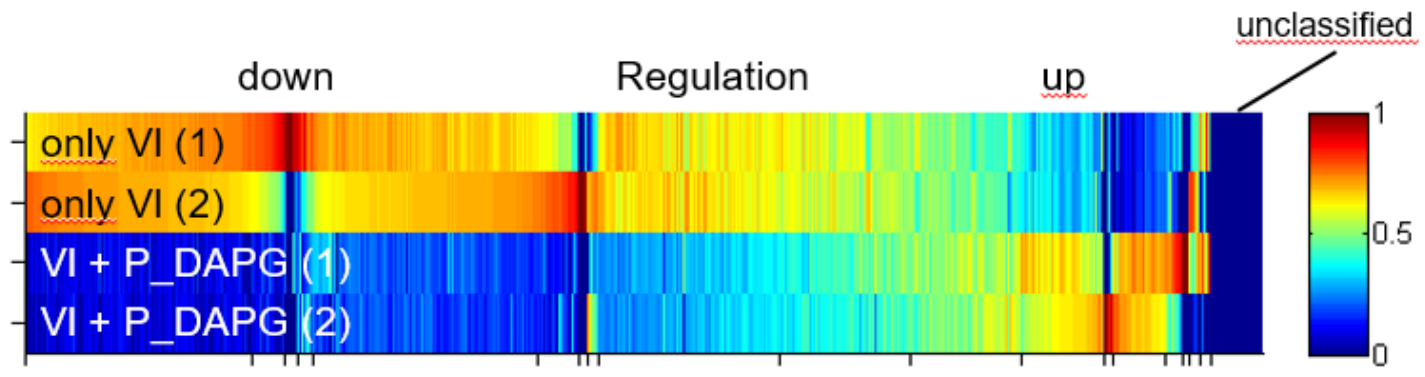

(b)

Down-regulation in \%

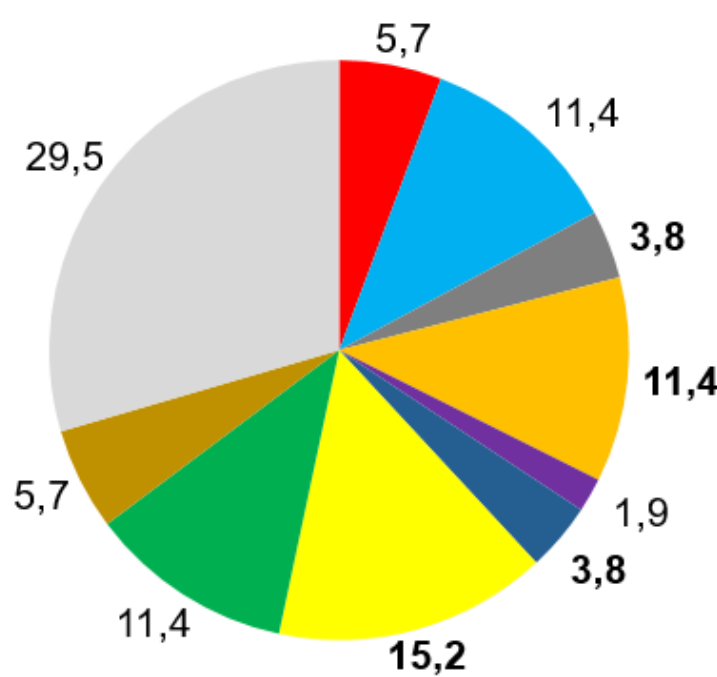

- Amino acid metabolism

- Chromosomal organization/DNA repair

- Detoxification

- Lipid metabolism

- Transport

- Unknown
Up-regulation in \%

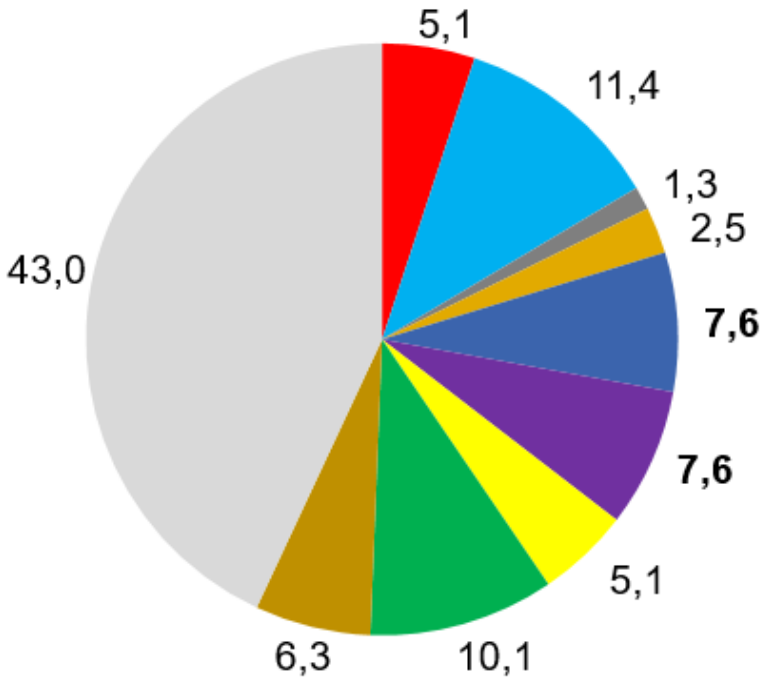

n Carbon metabolism

- Degradation of plant polysaccharides

- Energy

Protein - metabolism/biosynthesis/regulation

n Others 
Figure 5.4: Transcriptome analysis of V. longisporum VI43 after unconstrained co-cultivation with $\boldsymbol{P}$. protegens CHAO (P_DAPG). Different liquid cultures of $V$. longisporum in simulated xylem medium ( $\bar{S} X M)$ were pooled after 5 days. The fungal cultures were further cultivated in the presence or absence of $P$. protegens for $120 \mathrm{~min}$. Bacterial and fungal total RNA was extracted and fungal mRNA was sequenced. Two individual replicates were obtained. (a) The heat map shows a one-dimensional self-organizing map of all 11,439 sequenced fungal Verticillium transcripts classified in MarVis-Cluster. The lines underneath the heatmap mark the cluster borders that describe similar expression profiles, respectively. Transcripts that show an inconsistent expression profile have been regarded as unclassified. The colors code for transcript frequency as normalized quantities according to the color scale right to the heat map. Red indicates transcripts with high abundance; blue indicates transcripts with low abundance. (b) Most up-regulated candidates with Log2_Fold_Change $>4$ and padj $<0,01$ and most down-regulated candidates with Log 2 Fold_Change $<-3$ and padj $<0,01$ were manually assigned to functional categories. The percentage of transcripts referring to the specific functional category (left: down-regulated, right: upregulated) is depicted. Bold figures mark the biggest differences between the down- and the up-regulated transcripts indicating the functional categories with the most impact on Verticillium expression due to the presence of Pseudomonas. The transcripts belonging to these categories are listed in Table 5.2, S5 and S6.

After an automated annotation with the Ensembl- (Howe et al., 2019) and Gene Ontology (GO; Ashburner et al., 2000; Gene Ontology Consortium, 2019) database all transcripts with an adjusted p-value (padj) $<0,01$ were chosen for further analysis. The automated annotation of all transcripts with $\log _{2}$ Fold_Change $>4$ (most up-regulated genes) and transcripts with Log2_Fold_Change < -3 (most down-regulated genes) has been manually curated by additional amino-acid sequence BLAST for domain prediction in SMART (http://smart.emblheidelberg.de/; Letunic et al. 2015 and 2018) and sorted to functional categories (Figure 5.4b). The complete dataset is attached in Annex Tables S5, S6 and S7.

Out of the complete dataset of 4020 differentially down-regulated Verticillium genes due to Pseudomonas co-cultivation 105 genes belong to the most downregulated genes with a Log$_{2}$ Fold_Change $<-3$ and padj< 0,01 (Figure 5.4). Bacterial co-cultivation leads to an overall decrease of 14 out of 105 most downregulated transcripts for general fungal protein synthesis which is consistent to the observed lower fungal growth rate (Figure 5.4b). Many transcripts putatively involved in degradation of plant polysaccharides like fungal pectin lyases, methylesterases and cell wall glycosyl hydrolases are down-regulated. In total, 12 
out of 105 most down-regulated Verticillium genes belong to processes of plant degradation, which comprises a ratio of $11,4 \%$. In comparison, only 2 out of 79 most up-regulated genes refer to plant degradation, which is a ratio of $2,5 \%$. This slows down plant material breakage for nutrition uptake, which could be correlated to the Pseudomonas induced decrease of Verticillium growth in a pectin medium mimicking plant environment. The transcription of genes for different putative endopeptidases (VDAG_JR2_Chr5g09370a: -4,8 Log2_Fold; VDAG_JR2_Chr2g04680a: -3,7 Log2_Fold; VDAG_JR2_Chr5g04770a: -3,3 Log2_Fold; Table S6) has also been reduced, which suggests less proteolytic activity of Verticillium.

79 out of 4277 genes belong to the most up-regulated differentially regulated genes with a Log2_Fold_Change $>4$ and padj< 0,01. Inhibition of fungal growth during Pseudomonas co-cultivation might be reflected by six transcripts encoding proteins with potential functions in detoxification reactions out of the 79 most up-regulated Verticillium (Table 5.2).

Table 5.2. Most up- regulated Verticillium related genes related to detoxification reactions after $120 \mathrm{~min}$ of Pseudomonas co-cultivation. The reads of $V$. longisporum VI43 have been mapped to the $V$. dahliae genome of JR2. Most up-regulated genes related to detoxification of cyanide or reactive oxygen species with Log2_Fold Change $>4$ are shown. Genes were automatically annotated and manually curated and assigned to functional categories (entire list in Table S5 \& S6). E-values describe similarities to the SMART database. The complete transcriptomic dataset is deposited at NCBI under the accession-number SRP068348; http://www.ncbi.nlm.nih.gov/sra/?term=SRP068348. Gene-IDs refer to genome assembly of V. dahliae JR2 (VDAG_JR2v.4.0; de Jonge et al., 2012) deposited at www.fungi.ensembl.org/Verticillium dahliaejr2/Info/Index (Howe et al., 2019). $\log _{2}$ FC $=\log _{2}$ Fold_Change; ${ }^{*}$ Possible predicted function according to domain description at www.smart.embl-heidelberg.de (Letunic et al. 2015 and 2018) 


\begin{tabular}{|c|c|c|c|c|c|}
\hline Gene-ID & padj & $\begin{array}{l}\log _{2} \\
\text { FC }\end{array}$ & $\begin{array}{l}\text { Domain } \\
\text { name }\end{array}$ & Predicted domain function* & $\begin{array}{c}\text { e- } \\
\text { value }\end{array}$ \\
\hline $\begin{array}{l}\text { VDAG_JR2_C } \\
\text { hr7g05440a }\end{array}$ & $1,4 \mathrm{e}^{-288}$ & 6,6 & RPE65 & $\begin{array}{l}\text { Oxidoreductase activity, acting on } \\
\text { single donors with incorporation of } \\
\text { molecular oxygen; in plants } \\
\text { scavengers of oxygen radicals (in } \\
\text { vertebrates retinal pigment } \\
\text { epithelium } 65 \mathrm{kDa} \text { protein (RPE65)) }\end{array}$ & $3,2 \mathrm{e}^{-102}$ \\
\hline $\begin{array}{l}\text { VDAG_JR2_C } \\
\text { hr3g06110a }\end{array}$ & $2,2 \mathrm{e}^{-250}$ & 6,2 & $\begin{array}{l}\mathrm{CN} \text { hyd } \\
\text { rolase }\end{array}$ & $\begin{array}{l}\text { Cyanide hydratase of pathogenic } \\
\text { fungi; putatively detoxifies } \mathrm{HCN}\end{array}$ & $7,4 e^{-42}$ \\
\hline $\begin{array}{l}\text { VDAG_JR2_C } \\
\text { hr1g24680a }\end{array}$ & $1,1 \mathrm{e}^{-171}$ & 5,8 & GFA & $\begin{array}{l}\text { Glutathione-dependent } \\
\text { formaldehyde-activating enzyme } \\
\text { (GFA); carbon-sulfur lyase activity; } \\
\text { catalyzes the first step in } \\
\text { detoxification of formaldehyde }\end{array}$ & $1,1 \mathrm{e}^{-10}$ \\
\hline $\begin{array}{l}\text { VDAG_JR2_C } \\
\text { hr5g10540a }\end{array}$ & $4,4 e^{-8}$ & 5,0 & $\begin{array}{l}\text { Pyr_red } \\
\text { ox_2 }\end{array}$ & $\begin{array}{l}\text { Pyridine nucleotide-disulfide } \\
\text { oxidoreductases; e.g. glutathione } \\
\text { reductase (i.a. ROS-defense), } \\
\text { thioredoxin reductase (i.a. cell wall } \\
\text { integrity) }\end{array}$ & $7,4 \mathrm{e}^{-8}$ \\
\hline $\begin{array}{l}\text { VDAG_JR2_C } \\
\text { hr3g09580a }\end{array}$ & $2,6 \mathrm{e}^{-175}$ & 4,9 & DSBA & $\begin{array}{l}\text { Key component (A) of the disulfide } \\
\text { bond (DSB) family; thiol disulfide } \\
\text { oxidoreductase; sub-family of } \\
\text { thioredoxin family; catalyzes } \\
\text { oxidation of cysteine residues of e.g. } \\
\text { toxins, virulence factors, adhesion } \\
\text { machinery, and motility structures }\end{array}$ & $4,6 e^{-16}$ \\
\hline $\begin{array}{l}\text { VDAG_JR2_C } \\
\text { hr4g00930a }\end{array}$ & $1,1 \mathrm{e}^{-11}$ & 4,6 & $\begin{array}{l}\text { GST_N } \\
-3\end{array}$ & $\begin{array}{l}\text { Glutathione-S-transferase; catalyzes } \\
\text { conjugation of glutathione to } \\
\text { xenobiotic substrates for } \\
\text { detoxification }\end{array}$ & $8,6 \mathrm{e}^{-11}$ \\
\hline
\end{tabular}

An elevated gene expression of transcripts for genes that putatively function as cyanide hydratase (VDAG_JR2_Chr3g06110a; 6,2 Log2_Fold), thioredoxin (VDAG_JR2_Chr3g09580a; 4,9 Log2_Fold) or Glutathione-S-transferase (VDAG_JR2_Chr4g00930a; 4,6 Log2_Fold) might represent a potential detoxifying response to a possible GacA/GacS-controlled HCN secretion or further toxins secreted by Pseudomonas. The toxin $\mathrm{HCN}$ is a respiratory inhibitor and inactivates the essential enzyme cytochrome $\mathrm{C}$ oxidase that is responsible for electron transport in the respiratory chain (Rich, 2017). Cyanide hydratases detoxify HCN and are probably exclusively produced by filamentous fungi (Martinkova et al., 2015; Benedik and Sewell, 2017). VDAG_JR2_Chr3g06110a shows high sequence similarity to cyanide hydratases of other fungal genera like Fusarium, Colletotrichum, Pochonia, Neurospora, Metarhizium, Ophiocordyceps, 
Stachybotrys, Aspergillus and Trichoderma (Protein BLAST; Fig. S2). The role of the cyanide hydratase enzyme (chy) for HCN detoxification in Fusarium solani (Genbank accession-number AJ310936.1) was investigated by Barclay et al. (2002) and it shows sequence homology to VDAG_JR2_Chr3g06110a with an identity of $84 \%$ (Figure S2). The putative Pyridine nucleotide-disulfide oxidoreductases VDAG_JR2_Chr5g10540a refers to detoxification of reactive oxygen species (ROS) (Karplus and Schulz, 1987; Kuriyan et al., 1991; Schiering et al., 1991; Fernandez and Wilson, 2014) which can be produced by Pseudomonas spp. and are commonly released to the environment during interaction with other microbes (Jayamohan et al., 2018).

Co-cultivation of Pseudomonas with Verticillium, which inhibits fungal growth, correlates to changes in the fungal transcriptome even after a bacterial exposure of only two hours resulting in increased transcription of various detoxification enzymes as e.g. for HCN. The bacterial co-cultivation also leads to a reduced transcription for protein synthesis by Verticillium correlating to a reduced growth rate and reduces transcription of genes required for plant material acquisition. 


\section{Discussion}

Two different co-cultivation set-ups in liquid pectin amino acid medium have been chosen for Pseudomonas species with Verticillium longisporum. Depending on the conditions of the environment in which the interaction takes places, the fungus behaves accordingly. (i) If Verticillium has the option to escape from bacterial impact, the fungus tries to evade into areas with less bacterial and toxic concentration. Under Pseudomonas influence, this fungal behavior could be observed in a microfluidic confrontation assay in which the hyphal tips begin to curl and change their linear polar growth pattern even under physically constrained circumstances. (ii) If evasion is no option for the fungus as it is the case in an agitated liquid flask co-cultivation where a constant mixing leads to recurring close contact between fungus and bacterium, $V$. longisporum tries to withstand the antifungal conditions by detoxification. In a differential expression analysis during flask co-cultivation it has been shown that the fungus increases the expression of detoxification related genes to cope with the bacterium. Additionally, the fungus down-regulates the expression of genes involved in protein biosynthesis and plant polysaccharide degradation. As under natural conditions there are zones with heterogeneous suppressive concentrations in the rhizosphere the evasion strategy is expected to be the more relevant one for Verticillium in nature. This hypothesis is supported by previous observations with Pseudomonas-Verticillium cocultivation on surfaces that show a pronounced fungal free zone around the bacterial colony giving the impression that Verticillium strictly follows a specific distance to the bacterium. The size of this inhibition zone depends on the nutritional conditions of the medium as well as the genetic abilities of the bacterium to produce antifungal secondary metabolites (Nesemann et al., 2018).

The observed polarity alteration in Verticillium hyphal growth induced by the presence of the bacterium were possibly caused by phenazines or GacA/GacS induced bacterial compounds, but not by DAPG itself. DAPG-induced polarity effects have been described for the phytopathogenic fungus Aphanomyces cochlioides (Islam and Fukushi, 2003) or for Pythium ultimum (de Souza et al., 2003), but were so far not observed for Verticillium. 
The presence of a phenazine cluster in the bacterial genome resulted in different effects on fungal growth, depending on the growth conditions. In a previous study (Nesemann at el., 2018) we determined a nutrition dependent impact on the antagonistic relevance of bacterial phenazines. In a surface interaction study on solid agar under rich nutrition with high amounts of glucose, a phenazine gene cluster could be identified as one crucial factor for Verticillium growth inhibition, whereas in poor amino acids and pectin environment the fungal growth suppression was independent from phenazines. However, in confrontation assays in liquid pectin amino acid medium phenazines seem to be an alternative strategy to the two-component GacA/GacS system regulating multiple antifungal compounds for fungal control. The presence of the phenazine cluster caused $30 \%$ inhibition of fungal growth, as well as a curly tip phenotype at the apex of the hyphae leading to polarity changes in the fungal growth direction.

Verticillium hyphae show a similar curly phenotype as well as a growth suppression when co-cultivated with the natural isolate from oilseed rape rhizosphere ( $P$ _rhizo), although in reduced intensity. $P_{-}$rhizo neither possesses the genetical ability to synthesize phenazines nor a genetically fully functional GacA/GacS system as it lacks the regulatory small RNAs rsmX and rsmZ (Nesemann et al., 2015a and 2018). This leads to the hypothesis that $P_{\text {_ }}$ rhizo produces other than the bioactive substances discussed above play a role to evoke the observed alteration in fungal polarity as well as inhibition in hyphal growth. Further investigation would be necessary to gain a better understanding what Pseudomonas molecules are responsible for this phenomenon.

Besides the evasion strategy, Verticillium also follows a detoxification approach against Pseudomonas. The transcriptional response to the presence of the bacterium includes an increased expression of genes responsible for fungal detoxification suggesting that the fungus has developed protection mechanisms against secreted mycotoxins like DAPG or cyanide. Barclay et al. clarified the mechanism of cyanide hydratase enzyme (chy) in Fusarium solani to detoxify cyanide complexes in a substrate-regulated manner. Evolutionary conservation has been described and sequence homology could be shown to Gloeocerospora sorghi, Fusarium lateritium and Leptosphaeria maculans as it is shown in this study to the V.dahliae gene VDAG_JR2_Chr3g06110a. The up-regulated gene 
VDAG_JR2_Chr5g10540a putatively belongs to the family of pyridine nucleotidedisulfide oxidoreductases including enzymes that also might be involved in detoxification like glutathione reductase (Karplus and Schulz, 1987) or thioredoxin reductase (Kuriyan et al., 1991). Glutathione reductase catalyzes the reduction of glutathione-disulfide to glutathione and this way recycling its capacity of neutralizing reactive oxygen species (ROS) as an antioxidant. In 2014, Fernandez and Wilson investigated the role of glutathione reductase as well as thioredoxin reductase of Magnaporthe oryzae during rice blast disease. Glutathione reductase but not thioredoxin was essential for the detoxification of ROS produced by the plant. Thioredoxin but not glutathione reductase was shown to be important for cell wall integrity in Magnaporthe oryzae.

A direct and distinct response for all Verticillium gene candidates that seem to be differentially expressed in Pseudomonas presence cannot be postulated and might also belong to a general or indirect reaction due to changing cultivation conditions such as competition for nutrients. The expression increase of VDAG_JR2_Chr1g24680a showing sequence similarity to the formaldehyde detoxifying domain GFA (Lupas et al., 2015; Chen et al., 2016) or of VDAG_JR2_Chr7g05440a carrying a domain involved in photo protection are not necessarily a close answer to Pseudomonas co-cultivation as it is not assumed that Pseudomonas releases formaldehyde in its surrounding or causes photo inhibition.

The slow-down in fungal growth was accompanied by a reduction in transcription levels of genes coding for plant polysaccharide breakdown putatively used for fungal nutrition. This finding coincides with results of a transcriptomic profiling of the fungal plant pathogen Rhizoctonia solani challenged by the antagonistic bacteria Serratia proteamaculans and S. plymuthica (Gkarmiri et al., 2015). A significant down-regulation of genes coding for plant degrading enzymes like pectin lyases or glycoside hydrolases has been observed in Rhizoctonia during bacterial co-cultivation.

Taken together, the results of this Verticillium-Pseudomonas interaction study suggest a detoxification and evasion strategy of the fungus. In a suppressive environment induced by different antifungal bioactive compounds such as DAPG, $\mathrm{HCN}$ or phenazines that have been expressed by antagonistic rhizobacteria, 
Verticillium tries to grow towards less suppressive areas in order to avoid close contact to the bacterium. If the fungus has no option to escape from bacterial impact, he increases the expression of genes related to detoxification while decreasing processes involved in protein biosynthesis and plant polysaccharide degradation. 


\section{Chapter 6: Discussion}

\section{Growth control of Verticillium by fluorescent pseudomonads}

This study investigated physical and molecular interaction between virulent Verticillium strains and different rhizobacteria in situ. All used bacterial strains belong to fluorescent pseudomonads. A visual growth suppression of the bacterium due to fungal impact has never been observed in this study. This includes co-cultivations in different media on solid surfaces or in liquids and confrontations in channels filled with liquid media. The bacterium could inhibit fungal growth. This bacterial antagonism against hyphal growth was expressed towards fungi that have been isolated out of the identical rhizosphere as well as out of others. The findings lead to the hypothesis that the fungus itself ultimately possesses rather little chances to actively keep the bacterium under control. Instead, a withdrawal strategy is followed by the fungus physically evading the bacterial influence when possible. Pathways that correspond to detoxification of external bioactive compounds are induced. The expression of genes involved in cellular processes that can be reduced under suppressed growth activity like protein synthesis and plant polysaccharide degradation is down-regulated.

\section{Relevance of fungal secondary metabolism during interaction with fluorescent pseudomonads}

In microbial interactions, secondary metabolism can play a crucial role (Koehl et al., 2019; Korenblum and Aharoni, 2019) and filamentous fungi cover a wide range of bioactive secondary metabolites to be secreted into their surrounding (Bayram and Braus, 2012; Keller, 2019). The regulatory genes for epigenetic Lae1 methyltransferase (Sarikaya-Bayram et al., 2015) and Csn5 deneddylase (Braus et al., 2010), which both contribute to the control of the expression of secondary metabolism genes in fungi have been investigated. The putative methyltransferase was originally found in Aspergillus nidulans, called LaeA, and is described as a global regulator of secondary metabolism crucial of biosynthesis of e.g. aflatoxin, 
penicillin and sterigmatocystin. Additionally, an important morphological role of LaeA could be found in $A$. nidulans to be involved in asexual development in a light-dependent manner (Bayram and Braus, 2012; Lan et al., 2020). Csn5 is the fifth subunit of the COP9-signalosome, a multiprotein complex consisting out of in total eight subunits and activating the cullin-RING E3 ubiquitin ligases responsible for protein degradation by the proteasome (Gerke and Braus, 2014; Meister et al., 2019). However, for both, Lae1 as well as Csn5, no impact on bacterial-fungal interaction could be determined (Nesemann et al., 2018). To investigate fungal genetic adaption during bacterial co-cultivation the Verticillium transcriptomic profile has been sequenced under the influence of $P$. protegens $\mathrm{CHA0}$ (P_DAPG). $P$. protegens CHAO contains a GacA/GacS two-component system and is genetically equipped with the ability to release a cocktail of different bioactive compounds including DAPG (Haas and Défago, 2005). A significant involvement of fungal secondary metabolism could also not be identified in the transcriptome dataset. For other pathogenic fungi co-cultivated with bacteria, a specific transcriptional activation of secondary metabolite clusters has been described previously. In bacteria-induced Aspergillus nidulans the synthesis of different natural products including polyketides is enhanced and requires a Saga/Adamediated histone acetylation (Schroeckh et al., 2009; Nützmann et al., 2011).

\section{The impact of phenazines and the GacA/GacS regulation system on fungal growth highly depends on nutrition.}

In contrast to fungal regulatory genes in secondary metabolism, the ability of fluorescent pseudomonads to secrete a heterogeneous panel of secondary metabolites with bioactive antibiotic properties has been well-explored (Sahu et al., 2018; Shah et al., 2020). The bacterial regulatory genes for the GacA/GacS translational control for the production of different bioactive metabolites and exoenzymes plays an important role for the different facets of the bacterial-fungal interaction (Yan et al., 2018; Mishra and Arora, 2018; Zhang et al., 2020). This study revealed that in most situations a complex combination of genes for several bacterial metabolites or mycotoxins rather than a gene for a single toxin provides Pseudomonas-mediated effects on vegetative Verticillium growth. In addition, 
genes involved in the production of bacterial phenazines had a major impact on fungal growth in optimal growth conditions with fast turnover glucose available. The bacterial genetic potential to synthesize phenazines was not required for fungal growth suppression when the co-cultivation took place in an environment containing high amounts of amino acids and complex pectins that are rather intricate to digest. The deleted phenazine gene cluster resulting in a deficient phenazines biosynthesis pathway could be compensated under the appropriate nutritional conditions.

For the two-component system GacA/GacS that regulates a variety of genes encoding for a cocktail of antifungal metabolites (Haas and Défago, 2005; Yan et al., 2018; Zhang et al., 2020), the nutritional impact appears in an opposite way compared to phenazines. The genes for the bacterial GacA translational regulator as well as for the sensor protein GacS were essential to suppress fungal growth on high amino acids and pectins. Only a poor inhibition potential could be shown for GacA and GacS on optimal growth surfaces with high amounts of glucose. The GacA/GacS genetic network regulates the formation of mycotoxins, such as 2,4 diacetylphloroglucinol, pyoluteorin and hydrogen cyanide, which on their own were unable to control fungal vegetative growth. Due to the shown relevance of the GacA/GacS system for fungal growth suppression, it can be assumed that also under natural conditions in the rhizosphere a cocktail of several Pseudomonas mycotoxins rather than a specific single one is relevant for the suppression of Verticillium. The strong nutrition impact of the surrounding for the respective chosen antagonistic pathway might also be reflected by the heterogeneous natural conditions and potentially supports the hypothesis of a diverse interplay of several antifungal compounds.

During this study, different Pseudomonas strains with individual genetic properties to synthesize antifungal compounds have been chosen for Verticillium cocultivation. A specific measurement of the actually secreted molecules as well as a general omics approach has not been performed yet. This is why, it has to be taken into account that the results that are presented here can be considered as an indication of which antifungal metabolites are key to explain the observations but not as a strong evidence so far. A subsequent metabolomic investigation during the Verticillium-Pseudomonas interaction would give further important insights into 
the fungal and bacterial metabolites that play a crucial role in this interaction. This metabolomic dataset might also include fungal candidates that potentially trigger the membrane associated sensor kinase GacS as a first step to activate GacA and start the whole two-component regulation system for release of toxic substances. For the GacA/GacS system of $P$. aeruginosa, a multikinase network it has been described that at least consists out of the two sensor kinases GacS and RetS that are able to detect and integrate external signals (Francis et al., 2018; Francis and Porter, 2019; Mancl et al., 2019). RetS possesses different mechanisms to inhibit the autophosphorilation of GacS and this way to block the activation of the subsequent signal transduction. For $P$. aeruginosa, this regulation is crucial for the expressing virulence factors. This level of understanding is so far lacking for P. protegens or P. synxantha in general but also in interaction with Verticillium.

\section{The fungal detoxification and evasion strategy}

The bacterial repertoire of multiple bioactive compounds activated in the described nutritional manner and secreted into its environment leads to heavy rearrangements and reactions by the fungus. In microfluidic channels, the interaction of the oilseed rape pathogen V. Iongisporum VI43 with different fluorescent pseudomonads was visualized in vivo. In $7 \mathrm{~mm}$ long and only $100 \mu \mathrm{m}$ wide micro racing channels, the hyphal growth direction was predefined in one direction. This way, the inhibition potential of different treatments could be quantified and compared. A Verticillium growth suppression of up to $90 \%$ was induced by $P$. protegens CHAO due to an additional DAPG gene cluster. Besides a pure growth inhibition, also a morphological alteration was observed. In an unstressed situation without the co-cultivation of bacteria, the hyphae showed a highly straight and parallel polar growth manner. Under stressed conditions, different Pseudomonas strains were able to influence this Verticillium growth pattern to a meanwhile highly curled hyphal tip. This can be interpreted as a fungal strategy to evade the bacterial influence and escape to an area with less suppressive potential. Under these artificial laboratory conditions, the concentration of bacterial organisms and this way also the concentration of antifungal metabolites in the interaction medium was highly enlarged and the 
microchannels were completely filled with bacterial cells. Under natural conditions, where many other biotic factors also influence the distribution and abundance of the bacterial antagonist, this evading strategy might be a successful strategy giving the fungus the chance to infect another root in a region of the rhizosphere with less antifungal impact.

Fungal evasion strategies to cope with host recognition is not only discussed as physical avoidance by translocation like we observed it for Verticillium but also by further morphological adaptations to withstand the host antagonism at the same place (Hernández-Chávez et al., 2017). Compared to plant pathogens like Verticillium, the knowledge for human pathogens is a lot wider. Main focus of human pathogens is to evade active surveillance mechanisms of mammalian hosts by phagocytosis that might be partially transferable to plant pathogens. Different strategies have been described, e.g.: (i) Compositional changes in the cell wall by increasing the amount of polysaccharide structures like chitin or melanin. Melanin storage to mechanically strengthen the cell wall has been described for Paracoccidioides brasiliensis and Sporothrix schenckii (Nosanchuk and Casadevall, 2006). Since it is known that Verticillium also embeds melanin in the microsclerotia (Tran et al., 2014), this might be a possible reaction in the Pseudomonas-Verticillium interaction as well. (ii) Formation of capsules as physical barrier to protect the cell from its environment. Cryptococcus neoformans possesses a large capsule, which is considered to be its main virulence factor to cause meningitis disease (Doering, 2009). (iii) So-called titan cells show a blown up cell size of 14 to 20 -fold (Okagaki et al., 2010) some even up to 300 -fold (Crabtree et al., 2012) compared to their normal size. Titan cells of $C$. neoformans are significantly more resistant against oxidative stress (Zaragoza et al., 2013; Okagaki et al., 2012). (iv) Asteroid bodies are concentric and spiked formations of extracellular components surrounding a central fungal cell giving the enlarged complex a crown-like structure. Asteroid bodies protect the central cell against its suppressive environment and have been found in different fungal genera including Aspergillus, Candida, Sporothrix, Histoplasma (Daniel Da Rosa et al., 2008). The given examples represent physical barrier systems of fungal cells to make them more resistant to harsh chemical conditions induced by their host. The listed techniques give the fungi to ability to physically stay within and withstand the 
suppressive environment. The need to escape to other regions of less suppressivness is not necessary in this case. Compared to our observations in the microfluidic confrontation devices, at the first glace none of the mentioned structures could be recognized for Verticillium. Following the hypothesis, that Verticillium is potentially not capable to build comparable morphological structures to increase its resistance against Pseudomonas, Verticillium chose an alternative escape strategy.

In an agitated interaction environment, this evasion/escape strategy cannot be applied by the fungus as the mixing motion leads to constantly recurring close contact between the fungus and the bacterium. A differential expression analysis of the fungal transcriptome has been performed under stressed and unstressed conditions triggered by co-cultivation with $P$. protegens $\mathrm{CHAO}$ (P_DAPG). Cellular processes that can be renounced due to hyphal growth reduction are downregulated. This refers to genes that are involved in general protein biosynthesis but also to genes specifically coding for degradation of complex plant materials like pectins. On the one hand, this can be interpreted as a provision to not invest cellular energy in further growth. On the other hand, less activity in plant cell wall lyses can also resemble a slowdown in food breakdown. Since Verticillium dramatically reduces growth, the need of energy supply is also decreased.

Besides down-regulating pathways that can be saved under less growth behavior, Verticillium induces the transcription of genes associated with detoxification. It can be assumed that the fungus is able to specifically focus and prioritize only the required pathways to cope with the bacterial toxicity.

Compared to the detoxification and evasion strategy followed by Verticillium to handle Pseudomonas' antagonism, for Aspergillus fumigatus a wait-and-see strategy has been described when living in human blood (Irmer et al., 2015). Both, the conditions for $A$. fumigatus to survive in blood as well as the situation for Verticillium surrounded by a high cell density culture of fluorescent pseudomonads are suppressive but the fungal reactions are different. Irmer et al. found a downregulated pattern of genes involved in up-take mechanisms as well as in energyconsuming metabolic processes. The hyphal behavior was interpreted as a resting mycelium stage lacking hardly any growth. The capabilities of $A$. fumigatus to take up sufficient nutrients are highly restricted leading to limited energy resources in 
the cell. Compared to the observations for Verticillium, Aspergillus fails in establishing sufficient self-defense mechanisms combined with growth activity. An active withdrawal like it has been investigated for Verticillium as a reaction on the vicinity of Pseudomonas was not described for Aspergillus in a blood cultivation.

Taken together, the results can be interpreted as a detoxification and evasion strategy followed by Verticillium to withstand the suppression caused by Pseudomonas. The fungus tries to evade the bacterial impact aiming to reach areas with less suppressive potential to infect its host plant. Transferring this Verticillium strategy to the natural conditions in the highly heterogeneous environment of the rhizosphere including plenty of influencing factors it will most likely not always be successful in terms of survival. In large areas with concentrated antagonistic species, the fungus might not be able to evade this suppressive zone. In this situation, Verticillium possibly activates detoxifying reactions but only up to a certain extent. Under an ecological perspective, it can be assumed that in largescale suppressive areas, the Verticillium evasion and detoxification strategy will be limited.

\section{The positive and negative connotation of beneficials and pathogens as an anthropocentric view}

The described relationship between the mutualistic bacterium, possessing a positive connotation, and the opportunistic fungus with a negative attribute, is a rather anthropocentric interpretation of their antagonism going on in the rhizosphere. On the one hand, this judgment is driven by the target of minimizing pathogenic damage of crops gaining maximal yield for the farmer. On the other hand, the beneficial and opportunistic roles of the two players are not constantly fixed and defined. Closely related species using very similar defense and pathogenicity techniques are considered as either pathogens or beneficial growth promoting and biocontrol agents depending on the respective view. Rodriguez et al. (2019) described this phenomenon as "Friends and Foes: Closely related beneficial and pathogens". In a phylogenetic dendrogramm (Figure 6.1), they 
compared the evolutionary relationship of mutualistic bacteria in black and pathogenic bacteria in red.

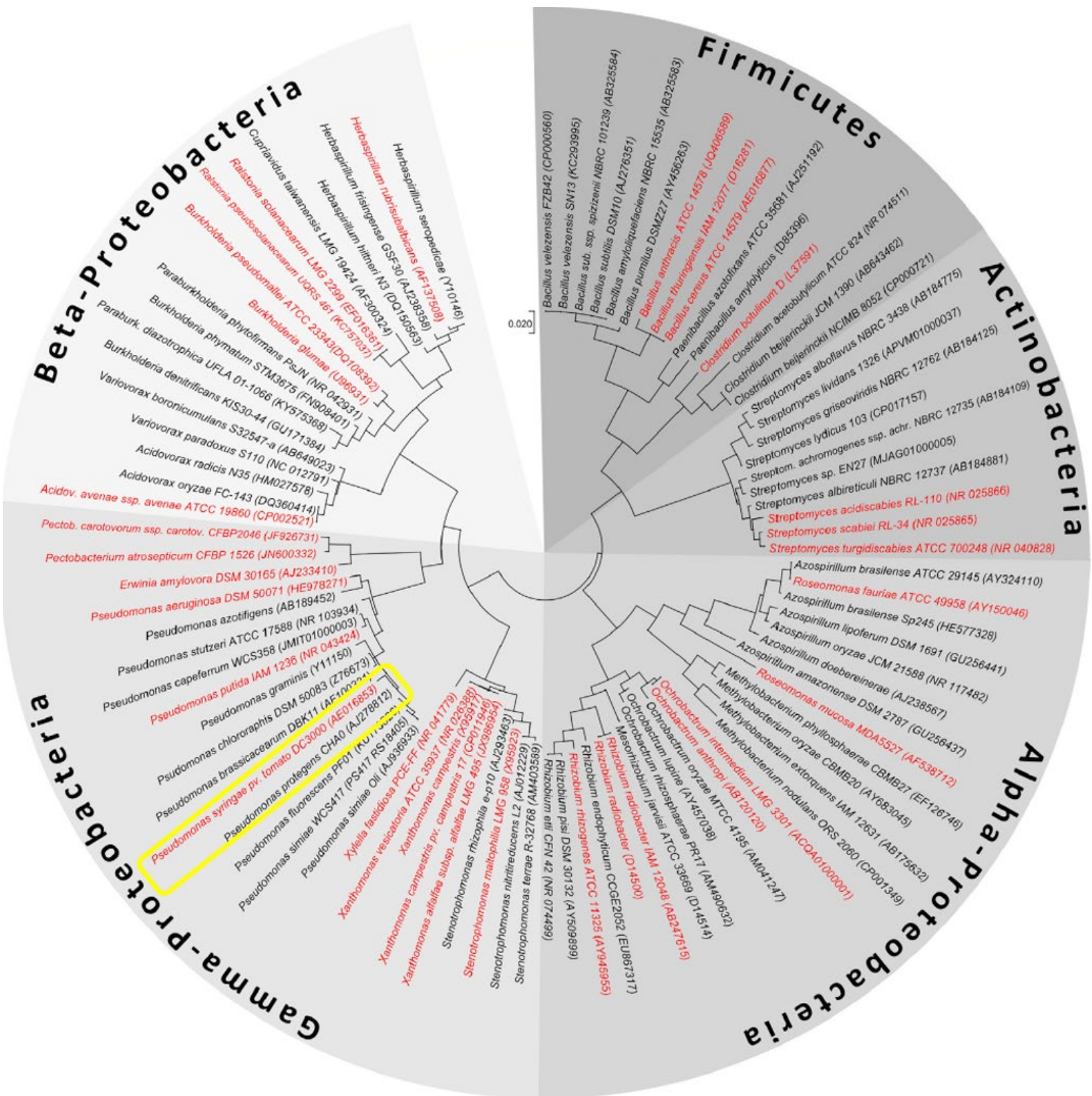

Figure 6.1: Phylogenetic dendrogramm to compare mutualistic and opportunistic bacterial species. The degrees of evolutionary relationship based on genomic differences are presented for different bacterial species. Taxonomic classification has been performed for the phyla Firmicutes, Actinobacteria and Proteobacteria. The Proteobacteria are further differentiated into the classes Alpha-, Beta- and Gamma-Proteobacteria. Species regarded as mutualistic are shown in black. Species regarded as opportunistic are shown in red. The yellow mark highlights the close relationship between the plant pathogen Pseudomonas syringae pv. tomato DC3000 and the beneficial biocontrol agent $P$. protegens CHAO (modified; from Rodriguez et al., 2019). 
Rodriguez et al. (2019) also presented different pseudomonads including the human pathogenic $P$. aeruginosa, the phytopathogenic $P$. syringae and beneficial fluorescent pseudomonads, like the DAPG producing strain $P$. protegens CHAO that was also investigated in this study. In the diagram it is indicated that the phytopathogenic strain Pseudomonas syringae pv. tomato DC3000 in red (Xin and $\mathrm{He}, 2013$ ) is closely related to the beneficial strain $P$. protegens CHAO in black.

Within the Verticillium genus, a quite similar phenomenon is described. Verticillia can be regarded as a rather heterogeneous genus including species that are plant pathogens like $V$. longisporum or $V$. dahliae as well as species that are virulent against insects, fungi or nematodes (Fahleson et al., 2004). Verticillia that infect nematode cysts are grouped to Pochonia (Sung et al., 2001). The mutualistic nematophage Pochonia chlamydosporia (formerly named Verticillium chlamydosporia) is closely related to the opportunistic $V$. longisporum or $V$. dahliae and has been widely characterized as a nematode antagonist utilized as a biocontrol agent in agriculture (Lin et al., 2018; Uddin et al., 2019). Particularly interesting in this regard is the described biocontrol effect even within the Verticillium genus. The endophytic biocontrol agent Verticillium Vt305 has been identified as V. isaacii (Franca et al., 2013) and protects cauliflower against Verticillium wilt (Tyvaert et al., 2014).

Not only within the Verticillium genus we find closely related species with rather opposite characteristics, but even different lineages within the $V$. longisporum species. In this study, the experiments have been performed with the isolate VI43 from oilseed rape, which is a plant pathogenic lineage in Brassicaceae (Timpner et al., 2013). The closely related strain VI32 has been isolated from the same host in the same region, but it does not show any virulence in B. napus (Tran et al., 2013).

These examples underline the statement that antagonistic properties of microbes are used to strengthen their own position compared to the competitors. Their defense and pathogenic mechanisms can be very similar or even identical used by sometimes closely related species. Whether this antagonism is judged as positive or negative is in close proximity to each other and goes back to the anthropomorphic behalf. 


\section{Main findings of Verticillium's interaction to cope with the impact of Pseudomonas}

The general investigations of this study are summarized in the model of Figure 6.2.

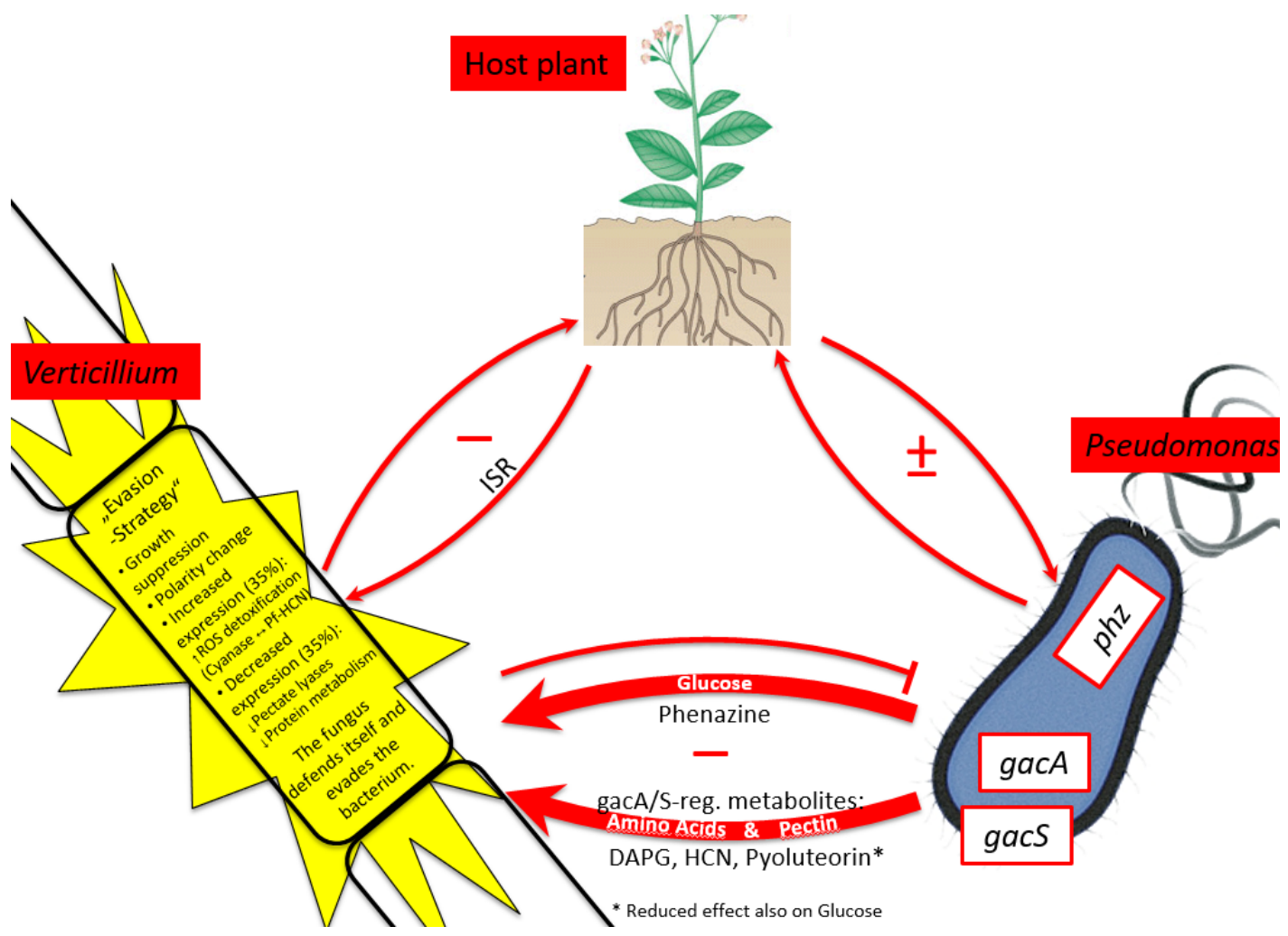

Figure 6.2: Model simplifying the three-dimensional interaction of a host plant, an antagonistic rhizobacterium (Pseudomonas) and a plant pathogen (Verticillium). Different fluorescent pseudomonads like $P$. fluorescens DSM8569 ( $P$ _rhizo) have been isolated out of the rhizosphere of Brassicaceae. In literature, a direct plant growth promoting effect due to root colonization by Pseudomonas has been described. Soil borne plant pathogens also interact directly with its host plant infecting the roots and colonizing the whole plant. As response, the plant can activate an inducible systemic resistance (ISR) to cope with fungal pathogenicity. The bacterialfungal interaction is rather antagonistic. Depending on the nutritional environment, different suppressive bioactive compounds are relevant. In high glucose conditions, phenazines play a crucial role for $P$. synxantha 2-79 ( $P$ _phen) to dominate fungal growth parameters. Under plant mimicking circumstances with high content of amino acids and pectin, $P$. protegens $\mathrm{CHAO}$ (P_DAPG) secrets antifungal metabolites like DAPG, HCN and pyoluteorin regulated by the two-component system GacA/GacS. Verticillium is highly suppressed in growth as well as it is interfered in its cellular polarity. Detoxification related genes like putative cyanide hydratase are up-regulated to possibly detoxify HCN secreted by Pseudomonas. Processes for further plant infection and fungal nutrition down-regulated explained by the decreased expression of pectate lyases coding genes. The observed fungal reactions can rather be interpreted as a detoxification and evasion strategy to escape from the bacterial antagonism. At the end, multiple suppressive effects on Verticillium by the presence of Pseudomonas indirectly lead to plant protection and constitute the biocontrol potential of the soil. 
By stockpiling melanin, Verticillium reaches distinct robustness in a dormant stage, so-called microsclerotia, to survive up to 15 years in the soil during harsh temperature conditions without infecting a host plant in between (Pegg, 1989; Pegg and Brady 2002; Tran et al., 2014). Specific plant molecules secreted by the roots of a host plant awake the fungal resting structure and start the Verticillium life cycle (Zhou et al., 2006; Eynck et al., 2007). Verticillium hyphae grow towards the host root passing the rhizosphere, which is a multifactorial conglomerate consisting of a diverse microbiome as well as varying abiotic factors (Mohanram and Kumar, 2019). Fluorescent pseudomonads are typically part of the rhizosphere biocoenosis of $B$. napus, one host plant of $V$. longisporum (Berg and Ballin, 1994). They possess different antagonistic strategies to suppress Verticillium growth on its way to their host root. Curled hyphal tip extension might reflect an appropriate fungal strategy under the physiological conditions of the rhizosphere to avoid antagonistic bacterial crowds and to reach less competitive environments targeting another root that might be more appropriate to be infected. This observation might be interpreted as an evading strategy by the fungus. Co-cultivation of the fungus with the bacterium results in a down-regulation of genes for plant cell wall degrading enzymes such as pectin lyase. This could be a specific reaction of the fungus to change its strategy from nutrition in conditions without bacterial stress in a plant simulating environment, to a withdrawal strategy to reach less suppressive conditions.

The transcriptional response of Verticillium in the presence of the bacterium indicates that the fungus also prepares itself for detoxification against Pseudomonas' mycotoxins. GacA/GacS-controlled bacterial hydrogen cyanide can occupy the oxygen binding-site of the respiratory chain in mitochondria and inactivates cytochromes, resulting in impaired respiration (Cooper and Brown, 2008). The fungus increases the transcription of the putative fungal cyanate lyase transcripts in the presence of the bacteria, presumably as a response that leads to the detoxification of the bacterial metabolite HCN. The induction of Verticillium transcripts for predicted thioredoxin can also be interpreted as a protective approach, because the protein is capable to detoxify reactive oxygen species. 
During this study, neither morphologically nor genetically strong indications were observed that would support the theory of an active fungal counterstrike to suppress the vitality of the bacterium. All findings rather draw a picture of an avoiding fungus that tries to defend itself and evades the bacterium. Cellular pathways that are crucial for detoxification and protection are elevated whereas hyphal growth as well as corresponding processes related to further nutrient uptake or general protein biosynthesis are driven back. In a potential biocontrol setting, the fungal growth suppression due to the presence of the bacterium could result in a biocontrol effect indirectly protecting the crop plant against fungal pathogenicity.

It should be noted that the view on the described bacterial-fungal interaction in this study has a highly artificial and abstract angle. It has to be considered that the interaction investigated separately in this study naturally takes place in the plant rhizosphere, a highly dynamic and multifactorial location, where countless abiotic and biotic factors install an individual environment for all organisms to interact with each other (Dash et al., 2019; Mohanram and Kumar, 2019; Rodriguez et al., 2019; Pathan et al., 2020).

For the investigation of single influencing factors, it was necessary in this study to reduce the complexity as much as possible. This goes along with a reduction of the experimental set up to only two players, one fungus and one bacterium, as well as controlling the nutritional environment in specific growth media. The setting of the interaction was predefined and simplified compared to natural conditions as well, either in surface co-cultivation experiments on agar surfaces or in liquid medium with and without physical restriction. Especially the interaction studies in the microfluidic devices were necessary to investigate fungal morphological behavior under Pseudomonas co-cultivation in detail. However, at the same time this set-up dramatically changes the natural situation in the rhizosphere, where normally less physical growth limitation occurs.

It also has to be considered that the simplification process that is necessary for scientific purposes can also be accompanied by mistakes. In this Verticillium/Pseudomonas co-cultivation study, the fungus was inoculated by spores and the interaction predominantly took place in the developmental stages 
of spores and hyphae but only less microsclerotia. Contrary, in the soil, where the interaction with Pseudomonas naturally takes place, Verticillium mostly starts germinating out of the stage of microsclerotia before it develops hyphae to approach the roots, which was not addressed during this experimental setup.

Due to high experimental costs or laborious individual work, the number of biological replicates for the transcriptomic approach as well as for the microfluidic interaction studies was rather limited. Consequentely, the data interpretation has to be made carefully.

In this regard, all findings of this study have to be interpreted tentatively with respect to the fact that the highly complex and multifactorial natural network in the soil has been simplified dramatically. Therefore, the results have to be embedded and transferred to a broader ecological scope.

\section{Outlook}

In the present work, the potential of fluorescent pseudomonads isolated from the rhizosphere has been examined to suppress the growth of soil borne phytopathogenic Verticillia in situ. In a next step, it would be interesting to know if these findings can be transferred to an in planta set up as a biocontrol agent. A big selection of putatively active biocontrol agents with promising inhibition potential against Verticillium in vitro has been collected in literature already. However, many of these candidates lack the evidence for their antagonism in planta to increase the vitality of infected plants or avoid plant infection (Deketelaere et al., 2017). Further research is needed to evaluate the biocontrol potential of the three Pseudomonas isolates selected for this study towards Verticillium in planta. Initial approaches in planta to model the interaction of all three players - plant, bacterium and fungus - have been performed already but results are not shown due to a lack of consistency. Biocontrol experiments have been done in a greenhouse with little possibilities to adjust abiotic factors like light, temperature and humidity, but even biotic factors like vine louse infestation. These results could not be confirmed in growth chambers under more controlled circumstances. To create solid data, a robust experimental design has to be composed. In planta knowledge would 
narrow down the gap transferring the described findings of this study into practical usage in agriculture.

In further plant experiments, a preinoculation realized as a coating seeds of oilseed rape with lyophilized antagonistic bacteria adhering to the seed surface should also be investigated. This way, a suppressive potential of the rhizosphere, as described by Sikora et al. (1992) and Steinberg et al. (2019) can initially be installed limiting the pathogenic intensity of virulent fungi already at the beginning of a cultivation period. Particularly, different biocontrol agents could be preinoculated at the same time covering a broader spectrum of relevant growth conditions. By combining

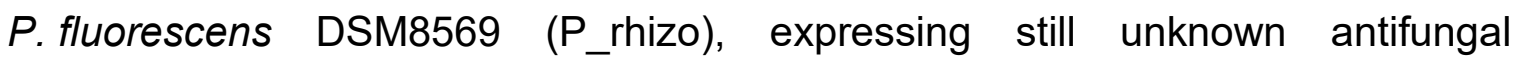
metabolites, $P$. synxantha 2-79 (P_phen), producing phenazines and $\mathrm{P}$. protegens ( $\mathrm{CHAO})$, secreting DAPG, pyoluteorin and $\mathrm{HCN}$, the chances of biocontrol success would be increased.

Another topic that remains unaddressed in the Verticillium-Pseudomonas interaction so far, are the trigger factors to activate the Pseudomonas sensor kinase GacS that is integrated in the cell membrane and responsible to detect specific external activation signals to start the signal transduction in the twocomponent system. It is still unclear whether the activation of GacS goes back to a general induction based on an unspecific reaction like reduced nutrition or due to rather specific recognition motifs of Verticillium structures, enzymes or metabolites. A metabolomics analysis of the Verticillium-Pseudomonas cocultivation could be a valuable addition to gain further insights to relevant trigger signals of GacS.

\section{Closing remark}

This study shows that fluorescent pseudomonads possess many different strategies that are effective to oppose against phytopathogenic antagonists under various interaction conditions. This antagonistic potential should be used more regularly in agriculture with respect to ecologically responsible and sustainable management particularly of the soil ecosystems but also of contiguous aquatic ecosystems and grasslands. The current industrialized agriculture, that is highly price-driven by the consuming market, is considered to be one of the most crucial 
factors for ecological depreciation and species extinction on a global scale (Golson et al., 2015; Sanchez-Bayou and Wyckhuys, 2019). This includes homogenized field structures of huge size lacking substructures like hedges, woodland and areas of dense undergrowth, as well as intensified application of pesticides. Further evaluation of the ecological potential using antagonistic rhizobacteria for effective biocontrol of phytopathogens should be realized. This might contribute to a reduced usage of pesticides. The practical usage of applying bacteria to the ecosystem especially the final concentration of the biocontrol agents in the rhizosphere still has to be carefully balanced to avoid unintentional negative side effects due to the artificial influence. 


\section{References}

Abuamsha R, Salman M, Ehlers RU. 2010. Differential resistance of oilseed rape cultivars (Brassica napus ssp. oleifera) to Verticillium longisporum infection is affected by rhizosphere colonisation with antagonistic bacteria, Serratia plymuthica and Pseudomonas chlororaphis. Biocontrol 56: 201-112.

Albayrak ÇB. 2019. Bacillus Species as Biocontrol Agents for Fungal Plant Pathogens. In: Islam M, Rahman M, Pandey P, Boehme M, Haesaert G, eds. Bacilli and Agrobiotechnology: Phytostimulation and Biocontrol. Cham, $\mathrm{CH}$ : Springer, 239-265.

Ashburner M, Ball CA, Blake JA, Botstein D, Butler H, Cherry JM, Harris MA. 2000. Gene ontology: tool for the unification of biology. Nature Genetics 25: 25-29.

Atallah ZK, Maruthachalam K, Toit DL, Koike ST, Davis RM, Klosterman SJ, Hayes RJ, Subbarao KV. 2010. Population analyses of the vascular plant pathogen Verticillium dahliae detect recombination and transcontinental gene flow. Fungal Genetics and Biology 47: 416-422.

Barclay M, Day JC, Thompson IP, Knowles CJ, Bailey MJ. 2002. Substrateregulated cyanide hydratase (chy) gene expression in Fusarium solani: the potential of a transcription-based assay for monitoring the biotransformation of cyanide complexes. Environmental Microbiology 4: 183-189.

Baron NC, Rigobelo EC, Zied DC. 2019. Filamentous fungi in biological control: current status and future perspectives. Chilean Journal of Agricultural Research 79: 307-315.

Bayram Ö, Krappmann S, Ni M, Woo Bok J, Helmstaedt K, Valerius O, BrausStromeyer S, Kwon NJ, Keller NP, Yu JH, Braus GH. 2008. VelB/VeA/LaeA 
Complex Coordinates Light Signal with Fungal Development and Secondary Metabolism. Science 320: 1504-1506.

Bayram Ö, Braus GH. 2012. Coordination of secondarymetabolism and development in fungi: the velvet family of regulatory proteins. FEMS Microbiology Reviews 36: 1-24.

Beckman CH. 1987. The nature of wilt diseases of plants. St. Paul, USA: APS Press.

Benedik MJ, Sewell BT. 2017. Cyanide-degrading nitrilases in nature. The Journal of General and Applied Microbiology 64: 90-93.

Berendsen RL, Pieterse CMJ, Bakker PAHM. 2012. The rhizosphere microbiome and plant health. Trends in Plant Science 17: 478-86.

Berg G, Ballin G. 1994. Bacterial antagonists to Verticillium dahliae Kleb.. Journal of Phytopathology 141: 99-110.

Berlanger I, Powelson ML. 2000. Verticillium wilt. The Plant Health Instructor.

Bertani G. 1951. Studies on lysogenesis. I. The mode of phage liberation by lysogenic Escherichia coli. Journal of Bacteriology 62: 293-300.

Biessy A, Filion M. 2018. Phenazines in plant-beneficial Pseudomonas spp.: biosynthesis, regulation, function and genomics. Environmental Microbiology 20: 3905-3917.

Birren B, Fink G, Lander E. 2002. Fungal genome initiative: white paper developed by the fungal research community. Cambridge, MA: Whitehead Institute Center for Genome Research. 
Bok JW, Keller NP. 2004. LaeA, a regulator of secondary metabolism in Aspergillus spp. Eukaryotic Cell 3: 527-535.

Bönnighausen J, Schauer N, Schäfer W, Bormann J. 2019. Metabolic profiling of wheat rachis node infection by Fusarium graminearum - decoding deoxynivalenol-dependent susceptibility. New Phytologist 221: 459-469.

Braus GH, Irniger S, Bayram Ö 2010. Fungal development and the COP9 signalosome. Current Opinion in Microbiology 13: 1-5.

Brencic A, McFarland KA, McManus HR, Castang S, Mogno I, Dove S, Lory S. 2009. The GacS/GacA signal transduction system of Pseudomonas aeruginosa acts exclusively through its control over the transcription of the RsmY and RsmZ regulatory small RNAs. Molecular Microbiology 73: 434-445.

Brodhun F, Cristobal-Sarramian A, Zabel S, Newie J, Hamberg M, Feussner I. 2013. An Iron 13S-Lipoxygenase with an a-Linolenic Acid Specific Hydroperoxidase Activity from Fusarium oxysporum. Plos One 8: e64919.

Bui TT, Harting R, Braus-Stromeyer SA, Tran VT, Leonard M, Höfer A, Abelmann A, Bakti F, Valerius O, Schlüter R, Stanley CE, Ambrósio A, Braus GH. 2019. Verticillium dahliae transcription factors Som1 and Vta3 control microsclerotia formation and sequential steps of plant root penetration and colonisation to induce disease. New Phytologist 221: 2138-2159.

Carmona-Hernandez S, Reyes-Perez JJ, Chiquito-Contreras RG, RinconEnriquez G, Cerdan-Cabrera, Hernandez-Montiel LG. 2019. Biocontrol of Postharvest Fruit Fungal Diseases by Bacterial Antagonists: A Review. Agronomy 9: 121.

Carroll CL, Carter CA, Goodhue RE, Lin Lawell CC, Subbarao KV. 2018. A Review of Control Options and Externalities for Verticillium Wilts. Phytopathology 108: $160-171$. 
Chen Y, Yan F, Chai Y, Liu H, Kolter R, Losick R, Guo JH. 2013. Biocontrol of tomato wilt disease by Bacillus subtilis isolates from natural environments depends on conserved genes mediating biofilm formation. Environmental microbiology 15: 848-864.

Chen NH, Djoko KY, Veyrier FJ, McEwan AG. 2016. Formaldehyde Stress Responses in Bacterial Pathogens. Frontiers in Microbiology 7: 257.

Compant S, Samad A, Faist H, Sessitsch A. 2019. A review on the plant microbiome: Ecology, functions, and emerging trends in microbial application. Journal of Advanced Research 19: 29-37.

Conrath U, Pieterse CMJ, Mauch-Mani B. 2002. Priming in plant-pathogen interactions. Trends in Plant Science 7: 210-216.

Cooper CE, Brown GC. 2008. The inhibition of mitochondrial cytochrome oxidase by the gases carbon monoxide, nitric oxide, hydrogen cyanide and hydrogen sulfide: chemical mechanism and physiological significance. Journal of Bioenergetics and Biomembranes 40: 533-539.

Crabtree JN, Okagaki LH, Wiesner DL, Strain AK, Nielsen JN, Nielsen K. 2012. Titan cell production enhances the virulence of Cryptococcus neoformans. Infection and Immunity 80: 3776-3785.

Cui J, Bahrami AK, Pringle EG, Hernandez-Guzman G, Bender CL, Naomi EP, Ausubel FM. 2005. Pseudomonas syringae manipulates systemic plant defenses against pathogens and herbivores. Proceedings of the National Academy of Sciences of the United States of America 102: 1791-1796.

Daniel Da Rosa W, Gezuele E, Calegari L, Goni F. 2008. Asteroid body in sporotrichosis. Yeast viability and biological significance within the host immune response. Medical Mycology 46: 443-448. 
Dash B, Soni R, Kumar V, Suyal DC, Dash D, Goel R. 2019. Mycorrhizosphere: Microbial Interactions for Sustainable Agricultural Production. In: Varma A, Choudhary D, eds. Mycorrhizosphere and Pedogenesis. Singapore: Springer, 321338.

Deketelaere S, Tyvaert L, França SC, Höfte M. 2017. Desirable traits of a good biocontrol agent against Verticillium wilt. Frontiers in Microbiology 8: 1186.

Depotter JRL, Deketelaere S, Inderbitzin P, Tiedemann A Von, Hoefte M, Subbarao KV, Wood TA, Thomma BPHJ. 2016. Verticillium longisporum, the invisible threat to oilseed rape and other brassicaceous plant hosts. Molecular Plant Pathology 17: 1004-1016.

Depotter JR, Seidl MF, van den Berg, GC, Thomma BP, Wood TA. 2017. A distinct and genetically diverse lineage of the hybrid fungal pathogen Verticillium longisporum population causes stem striping in British oilseed rape. Environmental Microbiology 19: 3997-4009.

Depotter JR, Thomma BP, Wood TA. 2019b. Measuring the impact of Verticillium longisporum on oilseed rape (Brassica napus) yield in field trials in the United Kingdom. European Journal of Plant Pathology 153: 321-326.

Depotter JRL, Shi-Kunne X, Missonnier H, Liu T, Fain L, van den Berg GCM, Wood TA, Zhang B, Jacques A, Seidl MF, Thomma BPHJ. 2019a. Dynamic virulence-related regions of the plant pathogenic fungus Verticillium dahliae display enhanced sequence conservation. Molecular Ecology 28: 3482-3495.

Doering TL. 2009. How sweet it is! Cell wall biogenesis and polysaccharide capsule formation in Cryptococcus neoformans. Annual Reiew of Microbiology 63: 223-247. 
Eynck C, Koopmann B, Grunewaldt-Stoecker G, Karlowsky P, von Tiedemann A. 2007. Differential interaction of Verticillium longisporum and Verticillium dahliae with Brassica napus detected with molecular and histological techniques. European Journal of Plant Pathology 118: 259-274.

Fahleson J, Hu Q, Dixelius C. 2004. Phylogenetic analysis of Verticillium species based on nuclear and mitochondrial sequences. Archives of Microbiology 181: 435-442.

Fernandez J, Wilson RA. 2014. Characterizing Roles for the Glutathione Reductase, Thioredoxin Reductase and Thioredoxin Peroxidase-Encoding Genes of Magnaporthe oryzae during Rice Blast Disease. Plos One 9: e87300.

Figueroa M, Hammond-Kosack K, Solomon PS. 2018. A review of wheat diseases - a filed perspective. Molecular Plant Pathology 19: 1523-1536.

Flury $\mathrm{P}$, Vesga $\mathrm{P}$, Dominguez-Ferreras A, Tinguely $\mathrm{C}$, Ullrich $\mathrm{Cl}$, Kleespies RG, Keel C, Maurhofer M. 2019. Persistence of root-colonizing Pseudomonas protegens in herbivorous insects throughout different developmental stages and dispersal to new host plants. ISME Journal - Multidisciplinary Journal of Microbial Ecology 13: 860-872.

Fogelqvist J, Tzelepis G, Bejai S, Ilbäck J, Schwelm A, Dixelius C. 2018. Analysis of the hybrid genomes of two field isolates of the soil-borne fungal species Verticillium longisporum. BMC Genomics 191:14.

Fradin EF, Thomma BPHJ. 2006. Physiology and molecular aspects of Verticillium wilt diseases caused by $V$. dahliae and V. albo-atrum. Molecular Plant Pathology 7: 71-86.

Fradin EF, Zhang Z, Juarez Ayala JC, Castroverde CD, Nazar RN, Robb J, Liu CM, Thomma BP. 2009. Genetic dissection of Verticillium wilt resistance mediated by tomato Ve1. Plant Physiology 150: 320-332. 
França SC, Spiessens K, Pollet S, Debode J, De Rooster L, Callens D, Höfte M. 2013. Population dynamics of Verticillium species in cauliflower fields: influence of crop rotation, debris removal and ryegrass incorporation. Crop protection 54: 134-141.

Francis VI, Waters EM, Finton-James SE, Gor A, Kadioglu A, Brown AR, Porter SL. 2018. Multiple communication mechanisms between sensor kinases are crucial for virulence in Pseudomonas aeruginosa. Nature Communications 9: 1-11.

Francis VI, Porter SL. 2019. Multikinase networks: two-component signaling networks integrating multiple stimuli. Annual Review of Microbiology 73. 199-223.

Frisvad JC, Hubka V, Ezekiel CN, Hong SB, Novakova A, Chen J, Arzanlou M, Larsen TO, Sklenar F, Mahakarnchanaku W, Samson RA, Houbraken J. 2019. Taxonomy of Aspergillus section Flavi and their production of aflatoxins, ochratoxins and other mycotoxins. Studies in Mycology 93: 1-63.

\section{García-Gutiérrez L, Zeriouh H, Romero D, Cubero J, Vicente A, Pérez-García} A. 2013. The antagonistic strain Bacillus subtilis UMAF6639 also confers protection to melon plants against cucurbit powdery mildew by activation of jasmonate-and salicylic acid-dependent defense responses. Microbial Biotechnology 6: 264-274.

Gene Ontology Consortium. 2019. The gene ontology resource: 20 years and still GOing strong. Nucleic Acids Research 47: D330-D338.

Gerke J, Braus GH. 2014. Manipulation of fungal development as source of novel secondary metabolites for biotechnology. Applied Microbiology and Biotechnology 98: 8443-8455.

Gkarmiri K, Finlay RD, Alström S, Thomas E, Cubeta MA, Högberg N. 2015. Transcriptomic changes in the plant pathogenic fungus Rhizoctonia solani AG-3 in 
response to the antagonistic bacteria Serratia proteamaculans and Serratia plymuthica. BMC Genomics 16: 630.

Gordon TR, Kirkpatrick SC, Hansen J, Shaw D. 2006. Response of strawberry genotypes to inoculation with isolates of Verticillium dahliae differing in host origin. Plant Pathology 55: 766-769.

Goh C-H, Veliz Vallejos DF, Nicotra AB, Mathesius U. 2013. The Impact of Beneficial Plant-Associated Microbes on Plant Phenotypic Plasticity. Journal of Chemical Ecology 39: 826-839.

Gomaa EZ. 2012. Chitinase production by Bacillus thuringiensis and Bacillus licheniformis: Their potential in antifungal biocontrol. The Journal of Microbiology 50: 103-111.

González N, Heeb S, Valverde C, Kay E, Reimmann C, Junier T, Haas D. 2008. Genome-wide search reveals a novel GacA-regulated small RNA in Pseudomonas species. BMC Genomics 9: 167.

Gouda S, Kerry RG, Das G, Paramithiotis S, Shin HS, Patra JK. 2018. Revitalization of plant growth promoting rhizobacteria for sustainable development in agriculture. Microbiological Research 206: 131-140.

Goulson D, Nicholls E, Botías C, Rotheray EL. 2015. Bee declines driven by combined stress from parasites, pesticides, and lack of flowers. Science 347: 1255957.

Haas D, Défago G. 2005. Biological control of soil-borne pathogens by fluorescent pseudomonads. Nature Reviews Microbiology 3: 307-319.

Harting R, Höfer A, Tran VT, Weinhold LM, Barghahn S, Schlüter R, Braus GH. 2020. The Vta1 transcriptional regulator is required for microsclerotia melanization in Verticillium dahliae. Fungal Biology 124: 490-500. 
Heale JB, Karapapa K. 1999. The Verticillium threat to Canada's major oilseed crop: canola. Canadian Journal of Plant Pathology 21: 1-7.

Heeb S, Valverde C, Gigot-Bonnefoy C, Haas D. 2005. Role of the stress sigma factor RpoS in GacA/RsmA-controlled secondary metabolism and resistance to oxidative stress in Pseudomonas fluorescens CHA0. FEMS Microbiology Letters 243: 251-8.

Hernández-Chávez MJ, Pérez-García LA, Niño-Vega GA, Mora-Montes HM. 2017. Fungal strategies to evade the host immune recognition. Journal of Fungi 3 : 51.

Hollensteiner J, Wemheuer F, Harting R, Kolarzyk AM, Valerio SMD, Poehlein A, Brzuszkiewicz EB, Nesemann K, Braus-Stromeyer SA, Braus GH, Daniel R, Liesegang H. 2017. Bacillus thuringiensis and Bacillus weihenstephanensis inhibit the growth of phytopathogenic Verticillium species. Frontiers in Microbiology 7: 2171.

Hoppenau CE, Tuan VT, Kusch H, Aßhauer KP, Landesfeind M, Meinicke P, Popova B, Braus-Stromeyer SA, Braus GH. 2014. Verticillium dahliae VdTHI4 involved in thiazole biosynthesis, stress response and DNA repair functions, is required for vascular disease induction in tomato. Environmental and Experimental Botany 108: 14-22.

Horbach R, Navarro-QuesadacAR, Knoggec W, Deisinga HB. 2011. When and how to kill a plant cell: Infection strategies of plant pathogenic fungi. Journal of Plant Physiology 168: 51-62.

Howe KL, Contreras-Moreira B, De Silva N, Maslen G, Akanni W, Allen J, Alvarez-Jarreta J, Barba M, Bolser DM, Cambell L, Carbajo M, Chakiachvili M, Christensen M, Cummins C, Cuzick A, Davis P, Fexova S, Gall A, George N, Gil L, Gupta P, Hammond-Kosack KE, Haskell E, Hunt SE, Jaiswal P, Janacek 
SH, Kersey PJ, Langridge N, Maheswari U, Maurel T, McDowall MD, Moore B, Muffato M, Naamati G, Naithani S, Olson A, Papatheodorou I, Patricio M, Paulini M, Pedro H, Perry E, Preece J, Rosello M, Russell M, Sitnik V, Staines DM, Stein J, Tello-Ruiz MK, Trevanion SJ, Urban M, Wei S, Ware D, Williams G, Yates AD, Flicek P. 2019. Ensembl Genomes 2020 - enabling non-vertebrate genomic research. Nucleic Acids Research 48: 689-695.

Inderbitzin P, Davis RM, Bostock RM, Subbarao KV. 2011. The Ascomycete Verticillium longisporum is a Hybrid and a Plant Pathogen with an Expanded Host Range. Plos One 6: e18260.

Irmer H, Tarazona S, Sasse C, Olbermann P, Loeffler J, Krappmann S, Conesa A, Braus GH. 2015. RNAseq analysis of Aspergillus fumigatus in blood reveals a just wait and see resting stage behavior BMC Genomics 16: 604.

Islam MT, Fukushi Y. 2003. Growth inhibition and excessive branching in Aphanomyces cochlioides induced by 2,4-diacetylphloroglucinol is linked to disruption of filamentous actin cytoskeleton in the hyphae. World Journal of Microbiology and Biotechnology 26: 1163-70.

Islam S. 2018. Microorganisms in the Rhizosphere and their Utilization in Agriculture: A Mini Review. PSM Microbiology 3: 105-110.

Jain A, Sarsaiya S, Wu Q, Lu Y, Shi J. 2019. A review of plant leaf fungal diseases and its environment speciation. Bioengineered 10: 409-424.

Jayamohan NS, Patil SV, Kumudini BS. 2018. Reactive oxygen species (ROS) and antioxidative enzyme status in Solanum lycopersicum on priming with fluorescent Pseudomonas spp. against Fusarium oxysporum. Biologia 73: 10731082.

de Jonge R, van Esse HP, Maruthachalam K, Bolton MD, Santhanam P, Saber MK, Zhang Z, Usami T, Lievens B, Subbarao KV, Thomma BPHJ. 2012. 
Tomato immune receptor Ve1 recognizes effector of multiple fungal pathogens uncovered by genome and RNA sequencing. Proceedings of the National Academy of Sciences of the United States of America 109: 5110-5115.

Kaever A, Lingner T, Feussner K, Göbel C, Feussner I, Meinicke P. 2009. MarVis: a tool for clustering and visualization of metabolic biomarkers. $B M C$ Bioinformatics 10: 92.

Kaever A, Landesfeind M, Feussner K, Mosblech A, Heilmann I, Morgenstern B, Feussner I, Meinicke P. 2015. MarVis-Pathway: integrative and exploratory pathway analysis of non-targeted metabolomics data. Metabolomics 11: 764-777.

Kang IJ, Shim HK, Roh JH, Heu S, Shin DB. 2018. Simple Detection of Cochliobolus Fungal Pathogens in Maize. Plant Pathology Journal 34: 327-334.

Kannojia P, Choudhary KK, Srivastava AK, Singh AK. 2019. PGPR Bioelicitors: Induced Systemic Restiance (ISR) and Proteomic Perspective on Biocontrol. In: Singh AK, Kumar A, Singh PK, eds. PGPR Amelioration in Sustainable Agriculture, Food Security and Environmental Management. Amsterdam, NL: Elsevier, 67-84.

Karplus PA, Schulz GE. 1987. Refined structure of glutathione reductase at 1.54 A resolution. Journal of Molecular Biology 195: 701-29.

Keller NP. 2019. Fungal secondary metabolism: regulation, function and drug discovery. Nature Reviews Microbiology 17: 167-180.

Khan A, Ishaq M, Ahmed AA, Guo X, Khan I, Khan AQ. 2019. Beneficial Plant Growth Promoting Rhizobacteria in Rhizosphere, it's Application and Plant Growth: A Review. Natural Products Chemistry and Research 7: 359.

Khaneghah AM, Martins LM, von Hertwig AM, Bertoldo R, Sant'Ana AS. 2018. Deoxynivalenol and its masked forms: Characteristics, incidence, control and fate 
during wheat and wheat based products processing - A review. Trends in Food Science and Technology 71: 13-24.

Klosterman SJ, Atallah ZK, Vallad GE, Subbarao KV. 2009. Diversity, pathogenicity and management of Verticillium species. Annual Review of Phytopathology 47: 39-62.

Koehl J, Kolnaar R, Ravensberg WJ. 2019. Mode of Action of Microbial Biological Control Agents Against Plant Diseases: Relevance Beyond Efficacy. Frontiers in Plant Science 10: 845.

Korenblum E, Aharoni A. 2019. Phytobiome metabolism: beneficial soil microbes steer crop plants' secondary metabolism. Pest Management Science 75: 23782384.

Kosawang C, Karlsson M, Velez H, Rasmussen PH, Collinge DB, Jensen B, Jensen DJ. 2014. Zearalenone detoxification by zearalenone hydrolase is important for the antagonistic ability of Clonostachys rosea against mycotoxigenic Fusarium graminearum. Fungal Biology 118: 364-373.

Kretschmer M, Leroch M, Mosbach A, Walker AS, Fillinger S, Mernke D, Schoonbeek HJ, Pradier JM, Leroux P, De Waard MA, Hahn M. 2009. Fungicide-driven evolution and molecular basis of multidrug resistance in field populations of the grey mould fungus Botrytis cinerea. Plos Pathogens. 5: e1000696.

Kupferschmied P, Maurhofer M, Keel C. 2013. Promise for plant pest control: root-associated pseudomonads with insecticidal activities. Frontiers in Plant Science 4: 287.

Kuriyan J, Krishna TS, Wong L, Guenther B, Pahler A, Williams CH, Model P. 1991. Convergent evolution of similar function in two structurally divergent enzymes. Nature 352: 172-4. 
Lan N, Yue Q, An Z, Bills GF. 2020. Apc. LaeA and Apc. VeA of the velvet complex govern secondary metabolism and morphological development in the echinocandin-producing fungus Aspergillus pachycristatus. Journal of Industrial Microbiology \& Biotechnology 47: 155-168.

Laville J, Voisard C, Keel C, Maurhofer M, Défago G, Haas D. 1992. Global control in Pseudomonas fluorescens mediating antibiotic synthesis and suppression of black root rot of tobacco. Proceedings of the National Academy of Sciences of the United States of America 89: 1562-1566.

Laville J, Blumer C, von Schroetter C, Gaia V, Defago G, Keel C, Haas D. 1998. Characterization of the $h c n A B C$ gene cluster encoding hydrogen cyanide synthase and anaerobic regulation by anr in the strictly aerobic biocontrol agent Pseudomonas fluorescens CHA0. Journal of Bacteriology 180: 3187-3196.

Leonard M, Kühn A, Harting R, Maurus I, Nagel A, Starke J, Kusch H, Valerius O, Feussner K, Feussner I, Kaever, A., Landesfeind M, Morgenstern B, Becher D, Hecker M, Braus-Stromeyer SA, Kronstad JW, Braus GH. 2020. $V$. longisporum elicits media-dependent secretome responses with a further capacity to distinguish between plant-related environments. Frontiers in Microbiology 11: 1876.

Letunic I, Doerks T, Bork P. 2015. SMART: recent updates, new developments and status in 2015. Nucleic Acids Research 43: D257-D260.

Letunic I, Bork P. 2018. 20 years of the SMART protein domain annotation resource. Nucleic Acids Research 46: D493-D496.

Lin R, Qin F, Shen B, Shi Q, Liu C, Zhang X, Jiao Y, Lu J, Gao Y, SuarezFernandez M, Lopez-Moya F, Lopez-Llorca LV, Wang G, Mao Z, Ling J, Yang Y, Cheng X, Xie B. 2018. Genome and secretome analysis of Pochonia chlamydosporia provide new insight into egg-parasitic mechanisms. Scientific 
Reports 8: 1123.

Longley R, Halliwell J, Campbell J, Ingledew W. 1972. The branchpoint of pyocyanine biosynthesis. Canadian Journal of Microbiology 18: 1357-1363.

Lupas AN, Zhu H, Korycinski M. 2015. The thalidomide-binding domain of cereblon defines the CULT domain family and is a new member of the beta-tent fold. Plos Computational Biology 11: e1004023.

Mancl JM, Ray WK, Helm RF, Schubot FD. 2019. Helix cracking regulates the critical interaction between RetS and GacS in Pseudomonas aeruginosa. Structure 27: 785-793.

Markakis EA, Tjamos SE, Antoniou PP, Paplomatas EJ, Tjamos EC. 2016. Biological control of Verticillium wilt of olive by Paenibacillus alvei, strain K165. BioControl 61: 293-303.

Martínez-García PM, Ruano-Rosa D, Schilirò E, Prieto P, Ramos C, Rodríguez-Palenzuela P, Mercado-Blanco J. 2015. Complete genome sequence of Pseudomonas fluorescens strain PICF7, an indigenous root endophyte from olive (Olea europaea L.) and effective biocontrol agent against Verticillium dahliae. Standards in Genomic Sciences 10: 10.

Martínková L, Veselá AB, Rinágelová A, Chmátal M. 2015. Cyanide hydratases and cyanide dihydratases: emerging tools in the biodegradation and biodetection of cyanide. Applied Microbiology and Biotechnology 99: 8875-8882.

Maurhofer M, Keel C, Haas D, Defago G. 1994. Pyoluteorin production by Pseudomonas fluorescens strain CHAO is involved in the suppression of Pythium damping-off of cress but nut of cucumber. European Journal of Plant Pathology 100: 221-232. 
Mavrodi DV, Ksenzenko VN, Bonsall RF, Cook JR, Boronin AM, Thomashow LS. 1998. A seven-gene locus for synthesis of phenazine-1-carboxylic acid by Pseudomonas fluorescens 2-79. Journal of Bacteriology 180: 2541-2548.

Mavrodi DV, Blankenfeldt W, Thomashow LS. 2006. Phenazine compounds in fluorescent Pseudomonas spp.: biosynthesis and regulation. Annual Review of Phytopathology 44: 417-445.

Mazurier S, Corberand T, Lemanceau P, Raaijmakers JM. 2009. Phenazine antibiotics produced by fluroscent pseudomonads contribute to natural soil suppressiveness to Fusarium wilt. ISME Journal - Multidisciplinary Journal of Microbial Ecology 3: 977-991.

Mazzola M. 2007. Manipulation of Rhizosphere Bacterial Communities to Induce Suppressive Soils. Journal of Nematology 39: 213-220.

Meister C, Thieme KG, Thieme S, Köhler AM, Schmitt K, Valerius O, Braus GH. 2019. COP9 Signalosome Interaction with UspA/Usp15 Deubiquitinase Controls VeA-Mediated Fungal Multicellular Development. Biomolecules 9: 238.

deMello AJ. 2006. Control and detection of chemical reactions in microfluidic systems. Nature 442: 394-402.

Meselson M, Yuan R. 1968. DNA restriction enzyme from E. coli. Nature 217: $1110-4$.

Mishra J, Arora NK. 2018. Secondary metabolites of fluorescent pseudomonads in biocontrol of phytopathogens for sustainable agriculture. Applied Soil Ecology 125: $35-45$.

Mohanram S, Kumar P. 2019. Rhizosphere microbiome: revisiting the synergy of plant-microbe interactions. Annals of Microbiology 69: 307-320. 
Nahlik K, Dumkow M, Baram Ö, Helmsteadt K, Busch S, Valerius O, Gerke J, Hoppert M, Schwier E, Opitz L, Westermann M, Grond S, Feussner K, Goebel C, Kaever A, Meinicke P, Feussner I, Braus GH. 2010. The COP9 signalosome mediates transcriptional and metabolic response to hormones, oxidative stress protection and cell wall rearrangement during fungal development. Molecular Microbiology 78: 964-79.

Nandi M, Selin C, Brassinga AKC, Belmonte MF, Fernando WGD, Loewen PC, de Kievit TR. 2015. Pyrrolnitrin and Hydrogen Cyanide Production by Pseudomonas chlororaphis Strain PA23 Exhibits Nematicidal and Repellent Activity against Caenorhabditis elegans. Plos One 10: e0123184

Nazir R, Warmink JA, Boersma H, van Elsas JD. 2009. Mechanisms that promote bacterial fitness in fungal-affected soil microhabitats. FEMS Microbiology Ecology 71: 169-185.

Nesemann K, Braus-Stromeyer SA, Thuermer A, Daniel R, Braus GH. 2015a. Draft genome sequence of the beneficial rhizobacterium Pseudomonas fluorescens DSM8569. Genome Announcements 3: e00137-15.

Nesemann K, Braus-Stromeyer SA, Thuermer A, Daniel R, Mavrodi DV, Thomashow LS, Weller DM, Braus GH. 2015b. Draft genome sequence of the phenazine producing Pseudomonas fluorescens 2-79. Genome Announcements 3: e00130-15.

Nesemann K, Braus-Stromeyer SA, Harting R, Hoefer A, Kusch H, Ambrosio AB, Timpner C, Braus GH. 2018. Fluorescent pseudomonads pursue mediadependent strategies to inhibit growth of pathogenic Verticillium fungi. Applied Microbiology and Biotechnology 102: 817-831.

Neumann MJ, Dobinson KF. 2003. Sequence tag analysis of gene expression during pathogenic growth and microsclerotia development in the vascular wilt pathogen Verticillium dahliae. Fungal Genetics and Biology 38: 54-62. 
Nosanchuk JD, Casadevall A. 2006. Impact of melanin on microbial virulence and clinical resistance to antimicrobial compounds. Antimicrobial Agents and Chemotherapy 50: 3519-3528.

Nützmann HW, Reyes-Dominguez Y, Scherlach K, Schroeckh V, Horn F, Gacek A, Schümann J, Hertweck C, Strauss J, Brakhage AA. 2011. Bacteriainduced natural product formation in the fungus Aspergillus nidulans requires Saga/Ada-mediatied histone acetylation. Proceedings of the National Academy of Sciences of the United States of America 108: 14282-14287.

Okagaki LH, Strain AK, Nielsen JN, Charlier C, Baltes NJ, Chretien F, Heitman J, Dromer F, Nielsen K. 2010. Cryptococcal cell morphology affects host cell interactions and pathogenicity. Plos Pathogens 6: e1000953.

Okagaki LH, Nielsen K. 2012. Titan cells confer protection from phagocytosis in Cryptococcus neoformans infections. Eukaryotic Cell 11: 820-826.

Orozco-Mosqueda MC, Rocha-Granados MC, Glick BR, Santoyo G. 2018. Microbiome engineering to improve biocontrol and plant growth-promoting mechanisms. Microbiological Research 208: 25-31.

Park SY, Choi J, Lim SE, Lee GW, Park J, Kim Y, Kong S, Se Ryun K, Rho HS, Jeon J, Chi MH, Kim S, Khang CH, Kang S, Lee YH. 2013. Global Expression Profiling of Transcription Factor Genes Provides New Insights into Pathogenicity and Stress Responses in the Rice Blast Fungus. Plos Pathogens 9: e1003350.

Pathan SI, Ceccherini MT, Sunseri F, Lupini A. 2020. Rhizosphere as Hotspot for Plant-Soil-Microbe Interaction. In: Datta R, Meena R, Pathan S, Ceccherini M, eds. Carbon and Nitrogen Cycling in Soil. Singapore: Springer, 17-43. 
Pegg GF. 1989. Pathogenesis in vascular diseases of plants. In: Tjamos EC, Beckmann $\mathrm{CH}$, eds. Vascular Wilt Diseases of Plants. Berlin, Heidelberg, Germany: Springer, NATO ASI Series (Series H: Cell Biology) 28.

Pegg GF, Brady BL. 2002. Verticillium Wilts. Wallingford, UK: CABI Publishing.

Petrasch S, Knapp SJ, van Kan JAL, Blanco-Ulat B. 2019. Grey mould of strawberry, a devastating disease caused by the ubiquitous necrotrophic fungal pathogen Botrytis cinerea. Molecular Plant Pathology 20: 877-892.

Rich PR. 2017. Mitochondrial cytochrome c oxidase: catalysis, coupling and controversies. Biochemical Society Transactions 45: 813-829.

Rochat L, Péchy-Tarr M, Baehler E, Maurhofer M, Keel C. 2010. Combination of fluorescent reporters for simultaneous monitoring of root colonization and antifungal gene expression by a biocontrol pseudomonad on cereals with flow cytometry. Molecular Plant Microbe Interactions 23: 949-961.

Rodenburg SYA, Seidl MF, de Ridder D, Govers F. 2018. Genome-wide characterization of Phytophthora infestans metabolism: a systems biology approach. Molecular Plant Pathology 19: 1403-1413.

Rodriguez PA, Rothballer M, Chowdhury SP, Nussbaumer T, Gutjahr C, Falter-Braun P. 2019. Systems Biology of Plant-Microbiome Interactions. Molecular Plant 12: 804-821.

Rodriguez-Moreno L, Ebert MK, Bolton MD, Thomma BPHJ. 2018. Tools of the crook-infection strategies of fungal plant pathogens. The Plant Journal 93: 664674.

Sahu B, Singh J, Shankar G, Pradhan A. 2018. Pseudomonas fluorescens PGPR bacteria as well as biocontrol agent: A review. International Journal of Chemical Studies 6: 01-07. 
Sanchez-Bayo F, Wyckhuys KAG. 2019. Worldwide decline of the entomofauna: A review of its drivers. Biological Conservation 232: 8-27.

Sarikaya-Bayram SÖ, Bayram Ö, Valerius O, Park HS, Irninger S, Gerke J, Ni M, Han KH, Yu JH, Braus GH. 2010. LaeA control of velvet family regulatory proteins for light-dependent development and fungal cell-type specificity. Plos Genetics 6: e1001226.

Sarikaya-Bayram SÖ, Palmer JM, Keller N, Braus GH, Bayram Ö. 2015. One Juliet and four Romeos: VeA and its methyltransferases. Frontiers in Microbiology 6: 1-7.

Schiering N, Kabsch W, Moore MJ, Distefano MD, Walsh CT, Pai EF. 1991. Structure of the detoxification catalyst mercuric ion reductase from Bacillus spp. strain RC607. Nature 352: 168-72.

Schnathorst WC. 1981. Life cycle and epidemiology of Verticillium. In: Mace ME, Bell AA, Beckman $\mathrm{CH}$, eds. Fungal wilt diseases of plants. New York, USA: Academic Press, 81-111.

Schnepf V, Vlot AC, Kugler K, Huckelhoven R. 2018. Barley susceptibility factor RACB modulates transcript levels of signalling protein genes in compatible interaction with Blumeria graminis f.sp. hordei. Molecular Plant Pathology 19: 393404.

Schnider-Keel U, Seematter A, Maurhofer M, Blumer C, Duffy B, GigotBonnefoy C, Reimmann C, Notz R, Defago G, Haas D, Keel C. 2000. Autoinduction of 2,4-Diacetylphloroglucinol Biosynthesis in the Biocontrol Agent Pseudomonas fluorescens $\mathrm{CHAO}$ and Repression by the Bacterial Metabolites Salicylate and Pyoluteorin. Journal of Bacteriology 182: 1215-1225. 
Schrempf H, Merling P. 2015. Extracellular Streptomyces lividans vesicles: composition, biogenesis and antimicrobial activity. Microbial Biotechnology 8: 644658.

Schroeckh V, Scherlach K, Nützmann HW, Shelest E, Schmidt-Heck W, Schuemann J, Martin K, Hertweck C, Brakhage AA. 2009. Intimate bacterialfungal interaction triggers biosynthesis of archetypal polyketides in Aspergillus nidulans. Proceedings of the National Academy of Sciences of the United States of America 106: 14558-14563.

Scott BR, Kaefer E. 1982. Aspergillus nidulans - An Organism for Detecting a Range of Genetic Damage. In: de Serres FJ, Hollaender A, eds. Chemical Mutagens. Boston, USA: Springer, 447-479.

Shah N, Gislason AS, Becker M, Belmonte MF, Fernando WD, de Kievit TR. 2020. Investigation of the quorum-sensing regulon of the biocontrol bacterium Pseudomonas chlororaphis strain PA23. Plos One 15: e0226232.

Shaikh SS, Wani SJ, Sayyed RZ. 2018. Impact of Interactions between Rhizosphere and Rhizobacteria: A Review. Journal of Bacteriology and Mycology 5: 1058.

Siebold M, von Tiedemann A. 2012. Potential effects of global warming on oilseed rape pathogens in Northern Germany. Fungal Ecology 5: 62-72.

Siebold M, von Tiedemann A. 2013. Effects of experimental warming on fungal disease progress in oilseed rape. Global Change Biology 19: 1736-1747.

Sikora RA. 1992. Management of the antagonistic potential in agricultural ecosystems for the biological control of plant parasitic nematodes. Annual Review of Phytopathology 30: 245-270. 
Singh S, Braus-Stromeyer SA, Timpner C, Valerius O, von Tiedemann A, Karlovsky P, Druebert C, Polle A, Braus GH. 2012. The plant host Brassica napus induces in the pathogen Verticillium longisporum the expression of functional catalase peroxidase which is required for the late phase of disease. Molecular Plant Microbe Interactions 25: 569-81.

de Souza JT, Arnould C, Deulvot C, Lemanceau P, Gianinazzi-Pearson V, Raaijmakers JM. 2003. Effect of 2,4-diacetylphloroglucinol on Pythium: cellular responses and variation in sensitivity among propagules and species. Phytopathology 93: 966-975.

Stanley CE, Stöckli M, van Swaay D, Sabotic J, Kallio PT, Künzler M, deMello AJ, Aebi M. 2014. Probing bacterial-fungal interactions at the single cell level. Integrative Biology 6: 935-45.

Steinberg C, Edel-Hermann V, Alabouvette C, Lemanceau P. 2019. Soil Suppressiveness to Plant Diseases. In: van Elsas JD, Trevors JT, Soares Rosado A, Nannipieri P, eds. Modern Soil Microbiology. Boca Raton, USA: Taylor and Francis, CRC Press, 343-360.

Stutz EW, Défago G, Kern H. 1986. Naturally occurring fluorescent pseudomonads involved in suppression of black root rot of tobacco. Phytopathology 76: 181-185.

Sung GH, Spatafora JW, Zare R, Hodge KT, Gams W. 2001. A revision of Verticillium sect. Prostrata. II. Phylogenetic analyses of SSU and LSU nuclear rDNA sequences from anamorphs and teleomorphs of the Clavicipitaceae. Nova Hedwigia 72: 311-328.

Timpner C, Braus-Stromeyer SA, Tran VT, Braus GH. 2013. The Cpc1 Regulator of the Cross-Pathway Control of Amino Acid Biosynthesis Is Required for Pathogenicity of the Vascular Pathogen Verticillium longisporum. Molecular Plant Microbe Interactions 26: 1312-1324. 
Tralamazza SM, Piacentini KC, Iwase CHT, de Oliveira Rocha L. 2018. Toxigenic Alternaria species: impact in cereals worldwide. Current Opinion in Food Science 23: 57-63.

Tran VT, Braus-Stromeyer SA, Timpner C, Braus GH. 2013. Molecular diagnosis to discriminate pathogen and apathogen species of the hybrid Verticillium longisporum on the oilseed crop Brassica napus. Applied Microbiology and Biotechnology 97: 4467-4483.

Tran VT, Braus-Stromeyer SA, Kusch H, Reusche M, Kaever A, Kuehn A, Valerius $\mathbf{O}$, Landesfeind M, Aßhauer K, Tech M, Hoff K, Pena-Centeno T, Stanke M, Lipka V, Braus GH. 2014. Verticillium transcription activator of adhesion Vta2 suppresses microsclerotia formation and is required for systemic infection of plant roots. New Phytologist 202: 565-81.

Traxler MF, Kolter R. 2015. Natural products in soil microbe interactions and evolution. Natural Product Reports 32: 956-70.

Tyvaert L, França SC, Debode J, Höfte M. 2014. The endophyte Verticillium V t305 protects cauliflower against Verticillium wilt. Journal of Applied Microbiology 116: $1563-1571$.

Tyvaert L, Everaert E, Lippens L, Cuijpers WJM, França SC, Höfte M. 2019. Interaction of Colletotrichum coccodes and Verticillium dahliae in pepper plants. European Journal of Plant Pathology 155: 1303-1317.

Uddin MN, Saifullah, Ahmad M, Khan W, Khan BM. 2019. Evaluation of Pochonia chlamydosporia (Goddard) Isolates for Suppression of Meloidogyne incognita, Root-Knot Nematode of Tomato. Journal of Agricultural Science 11: 7081. 
Veloso J, van Kan JAL. 2018. Many Shades of Grey in Botrytis-Host Plant Interactions. Trends in Plant Science 23: 613-622.

Warmink JA, Nazir R, Corten B, van Elsas JD. 2011. Hitchhikers on the fungal highway: the helper effect for bacterial migration via fungal hyphae. Soil Biology and Biochemistry 43: 760-765.

Wei X, Huang X, Tang L, Wu D, Xu Y. 2013. Global Control of GacA in Secondary Metabolism, Primary Metabolism, Secretion Systems, and Motility in the Rhizobacterium Pseudomonas aeruginosa M18. Journal of Bacteriology 195: 3387-3400.

Weller DM, Cook RJ. 1983. Suppression of take-all of wheat by seed treatments with fluorescent pseudomonads. Phytopathology 73: 463-469.

Weller DM. 2007. Pseudomonas biocontrol agents of soilborne pathogens: looking back over 30 years. Phytopathology 97: 250-256.

Wiemann P, Sieber CMK, von Bargen KW, Studt L, Niehaus EM, Espino JJ, Huß K, Michielse CB, Albermann S, Wagner D, Bergner SV, Connolly LR, Fischer A, Reuter G, Kleigrewe K, Bald T, Wingfield BD, Ophir R, Freeman S, Hippler M, Smith KM, Brown DW, Proctor RH, Münsterkötter M, Fretag M, Humpf HU, Göldener U, Tudzynski B. 2013. Deciphering the Cryptic Genome: Genome-wide Analyses of the Rice Pathogen Fusarium fujikuroi Reveal Complex Regulation of Secondary Metabolism and Novel Metabolites. Plos Pathogens 9: e1003475.

Wilhelm S. 1955. Longevity of the Verticillium wilt fungus in the laboratory and in the field. Phytopathology 45: 180-181.

Xin XF, He SY. 2013. Pseudomonas syringae pv. tomato DC3000: A Model Pathogen for Probing Disease Susceptibility and Hormone Signaling in Plants. Annual Review of Phytopathology 51: 473-498. 
Yan Q, Lopes LD, Shaffer BT, Kidarsa TA, Vining O, Philmus B, Song C, Stockwell VO, Raaijmakers JM, McPhail KL, Andreote FD, Chang JH, Loper JE. 2018. Secondary Metabolism and Interspecific Competition Affect Accumulation of Spontaneous Mutants in the GacS-GacA Regulatory System in Pseudomonas protegens. mBio 9: e01845-17.

Yan Y, Yuan Q, Tang J, Huang J, Hsiang T, Wei Y, Zheng L. 2018. Colletotrichum higginsianum as a Model for Understanding Host-Pathogen Interactions: A Review. International Journal of Molecular Sciences 19: 2142.

Yu D, Fang Y, Tang C, Klosterman SJ, Tian C, Wang Y. 2019a. Genomewide Transcriptome Profiles Reveal How Bacillus subtilis Lipopeptides Inhibit Microsclerotia Formation in Verticillium dahliae. Molecular Plant Microbe Interaction 32: 622-634.

Yu J, Li T, Tian L, Tang C, Klosterman SJ, Tian C, Wang Y. 2019b. Two Verticillium dahliae MAPKKKs, VdSsk2 and VdSte11, Have Distinct Roles in Pathogenicity, Microsclerotial Formation, and Stress Adaptation. mSphere 4: e00426-19.

Zaragoza O, Nielsen K. 2013. Titan cells in Cryptococcus neoformans: Cells with a giant impact. Current Opinion in Microbiology 16: 409-413.

Zeise K, von Tiedemann A. 2001. Morphological and physiological differentiation among vegetative compatibility groups of Verticillium dahliae in relation to Verticillium longisporum. Journal of Phytopathology 149: 469-475.

Zeng W, Dechun D, Kirk W, Hao J. 2012. Use of Coniothyrium minitans and other microorganisms for reducing Sclerotinia sclerotiorum. Biological Control 60: 225232.

Zhang QX, Kong XW, Li SY, Chen XJ, Chen XJ. 2020. Antibiotics of 
Pseudomonas protegens FD6 are essential for biocontrol activity. Australasian Plant Pathology 49: 307-317.

Zhang Y, Zhang J, Gao J, Zhang G, Yu Y, Zhou H, Chen W, Zhao J. 2018. The Colonization Process of Sunflower by a Green Fluorescent Protein-Tagged Isolate of Verticillium dahliae and its Seed Transmission. Plant Disease 102: 1772-1778.

Zhang Y, Zhang B, Wu X, Zhang LQ. 2020. Characterization the role of GacAdependent small RNAs and RsmA family proteins on 2,4-diacetylphloroglucinol production in Pseudomonas fluorescens 2P24. Microbiological Research 233: 126391.

Zheng X, Pfordt A, Khatri L, Eseola AB, Wilch A, Koopmann B, von Tiedemann A. 2019. Contrasting Patterns of Colonization with Verticillium longisporum in Winter- and Spring-Type Oilseed Rape (Brassica napus) in the Field and Greenhouse and the Role of Soil Temperature. Plant Disease 103: 20902099.

Zhou L, Hu Q, Johansson A, Dixelius C. 2006. Verticillium longisporum and V. dahliae: infection and disease in Brassica napus. Plant Pathology 55: 137-144.

Zuber S, Carruthers F, Keel C, Mattart A, Blumer C, Pessi G, Gigot-Bonnefoy C, Schnider-Keel U, Heeb S, Reimmann C, Haas D. 2003. GacS Sensor Domains Pertinent to the Regulation of Exoproduct Formation and to the Biocontrol Potential of Pseudomonas fluorescens CHAO. Molecular Plant Microbe Interactions 16: 634-644. 


\section{Appendix}

\section{Supplementary material for Chapter 4}

1

2

3

4

5

6

7

8

9 10

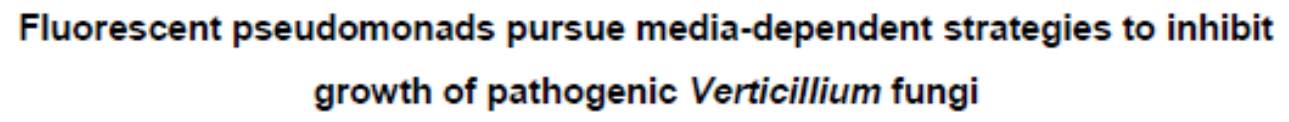




\section{Supplementary References}

Bao Y, Lies DP, Fu H, Roberts GP (1991) An improved Tn7-based system for the single-copy insertion of cloned genes into chromosomes of gram-negative bacteria. Gene 109:167-8.

Berg G, Ballin G (1994) Bacterial Antagonists to Verticillium dahliae Kleb. J Phytopathol 141:99-110. doi: 10.1111/j.1439-0434.1994.tb01449.x

Fradin EF, Zhang Z, Juarez Ayala JC, Castroverde CDM, Nazar RN, Robb J, Liu CM, Thomma BPHJ (2009) Genetic dissection of Verticillium wilt resistance mediated by tomato Ve1. Plant Physiol 150:320-32. doi: 10.1104/pp.109.136762

Khan SR, Mavrodi D V, Jog GJ, Suga H, Thomashow LS, Farrand SK (2005) Activation of the phz operon of Pseudomonas fluorescens 2-79 requires the LuxR homolog PhzR, N-(3-OH-Hexanoyl)-L-homoserine lactone produced by the Luxl homolog Phzl, and a cis-acting phz box. J Bacteriol 187:6517-27. doi: 10.1128/JB.187.18.6517-6527.2005

Krappmann S, Sasse C, Braus GH (2006) Gene targeting in Aspergillus fumigatus by homologous recombination is facilitated in a nonhomologous end- joiningdeficient genetic background. Eukaryot Cell 5:212-5. doi: 10.1128/EC.5.1.212215.2006

Laville J, Blumer C, Von Schroetter C, Gaia V, Défago G, Keel C, Haas D (1998) Characterization of the hcnABC gene cluster encoding hydrogen cyanide synthase and anaerobic regulation by ANR in the strictly aerobic biocontrol agent Pseudomonas fluorescens CHA0. J Bacteriol 180:3187-3196.

Laville J, Voisard C, Keel C, Maurhofer M, Défago G, Haas D (1992) Global control in Pseudomonas fluorescens mediating antibiotic synthesis and suppression of black root rot of tobacco. Proc Natl Acad Sci U S A 89:1562-6. doi: 10.1073/pnas.89.5.1562

Lazo GR, Stein PA, Ludwig RA (1991) A DNA transformation-competent Arabidopsis genomic library in Agrobacterium. Biotechnology (N Y) 9:963-7.

Maurhofer M, Keel C, Haas D, Défago G (1994) Pyoluteorin production by Pseudomonas fluorescens strain $\mathrm{CHAO}$ is involved in the suppression of Pythium damping-off of cress but not of cucumber. Eur J Plant Pathol 100:221-232. doi: 10.1007/BF01876237

McCluskey K, Wiest A, Plamann M (2010) The Fungal Genetics Stock Center: a repository for 50 years of fungal genetics research. J Biosci 35:119-26. 
Pontecorvo G, Roper JA, Hemmons LM, MacDonald KD, Bufton AWJ (1953) The genetics of Aspergillus nidulans. Adv Genet 5:141-238.

Rochat L, Péchy-Tarr M, Baehler E, Maurhofer M, Keel C (2010) Combination of fluorescent reporters for simultaneous monitoring of root colonization and antifungal gene expression by a biocontrol pseudomonad on cereals with flow cytometry. Mol Plant Microbe Interact 23:949-961. doi: 10.1094/MPMI-23-70949

Schnider-Keel U, Seematter A, Maurhofer M, Blumer C, Duffy B, Gigot-Bonnefoy C, Reimmann C, Notz R, Défago G, Haas D, Keel C (2000) Autoinduction of 2,4diacetylphloroglucinol biosynthesis in the biocontrol agent Pseudomonas fluorescens $\mathrm{CHAO}$ and repression by the bacterial metabolites salicylate and pyoluteorin. J Bacteriol 182:1215-25.

Stutz EW, Défago G, Kern H (1986) Naturally Occurring Fluorescent Pseudomonads Involved in Suppression of Black Root Rot of Tobacco. Phytopathology 76:181185. doi: 10.1094/Phyto-76-181

Timpner C, Braus-Stromeyer SA, Tran VT, Braus GH (2013) The Cpc1 Regulator of the Cross-Pathway Control of Amino Acid Biosynthesis Is Required for Pathogenicity of the Vascular Pathogen Verticillium longisporum. Mol PlantMicrobe Interact 26:1312-1324. doi: 10.1094/MPMI-06-13-0181-R

Weller DM, Cook RJ (1983) Supression of take-all of wheat by seed treatmetns with fluorescent pseudomonads. Phytopathology 73:463-469.

Zeise K, Von Tiedemann A (2002) Host specialization among vegetative compatibility groups of Verticillium dahliae in relation to Verticillium longisporum. J Phytopathol 150:112-119. doi: 10.1046/j.1439-0434.2002.00730.x Zuber S, Carruthers F, Keel C, Mattart A, Blumer C, Pessi G, Gigot-Bonnefoy C, Schnider-Keel U, Heeb S, Reimmann C, Haas D (2003) GacS Sensor Domains Pertinent to the Regulation of Exoproduct Formation and to the Biocontrol Potential of Pseudomonas fluorescens CHAO. Mol Plant-Microbe Interact 16:634-644. doi: 10.1094/MPMI.2003.16.7.634 


\section{Supplementary Figure Caption}

Figure S1: Southern hybridization of V. dahliae JR2 LAE1 and CSN5 deletion strains. Respective genes were replaced by nourseotricin (CNAT) resistance cassette by homologous recombination. (a) Left: Southern hybridization of LAE1 ( $L A E E 1)$ deletion strain compared to wild type (WT). Genomic DNA was restricted with Acc65I and the $5^{\prime}$ flanking region $\left(5^{\prime}\right)$ was used as a probe. Wild type shows a signal at $4.7 \mathrm{~kb}$, whereas the deletion strains displays a smaller band around $3.6 \mathrm{~kb}$. Right: Scheme of WT and deletion locus with restriction sites, probe and expected sizes. (b) Left: Southern hybridization of CSN5 deletion strain ( $\triangle C S N 5)$ in comparison to wild type (WT). Genomic DNA was restricted with Nhel and the $5^{\prime}$ flanking region (5') was used as a probe. Wild type displays two bands with the size of $1.9 \mathrm{~kb}$ and $2.6 \mathrm{~kb}$ whereas the deletion strain shows signals at $1.9 \mathrm{~kb}$ and $2.9 \mathrm{~kb}$. Right: Scheme of WT and deletion locus with restriction sites, probe and expected sizes. The additional small fragment of less than $200 \mathrm{bp}$ generated by two close Nhel restriction sites in the 5 ' flanking region is not visible on the membrane.

WT $=$ wild type $;$ CNAT = nourseothricin resistance cassette $5^{\prime}=5^{\prime}$ flanking region; $3^{\prime}=$ 3 ' flanking region

\section{Supplementary Tables}

Table S1: Organisms and strains used in this study.

\begin{tabular}{|l|l|l|}
\hline Organism & Characteristic & Reference \\
\hline Verticillium longisporum & wild type & $\begin{array}{l}\text { (Zeise and Von } \\
\text { Tiedemann 2002) }\end{array}$ \\
\hline VI 43 & \multicolumn{2}{|l|}{} \\
\hline Verticillium dahliae & wild type & (Fradin et al. 2009) \\
\hline JR2 & deletion of LAE1, derivative of & this study \\
\hline JR2 LAE1 & deletion of CSN5 derivative of & this study \\
\hline JR2 CSN5 & wild type & $\begin{array}{l}\text { (Pontecorvo et al. } \\
1953)\end{array}$ \\
\hline Aspergillus nidulans & \multicolumn{2}{|l}{} \\
\hline FGSC: A4 & wild type with deletion of akuA & $\begin{array}{l}\text { Derivative of AfS28 } \\
\text { (Krappmann et al. } \\
\text { 2006) }\end{array}$ \\
\hline Aspergillus fumigatus & \\
\hline $\begin{array}{l}\text { AfS35 } \\
\text { (FGSC: A1159) }\end{array}$
\end{tabular}




\begin{tabular}{|c|c|c|}
\hline \multicolumn{3}{|l|}{ Pseudomonas fluorescens } \\
\hline $\begin{array}{l}\text { P_rhizo } \\
\text { (DSMZ: DSM8569) }\end{array}$ & $\begin{array}{l}\text { wild type - natural isolate from } \\
\text { rapeseed rhizosphere }\end{array}$ & $\begin{array}{l}\text { (Berg and Ballin } \\
\text { 1994) }\end{array}$ \\
\hline $\begin{array}{l}\text { P.phenazine (2-79) } \\
\text { (NRRL: B-15132) }\end{array}$ & $\begin{array}{l}\text { wild type with i.a. phenazine } \\
\text { production }\end{array}$ & $\begin{array}{l}\text { (Weller and Cook } \\
\text { 1983) }\end{array}$ \\
\hline $\begin{array}{l}\text { P_phenazine } \Delta p h z \\
(2-79 Z)\end{array}$ & $\begin{array}{l}\text { production of phenazines } \\
\text { impaired (derivative of B-15132) }\end{array}$ & (Khan et al. 2005) \\
\hline \multicolumn{3}{|l|}{ Pseudomonas protegens } \\
\hline $\begin{array}{l}\text { P_DAPG (CHA0) } \\
\text { (DSMZ: DSM19095) }\end{array}$ & $\begin{array}{l}\text { wild type with i.a. DAPG } \\
\text { production }\end{array}$ & (Stutz et al. 1986) \\
\hline $\begin{array}{l}\text { P_DAPG } \Delta g a c A:: \Omega \mathrm{Km}^{r} \\
\text { (CHA89) }\end{array}$ & $\begin{array}{l}\text { deletion of gacA - key enzyme in } \\
\text { biosynthesis of several } \\
\text { antibiotics; no production of } \\
\text { DAPG, HCN, pyoluteorin } \\
\text { (derivative of DSM19095) }\end{array}$ & (Laville et al. 1992) \\
\hline $\begin{array}{l}\text { P_DAPG } \Delta g a c S \\
\text { (CHA19) }\end{array}$ & $\begin{array}{l}\text { deletion of gacS - key enzyme in } \\
\text { biosynthesis of several } \\
\text { antibiotics; no production of } \\
\text { DAPG, HCN, pyoluteorin } \\
\text { (derivative of DSM19095) }\end{array}$ & (Zuber et al. 2003) \\
\hline $\begin{array}{l}\text { P_DAPG } \triangle h c n A B C \\
\text { (CHA77) }\end{array}$ & $\begin{array}{l}\text { deletion of } h c n A B C \text { - almost no } \\
\text { production of } \mathrm{HCN} \text { (derivative of } \\
\text { DSM19095) }\end{array}$ & (Laville et al. 1998) \\
\hline $\begin{array}{l}\text { P_DAPG } \Delta \text { anr:: } \Omega H^{\prime} r \\
\text { (CHA21) }\end{array}$ & $\begin{array}{l}\text { deletion of anr - transcription } \\
\text { factor for HCN-production; } 8 \% \\
\text { HCN production compared to wild } \\
\text { type (derivative of DSM19095) }\end{array}$ & (Laville et al. 1998) \\
\hline $\begin{array}{l}\text { P_DAPG } \Delta \text { plt::Tn5 } \\
\text { (CHA660) }\end{array}$ & $\begin{array}{l}\text { deletion of plt - no production of } \\
\text { pyoluteorin (derivative of } \\
\text { DSM19095) }\end{array}$ & $\begin{array}{l}\text { (Maurhofer et al. } \\
\text { 1994) }\end{array}$ \\
\hline $\begin{array}{l}\text { P_DAPG } \Delta p h / A \\
\text { (C) } \mathrm{CH} 631)\end{array}$ & $\begin{array}{l}\text { deletion of phlA - gene in phl- } \\
\text { operon for DAPG synthesis; no } \\
\text { production of DAPG (derivative of } \\
\text { DSM19095) }\end{array}$ & $\begin{array}{l}\text { (Schnider-Keel et al. } \\
\text { 2000) }\end{array}$ \\
\hline $\begin{array}{l}\text { P_DAPG } \Delta p h / F: . \Omega K m r \\
\text { (CHA638) }\end{array}$ & $\begin{array}{l}\text { deletion of } p h / F \text { - repressor gene } \\
\text { for DAPG synthesis; enhanced } \\
\text { production of DAPG (derivative of } \\
\text { DSM19095) }\end{array}$ & $\begin{array}{l}\text { (Schnider-Keel et al. } \\
2000)\end{array}$ \\
\hline \multicolumn{3}{|l|}{ Escherichia coli } \\
\hline $\begin{array}{l}\text { DH5a } \\
\text { (DSZM: DSM6897) }\end{array}$ & & DSZM \\
\hline \multicolumn{3}{|l|}{ Agrobacterium tumefaciens } \\
\hline $\begin{array}{l}\text { AGL-1 } \\
\text { (ATCC: BAA-101) }\end{array}$ & & (Lazo et al. 1991) \\
\hline
\end{tabular}

FGSC = Fungal Genetic Stock Center (McCluskey et al. 2010); DSMZ = Leibniz-Institut Deutsche Sammlung von Mikroorganismen und Zellkulturen $\mathrm{GmbH}$; NRRL = ARS Culture Collection National Center for Agricultural Utilization Research; 111 ATCC = American Type Culture Collection, $\mathrm{Km}=$ kanamycin; $\mathrm{Hg}=$ hygromycin; GFP $112=$ green fluorescent protein; ${ }^{r}=$ resistance; DAPG $=2,4$-diacetylphloroglucinol 
113 Table S2: Primer used in this study.

\begin{tabular}{|c|c|c|}
\hline Primer & Sequence $\left(5^{\prime}-3^{\prime}\right)$ & Reference \\
\hline CSN5 P1 (ECORI) & $\begin{array}{l}\text { GGG GAA TTC TTA AGC TGG TGC } \\
\text { CTT TTC CAA G }\end{array}$ & this study \\
\hline CSN5 P2 (ECORV) & $\begin{array}{l}\text { GGG GAT ATC TTG ACT TCT GGC } \\
\text { GCG TTG }\end{array}$ & this study \\
\hline CSN5 P3 ( & $\begin{array}{l}\text { GGG TCT AGA GGC TTG CTT TGC } \\
\text { TTG TGA TG }\end{array}$ & this study \\
\hline CSN5 P4 (HindIII) & $\begin{array}{l}\text { GGG AAG CTT ACC TTT CTC CTG } \\
\text { CTG CTG AAT C }\end{array}$ & this study \\
\hline VDLAEF1Lc (EcoRI) & $\begin{array}{l}\text { GGG GAA TTC GTG CAG CAG GTA } \\
\text { CTG GCT TT }\end{array}$ & this study \\
\hline VDLAEF1Rc (EcoRV) & $\begin{array}{l}\text { GGG GAT ATC TGA TAG CTG ACA } \\
\text { CGC GAA AC }\end{array}$ & this study \\
\hline VDLAEF2Lc (BamHI) & $\begin{array}{l}\text { GGG GGA TCC GAA TAC ATC CTG } \\
\text { GTA GCC TTC G }\end{array}$ & this study \\
\hline VDLAEF2Rc (Pstl) & $\begin{array}{l}\text { GGG CTG CAG CCT GGA CAG GAA } \\
\text { GTA CAA CGA }\end{array}$ & this study \\
\hline
\end{tabular}

115 Table S3: Plasmids used in this study.

\begin{tabular}{|c|c|c|}
\hline Name & Description & Reference \\
\hline \begin{tabular}{|l|}
$\mathrm{pKO} 2$ \\
\end{tabular} & $\begin{array}{l}\text { Gene disruption vector with nourseotricin resistance } \\
\text { cassette }\end{array}$ & $\begin{array}{l}\text { (Timpner et al. } \\
\text { 2013) }\end{array}$ \\
\hline \begin{tabular}{|l|} 
pME4412 \\
\end{tabular} & $\begin{array}{l}\text { 5'flanking region CSN5 (EcoRl/ECORV) and 3' flanking } \\
\text { region CSN5 (Xbal/HindllI) in pKO2 } \\
\text { (5'CSN5:.gpdA: :nat::3'CSN5 in pKO2 backbone) }\end{array}$ & this study \\
\hline \begin{tabular}{|l|} 
pME3990 \\
\end{tabular} & $\begin{array}{l}\text { 5'flanking region } L A E 1(E C O R I / E C O R V) \text { and } 3 \text { ' flanking } \\
\text { region } L A E 1 \text { (Pstl/BamHI) in pKO2 } \\
\text { (5'LAE1::gpdA::nat::3'LAE1 in pKO2 backbone) }\end{array}$ & this study \\
\hline pME9407 & 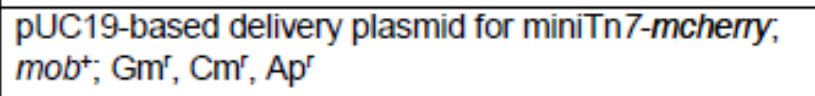 & $\begin{array}{l}\text { (Rochat et al. } \\
\text { 2010) }\end{array}$ \\
\hline \begin{tabular}{|l} 
pUX-BF13 \\
\end{tabular} & $\begin{array}{l}\text { Helper plasmid encoding Tn7 transposition functions; } \\
\text { R6K-replicon; } \mathrm{Ap}^{r}\end{array}$ & (Bao et al. 1991) \\
\hline
\end{tabular}


117 Table S4: Comparison of genetic constitution in secondary metabolism in

118 selected fluorescent pseudomonads.

\begin{tabular}{|c|c|c|c|c|c|c|}
\hline \multirow{2}{*}{ Function } & \multirow{2}{*}{ Gene } & \multirow{2}{*}{$\begin{array}{l}\text { GenBank- } \\
\text { ID }\end{array}$} & \multirow{2}{*}{$\begin{array}{l}\text { Length } \\
\text { (in kb) }\end{array}$} & \multicolumn{3}{|c|}{$\begin{array}{l}\text { Gene is present in } \\
\text { (in e-value) }\end{array}$} \\
\hline & & & & $\mathrm{P}_{-}$ & phen & $\mathrm{P}_{\bar{P} G}$ \\
\hline $\begin{array}{c}\text { part of } \\
\text { GacA/GacS- } \\
\text { system }\end{array}$ & gac $A$ & 15561521 & 641 & 0 & $2 e^{-104}$ & 0 \\
\hline \multirow{3}{*}{$\begin{array}{c}\text { part of } \\
\text { GacA/GacS- } \\
\text { system }\end{array}$} & gacS1 & 15558590 & 2786 & 0 & 0 & 0 \\
\hline & gacs2 & 15561193 & 1292 & 0 & 0 & 0 \\
\hline & gacs3 & 15562440 & 2717 & 0 & 0 & 0 \\
\hline \multirow{2}{*}{$\begin{array}{c}\text { synthesis of } \\
\mathrm{HCN}\end{array}$} & $h c n A$ & 15560558 & 317 & $4 e^{40}$ & $6 e^{-7}$ & 0 \\
\hline & anr & 15559866 & 735 & $1 \mathrm{e}^{-138}$ & $2 e^{-137}$ & 0 \\
\hline \multirow{4}{*}{$\begin{array}{l}\text { synthesis of } \\
\text { DAPG }\end{array}$} & $p h / G$ & 15563823 & 923 & 1 & 1 & 0 \\
\hline & phIA & AAF20927 & 362 & 1 & 1 & 0 \\
\hline & phll & 15563830 & 932 & $4 e^{-92}$ & 1 & 0 \\
\hline & ph/D/bscA & 15563828 & 1050 & $1 \mathrm{e}^{-177}$ & 1 & 0 \\
\hline \multirow{5}{*}{$\begin{array}{l}\text { synthesis of } \\
\text { pyoluteorin }\end{array}$} & pltA & 15560761 & 1349 & 1 & 1 & 0 \\
\hline & pltD & 15560764 & 1634 & 1 & 1 & 0 \\
\hline & pltM & 15560758 & 1508 & 1 & 1 & 0 \\
\hline & pltP & 15560774 & 605 & 1 & 1 & 0 \\
\hline & pltZ & 15560768 & 635 & 1 & 1 & 0 \\
\hline \multirow{5}{*}{$\begin{array}{c}\text { regulation of } \\
\text { GacA/GacS- } \\
\text { system }\end{array}$} & $r s m A / c s r A 2$ & 15562492 & 189 & $3 e^{-30}$ & $8 e^{-30}$ & 0 \\
\hline & rsmE/csrA1 & 15560057 & 195 & $5 e^{-30}$ & $3 e^{-30}$ & 0 \\
\hline & $r s m X$ & DQ137846 & 119 & 1 & 1 & 0 \\
\hline & $r s m Y$ & AY266632 & 118 & $\begin{array}{c}1,06 \mathrm{e}^{-} \\
40\end{array}$ & $\begin{array}{c}1,04 \mathrm{e}^{-} \\
57\end{array}$ & 0 \\
\hline & $r s m Z$ & AF245440 & 127 & 1 & $\begin{array}{c}1,50 \mathrm{e}^{-} \\
39\end{array}$ & 0 \\
\hline $\begin{array}{c}\text { antibiotic } \\
\text { resistence by } \\
\text { B-lactamase }\end{array}$ & $a m p C$ & 15562029 & 1173 & $1 e^{-129}$ & $3 e^{-13 \theta}$ & 0 \\
\hline $\begin{array}{l}\text { synthesis of } \\
\text { phenazines }\end{array}$ & $\begin{array}{c}\text { phzABCDEFG } \\
\text { phzl, phzR }\end{array}$ & L48616.1 & 8500 & 1 & 0 & 1 \\
\hline
\end{tabular}

119 Occurrence of selected secondary metabolism related genes in three fluorescent 120 pseudomonads, namely P_DAPG ( $P$. protegens $\mathrm{CHA0}), \mathrm{P} \_$phen ( $P$. fluorescens 2-79) 121 and P_rhizo ( $P$. fluorescens DSM8569). Values displayed in e-values; green $\hat{=} \mathrm{e}$ -

122 value $>\mathrm{e}^{-30}$, gene is assumed to be present; yellow $\hat{=} \mathrm{e}$-value $\mathrm{e}^{-30}<\mathrm{x}>1$, gene is 123 probably absent or only partially present; red $\hat{=}$ e-value $=1$, gene is absent. 

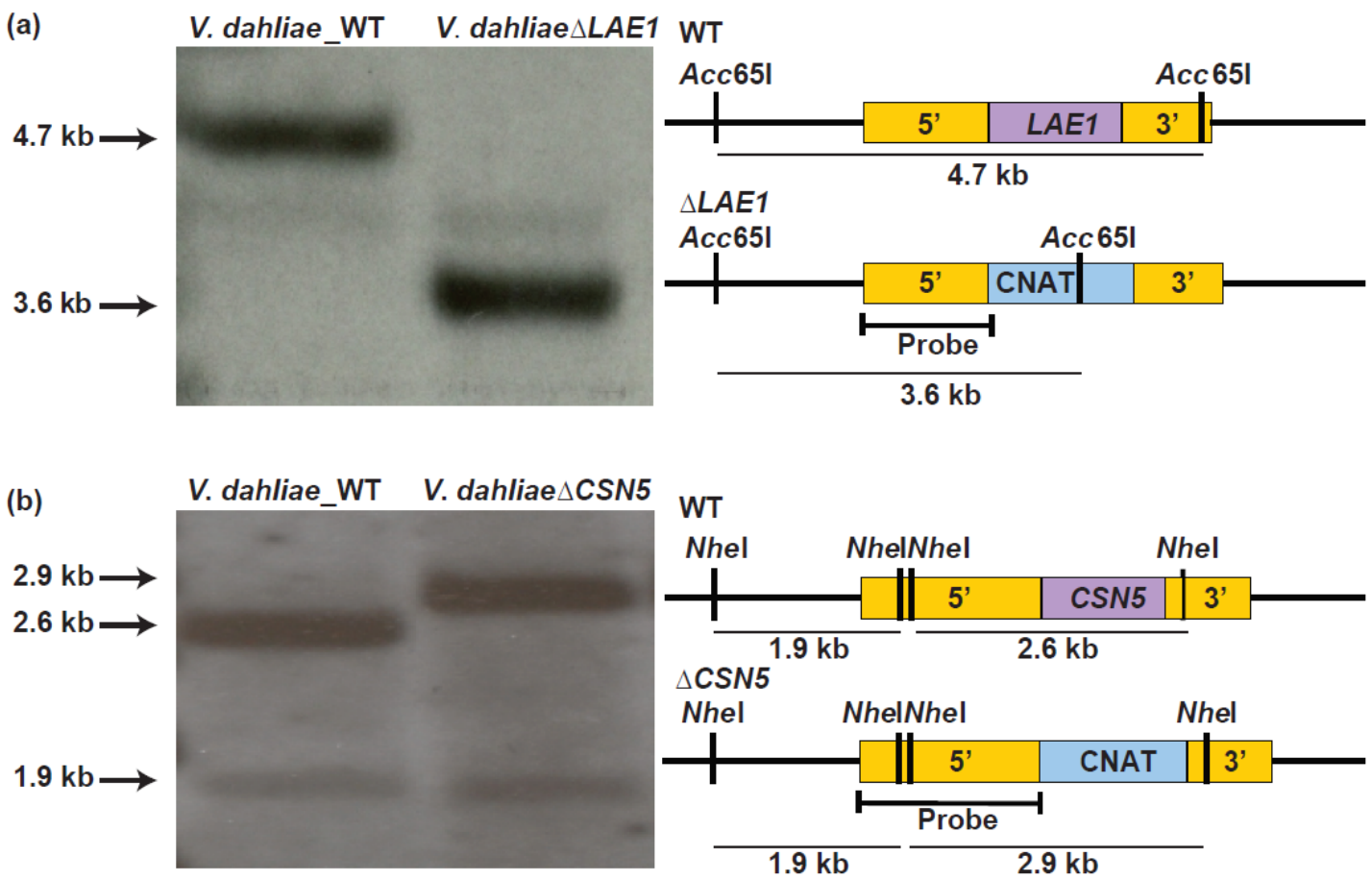

Figure S1 


\title{
Supplementary material for Chapter 5
}

\author{
Sequence ID: Query_55427 Length: 368 Number of Matches: 1 \\ Range 1: 8 to 360 Graphics \\ $\nabla \underline{\text { Next Match }} \Delta$ Previou

\begin{tabular}{|c|c|c|c|c|c|}
\hline Score & Expect & Method & Identities & Positives & Gaps \\
\hline 610 bits(1574) & 0.0 & Compositional matrix adjust. & $303 / 360(84 \%)$ & $326 / 360(90 \%)$ & $7 / 360(1 \%)$ \\
\hline
\end{tabular} \\ Query 1 MPITKYKAAAVTSEPGWFDLEAGVVKTIDFINEAGQAECKLVAFPEVWIPGYPYWMWKVT \\ MPITKYKAAA WFDLEAGV KTI+FINEAGQA CKLVAFPEVWIPGYPYWMWKVT \\ Sbjet 8 MPITKYKAAA------WFDLEAGVQKTINF INEAGQAGCKLVAFPEVWIPGYPYWMWKVT \\ Query 61 YLQSLPMLKKYRENSLTVDSEEMRRIRRAARDNQIYVSLGFSEIDHATLYLAQVLIGPDG \\ sict 62 YLQSLPMLK+YRENSL VDSEEMRRIRRAAR NQ++VS+GFSE+DHATLYLAQVLI P G \\ Query 121 SVVNHRRKIKPTHVEKLVYGDGPGDTFMSVSETDIGRVGQLNCWENMNPFLKALNVSCGE \\ ++ NHRRKIKPTHVEKLVYGDG GDTF SV ET+IGRVGQLNCWENMNPFLKALNVS GE \\ Sbjet 122 AIANHRRKIKPTHVEKLVYGDGAGDTFASVVETEIGRVGQLNCWENMNPFLKALNVSMGE \\ Query 181 QVHIAAWPVYPGRERQVAPDPATNYADPASDLVTPEYAIETGAWTLAPFQRLSVEGLKKN \\ Sbjct 182 QVH+AAWPVYPG+ER+VAPDPATNYADPASDLVTP YA+ETGAW LAPFQRLSVEGL+ $N$ \\ Query 241 TPEGVEPETDPSVYNGHARIYRPDGSLVVKPDKDFDGLLFVDIDLNETHLTKVLADFAGH \\ TPEGVEPETDPSVYNGHARIYRPDGSLVVKP+KDFDGLLFVDIDLNETHLTKVLADFAGH \\ Sbjet 242 TPEGVEPETDPSVYNGHARIYRPDGSLVVKPEKDFDGLLFVDIDLNETHLTKVLADFAGH \\ Query 301 YMRPDLIRLLVDTRRKELITEADPVGTIATYTTRHRLGLDKPLDGEKKEKEATKGRDSEA 360 \\ Sbjet 302 YMRPDLIRLLVDTRRKELVTEAEGQNGIVSYSTAHRLGLDRPLD-SVPERDAKKVGGNEA \\ 60 \\ 61 \\ 120

Figure S2: Multiple sequence alignment of cyanide hydratase enzymes in V. dahliae compared to Fusarium solani. The amino acid sequence of the putative cyanide hydratase in V. dahliae JR2 (VDAG_JR2_Chr3g06110a; subject) was aligned with the sequence of cyanide hydratase in F. solani (Genbank accession-number AJ310936.1; query). Sequence alignment was performed at NCBI Genbank (https://blast.ncbi.nlm.nih.gov/Blast.cgi). 
Table S5 List of up-regulated Verticillium genes after $120 \mathrm{~min}$ of Pseudomonas co-cultivation. The reads of $V$. longisporum VI43 have been mapped to the $V$. dahliae genome of JR2. Most up-regulated Verticillium genes with $\log _{2}$ Fold_Change $>4$ and padj $<0,01$ have been chosen for further analysis. Genes were automatically annotated and manually curated regarding conserved domains. Predicted gene functionality was assigned to functional categories manually. The e-value describes the similarity of the respective $V$. dahliae amino acid sequence to the domain sequence in the SMART database. The complete transcriptomic dataset is deposited at NCBI under the accessionnumber SRP068348; http://www.ncbi.nlm.nih.gov/sra/?term=SRP068348. GeneIDs refer to genome assembly of $V$. dahliae JR2 (VDAG_JR2v.4.0; de Jonge et al., 2012) deposited at www.fungi.ensembl.org/Verticillium dahliaejr2/Info/Index (Howe et al., 2019).

*Possible predicted function according to domain description at www.smart.emblheidelberg.de (Letunic et al. 2015 and 2018)

\begin{tabular}{|c|c|c|c|c|c|c|}
\hline ID & padj & $\begin{array}{l}\text { Log } \\
2 \mathrm{FC}\end{array}$ & $\begin{array}{l}\text { Dom } \\
\text { ain } \\
\text { name }\end{array}$ & Putative function / description* & $\begin{array}{c}\mathrm{E}- \\
\text { value }\end{array}$ & $\begin{array}{l}\text { Sourc } \\
\text { e } \\
\text { datab } \\
\text { ase }\end{array}$ \\
\hline \multicolumn{7}{|c|}{ Amino acid metabolism } \\
\hline $\begin{array}{l}\text { VDAG_JR2 } \\
\text { Chr4g10630a } \\
-00001\end{array}$ & $\begin{array}{r}2,56 \mathrm{E}- \\
011\end{array}$ & 5,56 & $\begin{array}{l}\text { Cycla } \\
\text { se }\end{array}$ & $\begin{array}{l}\text { Kynurenine formamidase; } \\
\text { arylformamidase activity; catalyzes } \\
\text { hydrolysis of N-formyl-L-kynurenine to } \\
\text { L-kynurenine, second step in } \\
\text { kynurenine pathway of tryptophan } \\
\text { degradation }\end{array}$ & $\begin{array}{r}3,10 \mathrm{E} \\
-011\end{array}$ & Pfam \\
\hline $\begin{array}{l}\text { VDAG_JR2 } \\
\text { Chr4g00950a } \\
-00001\end{array}$ & $\begin{array}{r}1,24 \mathrm{E}- \\
006\end{array}$ & 4,94 & TauD & $\begin{array}{l}\text { TauD/TfdA taurine catabolism } \\
\text { dioxygenases; in Escherichia coli } \\
\text { required for utilization of taurine ( } 2- \\
\text { aminoethanesulphonic acid) as sulphur } \\
\text { source and expressed only under } \\
\text { conditions of sulphate starvation }\end{array}$ & $\begin{array}{r}3,70 \mathrm{E} \\
-036\end{array}$ & Pfam \\
\hline $\begin{array}{l}\text { VDAG_JR2 } \\
\text { Chr1g23480a } \\
-00001\end{array}$ & $\begin{array}{r}1,79 \mathrm{E}- \\
115\end{array}$ & 4,25 & $\begin{array}{l}\text { GATa } \\
\text { se }\end{array}$ & $\begin{array}{l}\text { Glutamine amidotransferase; catalyses } \\
\text { removal of ammonia group from } \\
\text { glutamine and transfers it to a substrate } \\
\text { to form new carbon-nitrogen group }\end{array}$ & $\begin{array}{r}2,90 \mathrm{E} \\
-015\end{array}$ & $\begin{array}{l}\text { Pfam/ } \\
\text { UniPr } \\
\text { ot/Inte } \\
\text { rpro }\end{array}$ \\
\hline $\begin{array}{l}\text { VDAG_JR2 } \\
\text { Chr3g00260a } \\
-00001\end{array}$ & $\begin{array}{r}1,99 \mathrm{E}- \\
108\end{array}$ & 4,13 & $\begin{array}{l}\text { YbjQ } \\
-1\end{array}$ & $\begin{array}{l}\text { Putative heavy-metal-binding; similarity } \\
\text { to Selenium binding }\end{array}$ & $\begin{array}{r}7,20 \mathrm{E} \\
-032\end{array}$ & $\begin{array}{l}\text { Pfam/ } \\
\text { UniPr } \\
\text { ot/Inte } \\
\text { rpro }\end{array}$ \\
\hline \multicolumn{7}{|c|}{ Carbon metabolism } \\
\hline $\begin{array}{l}\text { VDAG_JR2_ } \\
\text { Chr5g04460a } \\
-00001\end{array}$ & $\begin{array}{r}0,00 \mathrm{E} \\
+000\end{array}$ & 6,23 & $\begin{array}{l}\text { Cupin } \\
-1\end{array}$ & $\begin{array}{l}\text { Oxalate decarboxylase; involved in } \\
\text { glyoxylate and dicarboxylate } \\
\text { metabolism }\end{array}$ & $\begin{array}{r}2,80 \mathrm{E} \\
-028\end{array}$ & Pfam \\
\hline $\begin{array}{l}\text { VDAG_JR2 } \\
\text { Chr7g02830a } \\
-00001\end{array}$ & $\begin{array}{r}1,40 \mathrm{E}- \\
030\end{array}$ & 5,50 & $\begin{array}{l}\text { Epim } \\
\text { erase }\end{array}$ & $\begin{array}{l}\text { Utilizes NAD as a cofactor and uses } \\
\text { nucleotide-sugar substrates for a variety } \\
\text { of chemical reactions; coenzyme } \\
\text { binding; catalytic activity; e.g. }\end{array}$ & $\begin{array}{r}4,00 \mathrm{E} \\
-007\end{array}$ & $\begin{array}{l}\text { Pfam/ } \\
\text { UniPr } \\
\text { ot }\end{array}$ \\
\hline
\end{tabular}




\begin{tabular}{|c|c|c|c|c|c|c|}
\hline & & & & $\begin{array}{l}\text { conversion of UDP-galactose to UDP- } \\
\text { glucose during galactose metabolism }\end{array}$ & & \\
\hline $\begin{array}{l}\text { VDAG_JR2 } \\
\text { Chr2g00240a } \\
-00001\end{array}$ & $\begin{array}{r}1,70 \mathrm{E}- \\
115\end{array}$ & 5,28 & $\begin{array}{l}\text { Glyco } \\
\text { hydr } \\
\text { o_24 }\end{array}$ & $\begin{array}{l}\text { Glycoside hydrolase of family 24: } \\
\text { hydrolyzes glycosidic bonds }\end{array}$ & $\begin{array}{r}1,10 \mathrm{E} \\
-016\end{array}$ & $\begin{array}{l}\text { Pfam/ } \\
\text { UniPr } \\
\text { ot }\end{array}$ \\
\hline $\begin{array}{l}\text { VDAG_JR2 } \\
\text { Chr3g12620a } \\
-00001\end{array}$ & $\begin{array}{r}1,44 \mathrm{E}- \\
005\end{array}$ & 4,92 & $\begin{array}{l}\mathrm{ADH}_{-} \\
\text {zinc_- } \\
\mathrm{N}\end{array}$ & Zinc-containing alcohol dehydrogenase & $\begin{array}{r}2,80 \mathrm{E} \\
-010\end{array}$ & $\begin{array}{l}\text { Pfam/ } \\
\text { UniPr } \\
\text { ot }\end{array}$ \\
\hline $\begin{array}{l}\text { VDAG_JR2 } \\
\text { Chr2g07170a } \\
-00001\end{array}$ & $\begin{array}{r}4,85 \mathrm{E}- \\
156\end{array}$ & 4,41 & $\begin{array}{l}\text { Lacta } \\
\text { mase } \\
\text { B }\end{array}$ & $\begin{array}{l}\text { Beta-lactamase; catalyzes S-D-lactoyl- } \\
\text { glutathione to glutathione and D-lactic } \\
\text { acid; Pyruvate metabolism; possibly } \\
\text { also transporter for DNA-uptake }\end{array}$ & $\begin{array}{r}2,87 \mathrm{E} \\
-020\end{array}$ & $\begin{array}{l}\text { Pfam/ } \\
\text { Interp } \\
\text { ro }\end{array}$ \\
\hline $\begin{array}{l}\text { VDAG_JR2 } \\
\text { Chr2g01440a } \\
-00001\end{array}$ & $\begin{array}{r}4,78 \mathrm{E}- \\
251\end{array}$ & 4,37 & $\begin{array}{l}\text { TPP- } \\
\text { enzy } \\
\text { me }\end{array}$ & $\begin{array}{l}\text { Thiamine pyrophosphate (vitamin B1); } \\
\text { cofactor; involved in many aldehyd- } \\
\text { transfer reactions; prosthetic group of } \\
\text { e.g. transketolase in pentosephosphat } \\
\text { pathway, pyruvate dehydrogenase, - } \\
\text { oxidase, - decarboxylase }\end{array}$ & $\begin{array}{r}7,30 \mathrm{E} \\
-036\end{array}$ & $\begin{array}{l}\text { Pfam/ } \\
\text { Interp } \\
\text { ro }\end{array}$ \\
\hline $\begin{array}{l}\text { VDAG_JR2 } \\
\text { Chr4g10640a } \\
-00001\end{array}$ & $\begin{array}{r}1,58 \mathrm{E}- \\
229\end{array}$ & 4,31 & $\begin{array}{l}\text { Alded } \\
\mathrm{h}\end{array}$ & $\begin{array}{l}\text { Aldehyde dehydrogenase; catalyzes } \\
\text { reaction of aldehydes to carboxylic } \\
\text { acids and reverse (redox) }\end{array}$ & $\begin{array}{r}2,20 \mathrm{E} \\
-078\end{array}$ & $\begin{array}{l}\text { Pfam/ } \\
\text { Interp } \\
\text { ro }\end{array}$ \\
\hline $\begin{array}{l}\text { VDAG_JR2 } \\
\text { Chr1g29310a } \\
-00001\end{array}$ & $\begin{array}{r}1,09 \mathrm{E}- \\
126\end{array}$ & 4,27 & $\mathrm{ADH}_{-}$ & $\begin{array}{l}\text { Alcohol dehydrogenase GroES-like } \\
\text { domain; catalyzes reaction alcohols to } \\
\text { aldehydes and reverse (redox) }\end{array}$ & $\begin{array}{r}2,10 \mathrm{E} \\
-006\end{array}$ & $\begin{array}{l}\text { Pfam/ } \\
\text { UniPr } \\
\text { ot }\end{array}$ \\
\hline $\begin{array}{l}\text { VDAG_JR2 } \\
\text { Chr4g12020a } \\
-00001\end{array}$ & $\begin{array}{r}3,44 \mathrm{E}- \\
020\end{array}$ & 4,23 & $\begin{array}{l}\mathrm{ADH}_{-} \\
\mathrm{N}\end{array}$ & $\begin{array}{l}\text { Alcohol dehydrogenase GroES-like } \\
\text { domain; catalyzes reaction alcohols to } \\
\text { aldehydes and reverse (redox) }\end{array}$ & $\begin{array}{r}2,10 \mathrm{E} \\
-006\end{array}$ & $\begin{array}{l}\text { Pfam/ } \\
\text { UniPr } \\
\text { ot } \\
\end{array}$ \\
\hline \multicolumn{7}{|c|}{ Degradation of plant polysaccharides } \\
\hline $\begin{array}{l}\text { VDAG_JR2 } \\
\text { Chr1g00390a } \\
-00001\end{array}$ & $\begin{array}{r}4,81 \mathrm{E}- \\
226\end{array}$ & 5,36 & $\begin{array}{l}\text { Cu- } \\
\text { oxida } \\
\text { se }\end{array}$ & $\begin{array}{l}\text { Multi-copper oxidase; copper-containing } \\
\text { oxidase enzymes; acts on phenols and } \\
\text { similar substrates, performing one- } \\
\text { electron oxidations, leading to } \\
\text { crosslinking; in fungi laccase / Urishiol } \\
\text { oxidase; in Pleurotus ostreatus, involved } \\
\text { in degradation of lignin }\end{array}$ & $\begin{array}{r}2,50 \mathrm{E} \\
-040\end{array}$ & Pfam \\
\hline $\begin{array}{l}\text { VDAG_JR2 } \\
\text { Chr2g04470a } \\
-00001\end{array}$ & $\begin{array}{r}8,06 \mathrm{E}- \\
018\end{array}$ & 4,44 & $\begin{array}{l}\text { Glyco } \\
\text { hydr } \\
\text { o_7 }\end{array}$ & $\begin{array}{l}\text { Exoglucanases and cellobiohydrolases: } \\
\text { conversion of cellulose to glucose }\end{array}$ & $\begin{array}{r}1,40 \mathrm{E} \\
-182\end{array}$ & $\begin{array}{l}\text { Pfam/ } \\
\text { Interp } \\
\text { ro }\end{array}$ \\
\hline \multicolumn{7}{|l|}{ Detoxification } \\
\hline $\begin{array}{l}\text { VDAG_JR2 } \\
\text { Chr7g05440a } \\
-00001\end{array}$ & $\begin{aligned} 1,37 \mathrm{E}- \\
288\end{aligned}$ & 6,64 & $\begin{array}{l}\text { RPE6 } \\
5\end{array}$ & $\begin{array}{l}\text { Oxidoreductase activity, acting on single } \\
\text { donors with incorporation of molecular } \\
\text { oxygen, incorporation of two atoms of } \\
\text { oxygen; in plants scavengers of oxygen } \\
\text { radicals (in vertebrates retinal pigment } \\
\text { epithelium } 65 \mathrm{kDa} \text { protein (RPE65)) }\end{array}$ & $\begin{array}{r}3,20 \mathrm{E} \\
-102\end{array}$ & Pfam \\
\hline $\begin{array}{l}\text { VDAG_JR2_- } \\
\text { Chr3g06110a } \\
-00001\end{array}$ & $\begin{array}{r}2,18 \mathrm{E}- \\
250\end{array}$ & 6,22 & \begin{tabular}{|l|} 
CN_h \\
ydrol \\
ase \\
\end{tabular} & $\begin{array}{l}\text { Cyanide hydratase (EC 4.2.1.66) of } \\
\text { pathogenic fungi, which detoxifies HCN }\end{array}$ & $\begin{array}{r}7.4 \mathrm{e}- \\
42\end{array}$ & Pfam \\
\hline $\begin{array}{l}\text { VDAG_JR2 } \\
\text { Chr1g24680a } \\
-00001\end{array}$ & $\begin{array}{r}1,10 \mathrm{E}- \\
171\end{array}$ & 5,77 & GFA & $\begin{array}{l}\text { Glutathione-dependent formaldehyde- } \\
\text { activating enzyme (GFA); carbon-sulfur } \\
\text { lyase activity; catalyzes the first step in } \\
\text { detoxification of formaldehyde }\end{array}$ & $\begin{array}{r}1,10 \mathrm{E} \\
-010\end{array}$ & $\begin{array}{l}\text { Pfam/ } \\
\text { UniPr } \\
\text { ot }\end{array}$ \\
\hline
\end{tabular}




\begin{tabular}{|c|c|c|c|c|c|c|}
\hline $\begin{array}{l}\text { VDAG_JR2 } \\
\text { Chr5g10540a } \\
-00001\end{array}$ & \begin{tabular}{r|}
$4,36 \mathrm{E}-$ \\
008
\end{tabular} & 5,00 & $\begin{array}{l}\text { Pyr_r } \\
\text { edox } \\
2\end{array}$ & $\begin{array}{l}\text { Pyridine nucleotide-disulfide } \\
\text { oxidoreductases (Pyr_redox_2); NAD } \\
\text { binding domain within a larger FAD } \\
\text { binding domain; e.g. glutathione } \\
\text { reductase (reduction of glutathione } \\
\text { disulfide to glutathione - ROS-defense), } \\
\text { thioredoxin reductase (reduction of } \\
\text { thioredoxin- ROS control), mercuric } \\
\text { reductase (reduction of Hg2+ to Hg0 - } \\
\text { converts toxic mercury ions into } \\
\text { relatively inert elemental mercury) }\end{array}$ & $\begin{array}{r}7,40 \mathrm{E} \\
-008\end{array}$ & Pfam \\
\hline $\begin{array}{l}\text { VDAG_JR2 } \\
\text { Chr3g09580a } \\
-00001\end{array}$ & $\begin{array}{r}2,62 \mathrm{E}- \\
175\end{array}$ & 4,88 & $\begin{array}{l}\text { DSB } \\
\text { A }\end{array}$ & $\begin{array}{l}\text { Key component (A) of the Dsb (disulfide } \\
\text { bond) family of enzymes; is a bacterial } \\
\text { thiol disulfide oxidoreductase; catalyzes } \\
\text { intrachain disulfide bond formation as } \\
\text { peptides emerge into the cell's } \\
\text { periplasm; sub-family of the Thioredoxin } \\
\text { family; catalyzes oxidation of a pair of } \\
\text { cysteine residues on normally secreted } \\
\text { substrate proteins including important } \\
\text { toxins, virulence factors, adhesion } \\
\text { machinery, and motility structures }\end{array}$ & $\begin{array}{r}4,60 \mathrm{E} \\
-016\end{array}$ & $\begin{array}{l}\text { Pfam/ } \\
\text { UniPr } \\
\text { ot }\end{array}$ \\
\hline $\begin{array}{l}\text { VDAG_JR2 } \\
\text { Chr4g00930a } \\
-00001\end{array}$ & \begin{tabular}{r|}
$1,05 \mathrm{E}-$ \\
011
\end{tabular} & 4,59 & $\begin{array}{l}\text { GST_- } \\
\text { N_3 }\end{array}$ & $\begin{array}{l}\text { Glutathione S-transferase: catalylzes } \\
\text { conjugation of glutathione to xenobiotic } \\
\text { substrates for detoxification }\end{array}$ & $\begin{array}{r}8,60 \mathrm{E} \\
-011\end{array}$ & $\begin{array}{l}\text { Pfam/ } \\
\text { UniPr } \\
\text { ot }\end{array}$ \\
\hline \multicolumn{7}{|c|}{ Chromosomal organization / DNA repair } \\
\hline $\begin{array}{l}\text { VDAG_JR2_- } \\
\text { Chr2g06150a } \\
-00001\end{array}$ & $\begin{array}{r}5,92 \mathrm{E}- \\
167\end{array}$ & 4,37 & $\begin{array}{l}\text { SMC } \\
{ }_{1} \text { Nse }\end{array}$ & $\begin{array}{l}\text { Non-structural maintenance of } \\
\text { chromosomes (SMC); essential role in } \\
\text { genomic stability; involved in DNA repair } \\
\text { and DNA metabolism }\end{array}$ & $\begin{array}{r}3,40 \mathrm{E} \\
-072\end{array}$ & $\begin{array}{l}\text { Pfam/ } \\
\text { Interp } \\
\text { ro }\end{array}$ \\
\hline \multicolumn{7}{|l|}{ Energy } \\
\hline $\begin{array}{l}\text { VDAG_JR2 } \\
\text { Chr5g03930a } \\
-00001\end{array}$ & \begin{tabular}{|r|}
$1,02 \mathrm{E}-$ \\
126
\end{tabular} & 5,22 & $\begin{array}{l}\text { Oxido } \\
\text { red_F } \\
\text { MN }\end{array}$ & $\begin{array}{l}\text { NADH:flavin oxidoreductase / NADH } \\
\text { oxidase; uses FMN/FAD as cofactor; } \\
\text { catalytic activity, oxidoreductase activity }\end{array}$ & $\begin{array}{r}1,60 \mathrm{E} \\
-090\end{array}$ & Pfam \\
\hline $\begin{array}{l}\text { VDAG_JR2 } \\
\text { Chr8g07330a } \\
-00001\end{array}$ & $\begin{array}{r}5,95 \mathrm{E}- \\
254\end{array}$ & 5,15 & AOX & $\begin{array}{l}\text { Alternative oxidase (AOX); part of } \\
\text { mitochondrial electron transport chain }\end{array}$ & $\begin{array}{r}1,60 \mathrm{E} \\
-093\end{array}$ & Pfam \\
\hline $\begin{array}{l}\text { VDAG_JR2 } \\
\text { Chr6g10000a } \\
-00001\end{array}$ & $\begin{array}{r}2,20 \mathrm{E}- \\
035\end{array}$ & 4,97 & $\begin{array}{l}\text { NAD( } \\
\text { P)- } \\
\text { bindin } \\
\mathrm{g} \\
\text { Ross } \\
\text { mann } \\
\text {-fold }\end{array}$ & $\begin{array}{l}\text { Structural motif in proteins that bind } \\
\text { nucleotides, such as enzyme cofactors } \\
\text { FAD, NAD+, and NADP+ }\end{array}$ & $\begin{array}{r}8,80 \mathrm{E} \\
-013\end{array}$ & $\begin{array}{l}\text { Pfam/ } \\
\text { Super } \\
\text { family }\end{array}$ \\
\hline $\begin{array}{l}\text { VDAG_JR2 } \\
\text { Chr2g01950a } \\
-00001\end{array}$ & $\begin{array}{r}2,58 \mathrm{E}- \\
064\end{array}$ & 4,61 & Ytp1 & $\begin{array}{l}\text { Putative mitochondrial electron transport } \\
\text { protein }\end{array}$ & $\begin{array}{r}, 70 \mathrm{E} \\
-114\end{array}$ & $\begin{array}{l}\text { Pfam/ } \\
\text { UniPr } \\
\text { ot }\end{array}$ \\
\hline $\begin{array}{l}\text { VDAG_JR2 } \\
\text { Chr4g10710a } \\
-00001\end{array}$ & $\begin{array}{r}6,47 \mathrm{E}- \\
013\end{array}$ & 4,43 & $\begin{array}{l}\text { Acyl- } \\
\text { CoA } \\
\text { dh }\end{array}$ & $\begin{array}{l}\text { Acyl-CoA dehydrogenase; catalyzes } \\
\text { initial step in each cycle of fatty acid } \beta \text { - } \\
\text { oxidation; flavoprotein, mitochondrial }\end{array}$ & $\begin{array}{r}9,00 \mathrm{E} \\
-019\end{array}$ & $\begin{array}{l}\text { Pfam/ } \\
\text { Interp } \\
\text { ro }\end{array}$ \\
\hline $\begin{array}{l}\text { VDAG_JR2 } \\
\text { Chr1g22790a } \\
-00001\end{array}$ & $\begin{array}{r}6,03 E- \\
049\end{array}$ & 4,32 & $\begin{array}{l}F A D \\
\text { bindin } \\
g \_6\end{array}$ & $\begin{array}{l}\text { Oxidodrductase FAD-/NAD-binding } \\
\text { domain; involved in mitochondrial }\end{array}$ & $\begin{array}{l}3,0 \\
\text { and } 8,\end{array}$ & $\begin{array}{l}0 \mathrm{E}-015 \\
2 \mathrm{E}-020\end{array}$ \\
\hline
\end{tabular}




\begin{tabular}{|c|c|c|c|c|c|c|}
\hline & & & $\begin{array}{l}\text { and } \\
\text { NAD_- } \\
\text { bindin } \\
\text { g_1 }\end{array}$ & $\begin{array}{l}\text { electron chain e.g. in NADH-cytochrome } \\
\text { b5 reductase }\end{array}$ & & \\
\hline \multicolumn{7}{|c|}{ Protein - metabolism/biosynthesis/regulation } \\
\hline $\begin{array}{l}\text { VDAG_JR2_- } \\
\text { Chr4g08470a } \\
-00001\end{array}$ & $\begin{array}{r}5,74 \mathrm{E}- \\
004\end{array}$ & 5,37 & $\begin{array}{l}\mathrm{ZnF} \\
\mathrm{C} 2 \mathrm{H} 2\end{array}$ & Zink finger nucleic acid binding & $\begin{array}{r}8,81 \mathrm{E} \\
-002\end{array}$ & Pfam \\
\hline $\begin{array}{l}\text { VDAG_JR2 } \\
\text { Chr2g01450a } \\
-00001\end{array}$ & $\begin{array}{r}1,29 \mathrm{E}- \\
077\end{array}$ & 4,15 & $\begin{array}{l}\text { THU } \\
\text { MP }\end{array}$ & $\begin{array}{l}\text { Named after thiouridine synthases, RNA } \\
\text { methylases and pseudouridine } \\
\text { synthases (THUMP); involved in RNA } \\
\text { modification }\end{array}$ & $\begin{array}{r}3,40 \mathrm{E} \\
-003\end{array}$ & $\begin{array}{l}\text { Pfam/ } \\
\text { UniPr } \\
\text { ot/Inte } \\
\text { rpro }\end{array}$ \\
\hline $\begin{array}{l}\text { VDAG_JR2 } \\
\text { Chr4g05910a } \\
-00001\end{array}$ & $\begin{array}{r}3,68 \mathrm{E}- \\
059\end{array}$ & 4,09 & RPT1 & $\begin{array}{l}\text { Proteasome-activating ATPase activity; } \\
\text { ATP binding; protein catabolic process }\end{array}$ & $\begin{array}{r}1,97 \mathrm{E} \\
-067\end{array}$ & $\begin{array}{l}\text { Pfam/ } \\
\text { UniPr } \\
\text { ot }\end{array}$ \\
\hline $\begin{array}{l}\text { VDAG_JR2 } \\
\text { Chr2g04990a } \\
-00001\end{array}$ & $\begin{array}{r}6,20 \mathrm{E}- \\
080\end{array}$ & 4,02 & $\begin{array}{l}\text { TRN } \\
\text { A- } \\
\text { synt } \\
2 \\
\end{array}$ & $\begin{array}{l}\text { Aminoacyl-tRNA synthetase; catalyzes } \\
\text { attachment of amino acid to its cognate } \\
\text { transfer RNA molecule for protein } \\
\text { translation }\end{array}$ & $\begin{array}{r}7,70 \mathrm{E} \\
-040\end{array}$ & $\begin{array}{l}\text { Pfam/ } \\
\text { Interp } \\
\text { ro }\end{array}$ \\
\hline \multicolumn{7}{|l|}{ Transport } \\
\hline $\begin{array}{l}\text { VDAG_JR2_- } \\
\text { Chr4g00860a } \\
-00001\end{array}$ & $\begin{array}{r}5,72 \mathrm{E}- \\
243\end{array}$ & 5,29 & \begin{tabular}{|l} 
ABC2 \\
- \\
mem \\
brane
\end{tabular} & $\begin{array}{l}\text { ATP-Binding Cassette (ABC) } \\
\text { superfamily; uses hydrolysis of ATP to } \\
\text { translocate a variety of compounds } \\
\text { across biological membranes }\end{array}$ & $\begin{array}{r}1,20 \mathrm{E} \\
-030\end{array}$ & Pfam \\
\hline $\begin{array}{l}\text { VDAG_JR2 } \\
\text { Chr3g13170a } \\
-00001\end{array}$ & $\begin{array}{r}3,62 \mathrm{E}- \\
040\end{array}$ & 5,14 & $\begin{array}{l}\text { Sugar } \\
\text { tr }\end{array}$ & $\begin{array}{l}\text { Transmembrane transport of sugar and } \\
\text { other molecules; major facilitator } \\
\text { superfamily MFS }\end{array}$ & $\begin{array}{r}1,40 \mathrm{E} \\
-052\end{array}$ & Pfam \\
\hline $\begin{array}{l}\text { VDAG_JR2 } \\
\text { Chr1g28420a } \\
-00001\end{array}$ & $\begin{array}{r}1,75 \mathrm{E}- \\
256\end{array}$ & 5,04 & $\begin{array}{l}\text { MFS } \\
1\end{array}$ & $\begin{array}{l}\text { Major Facilitator Superfamily (MFS); } \\
\text { single-polypeptide secondary carriers } \\
\text { transporting small solutes in response to } \\
\text { chemiosmotic ion gradients }\end{array}$ & $\begin{array}{r}9,40 \mathrm{E} \\
-042\end{array}$ & $\begin{array}{l}\text { Pfam/ } \\
\text { UniPr } \\
\text { ot }\end{array}$ \\
\hline $\begin{array}{l}\text { VDAG_JR2_- } \\
\text { Chr1g00400a } \\
-00001\end{array}$ & $\begin{array}{r}1,17 \mathrm{E}- \\
087\end{array}$ & 4,42 & FTR1 & $\begin{array}{l}\text { Iron ion transmembrane transporter } \\
\text { activity; permease }\end{array}$ & $\begin{array}{r}1,60 \mathrm{E} \\
-063\end{array}$ & $\begin{array}{l}\text { Pfam/ } \\
\text { Interp } \\
\text { ro }\end{array}$ \\
\hline $\begin{array}{l}\text { VDAG_JR2 } \\
\text { Chr4g09800a } \\
-00001\end{array}$ & $\begin{array}{r}7,89 \mathrm{E}- \\
169\end{array}$ & 4,18 & $\begin{array}{l}\text { MFS } \\
1\end{array}$ & $\begin{array}{l}\text { Major Facilitator Superfamily (MFS), } \\
\text { single-polypeptide secondary carriers } \\
\text { transporting small solutes in response to } \\
\text { chemiosmotic ion gradients }\end{array}$ & $\begin{array}{r}1,40 \mathrm{E} \\
-022\end{array}$ & $\begin{array}{l}\text { Pfam/ } \\
\text { UniPr } \\
\text { ot/Inte } \\
\text { rpro }\end{array}$ \\
\hline $\begin{array}{l}\text { VDAG_JR2 } \\
\text { Chr1g22630a } \\
-00001\end{array}$ & $\begin{array}{r}3,36 \mathrm{E}- \\
164\end{array}$ & 4,15 & $\begin{array}{l}\text { MFS } \\
1\end{array}$ & $\begin{array}{l}\text { Major Facilitator Superfamily (MFS), } \\
\text { single-polypeptide secondary carriers } \\
\text { transporting small solutes in response to } \\
\text { chemiosmotic ion gradients }\end{array}$ & $\begin{array}{r}7,20 \mathrm{E} \\
-009\end{array}$ & $\begin{array}{l}\text { Pfam/ } \\
\text { UniPr } \\
\text { ot/Inte } \\
\text { rpro }\end{array}$ \\
\hline $\begin{array}{l}\text { VDAG_JR2 } \\
\text { Chr3g11870a } \\
-00001\end{array}$ & $\begin{array}{r}1,41 \mathrm{E}- \\
117\end{array}$ & 4,13 & $\begin{array}{l}\text { Sugar } \\
\text { tr }\end{array}$ & $\begin{array}{l}\text { Transmembrane transport of sugar and } \\
\text { other molecules; major facilitator } \\
\text { superfamily MFS }\end{array}$ & $\begin{array}{r}2,20 E \\
-132\end{array}$ & $\begin{array}{l}\text { Pfam/ } \\
\text { UniPr } \\
\text { ot/Inte } \\
\text { rpro }\end{array}$ \\
\hline $\begin{array}{l}\text { VDAG_JR2 } \\
\text { Chr4g08540a } \\
-00001\end{array}$ & $\begin{array}{r}6,62 \mathrm{E}- \\
085\end{array}$ & 4,02 & $\begin{array}{l}\text { Sulf_t } \\
\text { ransp }\end{array}$ & $\begin{array}{l}\text { Transport of sulphur-containing } \\
\text { molecules; integral membrane protein }\end{array}$ & $\begin{array}{r}1,20 \mathrm{E} \\
-035\end{array}$ & $\begin{array}{l}\text { Pfam/ } \\
\text { UniPr } \\
\text { ot }\end{array}$ \\
\hline \multicolumn{7}{|l|}{ Others } \\
\hline
\end{tabular}




\begin{tabular}{|c|c|c|c|c|c|c|}
\hline $\begin{array}{l}\text { VDAG_JR2 } \\
\text { Chr4g10650a } \\
-00001\end{array}$ & \begin{tabular}{|r|}
$6,17 \mathrm{E}-$ \\
003
\end{tabular} & 6,01 & $\begin{array}{l}\text { Abhy } \\
\text { drola } \\
\text { se_5 }\end{array}$ & $\begin{array}{l}\text { Alpha/beta hydrolase; superfamily of } \\
\text { hydrolytic enzymes of widely differing } \\
\text { phylogenetic origin; included in } \\
\text { proteases, lipases, peroxidases, } \\
\text { esterases, epoxide hydrolases and } \\
\text { dehalogenases }\end{array}$ & $\begin{array}{r}2,20 \mathrm{E} \\
-008\end{array}$ & $\begin{array}{l}\text { Pfam/ } \\
\text { UniPr } \\
\text { ot }\end{array}$ \\
\hline $\begin{array}{l}\text { VDAG_JR2 } \\
\text { Chr5g10380a } \\
-00001\end{array}$ & \begin{tabular}{|r|}
$2,27 \mathrm{E}-$ \\
003
\end{tabular} & 5,93 & GAL4 & $\begin{array}{l}\text { Gal4; positive regulator for gene } \\
\text { expression of galactose-induced genes } \\
\text { of S. Cerevisiae; only in fungi. }\end{array}$ & $\begin{array}{r}2,35 \mathrm{E} \\
-007\end{array}$ & $\begin{array}{l}\text { UniPr } \\
\text { ot }\end{array}$ \\
\hline $\begin{array}{l}\text { VDAG_JR2 } \\
\text { Chr6g05240a } \\
-00001\end{array}$ & \begin{tabular}{|r|}
$2,21 \mathrm{E}-$ \\
003
\end{tabular} & 4,67 & $\begin{array}{l}\text { Adhy } \\
\text { drola } \\
\text { se_5 }\end{array}$ & $\begin{array}{l}\text { Alpha/beta hydrolase; superfamily of } \\
\text { hydrolytic enzymes of widely differing } \\
\text { phylogenetic origin; included in } \\
\text { proteases, lipases, peroxidases, } \\
\text { esterases, epoxide hydrolases and } \\
\text { dehalogenases }\end{array}$ & $\begin{array}{r}2,00 \mathrm{E} \\
-054\end{array}$ & $\begin{array}{l}\text { Pfam/ } \\
\text { UniPr } \\
\text { ot }\end{array}$ \\
\hline $\begin{array}{l}\text { VDAG_JR2 } \\
\text { Chr8g10540a } \\
-00001\end{array}$ & $\begin{array}{r}2,65 \mathrm{E}- \\
064\end{array}$ & 4,23 & KR & $\begin{array}{l}\text { Polyketide synthase ketoreductase; } \\
\text { catalyzes first step in reductive } \\
\text { modification of the beta-carbonyl } \\
\text { centres in growing polyketide chain }\end{array}$ & $\begin{array}{r}5,30 \mathrm{E} \\
-009\end{array}$ & $\begin{array}{l}\text { Pfam/ } \\
\text { UniPr } \\
\text { ot/Inte } \\
\text { rpro }\end{array}$ \\
\hline $\begin{array}{l}\text { VDAG_JR2 } \\
\text { Chr8g01720a } \\
-00001\end{array}$ & \begin{tabular}{|r|}
$1,92 \mathrm{E}-$ \\
067
\end{tabular} & 4,02 & $\begin{array}{l}\text { CFE } \\
M\end{array}$ & $\begin{array}{l}\text { Eight cysteine-containing domain } \\
\text { present in fungal extracellular } \\
\text { membrane proteins (for Magnaporthe } \\
\text { grisea described as protein in fungal } \\
\text { pathogenesis) }\end{array}$ & $\begin{array}{r}2,60 \mathrm{E} \\
-004\end{array}$ & $\begin{array}{l}\text { Pfam/ } \\
\text { UniPr } \\
\text { ot }\end{array}$ \\
\hline \multicolumn{7}{|l|}{ Unknown } \\
\hline $\begin{array}{l}\text { VDAG_JR2 } \\
\text { Chr2g10250a } \\
-00001\end{array}$ & \begin{tabular}{|r|}
$3,27 \mathrm{E}-$ \\
007
\end{tabular} & 8,39 & - & Unknown & & - \\
\hline $\begin{array}{l}\text { VDAG_JR2 } \\
\text { Chr2g01460a } \\
-00001\end{array}$ & \begin{tabular}{|r|}
$2,76 \mathrm{E}-$ \\
166
\end{tabular} & 7,24 & - & Unknown & & - \\
\hline $\begin{array}{l}\text { VDAG_JR2 } \\
\text { Chr5g02060a } \\
-00001\end{array}$ & $\begin{array}{r}1,61 \mathrm{E}- \\
003\end{array}$ & 6,58 & - & Unknown & & $\begin{array}{l}\text { UniPr } \\
\text { ot }\end{array}$ \\
\hline $\begin{array}{l}\text { VDAG_JR2 } \\
\text { Chr5g04450a } \\
-00001\end{array}$ & \begin{tabular}{|r|}
$7,55 \mathrm{E}-$ \\
222
\end{tabular} & 6,17 & $\begin{array}{l}\text { DUF1 } \\
275\end{array}$ & Unknown & $\begin{array}{r}4,50 \mathrm{E} \\
-041\end{array}$ & Pfam \\
\hline $\begin{array}{l}\text { VDAG_JR2 } \\
\text { Chr2g00050a } \\
-00001\end{array}$ & \begin{tabular}{|r|}
$2,05 \mathrm{E}-$ \\
003
\end{tabular} & 6,17 & EthD & $\begin{array}{l}\text { Ethyl tert-butyl ether degradation } \\
\text { (EthD); putatively involved in } \\
\text { degradation of ethyl tert-butyl ether } \\
\text { (ETBE); EthD synthesis induced by } \\
\text { ETBE; exact function is unknown }\end{array}$ & $\begin{array}{r}2,30 \mathrm{E} \\
-022\end{array}$ & Pfam \\
\hline $\begin{array}{l}\text { VDAG_JR2_- } \\
\text { Chr1g10360a } \\
-00001\end{array}$ & $\begin{array}{r}5,99 \mathrm{E}- \\
172\end{array}$ & 5,83 & - & Unknown & - & - \\
\hline $\begin{array}{l}\text { VDAG_JR2 } \\
\text { Chr1g11690a } \\
-00001\end{array}$ & $\begin{array}{r}9,70 \mathrm{E}- \\
018\end{array}$ & 5,77 & - & Unknown & - & - \\
\hline $\begin{array}{l}\text { VDAG_JR2 } \\
\text { Chr1g28990a } \\
-00001\end{array}$ & $\begin{array}{r}6,08 \mathrm{E}- \\
003\end{array}$ & 5,51 & - & Unknown & - & - \\
\hline $\begin{array}{l}\text { VDAG_JR2 } \\
\text { Chr4g12370a } \\
-00001\end{array}$ & \begin{tabular}{|r|}
$8,21 \mathrm{E}-$ \\
007
\end{tabular} & 5,30 & - & Unknown & & - \\
\hline
\end{tabular}




\begin{tabular}{|c|c|c|c|c|c|c|}
\hline $\begin{array}{l}\text { VDAG_JR2 } \\
\text { Chr5g01940a } \\
-00001\end{array}$ & \begin{tabular}{r|}
$2,10 \mathrm{E}-$ \\
006
\end{tabular} & 5,27 & - & Unknown & - & - \\
\hline $\begin{array}{l}\text { VDAG_JR2 } \\
\text { Chr2g07850a } \\
-00001\end{array}$ & $\begin{array}{r}4,26 \mathrm{E}- \\
006\end{array}$ & 5,22 & - & Unknown & - & - \\
\hline $\begin{array}{l}\text { VDAG_JR2 } \\
\text { Chr4g07760a } \\
-00001\end{array}$ & $\begin{array}{r}7,77 \mathrm{E}- \\
003\end{array}$ & 5,06 & - & Unknown & - & - \\
\hline $\begin{array}{l}\text { VDAG_JR2 } \\
\text { Chr1g20620a } \\
-00001\end{array}$ & \begin{tabular}{r|}
$2,81 \mathrm{E}-$ \\
181
\end{tabular} & 5,00 & - & Unknown & - & - \\
\hline $\begin{array}{l}\text { VDAG_JR2 } \\
\text { Chr2g10220a } \\
-00001\end{array}$ & $\begin{array}{r}1,91 \mathrm{E}- \\
010\end{array}$ & 4,83 & - & $\begin{array}{l}\text { Uncharacterized protein within V. } \\
\text { dahliae VdLS.17 G2XFL9_VERDV }\end{array}$ & - & $\begin{array}{l}\text { UniPr } \\
\text { ot }\end{array}$ \\
\hline $\begin{array}{l}\text { VDAG_JR2 } \\
\text { Chr2g03260a } \\
-00001\end{array}$ & $\begin{array}{r}8,84 \mathrm{E}- \\
175\end{array}$ & 4,76 & - & Unknown & - & - \\
\hline $\begin{array}{l}\text { VDAG_JR2 } \\
\text { Chr5g10520a } \\
-00001\end{array}$ & $\begin{array}{r}2,05 \mathrm{E}- \\
055\end{array}$ & 4,60 & - & Unknown & - & - \\
\hline $\begin{array}{l}\text { VDAG_JR2 } \\
\text { Chr2g05140a } \\
-00001\end{array}$ & $\begin{array}{r}3,10 \mathrm{E}- \\
003\end{array}$ & 4,58 & - & Unknown & - & - \\
\hline $\begin{array}{l}\text { VDAG_JR2_ } \\
\text { Chr6g04720a } \\
-00001\end{array}$ & $\begin{array}{r}2,02 \mathrm{E}- \\
051\end{array}$ & 4,52 & - & Unknown & - & - \\
\hline $\begin{array}{l}\text { VDAG_JR2 } \\
\text { Chr8g01890a } \\
-00001\end{array}$ & \begin{tabular}{r|}
$4,53 \mathrm{E}-$ \\
044
\end{tabular} & 4,52 & - & $\begin{array}{l}\text { uncharacterized protein within V. } \\
\text { dahliae VdLS.17 G2XFL9_VERDV }\end{array}$ & - & $\begin{array}{l}\text { UniPr } \\
\text { ot }\end{array}$ \\
\hline $\begin{array}{l}\text { VDAG_JR2 } \\
\text { Chr4g11670a } \\
-00001\end{array}$ & $\begin{array}{r}1,30 \mathrm{E}- \\
006\end{array}$ & 4,48 & - & Unknown & - & - \\
\hline $\begin{array}{l}\text { VDAG_JR2 } \\
\text { Chr3g09400a } \\
-00001\end{array}$ & $\begin{array}{r}4,68 \mathrm{E}- \\
009\end{array}$ & 4,46 & - & Unknown & - & - \\
\hline $\begin{array}{l}\text { VDAG_JR2 } \\
\text { Chr1g27610a } \\
-00001\end{array}$ & $\begin{array}{r}1,08 \mathrm{E}- \\
045\end{array}$ & 4,44 & \begin{tabular}{|l} 
DUF4 \\
360
\end{tabular} & Domain of unknown funktion & $\begin{aligned} 3,10 \mathrm{E} \\
-066\end{aligned}$ & $\begin{array}{l}\text { Pfam/ } \\
\text { UniPr } \\
\text { ot/Inte } \\
\text { rpro }\end{array}$ \\
\hline $\begin{array}{l}\text { VDAG_JR2 } \\
\text { Chr1g27430a } \\
-00001\end{array}$ & \begin{tabular}{r|}
$4,63 \mathrm{E}-$ \\
007
\end{tabular} & 4,32 & - & $\begin{array}{l}\text { Uncharacterized protein within V. } \\
\text { dahliae VdLS.17 G2XFL9_VERDV }\end{array}$ & - & $\begin{array}{l}\text { UniPr } \\
\text { ot }\end{array}$ \\
\hline $\begin{array}{l}\text { VDAG_JR2 } \\
\text { Chr1g29320a } \\
-00001\end{array}$ & \begin{tabular}{r|}
$1,81 \mathrm{E}-$ \\
055
\end{tabular} & 4,27 & $\begin{array}{l}\text { DUF3 } \\
533\end{array}$ & Domain of unknown funktion & $\begin{aligned} 1,80 \mathrm{E} \\
-113\end{aligned}$ & $\begin{array}{l}\text { Pfam/ } \\
\text { Interp } \\
\text { ro }\end{array}$ \\
\hline $\begin{array}{l}\text { VDAG_JR2 } \\
\text { Chr6g01730a } \\
-00001\end{array}$ & $\begin{array}{r}8,80 \mathrm{E}- \\
066\end{array}$ & 4,26 & - & Unknown & - & - \\
\hline $\begin{array}{l}\text { VDAG_JR2_ } \\
\text { Chr5g10340a } \\
-00001\end{array}$ & $\begin{array}{r}5,30 \mathrm{E}- \\
004\end{array}$ & 4,25 & - & Unknown & - & - \\
\hline $\begin{array}{l}\text { VDAG_JR2 } \\
\text { Chr5g05720a } \\
-00001\end{array}$ & $\begin{array}{r}1,59 \mathrm{E}- \\
136\end{array}$ & 4,24 & - & Unknown & - & - \\
\hline $\begin{array}{l}\text { VDAG_JR2 } \\
\text { Chr7g05430a } \\
-00001\end{array}$ & \begin{tabular}{r|}
$1,39 E-$ \\
087
\end{tabular} & 4,24 & - & Unknown & - & - \\
\hline
\end{tabular}




\begin{tabular}{|l|r|l|l|l|r|l|}
\hline $\begin{array}{l}\text { VDAG_JR2 } \\
\text { Chr3g11760a } \\
-00001\end{array}$ & $\begin{array}{r}5,84 \mathrm{E}- \\
006\end{array}$ & 4,24 & - & Unknown & - & \\
\hline $\begin{array}{l}\text { VDAG_JR2 } \\
\text { Chr4g10800a } \\
-00001\end{array}$ & $\begin{array}{r}1,22 \mathrm{E}- \\
048\end{array}$ & 4,11 & $\begin{array}{l}\text { DUF3 } \\
433\end{array}$ & Domain of unknown funktion & $\begin{array}{r}2,10 \mathrm{E} \\
-020\end{array}$ & $\begin{array}{l}\text { Pfam/ } \\
\text { UniPr } \\
\text { ot }\end{array}$ \\
\hline $\begin{array}{l}\text { VDAG_JR2 } \\
\text { Chr2g08090a } \\
-00001\end{array}$ & $\begin{array}{r}4,20 \mathrm{E}- \\
005\end{array}$ & 4,10 & - & Unknown & - & \\
\hline $\begin{array}{l}\text { VDAG_JR2 } \\
\text { Chr8g10750a } \\
-00001\end{array}$ & $\begin{array}{r}4,09 \mathrm{E}- \\
074\end{array}$ & 4,08 & - & Unknown & - & - \\
\hline $\begin{array}{l}\text { VDAG_JR2_- } \\
\text { Chr5g05540a } \\
-00001\end{array}$ & $\begin{array}{r}5,35 \mathrm{E}- \\
032\end{array}$ & 4,05 & - & Unknown & & - \\
\hline $\begin{array}{l}\text { VDAG_JR2 } \\
\text { Chr6g10010a } \\
-00001\end{array}$ & $\begin{aligned} 1,22 \mathrm{E}- \\
023\end{aligned}$ & 4,04 & - & Unknown & & - \\
\hline
\end{tabular}


Table S6 List of down-regulated Verticillium genes after $120 \mathrm{~min}$ of Pseudomonas co-cultivation. The reads of $V$. longisporum VI43 have been mapped to the $V$. dahliae genome of JR2. Most down-regulated Verticillium genes with $\log _{2}$ Fold_Change $>-3$ and padj $<0,01$ have been chosen for further analysis. Genes were automatically annotated and manually curated regarding conserved domains. Predicted gene functionality was assigned to functional categories manually. The e-value describes the similarity of the respective $V$. dahliae amino acid sequence to the domain sequence in the SMART database. The complete transcriptomic dataset is deposited at NCBI under the accessionnumber SRP068348; http://www.ncbi.nlm.nih.gov/sra/?term=SRP068348. GeneIDs refer to genome assembly of V. dahliae JR2 (VDAG_JR2v.4.0; de Jonge et al., 2012) deposited at www.fungi.ensembl.org/Verticillium dahliaejr2/Info/Index. (Howe et al., 2019).

${ }^{*}$ Possible predicted function according to domain description at www.smart.emblheidelberg.de (Letunic et al. 2015 and 2018)

\begin{tabular}{|c|c|c|c|c|c|c|}
\hline ID & padj & $\begin{array}{l}\text { Log2 } \\
\text { FC }\end{array}$ & $\begin{array}{c}\text { Domain } \\
\text { name }\end{array}$ & $\begin{array}{c}\text { Putative function / } \\
\text { description* }\end{array}$ & $\begin{array}{c}\mathrm{E}- \\
\text { value }\end{array}$ & $\begin{array}{c}\text { Source } \\
\text { database }\end{array}$ \\
\hline \multicolumn{7}{|c|}{ Amino acid metabolism } \\
\hline $\begin{array}{l}\text { VDAG_JR2_Ch } \\
\text { r5g01710a- } \\
00001\end{array}$ & \begin{tabular}{r|}
$1,99 \mathrm{E}$ \\
-043
\end{tabular} & $-4,05$ & $\begin{array}{l}\text { Asparagin } \\
\text { ase_II }\end{array}$ & $\begin{array}{l}\text { Catalyzes the hydrolysis of } \\
\text { L-asparagine to L-aspartate } \\
\text { and ammonium }\end{array}$ & $\begin{array}{r}2,90 \mathrm{E} \\
-118 \\
\end{array}$ & $\begin{array}{l}\text { Pfam/UniPr } \\
\text { ot/Interpro }\end{array}$ \\
\hline $\begin{array}{l}\text { VDAG_JR2_Ch } \\
\text { r6g09090a- } \\
00001\end{array}$ & $\begin{array}{r}1,13 \mathrm{E} \\
-095\end{array}$ & $-3,75$ & $\begin{array}{l}\text { Aminotra } \\
\text { n_3 }\end{array}$ & $\begin{array}{l}\text { Aminotransferase class III; } \\
\text { catalyzes a transamination } \\
\text { reaction between an amino } \\
\text { acid and an a-keto acid; } \\
\text { involved in amino acid } \\
\text { metabolism }\end{array}$ & $\begin{array}{r}2,30 \mathrm{E} \\
-098 \\
\end{array}$ & $\begin{array}{l}\text { Pfam/UniPr } \\
\text { ot/Interpro }\end{array}$ \\
\hline $\begin{array}{l}\text { VDAG_JR2_Ch } \\
\text { r3g01510a- } \\
00001\end{array}$ & $\begin{array}{r}1,51 \mathrm{E} \\
-065\end{array}$ & $-3,27$ & $\begin{array}{l}\text { Aminotra } \\
\text { n_MocR }\end{array}$ & $\begin{array}{l}\text { Alanine-glyoxylate amino- } \\
\text { transferase; catalyzes the } \\
\text { reversible transfer of amino } \\
\text { group from amino acid } \\
\text { substrate to acceptor alpha- } \\
\text { keto acid; require pyridoxal } \\
\text { 5'-phosphate (PLP) as } \\
\text { cofactor }\end{array}$ & $\begin{array}{r}6,00 \mathrm{E} \\
-007 \\
\end{array}$ & $\begin{array}{l}\text { Pfam/Interpr } \\
\text { o }\end{array}$ \\
\hline $\begin{array}{l}\text { VDAG_JR2_Ch } \\
\text { r3g11140a- } \\
00001\end{array}$ & $\begin{array}{r}1,22 \mathrm{E} \\
-028\end{array}$ & $-3,19$ & $\begin{array}{l}\text { Aminotra } \\
\text { n_1_2 }\end{array}$ & $\begin{array}{l}\text { Transfer of alpa- } \\
\text { aminogroups to donor } \\
\text { aceptor molecule, normaly } \\
\text { amino acids }\end{array}$ & $\begin{array}{r}1,70 \mathrm{E} \\
-040 \\
\end{array}$ & $\begin{array}{l}\text { Pfam/Interpr } \\
\text { o }\end{array}$ \\
\hline $\begin{array}{l}\text { VDAG_JR2_Ch } \\
\text { r3g08090a- } \\
00001\end{array}$ & $\begin{array}{r}5,79 E \\
-041\end{array}$ & $-3,16$ & $\begin{array}{l}\text { Homoseri } \\
\text { ne_dh }\end{array}$ & $\begin{array}{l}\text { Homoserine dehydrogenase } \\
\text { catalyzes the third step in } \\
\text { the aspartate pathway; } \\
\text { homoserine is an } \\
\text { intermediate in the } \\
\text { biosynthesis of threonine, } \\
\text { isoleucine, and methionine }\end{array}$ & $\begin{array}{r}1,30 \mathrm{E} \\
-051 \\
\end{array}$ & $\begin{array}{l}\text { Pfam/Interpr } \\
\text { o }\end{array}$ \\
\hline $\begin{array}{l}\text { VDAG_JR2_Ch } \\
\text { r7g07480a- } \\
00001\end{array}$ & $\begin{array}{r}5,19 \mathrm{E} \\
-008\end{array}$ & $-3,08$ & Arginase & $\begin{array}{l}\text { Part of ureohydrolase } \\
\text { superfamily; catalyzes the } \\
\text { conversion of arginine to } \\
\text { urea and ornithine; involved }\end{array}$ & $\begin{array}{r}1,60 \mathrm{E} \\
-092 \\
\end{array}$ & $\begin{array}{l}\text { Pfam/Interpr } \\
\text { o }\end{array}$ \\
\hline
\end{tabular}




\begin{tabular}{|c|c|c|c|c|c|c|}
\hline & & & & $\begin{array}{l}\text { in arginine/agmatine } \\
\text { metabolism, the urea cycle, } \\
\text { histidine degradation }\end{array}$ & & \\
\hline \multicolumn{7}{|c|}{ Carbon metabolism } \\
\hline $\begin{array}{l}\text { VDAG_JR2_Ch } \\
\text { r5g11770a- } \\
00002\end{array}$ & \begin{tabular}{r|}
$9,72 \mathrm{E}$ \\
-003
\end{tabular} & $-4,83$ & MR_MLE & $\begin{array}{l}\text { Mandelate racemase (MR) } \\
\text { and muconate lactonizing } \\
\text { enzyme (MLE) are two } \\
\text { bacterial enzymes involved } \\
\text { in aromatic acid catabolism }\end{array}$ & $\begin{array}{r}7,70 \mathrm{E} \\
-017 \\
\end{array}$ & $\begin{array}{l}\text { Pfam/Interpr } \\
\text { o }\end{array}$ \\
\hline $\begin{array}{l}\text { VDAG_JR2_Ch } \\
\text { r4g00510a- } \\
00001\end{array}$ & $\begin{array}{r}3,62 \mathrm{E} \\
-074\end{array}$ & $-3,53$ & $\begin{array}{l}\text { Galactosy } \\
\text { I_T }\end{array}$ & $\begin{array}{l}\text { Glycosyltransferases; } \\
\text { biosynthesis of } \\
\text { disaccharides, } \\
\text { oligosaccharides and } \\
\text { polysaccharides }\end{array}$ & $\begin{array}{r}2,00 E \\
-014\end{array}$ & $\begin{array}{l}\text { Pfam/Interpr } \\
\text { o }\end{array}$ \\
\hline $\begin{array}{l}\text { VDAG_JR2_Ch } \\
\text { r2g10000a- } \\
00001\end{array}$ & $\begin{array}{r}6,75 \mathrm{E} \\
-050\end{array}$ & $-3,48$ & adh short & $\begin{array}{l}\text { Short-chain alcohol } \\
\text { dehydrogenase; } \\
\text { oxidoreductase activity, } \\
\text { metabolic process }\end{array}$ & $\begin{array}{r}2,10 \mathrm{E} \\
-049\end{array}$ & $\begin{array}{l}\text { Pfam/Interpr } \\
\text { o }\end{array}$ \\
\hline $\begin{array}{l}\text { VDAG_JR2_Ch } \\
\text { r3g08340a- } \\
00001\end{array}$ & $\begin{array}{r}3,21 \mathrm{E} \\
-122\end{array}$ & $-3,39$ & MR_MLE & $\begin{array}{l}\text { Mandelate racemase (MR) } \\
\text { and muconate lactonizing } \\
\text { enzyme (MLE) are two } \\
\text { bacterial enzymes involved } \\
\text { in aromatic acid catabolism }\end{array}$ & $\begin{array}{r}3,25 \mathrm{E} \\
-019\end{array}$ & $\begin{array}{l}\text { Pfam/UniPr } \\
\text { ot/Interpro }\end{array}$ \\
\hline $\begin{array}{l}\text { VDAG_JR2_Ch } \\
\text { r4g09100a- } \\
00001\end{array}$ & $\begin{array}{r}3,94 \mathrm{E} \\
-003\end{array}$ & $-3,32$ & Pro_CA & $\begin{array}{l}\text { Carbonic anhydrases }(\mathrm{CA}) \\
\text { zinc metalloenzymes which } \\
\text { catalyze the reversible } \\
\text { hydration of carbon dioxide; } \\
\text { carbonate dehydratase } \\
\text { activity; zinc ion binding }\end{array}$ & $\begin{array}{r}1,97 \mathrm{E} \\
-027\end{array}$ & $\begin{array}{l}\text { Pfam/Interpr } \\
\text { o }\end{array}$ \\
\hline $\begin{array}{l}\text { VDAG_JR2_Ch } \\
\text { r1g21830a- } \\
00001\end{array}$ & $\begin{array}{r}6,32 \mathrm{E} \\
-064\end{array}$ & $-3,25$ & adh_short & $\begin{array}{l}\text { Short-chain alcohol } \\
\text { dehydrogenase; } \\
\text { oxidoreductase activity, } \\
\text { metabolic process } \\
\end{array}$ & $\begin{array}{r}3,00 \mathrm{E} \\
-039 \\
\end{array}$ & $\begin{array}{l}\text { Pfam/UniPr } \\
\text { ot/Interpro }\end{array}$ \\
\hline $\begin{array}{l}\text { VDAG_JR2_Ch } \\
\text { r8g08760a- } \\
00001\end{array}$ & $\begin{array}{r}7,30 \mathrm{E} \\
-007\end{array}$ & $-3,19$ & $\begin{array}{l}\text { GFO_IDH } \\
\text { MocA }\end{array}$ & $\begin{array}{l}\text { Glucose-fructose } \\
\text { oxidoreductase (GFO); } \\
\text { converts D-glucose and D- } \\
\text { fructose into D- } \\
\text { gluconolactone and D- } \\
\text { glucitol in the sorbitol- } \\
\text { gluconate pathway }\end{array}$ & $\begin{array}{r}2,70 \mathrm{E} \\
-011 \\
\end{array}$ & $\begin{array}{l}\text { Pfam/UniPr } \\
\text { ot/Interpro }\end{array}$ \\
\hline $\begin{array}{l}\text { VDAG_JR2_Ch } \\
\text { r1g02490a- } \\
00001\end{array}$ & $\begin{array}{r}8,16 \mathrm{E} \\
-084\end{array}$ & $-3,19$ & $\begin{array}{l}\text { TPP_enz } \\
\text { yme }\end{array}$ & $\begin{array}{l}\text { Thiamine pyrophosphate } \\
\text { (TPP); cofactor vitamin B1; } \\
\text { involved in aldehyd-trasnfer } \\
\text { reactions e.g. in pentose- } \\
\text { phosphate pathway and } \\
\text { glycolysis }\end{array}$ & $\begin{array}{r}3,80 \mathrm{E} \\
-034 \\
\end{array}$ & $\begin{array}{l}\text { Pfam/Interpr } \\
\text { o }\end{array}$ \\
\hline $\begin{array}{l}\text { VDAG_JR2_Ch } \\
\text { r6g10790a- } \\
00001\end{array}$ & $\begin{array}{r}2,70 \mathrm{E} \\
-038\end{array}$ & $-3,16$ & $\begin{array}{l}\text { PRKCSH- } \\
\text { like }\end{array}$ & $\begin{array}{l}\text { Protein kinase C substrate } \\
80 \mathrm{~K}-\mathrm{H} \text { (PRKCSH); } \\
\text { glucosidase } 2 \text { subunit beta; } \\
\text { catalyzes the sequential } \\
\text { removal of two alpha-1,3- } \\
\text { linked glucose residues in } \\
\text { the second step of } N-\text {-linked } \\
\text { oligosaccharide processing }\end{array}$ & $\begin{array}{r}6,10 \mathrm{E} \\
-028 \\
\end{array}$ & $\begin{array}{l}\text { Pfam/UniPr } \\
\text { ot/Interpro }\end{array}$ \\
\hline
\end{tabular}




\begin{tabular}{|c|c|c|c|c|c|c|}
\hline $\begin{array}{l}\text { VDAG_JR2_Ch } \\
\text { r2g09990a- } \\
00001\end{array}$ & $\begin{array}{r}7,95 \mathrm{E} \\
-048\end{array}$ & $-3,08$ & $\begin{array}{l}\text { ADH_zinc } \\
\mathrm{N}\end{array}$ & $\begin{array}{l}\text { Zinc-containing alcohol } \\
\text { dehydrogenase }\end{array}$ & $\begin{array}{r}8,50 \mathrm{E} \\
-018\end{array}$ & $\begin{array}{l}\text { Pfam/UniPr } \\
\text { ot/Interpro }\end{array}$ \\
\hline $\begin{array}{l}\text { VDAG_JR2_Ch } \\
\text { r2g08710a- } \\
00001\end{array}$ & $\begin{array}{r}2,15 E \\
-020\end{array}$ & $-3,05$ & adh short & \begin{tabular}{|l|} 
Short-chain alcohol \\
dehydrogenase; \\
oxidoreductase activity, \\
metabolic process
\end{tabular} & $\begin{array}{r}1,10 \mathrm{E} \\
-051\end{array}$ & $\begin{array}{l}\text { Pfam/UniPr } \\
\text { ot/Interpro }\end{array}$ \\
\hline $\begin{array}{l}\text { VDAG_JR2_Ch } \\
\text { r1g01970a- } \\
00001\end{array}$ & $\begin{array}{r}4,38 \mathrm{E} \\
-063\end{array}$ & $-3,04$ & iPGM_N & $\begin{array}{l}\text { 2,3-bisphosphoglycerate- } \\
\text { independent } \\
\text { phosphoglycerate mutase } \\
\text { (iPGM) / } \\
\text { phosphoglyderomutase; } \\
\text { metalloenzyme; Catalyzes } \\
\text { the interconversion of 2-- } \\
\text { phosphoglycerate and 3- } \\
\text { phosphoglycerate; } \\
\text { manganese ion binding; } \\
\text { glucose catabolism }\end{array}$ & $\begin{array}{r}1,60 \mathrm{E} \\
-075\end{array}$ & $\begin{array}{l}\text { Pfam/Interpr } \\
\text { o }\end{array}$ \\
\hline \multicolumn{7}{|c|}{ Chromosomal organization/DNA repair } \\
\hline $\begin{array}{l}\text { VDAG_JR2_Ch } \\
\text { r2g00060a- } \\
00001\end{array}$ & $\begin{array}{r}1,86 \mathrm{E} \\
-032\end{array}$ & $-4,86$ & $\begin{array}{l}\mathrm{Zf}- \\
\mathrm{C} 2 \mathrm{H} 2 \_2 \\
\end{array}$ & $\begin{array}{l}\text { C2H2 type zinc-finger (2 } \\
\text { copies) proteins include } \\
\text { strong and specific binding } \\
\text { to a long and unique DNA } \\
\text { recognition target sequence; } \\
\text { putative chromosomal } \\
\text { organizing function in } \\
\text { chromatin architecture } \\
\end{array}$ & $\begin{array}{r}6,00 E \\
-029 \\
\end{array}$ & $\begin{array}{l}\text { Pfam/UniPr } \\
\text { ot }\end{array}$ \\
\hline $\begin{array}{l}\text { VDAG_JR2_Ch } \\
\text { r8g08640a- } \\
00001\end{array}$ & $\begin{array}{r}4,28 \mathrm{E} \\
-003\end{array}$ & $-3,48$ & SET & $\begin{array}{l}\text { Su(var)3-9, Enhancer-of- } \\
\text { zeste, Trithorax (SET); } \\
\text { putative methyl transferase; } \\
\text { chromosomal proteins; } \\
\text { chromatin structure }\end{array}$ & $\begin{array}{r}2,08 \mathrm{E} \\
-002\end{array}$ & $\begin{array}{l}\text { Pfam/Interpr } \\
\text { o }\end{array}$ \\
\hline $\begin{array}{l}\text { VDAG_JR2_Ch } \\
\text { r5g05060a- } \\
00001\end{array}$ & $\begin{array}{r}1,97 \mathrm{E} \\
-004\end{array}$ & $-3,33$ & ENDO3c & $\begin{array}{l}\text { Includes endonuclease III } \\
\text { (DNA-(apurinic or } \\
\text { apyrimidinic site) lyase), } \\
\text { alkylbase DNA glycosidases } \\
\text { (Alka-family) and other DNA } \\
\text { glycosidases; DNA repair } \\
\text { enzyme which removes a } \\
\text { number of damaged } \\
\text { pyrimidines from DNA via its } \\
\text { glycosylase activity and also } \\
\text { cleaves the phosphodiester } \\
\text { backbone at apurinic / } \\
\text { apyrimidinic sites via a beta- } \\
\text { elimination mechanism }\end{array}$ & $\begin{array}{r}8,05 E \\
-032\end{array}$ & $\begin{array}{l}\text { Pfam/Interpr } \\
\text { o }\end{array}$ \\
\hline $\begin{array}{l}\text { VDAG_JR2_Ch } \\
\text { r5g03360a- } \\
00001\end{array}$ & $\begin{array}{r}7,88 \mathrm{E} \\
-005\end{array}$ & $-3,12$ & d1d3ya & $\begin{array}{l}\text { DNA topoisomerase VI A } \\
\text { subunit; DNA binding } \\
\text { protein; essential in the } \\
\text { separation of entangled DNA } \\
\text { daughter strands during } \\
\text { replication }\end{array}$ & $\begin{array}{r}9,00 E \\
-036\end{array}$ & $\begin{array}{l}\text { SCOP } \\
\text { (Structural } \\
\text { Classificatio } \\
\mathrm{n} \text { of } \\
\text { Proteins) }\end{array}$ \\
\hline \multicolumn{7}{|c|}{ egradation of plant polysaccharides } \\
\hline
\end{tabular}




\begin{tabular}{|c|c|c|c|c|c|c|}
\hline $\begin{array}{l}\text { VDAG_JR2_Ch } \\
\text { r5g00820a- } \\
00001\end{array}$ & $\begin{array}{r}4,22 \mathrm{E} \\
-032\end{array}$ & $-5,58$ & $\begin{array}{l}\text { Glyco_hy } \\
\text { dro_88 }\end{array}$ & $\begin{array}{l}\text { Cell wall glycosyl hydrolase } \\
\text { YteR; catalyzes the } \\
\text { hydrolytic release of } \\
\text { unsaturated glucuronic acids } \\
\text { from oligosaccharides } \\
\text { produced by the reactions of } \\
\text { polysaccharide lyases } \\
\end{array}$ & $\begin{array}{r}1,60 \mathrm{E} \\
-064 \\
\end{array}$ & $\begin{array}{l}\text { Pfam/UniPr } \\
\text { ot/Interpro }\end{array}$ \\
\hline $\begin{array}{l}\text { VDAG_JR2_Ch } \\
\text { r8g11250a- } \\
00001\end{array}$ & $\begin{array}{r}5,11 \mathrm{E} \\
-107\end{array}$ & $-5,55$ & $\begin{array}{l}\begin{array}{l}\text { Pectate_I } \\
\text { yase }\end{array} \\
\text {. }\end{array}$ & $\begin{array}{l}\text { Pectate lyase; maceration } \\
\text { and soft-rotting of plant } \\
\text { tissue; extracellular enzyme; } \\
\text { induced by pectin }\end{array}$ & $\begin{array}{r}2,30 E \\
-064\end{array}$ & nterpr \\
\hline $\begin{array}{l}\text { VDAG_JR2_Ch } \\
\text { r5g03290a- } \\
00001\end{array}$ & $\begin{array}{r}3,82 \mathrm{E} \\
-143\end{array}$ & $-4,26$ & $\mathrm{PbH} 1$ & $\begin{array}{l}\text { Part of pectate lyases and } \\
\text { rhamnogalacturonase A; } \\
\text { putatively involved in } \\
\text { polysaccharide metabolism }\end{array}$ & $\begin{array}{r}2,33 \mathrm{E} \\
+001 \\
\end{array}$ & $\begin{array}{l}\text { Pfam/UniPr } \\
\text { ot/Interpro }\end{array}$ \\
\hline $\begin{array}{l}\text { VDAG_JR2_Ch } \\
\text { r1g22090a- } \\
00001\end{array}$ & $\begin{array}{r}3,73 \mathrm{E} \\
-100\end{array}$ & $-4,21$ & $\begin{array}{l}\text { Glyco_hy } \\
\text { dro_28 }\end{array}$ & $\begin{array}{l}\text { Glycoside hydrolase of } \\
\text { family } 28 ; \text { hydrolyzes } \\
\text { glycosidic bond between two } \\
\text { or more carbohydrates, or } \\
\text { between a carbohydrate and } \\
\text { a non-carbohydrate moiety; } \\
\text { Cell wall glycosyl hydrolase; } \\
\text { in family 28: e.g. } \\
\text { polygalacturonase } \\
\text { (pectinase), } \\
\text { rhamnogalacturonase; } \\
\text { involved in maceration and } \\
\text { soft-rotting of plant tissue }\end{array}$ & $\begin{array}{r}2,30 \mathrm{E} \\
-048\end{array}$ & $\begin{array}{l}\text { Pfam/UniPr } \\
\text { ot/Interpro }\end{array}$ \\
\hline $\begin{array}{l}\text { VDAG_JR2_Ch } \\
\text { r1g28780a- } \\
00001\end{array}$ & $\begin{array}{r}1,18 \mathrm{E} \\
-054\end{array}$ & $-3,95$ & Amb & $\begin{array}{l}\text { Pectate lyase; involved in } \\
\text { the maceration and soft } \\
\text { rotting of plant tissue }\end{array}$ & $\begin{array}{r}6,22 \mathrm{E} \\
-040\end{array}$ & $\begin{array}{l}\text { Pfam/Interpr } \\
\text { o }\end{array}$ \\
\hline $\begin{array}{l}\text { VDAG_JR2_Ch } \\
\text { r8g02490a- } \\
00001\end{array}$ & $\begin{array}{r}2,83 \mathrm{E} \\
-004\end{array}$ & $-3,57$ & Amb_all & $\begin{array}{l}\text { Pectate lyase; involved in } \\
\text { the maceration and soft } \\
\text { rotting of plant tissue }\end{array}$ & $\begin{array}{r}9,93 E \\
-016\end{array}$ & $\begin{array}{l}\text { Pfam/Interpr } \\
\text { o }\end{array}$ \\
\hline $\begin{array}{l}\text { VDAG_JR2_Ch } \\
\text { r7g00010a- } \\
00001\end{array}$ & $\begin{array}{r}1,97 \mathrm{E} \\
-047\end{array}$ & $-3,56$ & $\begin{array}{l}\text { Pectinest } \\
\text { erase }\end{array}$ & $\begin{array}{l}\text { Pectin methylesterase; } \\
\text { catalyzes the de- } \\
\text { esterification of pectin into } \\
\text { pectate and methanol; } \\
\text { maceration and soft-rotting } \\
\text { of plant tissue }\end{array}$ & $\begin{array}{r}1,40 E \\
-048 \\
\end{array}$ & $\begin{array}{l}\text { Pfam/Interpr } \\
\text { o }\end{array}$ \\
\hline $\begin{array}{l}\text { VDAG_JR2_Ch } \\
\text { r5g08380a- } \\
00001\end{array}$ & $\begin{array}{r}1,61 \mathrm{E} \\
-019\end{array}$ & $-3,40$ & $\begin{array}{l}\text { Pectinest } \\
\text { erase }\end{array}$ & $\begin{array}{l}\text { Pectin methylesterase; } \\
\text { catalyzes the de- } \\
\text { esterification of pectin into } \\
\text { pectate and methanol; } \\
\text { maceration and soft-rotting } \\
\text { of plant tissue }\end{array}$ & $\begin{array}{r}1,60 \mathrm{E} \\
-053\end{array}$ & $\begin{array}{l}\text { Pfam } \\
\text { o }\end{array}$ \\
\hline $\begin{array}{l}\text { VDAG_JR2_Ch } \\
\text { r1g28720a- } \\
00001\end{array}$ & $\begin{array}{r}3,78 \mathrm{E} \\
-041\end{array}$ & $-3,31$ & PbhH1 & $\begin{array}{l}\text { Parallel beta-helix repeats; } \\
\text { tertiary structures of pectate } \\
\text { lyases and } \\
\text { rhamnogalacturonase A } \\
\text { show a stack of parallel beta } \\
\text { strands that are coiled into a } \\
\text { large helix }\end{array}$ & $\begin{array}{r}6,00 \mathrm{E} \\
-031 \\
\end{array}$ & $\begin{array}{l}\text { Interpro/sch } \\
\text { nipsel } \\
\text { database_s } \\
\text { mart }\end{array}$ \\
\hline $\begin{array}{l}\text { VDAG_JR2_Ch } \\
\text { r8g10280a- } \\
00001\end{array}$ & $\begin{array}{r}1,23 \mathrm{E} \\
-045\end{array}$ & $-3,24$ & $\begin{array}{l}\text { Glyco_hy } \\
\text { dro_28 }\end{array}$ & $\begin{array}{l}\text { Glycoside hydrolase of } \\
\text { family } 28 ; \text { hydrolyzes } \\
\text { glycosidic bond between two } \\
\text { or more carbohydrates, or } \\
\text { between a carbohydrate and }\end{array}$ & $\begin{array}{r}4,70 \mathrm{E} \\
-031 \\
\end{array}$ & $\begin{array}{l}\text { Pfam/Interpr } \\
\text { o }\end{array}$ \\
\hline
\end{tabular}




\begin{tabular}{|c|c|c|c|c|c|c|}
\hline & & & & $\begin{array}{l}\text { a non-carbohydrate moiety; } \\
\text { Cell wall glycosyl hydrolase; } \\
\text { in family 28: e.g. } \\
\text { polygalacturonase } \\
\text { (pectinase), } \\
\text { rhamnogalacturonase; } \\
\text { involved in maceration and } \\
\text { soft-rotting of plant tissue }\end{array}$ & & \\
\hline $\begin{array}{l}\text { VDAG_JR2_Ch } \\
\text { r6g00390a- } \\
00001\end{array}$ & $\begin{array}{r}5,72 \mathrm{E} \\
-028\end{array}$ & $-3,24$ & $\begin{array}{l}\text { Glyco_hy } \\
\text { dro_ } 4 \overline{3}\end{array}$ & $\begin{array}{l}\text { Glycoside hydrolase of } \\
\text { family } 43 \text {; hydrolyzes } \\
\text { glycosidic bond between two } \\
\text { or more carbohydrates, or } \\
\text { between a carbohydrate and } \\
\text { a non-carbohydrate moiety; } \\
\text { Cell wall glycosyl hydrolase; } \\
\text { in family 28: e.g. beta- } \\
\text { xylosidase, alpha-L- } \\
\text { arabinofuranosidase, } \\
\text { arabinanase, xylanase } \\
\end{array}$ & $\begin{array}{r}2,50 \mathrm{E} \\
-013 \\
\end{array}$ & $\begin{array}{l}\text { Pfam/Interpr } \\
\text { o }\end{array}$ \\
\hline $\begin{array}{l}\text { VDAG_JR2_Ch } \\
\text { r8g11000a- } \\
00001\end{array}$ & $\begin{array}{r}3,01 \mathrm{E} \\
-008\end{array}$ & $-3,04$ & $\begin{array}{l}\text { Glyco_hy } \\
\text { dro_67 }\end{array}$ & $\begin{array}{l}\text { Central catalytic domain of } \\
\text { alpha-glucuronidase; } \\
\text { removes the alpha-1,2 linked } \\
\text { 4-O-methyl glucuronic acid } \\
\text { from xylans; recycling of } \\
\text { photosynthetic biomass }\end{array}$ & $\begin{array}{r}1,00 E \\
-148 \\
\end{array}$ & $\begin{array}{l}\text { Pfam/UniPr } \\
\text { ot/Interpro }\end{array}$ \\
\hline \multicolumn{7}{|c|}{ Energy - electron transport } \\
\hline $\begin{array}{l}\text { VDAG_JR2_Ch } \\
\text { r2g11540a- } \\
00002\end{array}$ & $\begin{array}{r}1,31 \mathrm{E} \\
-003\end{array}$ & $-3,37$ & $\begin{array}{l}\text { Ubie_met } \\
\text { hyltran }\end{array}$ & $\begin{array}{l}\text { Methyltransferases involved } \\
\text { in the biosynthesis of } \\
\text { menaquinone and } \\
\text { ubiqinone; Q-10; involved in } \\
\text { mitochondrial electron and } \\
\text { proton transfer }\end{array}$ & $\begin{array}{r}4,30 E \\
-007\end{array}$ & $\begin{array}{l}\text { Pfam/Interpr } \\
\text { o }\end{array}$ \\
\hline $\begin{array}{l}\text { VDAG_JR2_Ch } \\
\text { r2g03470a- } \\
00001\end{array}$ & \begin{tabular}{r|}
$6,92 \mathrm{E}$ \\
-061
\end{tabular} & $-3,30$ & p450 & $\begin{array}{l}\text { Cytochrome P450 enzyme; } \\
\text { haem-containing mono- } \\
\text { oxygenases found in all } \\
\text { kingdoms; oxidation- } \\
\text { reduction process; } \\
\text { oxidoreductase activity; } \\
\text { acting on paired donors; with } \\
\text { incorporation or reduction of } \\
\text { molecular oxygen; iron ion } \\
\text { binding; heme binding } \\
\end{array}$ & $\begin{array}{r}1,00 E \\
-021 \\
\end{array}$ & $\begin{array}{l}\text { Pfam/UniPr } \\
\text { ot/Interpro }\end{array}$ \\
\hline \multicolumn{7}{|c|}{ Lipid metabolism } \\
\hline $\begin{array}{l}\text { VDAG_JR2_Ch } \\
\text { r4g11530a- } \\
00001\end{array}$ & $\begin{array}{r}9,94 \mathrm{E} \\
-004\end{array}$ & $-5,68$ & $\begin{array}{l}\text { Abhydrola } \\
\text { se_5 }\end{array}$ & $\begin{array}{l}\text { Alpha/beta hydrolase 5; } \\
\text { putatively involved in lipid } \\
\text { metabolic processes }\end{array}$ & $\begin{array}{r}1,90 \mathrm{E} \\
-014\end{array}$ & $\begin{array}{l}\text { Pfam/UniPr } \\
\text { ot }\end{array}$ \\
\hline $\begin{array}{l}\text { VDAG_JR2_Ch } \\
\text { r5g05070a- } \\
00001\end{array}$ & $\begin{array}{r}2,35 \mathrm{E} \\
-091\end{array}$ & $-3,94$ & PBP & $\begin{array}{l}\text { Phosphatidyl-Ethanolamine- } \\
\text { Binding Protein; involved in } \\
\text { lipid binding; inhibition of } \\
\text { serine protease and } \\
\text { inhibiation of singaling } \\
\text { pathways like MAP kinase } \\
\text { and NF-kappaB }\end{array}$ & $\begin{array}{r}4,20 \mathrm{E} \\
-020 \\
\end{array}$ & $\begin{array}{l}\text { Pfam/UniPr } \\
\text { ot/Interpro }\end{array}$ \\
\hline
\end{tabular}




\begin{tabular}{|c|c|c|c|c|c|c|}
\hline $\begin{array}{l}\text { VDAG_JR2_Ch } \\
\text { r5g08390a- } \\
00001\end{array}$ & $\begin{array}{r}, 60 \mathrm{E} \\
-018\end{array}$ & $-3,54$ & $\begin{array}{l}\text { Lipase_G } \\
\text { DSL_2 }\end{array}$ & $\begin{array}{l}\text { GDSL-like Lipase / } \\
\text { Acylhydrolase; exhibits a } \\
\text { Gly-Asp-Ser-(Leu) (GDSL) } \\
\text { motif } \\
\end{array}$ & $\begin{array}{r}1,00 E \\
-013 \\
\end{array}$ & $\begin{array}{l}\text { Pfam/UniPr } \\
\text { ot/Interpro }\end{array}$ \\
\hline $\begin{array}{l}\text { VDAG_JR2_Ch } \\
\text { r1g12020a- } \\
00001\end{array}$ & $\begin{array}{r}8,32 \mathrm{E} \\
-041\end{array}$ & $-3,11$ & $\begin{array}{l}\text { polypreny } \\
\text { I_synt }\end{array}$ & $\begin{array}{l}\text { Isoprenoid biosynthetic } \\
\text { pathway / Mevalonat } \\
\text { pathway; synthesis of e.g. } \\
\text { cholesterol, dolichol, } \\
\text { ubiquinone or coenzyme Q }\end{array}$ & $\begin{array}{r}6,90 \mathrm{E} \\
-082 \\
\end{array}$ & $\begin{array}{l}\text { Pfam/UniPr } \\
\text { ot/Interpro }\end{array}$ \\
\hline \multicolumn{7}{|c|}{ Protein - metabolism/biosynthesis/regulation } \\
\hline $\begin{array}{l}\text { VDAG_JR2_Ch } \\
\text { r5g09370a- } \\
00001\end{array}$ & $\begin{array}{r}1,44 \mathrm{E} \\
-005\end{array}$ & $-4,84$ & $\begin{array}{l}\text { Peptidase } \\
\text { S8 }\end{array}$ & $\begin{array}{l}\text { Serine-type endopeptidase } \\
\text { activity }\end{array}$ & $\begin{array}{r}7,40 E \\
-029\end{array}$ & $\begin{array}{l}\text { Pfam/UniPr } \\
\text { ot/Interpro }\end{array}$ \\
\hline $\begin{array}{l}\text { VDAG_JR2_Ch } \\
\text { r6g08190a- } \\
00001\end{array}$ & $\begin{array}{r}8,70 \mathrm{E} \\
-005\end{array}$ & $-3,98$ & Med11 & $\begin{array}{l}\text { Mediator 1; coactivator } \\
\text { involved in the regulated } \\
\text { transcription of RNA } \\
\text { polymerase II-dependent } \\
\text { genes }\end{array}$ & $\begin{array}{r}3,10 \mathrm{E} \\
-046 \\
\end{array}$ & terpr \\
\hline $\begin{array}{l}\text { VDAG_JR2_Ch } \\
\text { r2g04680a- } \\
00001\end{array}$ & $\begin{array}{r}1,18 \mathrm{E} \\
-011\end{array}$ & $-3,67$ & $\begin{array}{l}\text { Peptidase } \\
\text { M20 }\end{array}$ & $\begin{array}{l}\text { Metallopeptidases and non- } \\
\text { peptidase homologues } \\
\text { (amidohydrolases) that } \\
\text { belong to the MEROPS } \\
\text { peptidase family M20 }\end{array}$ & $\begin{array}{r}7,00 E \\
-034 \\
\end{array}$ & $\begin{array}{l}\text { Pfam/UniPr } \\
\text { ot/Interpro }\end{array}$ \\
\hline $\begin{array}{l}\text { VDAG_JR2_Ch } \\
\text { r2g12370a- } \\
00001\end{array}$ & $\begin{array}{r}1,01 \mathrm{E} \\
-025\end{array}$ & $-3,54$ & ELP6 & $\begin{array}{l}\text { Elongation complex protein } \\
6 \text { (ELP); subunit of RNA } \\
\text { polymerase II elongator } \\
\text { complex; promotes RNA- } \\
\text { polymerase II transcript } \\
\text { elongation through histone } \\
\text { acetylation in nucleus and } \\
\text { tRNA modification in } \\
\text { cytoplasm }\end{array}$ & $\begin{array}{r}1,60 \mathrm{E} \\
-012\end{array}$ & $\begin{array}{l}\text { Pfam/UniPr } \\
\text { ot/Interpro }\end{array}$ \\
\hline $\begin{array}{l}\text { VDAG_JR2_Ch } \\
\text { r2g02130a- } \\
00001\end{array}$ & $\begin{array}{r}3,75 \mathrm{E} \\
-017\end{array}$ & $-3,49$ & $\begin{array}{l}\text { UDP- } \\
\text { g_GGTas } \\
\text { e }\end{array}$ & $\begin{array}{l}\text { UDP-glucose: glycoprotein } \\
\text { glucosyltransferase activity; } \\
\text { protein glycosylation; quality } \\
\text { control for ER-folding for } \\
\text { correct transportation } \\
\text { processes }\end{array}$ & $\begin{array}{r}0,00 E \\
+000\end{array}$ & $\begin{array}{l}\text { Pfam/Interpr } \\
\text { o }\end{array}$ \\
\hline $\begin{array}{l}\text { VDAG_JR2_Ch } \\
\text { r3g00520a- } \\
00001\end{array}$ & $\begin{array}{r}9,27 \mathrm{E} \\
-020\end{array}$ & $-3,46$ & 1JV & $\begin{array}{l}\text { Ligase; structure of covalent } \\
\text { acyl-adenylate form of } \\
\text { Moeb-moad protein } \\
\text { complex; Molybdopterin } \\
\text { biosynthesis; involved in } \\
\text { activation of protein } \\
\text { ubiquitination } \\
\end{array}$ & $\begin{array}{r}3,00 \mathrm{E} \\
-031 \\
\end{array}$ & $\begin{array}{l}\text { PDB } \\
\text { (Protein } \\
\text { Data Bank) }\end{array}$ \\
\hline $\begin{array}{l}\text { VDAG_JR2_Ch } \\
\text { r2g07280a- } \\
00001\end{array}$ & $\begin{array}{r}1,48 \mathrm{E} \\
-018\end{array}$ & $-3,42$ & Tub & $\begin{array}{l}\text { GTPases; involved in } \\
\text { polymer formation; major } \\
\text { component of microtubules }\end{array}$ & $\begin{array}{r}1,99 \mathrm{E} \\
-055 \\
\end{array}$ & $\begin{array}{l}\text { Pfam/Interpr } \\
\text { o }\end{array}$ \\
\hline $\begin{array}{l}\text { VDAG_JR2_Ch } \\
\text { r1g04050a- } \\
00001\end{array}$ & $\begin{array}{r}3,58 \mathrm{E} \\
-055\end{array}$ & $-3,38$ & $\begin{array}{l}\text { Ribophori } \\
\text { n_II }\end{array}$ & $\begin{array}{l}\text { Essential subunit of the } \mathrm{N}- \\
\text { oligosaccharyl transferase } \\
\text { (OST) complex which } \\
\text { catalyses the transfer of a } \\
\text { high mannose } \\
\text { oligosaccharide from a lipid- } \\
\text { linked oligosaccharide donor } \\
\text { to an asparagine residue; }\end{array}$ & $\begin{array}{r}7,00 E \\
-021\end{array}$ & $\begin{array}{l}\text { Pfam/UniPr } \\
\text { ot/Interpro }\end{array}$ \\
\hline
\end{tabular}




\begin{tabular}{|c|c|c|c|c|c|c|}
\hline & & & & $\begin{array}{l}\text { protein N-linked } \\
\text { glycosylation }\end{array}$ & & \\
\hline $\begin{array}{l}\text { VDAG_JR2_Ch } \\
\text { r1g20320a- } \\
00001\end{array}$ & $\begin{array}{r}1,99 \mathrm{E} \\
-009\end{array}$ & $-3,32$ & $\begin{array}{l}\text { TFIIIC_de } \\
\text { Ita }\end{array}$ & $\begin{array}{l}\text { Domain of the } \mathrm{N} \text { terminus of } \\
\text { the } 90 \mathrm{kDa} \text { subunit of } \\
\text { transcription factor IIIC; } \\
\text { involved in RNA polymerase } \\
\text { III-mediated transcription }\end{array}$ & $\begin{array}{r}4,00 E \\
-016\end{array}$ & $\begin{array}{l}\text { Pfam/Interpr } \\
\text { o }\end{array}$ \\
\hline $\begin{array}{l}\text { VDAG_JR2_Ch } \\
\text { r5g04770a- } \\
00001\end{array}$ & $\begin{array}{r}1,44 \mathrm{E} \\
-051\end{array}$ & $-3,30$ & $\begin{array}{l}\text { Peptidase } \\
\text { M16 }\end{array}$ & $\begin{array}{l}\text { Metallopeptidases and non- } \\
\text { peptidase homologues } \\
\text { belonging to MEROPS } \\
\text { peptidase family M16 }\end{array}$ & $\begin{array}{r}3,50 \mathrm{E} \\
-020 \\
\end{array}$ & $\begin{array}{l}\text { Pfam/UniPr } \\
\text { ot/Interpro }\end{array}$ \\
\hline $\begin{array}{l}\text { VDAG_JR2_Ch } \\
\text { r4g11560a- } \\
00001\end{array}$ & $\begin{array}{r}4,65 \mathrm{E} \\
-006\end{array}$ & $-3,24$ & Zn_pept & $\begin{array}{l}\text { Metallocarboxypeptidase } \\
\text { activity; metalloprotease; } \\
\text { zinc ion binding }\end{array}$ & $\begin{array}{r}5,89 \mathrm{E} \\
-097 \\
\end{array}$ & $\begin{array}{l}\text { Pfam/UniPr } \\
\text { ot/Interpro }\end{array}$ \\
\hline $\begin{array}{l}\text { VDAG_JR2_Ch } \\
\text { r1g26400a- } \\
00001\end{array}$ & $\begin{array}{r}2,46 \mathrm{E} \\
-040\end{array}$ & $-3,21$ & $\begin{array}{l}\text { DDOST_ } \\
48 \mathrm{kD}\end{array}$ & $\begin{array}{l}\text { Dolichyl- } \\
\text { diphosphooligosaccharide- } \\
\text { protein (DD) oligosaccharyl } \\
\text { transferase complex (OST } \\
\text { complex); during N-linked } \\
\text { glycosylation of proteins, } \\
\text { oligosaccharide chains are } \\
\text { assembled on the carrier } \\
\text { molecule dolichyl } \\
\text { pyrophosphate }\end{array}$ & $\begin{array}{r}2,20 \mathrm{E} \\
-157\end{array}$ & $\begin{array}{l}\text { Pfam/UniPr } \\
\text { ot/Interpro }\end{array}$ \\
\hline $\begin{array}{l}\text { VDAG_JR2_Ch } \\
\text { r3g05790a- } \\
00001\end{array}$ & \begin{tabular}{r|}
$1,45 \mathrm{E}$ \\
-042
\end{tabular} & $-3,09$ & $\begin{array}{l}\text { Ribophori } \\
\text { n_l }\end{array}$ & $\begin{array}{l}\text { Essential subunit of the } \mathrm{N}- \\
\text { oligosaccharyl transferase } \\
\text { (OST) complex which } \\
\text { catalyses the transfer of a } \\
\text { high mannose } \\
\text { oligosaccharide from a lipid- } \\
\text { linked oligosaccharide donor } \\
\text { to an asparagine residue; } \\
\text { protein N-linked } \\
\text { glycosylation }\end{array}$ & $\begin{array}{r}5,30 \mathrm{E} \\
-154\end{array}$ & $\begin{array}{l}\text { Pfam/UniPr } \\
\text { ot/Interpro }\end{array}$ \\
\hline $\begin{array}{l}\text { VDAG_JR2_Ch } \\
\text { r3g05990a- } \\
00001\end{array}$ & $\begin{array}{r}4,53 \mathrm{E} \\
-010\end{array}$ & $-3,03$ & TBCA & $\begin{array}{l}\text { Tubulin-specific chaperone } \\
\text { A (TBCA); involved in folding } \\
\text { pathway of tubulins }\end{array}$ & $\begin{array}{r}5,60 \mathrm{E} \\
-025 \\
\end{array}$ & $\begin{array}{l}\text { Pfam/UniPr } \\
\text { ot/Interpro }\end{array}$ \\
\hline $\begin{array}{l}\text { VDAG_JR2_Ch } \\
\text { r6g03270a- } \\
00001\end{array}$ & $\begin{array}{r}, 40 \mathrm{E} \\
-016\end{array}$ & $-3,02$ & $\begin{array}{l}\text { Lectin_le } \\
\text { g-like }\end{array}$ & $\begin{array}{l}\text { Legume-like lectin; binds to } \\
\text { specific carbohydrates } \\
\text { mainly in cellwalls for e.g. } \\
\text { communication function, } \\
\text { protein folding quality control } \\
\text { (chaparone, production of } \\
\text { molecules with antibiotic-like } \\
\text { function) }\end{array}$ & $\begin{array}{r}5,00 \mathrm{E} \\
-025\end{array}$ & $\begin{array}{l}\text { Pfam/UniPr } \\
\text { ot/Interpro }\end{array}$ \\
\hline $\begin{array}{l}\text { VDAG_JR2_Ch } \\
\text { r3g04050a- } \\
00001\end{array}$ & $\begin{array}{r}8,94 \mathrm{E} \\
-003\end{array}$ & $-3,02$ & BTB & $\begin{array}{l}\text { Bric a brac (B), Tramtrack } \\
\text { (T), BR-C (B); zinc finger; } \\
\text { transcriptional repressor }\end{array}$ & $\begin{array}{r}2,00 E \\
-021 \\
\end{array}$ & $\begin{array}{l}\text { UniProt/sch } \\
\text { nipsel } \\
\text { databank_s } \\
\text { mart }\end{array}$ \\
\hline \multicolumn{7}{|l|}{ Transport } \\
\hline $\begin{array}{l}\text { VDAG_JR2_Ch } \\
\text { r4g12140a- } \\
00001\end{array}$ & \begin{tabular}{r|}
$3,07 \mathrm{E}$ \\
-042
\end{tabular} & $-5,67$ & MFS_4 & $\begin{array}{l}\text { Major Facilitator Superfamily } \\
\text { (MFS), single-polypeptide } \\
\text { secondary carriers } \\
\text { transporting small solutes in } \\
\text { response to chemiosmotic } \\
\text { ion gradients }\end{array}$ & $\begin{array}{r}9,10 \mathrm{E} \\
-036\end{array}$ & $\begin{array}{l}\text { Pfam/UniPr } \\
\text { ot/Interpro }\end{array}$ \\
\hline
\end{tabular}




\begin{tabular}{|c|c|c|c|c|c|c|}
\hline $\begin{array}{l}\text { VDAG_JR2_Ch } \\
\text { r6g04350a- } \\
00001\end{array}$ & $\begin{array}{r}1,17 \mathrm{E} \\
-035\end{array}$ & $-5,27$ & MFS_1 & $\begin{array}{l}\text { Major Facilitator Superfamily } \\
\text { (MFS), single-polypeptide } \\
\text { secondary carriers } \\
\text { transporting small solutes in } \\
\text { response to chemiosmotic } \\
\text { ion gradients } \\
\end{array}$ & $\begin{array}{r}8,10 \mathrm{E} \\
-044 \\
\end{array}$ & $\begin{array}{l}\text { Pfam/Interpr } \\
\text { o }\end{array}$ \\
\hline $\begin{array}{l}\text { VDAG_JR2_Ch } \\
\text { r6g09860a- } \\
00001\end{array}$ & $\begin{array}{r}4,85 E \\
-003\end{array}$ & $-4,93$ & Sugar_tr & $\begin{array}{l}\text { Transmembrane transport of } \\
\text { sugar and other molecules; } \\
\text { major facilitator superfamily } \\
\text { MFS }\end{array}$ & $\begin{array}{r}1,70 \mathrm{E} \\
-021\end{array}$ & $\begin{array}{l}\text { Pfam/UniPr } \\
\text { ot/Interpro }\end{array}$ \\
\hline $\begin{array}{l}\text { VDAG_JR2_Ch } \\
\text { r4g01380a- } \\
00001\end{array}$ & $\begin{array}{r}2,11 \mathrm{E} \\
-029\end{array}$ & $-4,28$ & $\mathrm{PHO} 4$ & $\begin{array}{l}\text { Phosphate permease (PHO- } \\
\text { 4) from Neurospora crassa } \\
\text { which is probably a sodium- } \\
\text { phosphate symporter; } \\
\text { phosphate-repressible } \\
\text { transporter }\end{array}$ & $\begin{array}{r}3,40 \mathrm{E} \\
-123 \\
\end{array}$ & $\begin{array}{l}\text { Pfam/UniPr } \\
\text { ot/Interpro }\end{array}$ \\
\hline $\begin{array}{l}\text { VDAG_JR2_Ch } \\
\text { r2g00600a- } \\
00001\end{array}$ & $\begin{array}{r}3,19 \mathrm{E} \\
-082\end{array}$ & $-4,03$ & Sugar tr & $\begin{array}{l}\text { Transmembrane transport of } \\
\text { sugar and other molecules; } \\
\text { major facilitator superfamily } \\
\text { MFS }\end{array}$ & $\begin{array}{r}3,30 \mathrm{E} \\
-119\end{array}$ & $\begin{array}{l}\text { Pfam/UniPr } \\
\text { ot/Interpro }\end{array}$ \\
\hline $\begin{array}{l}\text { VDAG_JR2_Ch } \\
\text { r5g03210a- } \\
00001\end{array}$ & $\begin{array}{r}1,01 \mathrm{E} \\
-157\end{array}$ & $-4,00$ & MFS_1 & $\begin{array}{l}\text { Major Facilitator Superfamily } \\
\text { (MFS), single-polypeptide } \\
\text { secondary carriers } \\
\text { transporting small solutes in } \\
\text { response to chemiosmotic } \\
\text { ion gradients } \\
\end{array}$ & $\begin{array}{r}2,90 \mathrm{E} \\
-034 \\
\end{array}$ & $\begin{array}{l}\text { Pfam/Interpr } \\
\text { o }\end{array}$ \\
\hline $\begin{array}{l}\text { VDAG_JR2_Ch } \\
\text { r1g27390a- } \\
00001\end{array}$ & $\begin{array}{r}7,29 \mathrm{E} \\
-014\end{array}$ & $-3,91$ & ABC_tran & $\begin{array}{l}\text { ABC transporters belong to } \\
\text { the ATP-Binding Cassette } \\
\text { (ABC) superfamily, which } \\
\text { uses the hydrolysis of ATP } \\
\text { to energise diverse } \\
\text { biological systems }\end{array}$ & $\begin{array}{r}4,20 \mathrm{E} \\
-021 \\
\end{array}$ & $\begin{array}{l}\text { Pfam/UniPr } \\
\text { ot/Interpro }\end{array}$ \\
\hline $\begin{array}{l}\text { VDAG_JR2_Ch } \\
\text { r7g00030a- } \\
00001\end{array}$ & $\begin{array}{r}4,97 \mathrm{E} \\
-003\end{array}$ & $-3,65$ & MFS_1 & $\begin{array}{l}\text { Major Facilitator Superfamily } \\
\text { (MFS), single-polypeptide } \\
\text { secondary carriers } \\
\text { transporting small solutes in } \\
\text { response to chemiosmotic } \\
\text { ion gradients }\end{array}$ & $\begin{array}{r}6,10 \mathrm{E} \\
-030 \\
\end{array}$ & $\begin{array}{l}\text { Pfam/Interpr } \\
\text { o }\end{array}$ \\
\hline $\begin{array}{l}\text { VDAG_JR2_Ch } \\
\text { r4g01080a- } \\
00001\end{array}$ & $\begin{array}{r}7,90 \mathrm{E} \\
-097\end{array}$ & $-3,56$ & AAA & $\begin{array}{l}\text { ATPases associated with a } \\
\text { variety of cellular activities } \\
\text { (AAA); here: putative ABC } \\
\text { transporter }\end{array}$ & $\begin{array}{r}7,96 \mathrm{E} \\
-011\end{array}$ & $\begin{array}{l}\text { Pfam/Interpr } \\
\text { o }\end{array}$ \\
\hline $\begin{array}{l}\text { VDAG_JR2_Ch } \\
\text { r8g01830a- } \\
00001\end{array}$ & $\begin{array}{r}1,74 \mathrm{E} \\
-033\end{array}$ & $-3,49$ & AAA & $\begin{array}{l}\text { ATPases associated with a } \\
\text { variety of cellular activities } \\
\text { (AAA); here: putative ABC } \\
\text { transporter }\end{array}$ & $\begin{array}{r}4,82 \mathrm{E} \\
-010\end{array}$ & $\begin{array}{l}\text { Pfam/Interpr } \\
\text { o }\end{array}$ \\
\hline $\begin{array}{l}\text { VDAG_JR2_Ch } \\
\text { r6g02160a- } \\
00001\end{array}$ & $\begin{array}{r}9,66 \mathrm{E} \\
-058\end{array}$ & $-3,40$ & MFS_1 & $\begin{array}{l}\text { Major Facilitator Superfamily } \\
\text { (MFS), single-polypeptide } \\
\text { secondary carriers } \\
\text { transporting small solutes in } \\
\text { response to chemiosmotic } \\
\text { ion gradients }\end{array}$ & $\begin{array}{r}1,10 \mathrm{E} \\
-025\end{array}$ & $\begin{array}{l}\text { Pfam/Interpr } \\
0\end{array}$ \\
\hline $\begin{array}{l}\text { VDAG_JR2_Ch } \\
\text { r6g05330a- } \\
00001\end{array}$ & $\begin{array}{r}1,96 \mathrm{E} \\
-008\end{array}$ & $-3,13$ & Sugar_tr & $\begin{array}{l}\text { Transmembrane transport of } \\
\text { sugar and other molecules; } \\
\text { major facilitator superfamily } \\
\text { MFS }\end{array}$ & $\begin{array}{l}1.9 e- \\
23\end{array}$ & $\begin{array}{l}\text { Pfam/Interpr } \\
0\end{array}$ \\
\hline
\end{tabular}




\begin{tabular}{|c|c|c|c|c|c|c|}
\hline \multicolumn{7}{|l|}{ Others } \\
\hline $\begin{array}{l}\text { VDAG_JR2_Ch } \\
\text { r1g25600a- } \\
00001\end{array}$ & $\begin{array}{r}1,83 \mathrm{E} \\
-079\end{array}$ & $-3,82$ & CFEM & $\begin{array}{l}\text { Eight cysteine-containing } \\
\text { domain present in fungal } \\
\text { extracellular membrane } \\
\text { proteins (for Magnaporthe } \\
\text { grisea described as protein } \\
\text { in fungal pathogenesis) }\end{array}$ & $\begin{array}{r}9,53 \mathrm{E} \\
-006\end{array}$ & $\begin{array}{l}\text { Pfam/Interpr } \\
\text { o }\end{array}$ \\
\hline $\begin{array}{l}\text { VDAG_JR2_Ch } \\
\text { r1g24920a- } \\
00001\end{array}$ & $\begin{array}{r}1,74 \mathrm{E} \\
-040\end{array}$ & $-3,42$ & $\begin{array}{l}\text { tRNA_lig_ } \\
\text { CPD }\end{array}$ & $\begin{array}{l}\text { Phosphodiesterase domain } \\
\text { found in fungal tRNA } \\
\text { ligases; tRNA splicing, via } \\
\text { endonucleolytic cleavage } \\
\text { and ligation; RNA ligase } \\
\text { (ATP) activity, ATP binding }\end{array}$ & $\begin{array}{r}3,30 \mathrm{E} \\
-089 \\
\end{array}$ & $\begin{array}{l}\text { Pfam/Interpr } \\
\text { o }\end{array}$ \\
\hline $\begin{array}{l}\text { VDAG_JR2_Ch } \\
\text { r8g08200a- } \\
00001\end{array}$ & $\begin{array}{r}1,10 \mathrm{E} \\
-020\end{array}$ & $-3,25$ & SPC25 & $\begin{array}{l}\text { Signal peptidase complex } \\
\text { (SPC); here subunit } 25 \mathrm{kDa} \text {; } \\
\text { cleavage of signal } \\
\text { sequences during } \\
\text { polypeptide transportation } \\
\text { across ER; peptidase activity }\end{array}$ & $\begin{array}{r}1,70 \mathrm{E} \\
-054\end{array}$ & $\begin{array}{l}\text { Pfam/UniPr } \\
\text { ot/Interpro }\end{array}$ \\
\hline $\begin{array}{l}\text { VDAG_JR2_Ch } \\
\text { r7g05170a- } \\
00001\end{array}$ & $\begin{array}{r}6,96 \mathrm{E} \\
-005\end{array}$ & $-3,06$ & Glyco_18 & $\begin{array}{l}\text { O-Glycosyl hydrolase; } \\
\text { hydrolyzes the glycosidic } \\
\text { bond between two or more } \\
\text { carbohydrates, or between a } \\
\text { carbohydrate and a non- } \\
\text { carbohydrate moiety; } \\
\text { chitinase activity }\end{array}$ & $\begin{array}{r}3,65 \mathrm{E} \\
-029\end{array}$ & $\begin{array}{l}\text { Pfam/Interpr } \\
\text { o }\end{array}$ \\
\hline $\begin{array}{l}\text { VDAG_JR2_Ch } \\
\text { r8g06100a- } \\
00001\end{array}$ & $\begin{array}{r}1,36 \mathrm{E} \\
-005\end{array}$ & $-3,04$ & NmrA & $\begin{array}{l}\text { Negative transcriptional } \\
\text { regulator involved in post- } \\
\text { translational modification of } \\
\text { transcription factor AreA; } \\
\text { part of a system controlling } \\
\text { nitrogen metabolite } \\
\text { repression in fungi; global } \\
\text { nitrogen regulatory GATA } \\
\text { factor }\end{array}$ & $\begin{array}{r}5,00 E \\
-035 \\
\end{array}$ & $\begin{array}{l}\text { Pfam/UniPr } \\
\text { ot/Interpro }\end{array}$ \\
\hline $\begin{array}{l}\text { VDAG_JR2_Ch } \\
\text { r4g04380a- } \\
00001\end{array}$ & $\begin{array}{r}1,42 \mathrm{E} \\
-004\end{array}$ & $-3,01$ & N2227 & $\begin{array}{l}\text { Putatively involved in } \\
\text { meiosis }\end{array}$ & \begin{tabular}{|r|}
$1,27 \mathrm{E}$ \\
-100 \\
\end{tabular} & $\begin{array}{l}\text { Pfam/Interpr } \\
\text { o }\end{array}$ \\
\hline \multicolumn{7}{|l|}{ Unknown } \\
\hline $\begin{array}{l}\text { VDAG_JR2_Ch } \\
\text { r4g01470a-- } \\
00001\end{array}$ & $\begin{array}{r}3,98 \mathrm{E} \\
-003\end{array}$ & $-5,99$ & - & Unknown & - & - \\
\hline $\begin{array}{l}\text { VDAG_JR2_Ch } \\
\text { r6g06440a- } \\
00001\end{array}$ & $\begin{array}{r}5,35 \mathrm{E} \\
-004\end{array}$ & $-5,82$ & - & Unknown & - & - \\
\hline $\begin{array}{l}\text { VDAG_JR2_Ch } \\
\text { r2g07750a- } \\
00001\end{array}$ & $\begin{array}{r}1,23 \mathrm{E} \\
-132\end{array}$ & $-4,97$ & - & Unknown & - & - \\
\hline $\begin{array}{l}\text { VDAG_JR2_Ch } \\
\text { r7g03750a- } \\
00001\end{array}$ & $\begin{array}{r}9,95 \mathrm{E} \\
-003\end{array}$ & $-4,77$ & - & Unknown & $1-$ & - \\
\hline $\begin{array}{l}\text { VDAG_JR2_Ch } \\
\text { r2g00830a- } \\
00001\end{array}$ & $\begin{array}{r}6,22 \mathrm{E} \\
-062\end{array}$ & $-4,60$ & $\begin{array}{l}\text { Transfera } \\
\text { se }\end{array}$ & Acyl-transferase activity & $\begin{array}{r}2,20 \mathrm{E} \\
-011 \\
\end{array}$ & $\begin{array}{l}\text { Pfam/UniPr } \\
\text { ot/Interpro }\end{array}$ \\
\hline
\end{tabular}




\begin{tabular}{|c|c|c|c|c|c|c|}
\hline \begin{tabular}{|l} 
VDAG_JR2_Ch \\
r8g01480a- \\
00001
\end{tabular} & $\begin{array}{r}6,38 \mathrm{E} \\
-013\end{array}$ & $-3,85$ & - & Unknown & - & - \\
\hline \begin{tabular}{|l} 
VDAG_JR2_Ch \\
r4g01070a- \\
00001
\end{tabular} & $\begin{array}{r}2,99 \mathrm{E} \\
-004\end{array}$ & $-3,73$ & - & Unknown & - & - \\
\hline $\begin{array}{l}\text { VDAG_JR2_Ch } \\
\text { r5g05050a- } \\
00001\end{array}$ & $\begin{array}{r}6,96 \mathrm{E} \\
-006\end{array}$ & $-3,71$ & - & Unknown & - & - \\
\hline $\begin{array}{l}\text { VDAG_JR2_Ch } \\
\text { r3g08230a- } \\
00001\end{array}$ & $\begin{array}{r}5,74 \mathrm{E} \\
-016\end{array}$ & $-3,63$ & - & Unknown & - & - \\
\hline \begin{tabular}{|l} 
VDAG_JR2_Ch \\
r1g22260a- \\
00001 \\
\end{tabular} & $\begin{array}{r}3,67 \mathrm{E} \\
-064\end{array}$ & $-3,61$ & $\begin{array}{l}\text { Acetyltran } \\
\text { sf_7 }\end{array}$ & Acetyltransferase & $\begin{array}{r}5,50 \mathrm{E} \\
-007 \\
\end{array}$ & $\begin{array}{l}\text { Pfam/Interpr } \\
\text { o }\end{array}$ \\
\hline \begin{tabular}{|l} 
VDAG_JR2_Ch \\
r8g10470a- \\
00001 \\
\end{tabular} & $\begin{array}{r}5,96 \mathrm{E} \\
-003\end{array}$ & $-3,59$ & - & Unknown & - & - \\
\hline $\begin{array}{l}\text { VDAG_JR2_Ch } \\
\text { r1g10080a- } \\
00001 \\
\end{array}$ & $\begin{array}{r}3,91 \mathrm{E} \\
-018\end{array}$ & $-3,54$ & - & Unknown & - & - \\
\hline $\begin{array}{l}\text { VDAG_JR2_Ch } \\
\text { r1g19100a- } \\
00001\end{array}$ & $\begin{array}{r}1,33 \mathrm{E} \\
-023\end{array}$ & $-3,48$ & - & Unknown & - & - \\
\hline \begin{tabular}{|l} 
VDAG_JR2_Ch \\
r8g08060a- \\
00001
\end{tabular} & $\begin{array}{r}1,05 \mathrm{E} \\
-011\end{array}$ & $-3,46$ & - & Unknown & - & - \\
\hline \begin{tabular}{|l} 
VDAG_JR2_Ch \\
r5g03170a- \\
00002 \\
\end{tabular} & $\begin{array}{r}3,40 \mathrm{E} \\
-019\end{array}$ & $-3,44$ & $2 \times 7 Q / A$ & $\begin{array}{l}\text { New subfamily of } \\
\text { periplasmic binding proteins } \\
\text { found in C. albicans }\end{array}$ & $\begin{array}{r}1,00 \mathrm{E} \\
-076 \\
\end{array}$ & \begin{tabular}{|l} 
PDB \\
(Protein \\
Data Bank) \\
\end{tabular} \\
\hline $\begin{array}{l}\text { VDAG_JR2_Ch } \\
\text { r7g05880a- } \\
00001\end{array}$ & $\begin{array}{r}6,07 \mathrm{E} \\
-065\end{array}$ & $-3,44$ & - & Unknown & - & - \\
\hline $\begin{array}{l}\text { VDAG_JR2_Ch } \\
\text { r1g05830a- } \\
00001\end{array}$ & $\begin{array}{r}3,96 \mathrm{E} \\
-005\end{array}$ & $-3,42$ & - & Unknown & - & - \\
\hline $\begin{array}{l}\text { VDAG_JR2_Ch } \\
\text { r1g18900a- } \\
00001 \\
\end{array}$ & $\begin{array}{r}1,06 \mathrm{E} \\
-047\end{array}$ & $-3,38$ & - & Unknown & - & - \\
\hline \begin{tabular}{|l} 
VDAG_JR2_Ch \\
r4g07050a- \\
00001 \\
\end{tabular} & $\begin{array}{r}1,55 \mathrm{E} \\
-008\end{array}$ & $-3,36$ & - & Unknown & - & - \\
\hline $\begin{array}{l}\text { VDAG_JR2_Ch } \\
\text { r1g14410a- } \\
00001\end{array}$ & $\begin{array}{r}4,17 \mathrm{E} \\
-010\end{array}$ & $-3,32$ & - & Unknown & - & - \\
\hline $\begin{array}{l}\text { VDAG_JR2_Ch } \\
\text { r1g16520a- } \\
00001\end{array}$ & $\begin{array}{r}5,18 \mathrm{E} \\
-012\end{array}$ & $-3,31$ & - & Unknown & - & - \\
\hline $\begin{array}{l}\text { VDAG_JR2_Ch } \\
\text { r3g04330a- } \\
00001\end{array}$ & $\begin{array}{r}5,88 \mathrm{E} \\
-005\end{array}$ & $-3,26$ & - & Unknown & - & - \\
\hline \begin{tabular}{|l} 
VDAG_JR2_Ch \\
r4g05100a- \\
00001 \\
\end{tabular} & $\begin{array}{r}5,16 \mathrm{E} \\
-007\end{array}$ & $-3,25$ & - & $\begin{array}{l}\text { Uncharacterized protein } \\
\text { within V. dahliae VdLS.17 } \\
\text { G2XFL9_VERDV }\end{array}$ & - & UniProt \\
\hline $\begin{array}{l}\text { VDAG_JR2_Ch } \\
\text { r6g04430a- } \\
00001\end{array}$ & $\begin{array}{r}6,47 \mathrm{E} \\
-012\end{array}$ & $-3,19$ & - & Unknown & - & tini \\
\hline
\end{tabular}




\begin{tabular}{|c|c|c|c|c|c|c|}
\hline $\begin{array}{l}\text { VDAG_JR2_Ch } \\
\text { r1g14270a- } \\
00001\end{array}$ & $\begin{array}{r}3,79 \mathrm{E} \\
-022\end{array}$ & $-3,18$ & - & Unknown & - & - \\
\hline $\begin{array}{l}\text { VDAG_JR2_Ch } \\
\text { r8g01090a- } \\
00001\end{array}$ & $\begin{array}{r}7,06 \mathrm{E} \\
-009\end{array}$ & $-3,17$ & - & Unknown & - & - \\
\hline $\begin{array}{l}\text { VDAG_JR2_Ch } \\
\text { r8g11260a- } \\
00001\end{array}$ & $\begin{array}{r}1,51 \mathrm{E} \\
-006\end{array}$ & $-3,12$ & 4MUB/A & Unknown & $\begin{array}{r}6,00 \mathrm{E} \\
-016 \\
\end{array}$ & $\begin{array}{l}\text { PDB } \\
\text { (Protein } \\
\text { Data } \\
\text { Bank)/UniPr } \\
\text { ot }\end{array}$ \\
\hline $\begin{array}{l}\text { VDAG_JR2_Ch } \\
\text { r6g10360a- } \\
00001\end{array}$ & $\begin{array}{r}3,80 E \\
-004\end{array}$ & $-3,04$ & - & Unknown & - & - \\
\hline $\begin{array}{l}\text { VDAG_JR2_Ch } \\
\text { r3g05770a- } \\
00001\end{array}$ & $\begin{array}{r}1,28 \mathrm{E} \\
-021\end{array}$ & $-3,03$ & d1ycsb1 & Unknown & $\begin{array}{r}3,00 \mathrm{E} \\
-005 \\
\end{array}$ & $\begin{array}{l}\text { SCOP } \\
\text { (Structural } \\
\text { Classificatio } \\
\text { n of } \\
\text { Proteins)/Un } \\
\text { iProt }\end{array}$ \\
\hline $\begin{array}{l}\text { VDAG_JR2_Ch } \\
\text { r1g11990a- } \\
00001\end{array}$ & $\begin{array}{r}3,25 \mathrm{E} \\
-055\end{array}$ & $-3,03$ & - & Unknown & 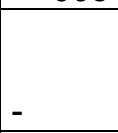 & 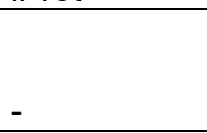 \\
\hline $\begin{array}{l}\text { VDAG_JR2_Ch } \\
\text { r8g06310a- } \\
00001\end{array}$ & $\begin{array}{r}2,52 \mathrm{E} \\
-006\end{array}$ & $-3,03$ & OPA3 & $\begin{array}{l}\text { Optic atrophy } 3 \text { (OPA3); } \\
\text { function unknown }\end{array}$ & $\begin{array}{r}1,20 \mathrm{E} \\
-042 \\
\end{array}$ & $\begin{array}{l}\text { Pfam/UniPr } \\
\text { ot/Interpro }\end{array}$ \\
\hline
\end{tabular}


Table S7 Assignment of all 184 selected most up- and down-regulated Verticillium genes after 120 min of Pseudomonas co-cultivation. Grouped to functional categories as described in Table S5 and S6. Bold figures mark the most distinct differences between the down- and the up-regulated transcripts indicating the functional categories with the most impact on Verticillium expression due to the presence of Pseudomonas.

\begin{tabular}{|l|r|r|r|r|}
\hline & \multicolumn{2}{|c|}{$\begin{array}{c}\text { Up-regulated } \\
\text { Verticillium genes }\end{array}$} & \multicolumn{2}{c|}{$\begin{array}{c}\text { down-regulated } \\
\text { Verticillium genes }\end{array}$} \\
\hline & $\begin{array}{c}\text { No. of genes } \\
\text { assigned to } \\
\text { category }\end{array}$ & \multicolumn{1}{|c|}{ Ratio } & $\begin{array}{c}\text { No. of genes } \\
\text { assigned to } \\
\text { category }\end{array}$ & \multicolumn{1}{|c|}{ Ratio } \\
\hline Amino acid metabolism & 4 & $5,1 \%$ & 6 & $5,7 \%$ \\
\hline Carbon metabolism & 9 & $11,4 \%$ & 12 & $11,4 \%$ \\
\hline $\begin{array}{l}\text { Chromosomal organization / DNA } \\
\text { repair }\end{array}$ & $\mathbf{1}$ & $\mathbf{1 , 3} \%$ & $\mathbf{4}$ & $\mathbf{3 , 8 \%}$ \\
\hline Degradation of plant polysaccharides & $\mathbf{2}$ & $\mathbf{2 , 5 \%}$ & $\mathbf{1 2}$ & $\mathbf{1 1 , 4 \%}$ \\
\hline Detoxification & $\mathbf{6}$ & $\mathbf{7 , 6 \%}$ & $\mathbf{0}$ & $\mathbf{0 \%}$ \\
\hline Energy & 6 & $7,6 \%$ & 2 & $1,9 \%$ \\
\hline Lipid metabolism & 0 & $0,0 \%$ & 4 & $3,8 \%$ \\
\hline $\begin{array}{l}\text { Protein - } \\
\text { metabolism/biosynthesis/regulation }\end{array}$ & $\mathbf{4}$ & $\mathbf{5 , 1 \%}$ & $\mathbf{1 6}$ & $\mathbf{1 5 , 2 \%}$ \\
\hline Transport & 8 & $10,1 \%$ & 12 & $11,4 \%$ \\
\hline Others & 5 & $6,3 \%$ & 6 & $\mathbf{5 , 7 \%}$ \\
\hline Unknown & 34 & $\mathbf{4 3 , 0 \%}$ & 31 & $\mathbf{2 9}, 5 \%$ \\
\hline TOTAL & 79 & $100,0 \%$ & 105 & $100,0 \%$ \\
\hline
\end{tabular}




\section{List of figures}

\begin{tabular}{|c|c|}
\hline Figure 1.1: Life cycle of the soil borne phytopathogen Verticillium. & p. 13 \\
\hline $\begin{array}{l}\text { Figure 1.2: Evolution of } V \text {. longisporum as an interspecific hybrid } \\
\text { of different Verticillium species. }\end{array}$ & p. $14 / 15$ \\
\hline $\begin{array}{l}\text { Figure 1.3: Morphological comparison of selected Verticillium } \\
\text { species and isolates with regard to asexual conidia as well as } \\
\text { resting structures. }\end{array}$ & p. 16 \\
\hline $\begin{array}{l}\text { Figure 1.4: Interactions between growth-promoting rhizobacteria, } \\
\text { plants, pathogens and soil. }\end{array}$ & p. 20 \\
\hline $\begin{array}{l}\text { Figure 1.5: Model of the GacA/GacS signal-transduction pathway } \\
\text { in Pseudomonas protegens strain } \mathrm{CHAO} \text {. }\end{array}$ & p. 23 \\
\hline $\begin{array}{l}\text { Figure 1.6: Phenazin seven-gene operon and pathway in } \\
\text { phenazine-secreting Pseudomonas spp. }\end{array}$ & p. 24 \\
\hline $\begin{array}{l}\text { Figure 5.1: Co-cultivation in microfluidic devices of } \mathrm{V} \text {. Iongisporum } \\
\text { VI43 and different wild type fluorescent pseudomonads as well as } \\
\text { deletion strains lacking genomic potential for phenazine or DAPG. }\end{array}$ & p. $64 / 65$ \\
\hline $\begin{array}{l}\text { Figure 5.2: Co-cultivation in microfluidic devices of } V \text {. longisporum } \\
\text { VI43 and wild type fluorescent pseudomonads as well as deletion } \\
\text { strains missing regulators for multiple or single metabolite } \\
\text { synthesis. }\end{array}$ & p. $66 / 67$ \\
\hline $\begin{array}{l}\text { Figure 5.3: Alteration in hyphal polarity of } \mathrm{V} \text {. longisporum } \mathrm{VI} 43 \\
\text { during co-cultivation with wild type fluorescent pseudomonads as } \\
\text { well as deletion strains. }\end{array}$ & p. 68 \\
\hline $\begin{array}{l}\text { Figure 5.4: Transcriptome analysis of } V \text {. longisporum } \mathrm{VI} 43 \text { after } \\
\text { unconstrained co-cultivation with } P \text {. protegens } \mathrm{CHAO} \text { (P_DAPG). }\end{array}$ & p. 71/72 \\
\hline $\begin{array}{l}\text { Figure 6.1: Phylogenetic dendrogramm to compare mutualistic } \\
\text { and opportunistic bacterial species. }\end{array}$ & p. 88 \\
\hline $\begin{array}{l}\text { Figure 6.2: Model simplifying the three-dimensional interaction of } \\
\text { a host plant, an antagonistic rhizobacterium (Pseudomonas) and } \\
\text { a plant pathogen (Verticillium). }\end{array}$ & p. 90 \\
\hline $\begin{array}{l}\text { Figure S1: Southern hybridization of } V . \text { dahliae JR2 LAE1 and } \\
\text { CSN5 deletion strains. }\end{array}$ & p. $126 / 130$ \\
\hline $\begin{array}{l}\text { Figure S2: Multiple sequence alignment of cyanide hydratase } \\
\text { enzymes in V. dahliae compared to Fusarium solani. }\end{array}$ & p. 131 \\
\hline
\end{tabular}




\section{List of tables}

\begin{tabular}{|l|l}
\hline Table 5.1: Organisms and strains used in this study. (Nesemann et & p. 58
\end{tabular} al., unpublished).

Table 5.2: Most up- regulated Verticillium related genes related to detoxification reactions after 120 min of Pseudomonas co-cultivation

Table S1: Organisms and strains used in this study.(Nesemann et

p. $126 / 127$ al., 2018)

Table S2: Primer used in this study.

p. 128

Table S3: Plasmids used in this study.

p. 128

Table S4: Comparison of genetic constitution in secondary metabolism in selected fluorescent pseudomonads.

Table S5: List of up-regulated Verticillium genes after 120 min of

p. 129

Pseudomonas co-cultivation

Table S6: List of down-regulated Verticillium genes after 120 min of

p. $132-138$

Pseudomonas co-cultivation.

Table S7: Assignment of all 184 selected most up- and down-

p. $139-149$ regulated Verticillium genes after 120 min of Pseudomonas cocultivation. 


\section{Abbreviations}

\begin{tabular}{|c|c|}
\hline ADIC & 2-amino-4-deoxychorismic acid \\
\hline Anr & Anaerobic regulation \\
\hline $\mathrm{AOCHC}$ & 2-amino-4-deoxychorismic acid \\
\hline ATP & Adenosine triphosphate \\
\hline ATPase & Adenosine triphosphatase \\
\hline BLAST & Basic local alignment search tool \\
\hline${ }^{\circ} \mathrm{C}$ & Degree Celsius \\
\hline CFU & Colony forming unit \\
\hline COP9 & Constitutive Photomorphogenesis 9 \\
\hline Csn5 & COP9 (Constitutive Photomorphogenesis 9) signalosome subunit 5 \\
\hline DAHP & 3-deoxy-D-arabinoheptulosonate-7-phosphate \\
\hline DAPG & 2,4-Diacetylphloroglucinol \\
\hline $\mathrm{DHHA}$ & Trans-2,3-dihydro-3-hydroxyanthranlic acid \\
\hline DHPCA & 5,10-dihydrophenazine-1-carboxylic acid \\
\hline DNA & Desoxyribonucleic acid \\
\hline DSMZ & Deutsche Sammlung für Mikroorganismen und Zellkulturen \\
\hline e.g. & Exempli gratia (for example) \\
\hline $\mathrm{E} 4 \mathrm{P}$ & Erythrose 4-phosphate \\
\hline gacA & Global activator of secondary metabolism A \\
\hline gacs & Global regulator of secondary metabolism S \\
\hline Gfp & Green fluorescent protein \\
\hline $\mathrm{HCN}$ & Hydrogen cyanide \\
\hline$h c n A$ & Hydrogen cyanide $\mathrm{A}$ \\
\hline HHPCD & Hexahydrophenazine-1,6-dicarboxylic acid \\
\hline i.a. & Inter alia (amoung others) \\
\hline ID & Identification \\
\hline Lae1 & Loss of afIR(alflatoxin)-expression \\
\hline mRNA & Messanger ribonucleic acid \\
\hline mfs & Major Facilitator Superfamily \\
\hline $\mathrm{MgSO}_{4}$ & Magnesium sulfate \\
\hline $\mathrm{ml}$ & Milliliter \\
\hline$\mu l$ & Microliter \\
\hline NAD & Nicotinamide adenine dinucleotide \\
\hline NADP & Nicotinamide adenine dinucleotide phosphate \\
\hline OD $600 \mathrm{~nm}$ & Optical density at a wave length of $600 \mathrm{~nm}$ \\
\hline P_DAPG & P. protegens $\mathrm{CHA} 0$ expressing DAPG \\
\hline P_Phen & $P$. synxantha $2-79$ expressing phenazines \\
\hline P_Rhizo & P. fluorescens DSM8569 isolate from Brassica rhizosphere \\
\hline Pãdj & Adjusted p-value \\
\hline PCA & Phenazine-1-carboxylic acid \\
\hline PDA & Potato dextrose agar \\
\hline PEP & Phosphoenolpyruvate \\
\hline Pfam & Protein family database \\
\hline Rfp & Red fluorescent protein \\
\hline PGPR & Plant growth-promoting rhizobacteria \\
\hline phIAFDGI & 2,4-diacetylphloroglucinol AFDGI \\
\hline
\end{tabular}


phz ABCDEFG Phenazine ABCDEFG

phz IR

Phenazine IR

pltADMPZ

Pyoluteorin ADMPZ

RNA

Ribonucleic acid

ROS

Reactive oxygen species

Rpm

Rounds per minutes

RsmAE

Regulatory small protein AE

rsmXYZ

Regulatory small RNA XYZ

SXM

Simulated xylem medium 


\section{Danksagung}

Den größten Dank möchte ich meinem Doktorvater Gerhard Braus aussprechen, der stets seine langjährige und vielseitige wissenschaftliche Erfahrung zum Gelingen der Arbeit eingebracht hat sowie mich während meiner gesamten Promotionszeit kompetent und konstruktiv beraten und begleitet hat. Ebenfalls gebührt mein Dank meinem zweiten Gutachter Rolf Daniel und seinem Team, der vor allem zu den bakteriellen Elementen der Arbeit sowie den Sequenzierungen gewinnbringenden Input geleistet hat.

Darüber hinaus möchte ich mich ganz herzlich bei Susanna Braus-Stromeyer bedanken, die mit ihren vielfältigen Ideen und den ausgiebigen Detailplanungen die Arbeit vorangetrieben hat - außerdem natürlich für eine tolle und erfolgreiche Woche in Zürich. Ebenfalls gilt mein besonderer Dank Rebekka Harting, die maßgeblich Anteil am Erfolg der Arbeit hat und mich durch ihre stets konsequente und verlässliche Art bestens begleitet hat. Harald Kusch war in all der Zeit ein immer zuverlässiger und wertvoller Ansprechpartner und Unterstützer vor allem bei bioinformatischen Fragen der Transkriptomauswertung.

Besonders wichtig war für mich Maria Meyer, die stets für alle Sorgen und Nöte ansprechbar war und durch ihren empathischen Charakter eine besondere Atmosphäre geschaffen hat. Herzlicher Dank geht auch an Heidi Northemann, die durch ihre Ungezwungenheit die Arbeit sehr angenehm gemacht hat. Christian Timpner war ein immer hilfsbereiter Kollege, dem ich mich oft und gerne bei schwierigen Fragen anvertrauen konnte. Ganz herzlicher Dank gilt auch Blaga Popova für ihre vertrauensvolle Begleitung und ihre freundliche und kompetente Hilfsbereitschaft. Von Clara Hoppenau habe ich bereits während meiner Masterarbeit viele grundlegende Labortechniken erlernt, so dass sie mich gut auf die Zeit der Doktorarbeit vorbereitet hat. Bedanken möchte ich mich auch bei Van Tuan Tran und Tri-Thuc Bui, da sie wichtige Ansprechpartner im Labor waren und zusätzlich mir wertvolle Einblicke in die vietnamesische Kultur (und Küche) verschafft haben. Auch Anika Kühn stand stets mit Rat und Tat zur Seite. Mein Dank geht auch an Nicole Scheiter, die sich zuverlässig um alle wichtigen Bestellungen kümmerte. Ebenfalls möchte ich Alline Ambrosio danken für ihre 
größte Hilfsbereitschaft und ihre Unterstützung bei den vielen hundert Platten, die wir gemeinsam untersucht haben. Von Henriette Irmer habe ich viele Grundlagen der real-time PCR erlernt. Bastian Jöhnk und Joshua Schinke danke ich vor allem für ihr sorgfältiges Korrekturlesen der Arbeit. Vielen Dank, Andrea Wäge, für den großartigen Einsatz in der Spülküche.

Claire Stanley und Martina Stöckli haben mir die Basics der Mikrofluidiktechnik beigebracht. Dieter Haas, Christoph Keel, Andreas von Tiedemann und Linda Thomashow haben mir dankenswerterweise diverse Pseudomonas- und Verticilliumstämme zur Verfügung gestellt. In den Gewächshäusern von Andrea Polle und ihrem Team konnte ich sämtliche Pflanzenversuche durchführen. Manuel Landesfeind und Alexander Kaever sowie das Team von Mario Starnke, v.a. Katharina Hoff, haben mich bei allen bioinformatischen Fragen und Berechnungen unterstützt. Vor allem für Durchführung des zweiten Mappings auf JR2 sowie die nachfolgende Bioinformatik war Eure Hilfe besonders wertvoll. Ebenfalls möchte ich meinen Studenten und Praktikanten Lisa Weinhold, Sarah Zunken, Pablo Tarazona und Malte Kölling danken, die mir viel Arbeit abgenommen haben.

Abschließend möchte ich meinem Vater Peter Schädle ganz herzlich danken. Schon zu Schulzeiten legte er bei mir ein grundlegendes molekulares und vor allem genetisches Interesse. Immer wieder haben seine Fachkompetenz und die vielen Diskussionen diese Arbeit bereichert. 
Publications:

Nesemann K, Braus-Stromeyer SA, Thuermer A, Daniel R, Braus GH. 2015. Draft Genome Sequence of the Beneficial Rhizobacterium Pseudomonas fluorescens DSM8569, a Natural Isolate of Oilseed Rape (Brassica napus). Genome Announcements 3: e00137-15.

Nesemann K, Braus-Stromeyer SA, Thuermer A, Daniel R, Mavrodi DV, Thomashow LS, Weller DM, Braus GH. 2015. Draft Genome Sequence of the Phenazines-Producing Pseudomonas fluorescens 2-79. Genome Announcements 3: e00130-15.

Hollensteiner J, Wemheuer F, Harting R, Kolarzyk AM, Valerio SMD, Poehlein A, Brzuszkiewicz EB, Nesemann K, Braus-Stromeyer SA, Braus GH, Daniel R, Liesegang H. 2017. Bacillus thuringiensis and Bacillus weihenstephanensis inhibit the growth of phytopathogenic Verticillium species. Frontiers in Microbiology 7: 2171.

Nesemann K, Braus-Stromeyer SA, Harting R, Hoefer A, Kusch H, Ambrosio AB, Timpner C, Braus GH. 2018. Fluorescent pseudomonads pursue mediadependent strategies to inhibit growth of pathogenic Verticillium fungi. Applied Microbiology and Biotechnology 102: 817-831. 